\title{
IMPROVING HEAT RECOVERY IN BIOMASS-FIRED BOILERS
}

\section{July 31, 2013}

\section{Prepared by}

James R. Keiser, ORNL, Principal Investigator

W. B. A. (Sandy) Sharp, SharpConsultant

Douglas L. Singbeil, FPInnovations

Preet M. Singh, Georgia Institute of Technology

Laurie A. Frederick, FPInnovations

Joseph F. Meyer, Georgia Institute of Technology

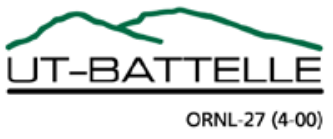




\title{
DOCUMENT AVAILABILITY
}

Reports produced after January 1, 1996, are generally available free via the U.S. Department of Energy (DOE) Information Bridge.

Web site http://www.osti.gov/bridge

Reports produced before January 1, 1996, may be purchased by members of the public from the following source.

\author{
National Technical Information Service \\ 5285 Port Royal Road \\ Springfield, VA 22161 \\ Telephone 703-605-6000 (1-800-553-6847) \\ TDD 703-487-4639 \\ Fax 703-605-6900 \\ E-mail info@ntis.gov \\ Web site http://www.ntis.gov/support/ordernowabout.htm
}

Reports are available to DOE employees, DOE contractors, Energy Technology Data Exchange (ETDE) representatives, and International Nuclear Information System (INIS) representatives from the following source.

Office of Scientific and Technical Information

P.O. Box 62

Oak Ridge, TN 37831

Telephone 865-576-8401

Fax 865-576-5728

E-mail reports@osti.gov

Web site http://www.osti.gov/contact.html

This report was prepared as an account of work sponsored by an agency of the United States Government. Neither the United States Government nor any agency thereof, nor any of their employees, makes any warranty, express or implied, or assumes any legal liability or responsibility for the accuracy, completeness, or usefulness of any information, apparatus, product, or process disclosed, or represents that its use would not infringe privately owned rights. Reference herein to any specific commercial product, process, or service by trade name, trademark, manufacturer, or otherwise, does not necessarily constitute or imply its endorsement, recommendation, or favoring by the United States Government or any agency thereof. The views and opinions of authors expressed herein do not necessarily state or reflect those of the United States Government or any agency thereof. 
Advanced Manufacturing Office

\title{
IMPROVING HEAT RECOVERY IN BIOMASS-FIRED BOILERS
}

\author{
Authors: \\ James R. Keiser, ORNL \\ W. B. A. (Sandy) Sharp, SharpConsultant \\ Douglas L. Singbeil, FPInnovations \\ Preet M. Singh, Georgia Institute of Technology \\ Laurie A. Frederick, FPInnovations \\ Joseph F. Meyer, Georgia Institute of Technology
}

Date Published: July 31, 2013

Prepared by

OAK RIDGE NATIONAL LABORATORY

Oak Ridge, Tennessee 37831-6283

managed by

UT-BATTELLE, LLC

for the

U.S. DEPARTMENT OF ENERGY

under contract DE-AC05-00OR22725 


\section{Contents}

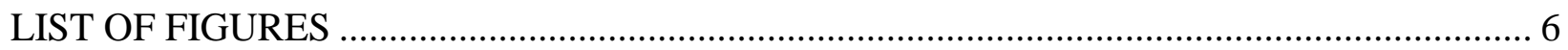

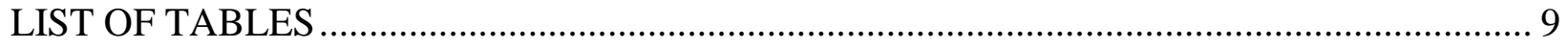

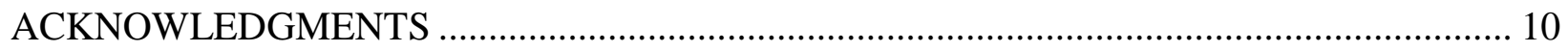

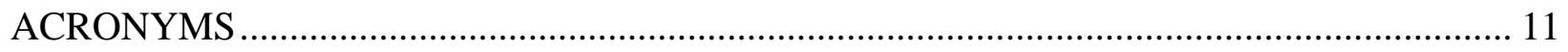

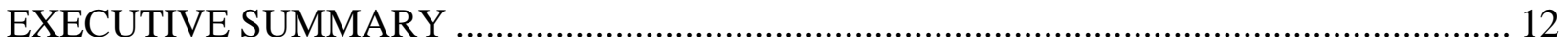

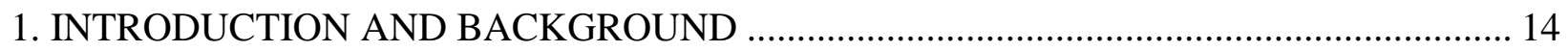

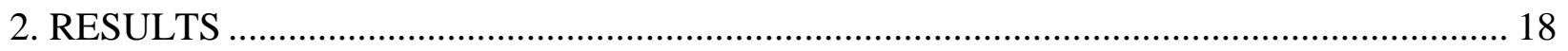

2.1 ASSESSMENT OF ALTERNATE TECHNOLOGIES ..................................................... 18

2.1.1 Design Modifications to Inhibit Superheater Corrosion............................................... 18

2.1.2 Process Modifications to Inhibit Superheater Corrosion ................................................ 29

2.1.3 Superheater Corrosion Produced By Biomass Fuels ................................................... 33

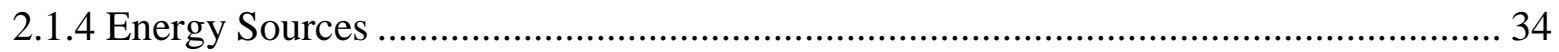

2.1.5 Alloys Resistant to High Temperature Corrosion........................................................ 34

2.1.6 Corrosion Mechanisms in Biomass Boiler Superheater Environments ........................ 36

2.1.7 Corrosion of Biomass Boiler Superheater Materials .................................................... 39

2.2 LABORATORY CORROSION STUDIES.................................................................... 45

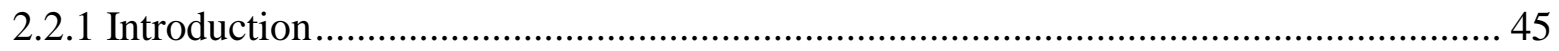

2.2.2 Experimental Procedure ......................................................................................... 45

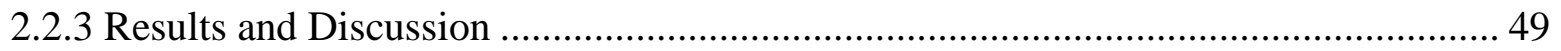

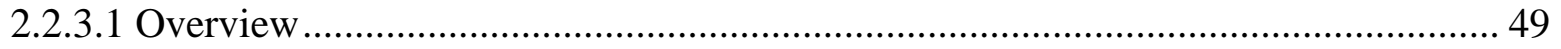

2.2.4 Comparison to Field Data ....................................................................................... 57

2.2.5 Summary and Conclusions ........................................................................................... 58

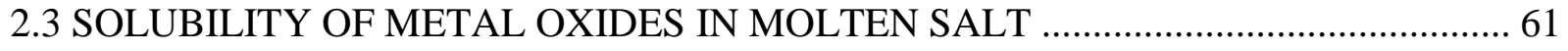

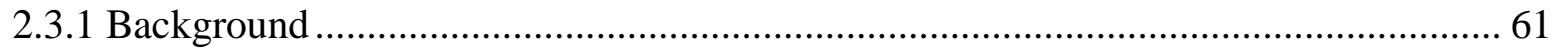

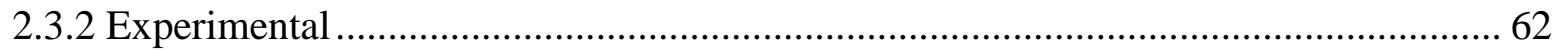

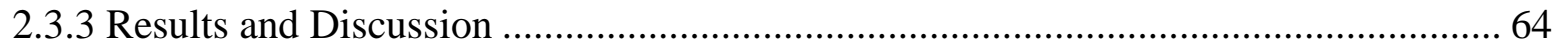

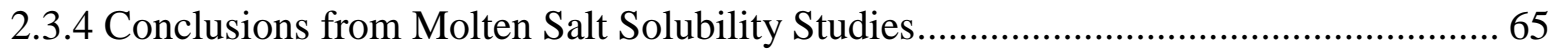

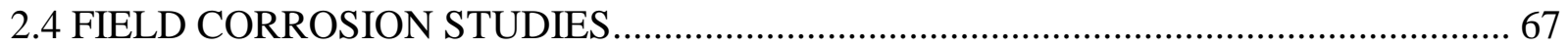

2.4.1 Experimental Procedure............................................................................................. 67

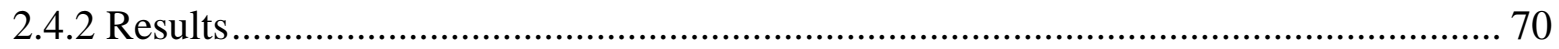

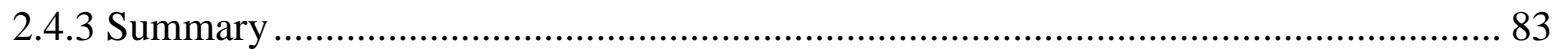

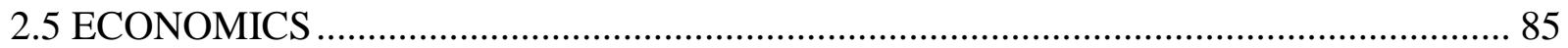

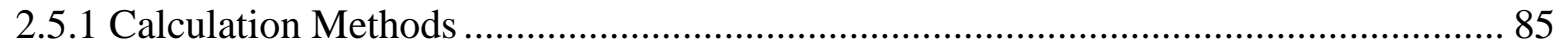


2.5.2 Components of the Steam Power Cycle Calculation Module......................................... 86

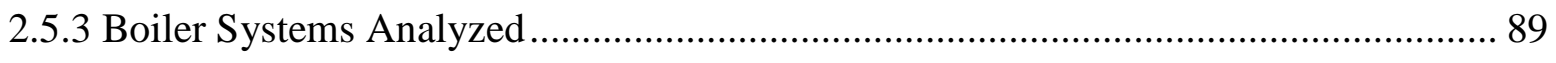

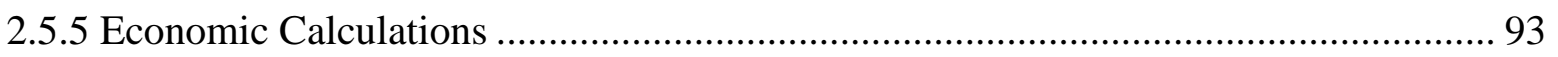

2.5.6 Issues Raised By Simplifying Assumptions .............................................................. 96

2.5.7 Environmental Benefits of Higher Steam Conditions .................................................. 98

2.5.8 Discussion and Conclusions .................................................................................. 99

3. BENEFITS ASSESSMENT AND COMMERCIALIZATION …….................................... 101

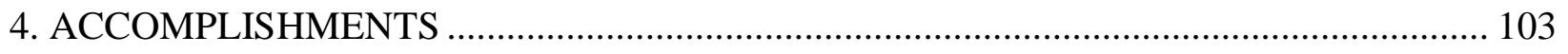

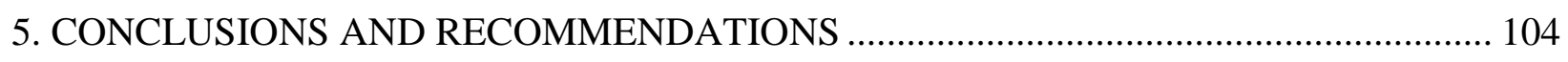

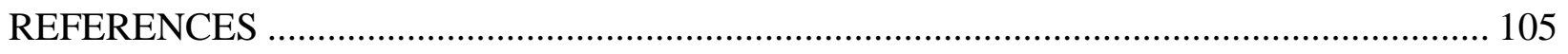




\section{LIST OF FIGURES}

Fig. 1. Type $310 \mathrm{H}$ stainless steel tube exposed 36 months in a wood-fired power boiler. 14

Fig. 2 Corrosion rate as a function of temperature for type 310 stainless steel exposed to low

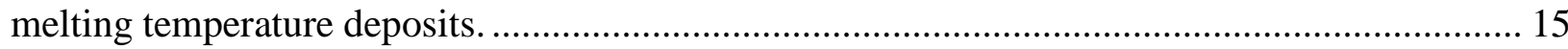

Fig. 3: Schematic drawing of Iglesta CHP boiler at, Södertälje, Sweden [6] ............................ 19

Fig. 4. General arrangement of Schweinfurt waste-to-energy boiler [10] ................................ 20

Fig. 5. "Chlorine trap” and Horizontal Wash System in Schweinfurt boiler [9] ......................... 21

Fig. 6. Accumulation of low-melting temperature deposits on Schweinfurt low temperature

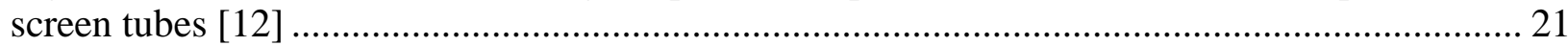

Fig. 7. Foster Wheeler INTREX loop seal superheater [15] ................................................. 22

Figure 8: Metso CYMIC biomass boiler with loop seal superheater [16] ................................. 23

Fig. 9. Lurgi design for superheater in external "ash” cooler [19] ............................................ 23

Fig. 10. Arrangement of Fluidized Bed Heat Exchanger in recirculated ash system [13] .......... 24

Fig. 11. Ensted EV3 biomass boiler with separate wood-fired superheater connected to steam

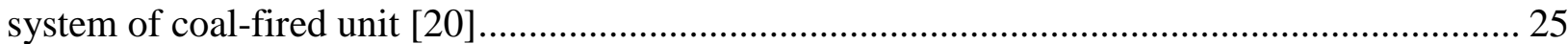

Fig. 12. Boiler 15 at E.ON Händelö waste-to-energy cogeneration plant, Norrköping, Sweden

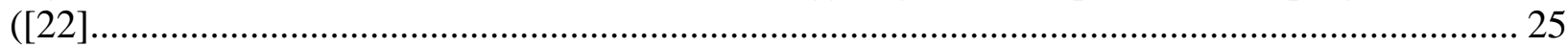

Fig. 13. City of Amsterdam waste-fired power plant [23] .................................................... 26

Fig. 14. Effects of increasing superheater tube temperature on concentrations of potential

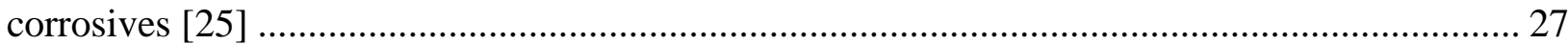

Fig. 15. Metso tube containing a thermally-insulating layer to raise its surface temperature ...... 27

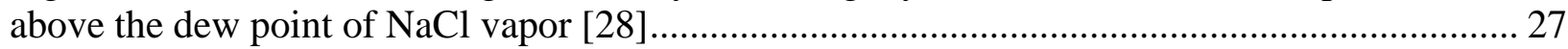

Fig. 16: Graphic representation of the three salt compositions used in this work..................... 46

Fig. 17. Alloy Set 1 laid out in preparation for insertion to a furnace, showing the reproducibility of the initial salt packing and surface height. The pre-oxidized coupons in the third and last rows from the right are darker than the remaining as ground coupons. Blank "guard" pots placed at the gas inlet are also visible.

Fig. 18. Six coupons embedded in epoxy with their support pins. The mount on the right has not

been machined square yet. The mount on the left has been dry sectioned. ....

Fig. 19. A mosaic image of a cross-section after analysis. Inset shows top right corner in more detail. The outer red circle is the original circumference of the coupon. The green lines indicate the depth measured for metal loss, and the blue lines indicate the total affected metal measurement for each of the 24 arcs around the circumference. The average of the 24 total affected metal measurements is defined as the TAM of the coupon. 50 Fig. 20. Shows variation with salt colour relating to corrosion of the coupon. Red circles indicate coupons of pre-oxidized HR214 (Alloy FP) in RB salts at $625^{\circ} \mathrm{C}$. Note that the only Alloy F coupon not to show substantial spalling is the one with the yellow-shaded salt........................ 51 Fig. 21. Variation of average TAM with time in PB2 salts at $650^{\circ} \mathrm{C}$ (T14, T15, T16), in microns.

Fig. 22. Test data from alloys exposed to PB2 salts for $1000 \mathrm{hrs}$ at $650{ }^{\circ} \mathrm{C}$. Alloys are listed in order of increasing nickel content left to right with the last four on the right being the alumina formers (E, EP, F, FP). Metal loss is blue portion of bar, TAM is green portion of bar. ............ 53 Fig. 23. Test data from alloys exposed to RB salts for $1000 \mathrm{hrs}$ at $625^{\circ} \mathrm{C}$. Metal loss is blue portion of bar, TAM is red portion of bar. The alloys are listed in order of increasing nickel content left to right with the alumina formers at the right (E, EP, F, FP). 
Fig. 24. Corrosion results for Alloy Set 3 after exposure to recovery boiler salts at (a) $530{ }^{\circ} \mathrm{C}$ and

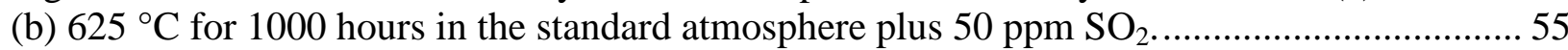
Fig. 25. Comparison of average TAM for the alloys that were in recovery boiler 1000 hour tests,

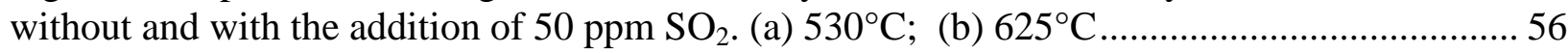
Fig. 26. The average TAM in microns for each alloy exposed to the PB2 environment at $650{ }^{\circ} \mathrm{C}$. Alloy performance is color coded as acceptable (green), intermediate (yellow) and unacceptable (red). 60

Fig. 27. The average TAM in microns for each alloy exposed to the recovery boiler environment at $530^{\circ} \mathrm{C}$. Alloy performance is color coded as acceptable (green), intermediate (yellow) and unacceptable (red).

Fig. 28. The average TAM in microns for each alloy exposed to the recovery boiler environment at $625^{\circ} \mathrm{C}$. Alloy performance is color coded as acceptable (green), intermediate (yellow) and unacceptable (red).

Fig. 29. Schematic of a negative solubility gradient throughout the molten salt that continually precipitates out to form an unproductive scale[112] ........................................................ 63

Fig. 30. Schematic of experimental apparatus .............................................................. 63

Fig. 31. Average solubility of metal oxides in a recovery boiler salt exposed for 8 hours at $750^{\circ} \mathrm{C}$

Fig. 32. Average solubility of alumina in the presence of an additional metal oxide during 8 hours of exposure. 66

Fig. 33. Left) Schematic of the corrosion samples, center) Photo of samples tack welded with thermocouples protruding from the surface of the samples, and right) Photo of samples welded together and with shim stock welded in place to hold thermocouples on the surface of the samples.

Fig. 34. Typical corrosion probe showing the arrangement of samples as they were assembled on the probe.

Fig. 35. Photo of the 30 samples removed from one of the corrosion probes. Samples \#6 and \#10 still contain the spacers used to position the support rod in the center of the probe. Several other samples still contain the remnants of the thermocouple that was attached to the outer surface of most samples.

Fig. 36. Average daily temperatures for each of the ten thermocouples on the deposit sampling probe.

Fig. 37. Typical example of thermocouple temperatures from the corrosion probe exposed in the Covington recovery boiler. Note that the orange line shows the temperature of thermocouple \#23 which was being used to control the flow of cooling air and thus the probe temperature..... 73 Fig. 38. Average daily temperatures of thermocouples in the Covington recovery boiler .......... 74 Fig. 39. Total affected material as a function of exposure temperature for samples exposed for 2,000 hours on the corrosion probe in the Covington recovery boiler.

Fig. 40. Total affected material versus exposure temperature for individual alloys exposed for 2,000 hours on the corrosion probe in the Covington recovery boiler.

Fig. 41. Results of X-ray diffraction measurements of deposits collected from the bottom of 7 samples on the corrosion probe in the Crofton hogged fuel boiler........................................ 76 Fig, 42. Daily average temperature of thermocouples exposed about 2,160 hours on the corrosion probe in the Crofton hogged fuel boiler............................................................. 77 Fig. 43. Total affected material as a function of exposure temperature for samples exposed for 2,160 hours on the corrosion probe in the Crofton hogged fuel boiler. 
Fig. 44. Total affected material versus exposure temperature for individual alloys exposed for 2,160 hours on the corrosion probe in the Crofton hogged fuel boiler.

Fig. 45. Photo of the corrosion probe in the Gadsden power boiler just prior to its removal (photo

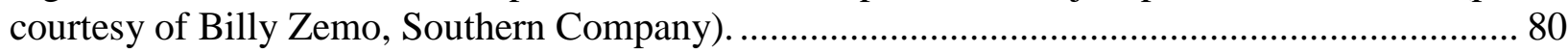
Fig. 46. Average daily temperatures of thermocouples on the corrosion probe exposed about 2, 540 hours in the coal and wood co-fired Gadsden power boiler.

Fig. 47. Total affected material as a function of exposure temperature for samples exposed for 2,540 hours on the corrosion probe in the Gadsden power boiler.

Fig. 48. Average daily temperatures of thermocouples on the corrosion probe exposed about 2,830 hours in the Port Mellon hogged fuel boiler.

Fig. 49. Total affected material as a function of exposure temperature for samples exposed about 2,830 hours on the corrosion probe in the Port Mellon hogged fuel boiler.

Fig. 50. Total affected material versus exposure temperature for individual alloys exposed for 2,830 hours on the corrosion probe in the Port Mellon hogged fuel boiler. Note the higher amount of material lost in the $400-430^{\circ} \mathrm{C}$ temperature range for most alloys............................... 83

Fig. 51. Process mass and energy streams included in the software model.................................... 86 Fig. 52. Types of steam turbine used in calculations of costs and benefits of increasing superheater steam temperature.

Fig. 53. Increase of specific enthalpy of steam with temperature at 50 and 100 bars pressure (725 and $1450 \mathrm{psi}$ ).

Fig. 54. Increase of specific entropy with temperature at 50 and 100 bars pressure (725 and 1450 psi)

Fig. 55. Increase in specific available energy in steam with increasing steam temperature at constant pressure. 


\section{LIST OF TABLES}

Table 1. The test matrix for the laboratory program. Cover gas for all experiments contained $5 \% \mathrm{O}_{2}, 10 \% \mathrm{CO}_{2}, 20 \% \mathrm{H}_{2} \mathrm{O}$, bal. $\mathrm{N}_{2}$. Makeup of Alloy Sets is shown in Table II.

Table 2. Alloys used in each alloy set. Due to limited space for data in tables and graphs, codes are used throughout the report to represent the alloys

Table 4. Standard deviation in average TAM for alloys for all the test environments. The data is separated into Vapor Phase and Under-Deposit results and sorted by the average of those results

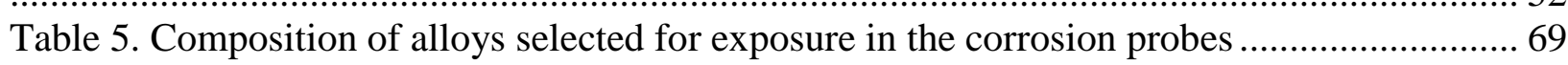

Table 6. Arrangement of samples on the corrosion probe and location of thermocouples ......... 70

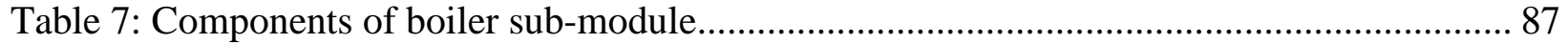

Table 8: Components of the steam turbine sub-module ...................................................... 87

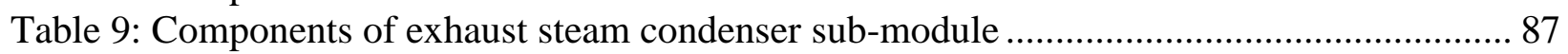

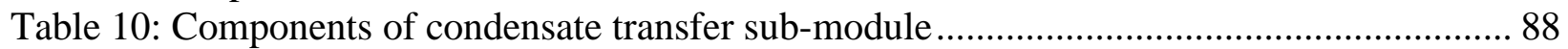

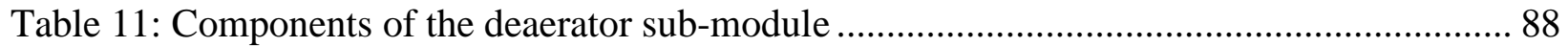

Table 12: Components of the boiler feedwater pump sub-module ......................................... 88

Table 13: Components of the combustion air sub-module ......................................................... 88

Table 14 Steam system parameters for the five boilers studied................................................ 93

Table 15: Value of increased energy production in the two example recovery boilers............... 94

Table 16: Value of increased power that could be produced by raising exit steam temperatures by

50 and by 100 Celsius degrees in the three example wood-fueled boilers. ................................ 95

Table 17: Summary of calculated value of additional power generated by raising exit steam

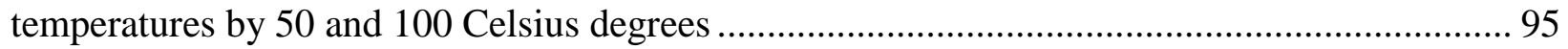

Table 18: Calculations of redirected steam flows in the steam turbines of Recovery Boilers B and

$\mathrm{M}$ as the inlet steam temperature is raised by 50 and by 100 Celsius degrees. ......................... 97

Table 19: Calculations of steam flow reductions in the steam turbines of Biomass-Fueled Boilers

$\mathrm{C}, \mathrm{H}$ and $\mathrm{M}$ as the inlet steam temperature is raised by 50 and 100 Celsius degrees.................. 98

Table 20: Cumulative energy benefits from using additional energy produced in improved biomass-fired boilers to displace energy from fossil (natural gas) fired boilers......................... 98

Table 21: Cumulative environmental benefits from using additional energy produced in

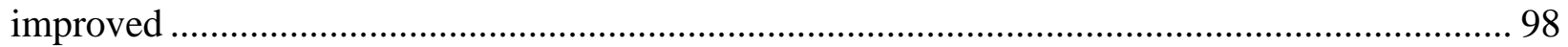

biomass-fired boilers to displace energy from fossil (natural gas) fired boilers......................... 98

Table 22: Cumulative energy benefits from replacing natural gas fired boilers with biomass-fired

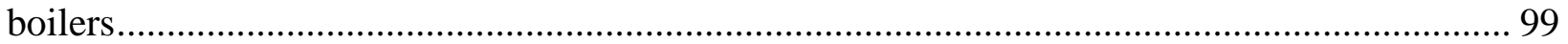

Table 23: Cumulative environmental benefits from replacing fossil fuel (natural gas) fired boilers

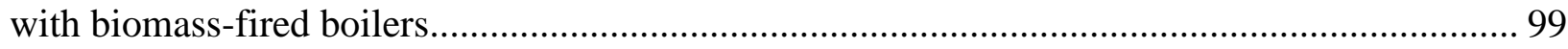




\section{ACKNOWLEDGMENTS}

This research was sponsored by the U.S. Department of Energy, Office of Energy Efficiency and Renewable Energy, Advanced Manufacturing Office, under contract DE-AC05-00OR22725 with UTBattelle, LLC, and was funded under the American Recovery and Reinvestment Act as CPS project 18991. The project was led by Oak Ridge National Laboratory and supported by in-kind contributions from the following project partners:

Ábo Akademi University, participant

Andritz Oy, cost sharing partner

Babcock \& Wilcox, cost sharing partner

Catalyst Paper, cost sharing partner

Chalmers University, participant

Domtar Corporation, cost sharing partner

FM Global, cost sharing partner

FPInnovations, participant and cost sharing partner

Foster Wheeler, cost sharing partner

Georgia Institute of Technology, participant and cost sharing partner

Haynes International, cost sharing partner

Howe Sound Pulp and Paper, cost sharing partner

International Paper, cost sharing partner

MeadWestvaco, cost sharing partner

Metso Power, cost sharing partner

OutoKumpu, cost sharing partner

Rolled Alloys, cost sharing partner

Sandvik Materials Technology, cost sharing partner

SharpConsultant, participant and cost sharing partner

Southern Company, cost sharing partner

Special Metals, cost sharing partner

ThyssenKrupp VDM, cost sharing partner

University of Toronto, participant

Vattenfall Power Consultant, cost sharing partner

Weyerhaeuser Company, cost sharing partner

Particular thanks are due to Hiram Rogers for his help in preparation, review and editing of this manuscript and to John D. Andrews, Jr. (MeadWestvaco) and to D. William Francis (FPInnovations) for helpful comments on the economic assessment. Adam Willoughby led the effort to assemble the probes and the data collection system. For the corrosion probe samples, Tyson Jordan and Hu Longmire carried out the metallographic sample preparation and light microscopy examinations, Tracie Lowe conducted the scanning electron microscope examinations, Robbie Meisner performed the X-ray diffraction and Maggie Connatser the Raman examinations of the deposits. Employees of all four of the facilities where probes were exposed assisted with installation and removal of the probes as well as help in troubleshooting several problems that arose. In particular, the help provided by Curtis Clemmons at Covington, Bob Erickson at Crofton, Billy Zemo at Gadsden and Peter Hildering at Port Mellon is appreciated. Neville Stead of FPInnovations provided considerable help in installation, maintenance and removal of the Crofton and Port Mellon corrosion probes. Material for the corrosion samples was provided by Haynes International, Rolled Alloys, Sandvik Materials Technology, Special Metals and Thyssen Krupp VDM. 


\section{ACRONYMS}

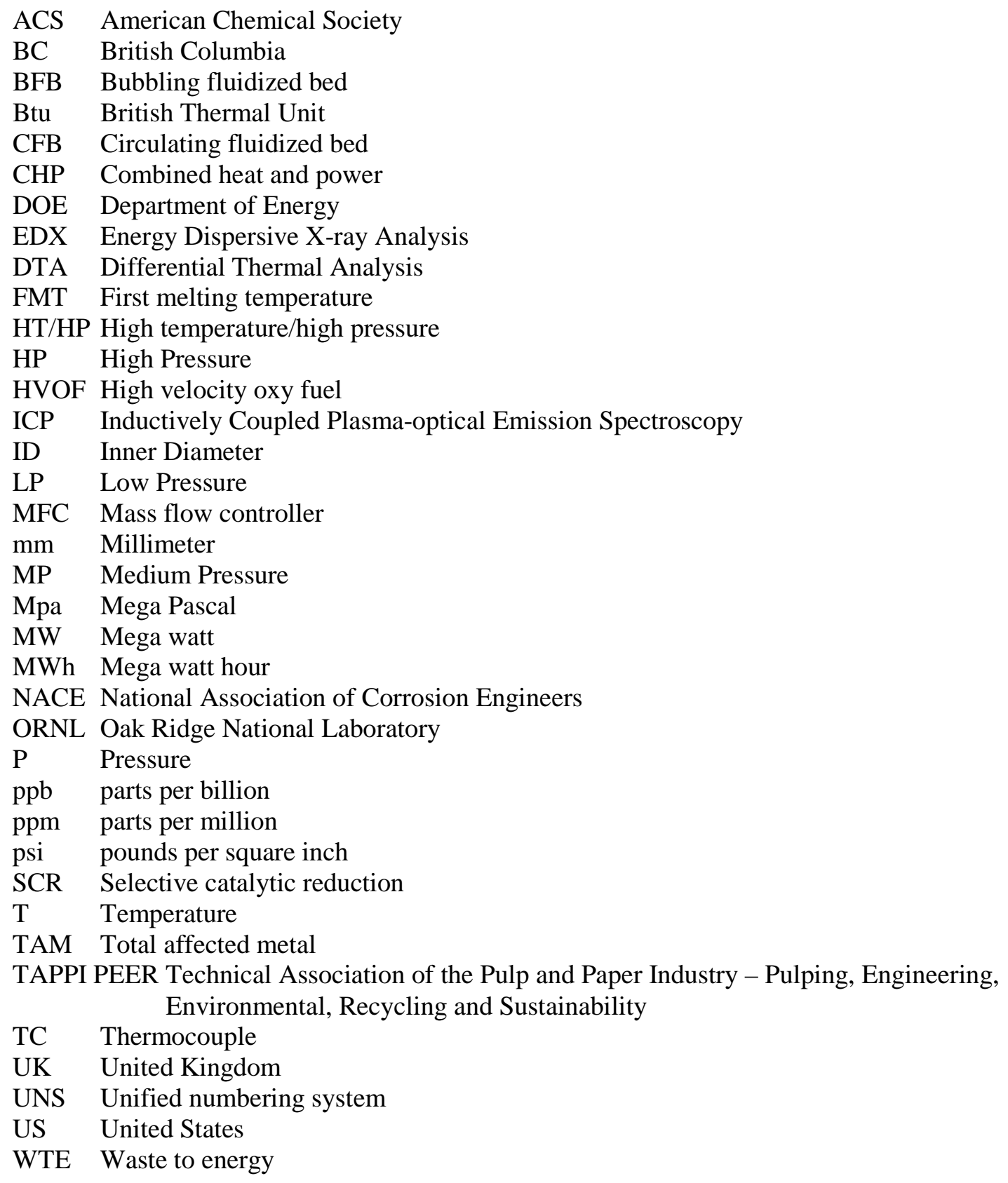




\section{EXECUTIVE SUMMARY}

Combustion of biomass has been used by industry to produce steam and power for many years, but new technologies are being introduced to better recover the energy from biomass as well as to produce a synthetic gas (syngas) that can be used as a starting point in the production of automotive and diesel fuels as well as higher value chemicals. It is of significance that operating temperatures in combustion and gasification systems are often restricted by materials limitations resulting from the degradation of materials in the highest temperature areas. For systems recovering heat and/or generating steam, operating limits are often imposed by degradation of the superheater tubes that recover heat from the combustion gases at the highest temperatures.

The steam temperature of biomass fueled boilers is limited by high temperature corrosion of superheater alloys in the ash deposit/flue gas environment. During visits with European researchers and boiler manufacturers and operators, it was learned that advanced European biomass boilers combine design modifications, process changes and corrosion resistant alloys to achieve substantially higher steam temperatures and efficiencies than U.S. biomass boilers. Design modifications to reduce superheater corrosion include adding an "empty pass" between the furnace and the superheater, installing cool tubes to trap low melting temperature chlorine deposits ahead of the superheater, heating the final superheater in the recirculated fluidizing medium of a circulating fluidized bed boiler, operating with a slagging superheater, designing superheaters for quick replacement, raising the superheater temperature above the dew point of the most corrosive deposits and installing an external superheater fired by a less-corrosive fuel. Process changes include diluting corrosive biomaterials with less-corrosive fuels, adding high sulfur fuels to convert alkali chlorides to lower melting temperature sulfates before they reach the superheater, washing chlorides out of agricultural residues and adding chemicals that convert alkali chlorides to aluminosilicates.

Another approach to enabling biomass boilers to operate at higher temperatures is to use superheater tube alloys that are resistant to corrosion in the ash deposit/flue gas environment. Alkali salts are generally the most aggressive components in the deposits that develop during combustion of biomass fuels. They can cause corrosion directly by fluxing the $\mathrm{Cr}_{2} \mathrm{O}_{3}$ layer, and they can reduce the ash FMT, either causing agglomeration and fouling or forming corrosive molten deposits. Lead and zinc impurities in demolition wood are very corrosive, primarily because they form very low melting temperature ash components.

A laboratory corrosion study was conducted to assess and compare the corrosion that occurs above and below deposits on the same coupon in simulated fireside superheater environments. Tests were conducted with three different salt environments that were selected on the basis of analysis of deposits collected from probes exposed in three boilers of interest. Tests were conducted at three temperatures, 510, 530 and $625^{\circ} \mathrm{C}$, which were chosen to be just below, just above and well above the first melting point of some of the salts of interest. Samples were selected from eleven different alloys that were included in the testing program. Exposure times ranged up to 1000 hours, and samples were evaluated through thorough examination of the cross-sections. Performance of the alloys varied considerably as a function of test conditions; under the most severe conditions none of the alloys was considered acceptable while all alloys tested were considered acceptable in the least aggressive environments. Overall, alloy N06025 was one of the top two alloys in terms of corrosion resistance in almost all the test conditions used.

Alkali metal salts and particularly molten salts are recognized as playing a major role in degradation of superheater tubes, and consequently, in limiting the maximum steam outlet temperature. Since nearly all metallic alloys depend on an oxide layer to limit corrosion rates, a study was conducted to determine the solubility of metal oxides that would be associated with common structural alloys in a molten salt typical 
of a biomass-fired boiler. A salt mixture of $73.9 \mathrm{wt} \% \mathrm{Na}_{2} \mathrm{SO}_{4}, 10.2 \mathrm{wt} \% \mathrm{KCl}, 11.5 \mathrm{wt} \% \mathrm{Na}_{2} \mathrm{CO}_{3}$, and 4.4wt $\% \mathrm{~K}_{2} \mathrm{SO}_{4}$ was used in this study and the solubility of metal oxides was found to be $\mathrm{NiO}<\mathrm{Fe}_{2} \mathrm{O}_{3}<$ $\mathrm{Cr}_{2} \mathrm{O}_{3}=\mathrm{Al}_{2} \mathrm{O}_{3}<\mathrm{SiO}_{2}$ where $\mathrm{NiO}$ was the least soluble, $\mathrm{SiO}_{2}$ the most soluble, while $\mathrm{Cr}_{2} \mathrm{O}_{3}$ and $\mathrm{Al}_{2} \mathrm{O}_{3}$ had roughly equivalent solubility.

Corrosion probes containing multiple specimens of nine different alloys were exposed for at least 2,000 hours in the superheater area of three biomass boilers where the deposits were determined to be enriched in potassium or chlorine. Similar specimens were also exposed in a boiler co-firing coal and wood. For the probes, specimen temperatures ranged from a low of less than $400^{\circ} \mathrm{C}$ to temperatures above $600^{\circ} \mathrm{C}$ for all but one case. Following exposure, a section was taken from each specimen and examined using light microscopy and scanning electron microscopy. Results of the examination of these specimens showed some alloys performed considerably better than others, and the performance was a function of the environment. For the potassium-rich environment, alloys S21500 and S34709 showed the greatest corrosion resistance at a temperature 100 Celsius degrees above the maximum boiler temperature. For the chloride-rich environment, alloys N08120, S21500 and S34709 showed the least amount of affected material at 100 Celsius degrees above the maximum boiler temperature.

In the fourth task of this project the relationship between the temperature of superheated steam produced by a boiler and the quantity of power that it can generate was addressed. Thermodynamic analysis determined the amount of additional power that could be generated by operating with higher superheated steam temperatures. Calculations were made for five plants that produce both steam and power two of which were powered by black liquor recovery boilers and three by wood-fired boilers. Steam generation parameters for these plants were supplied by industrial partners. Calculations using thermodynamicsbased plant simulation software showed that the value of the increased power that could be generated in these units by increasing superheated steam temperatures by 100 Celsius degrees above current operating conditions ranges between $\$ 2,410,000$ and $\$ 11,180,000$ per year. The costs and benefits of achieving higher superheated steam conditions in an individual boiler depend on local plant conditions and the price of power. However, the magnitude of the increased power that can be generated by increasing superheated steam temperatures is so great that it appears to justify the cost of corrosion-mitigation methods such as installing corrosion-resistant materials costing far more than current superheater alloys, redesigning biomass-fueled boilers to remove the superheater from the flue gas path, or adding chemicals to remove corrosive constituents from the flue gas. The most economic pathways to higher steam temperatures will very likely involve combinations of these methods. Particularly attractive approaches include installing more corrosion-resistant alloys in the hottest superheater locations, and relocating the superheater from the flue gas path to an externally-fired location or to the loop seal of a circulating fluidized bed boiler. 


\section{INTRODUCTION AND BACKGROUND}

Utilization of biomass is emerging as a promising approach to produce fuels and chemicals because it reduces the dependence of the United States on petroleum, and particularly petroleum imported from foreign countries whose political stability is uncertain. The U.S. has been highly dependent on foreign sources of petroleum, and there are well-publicized efforts underway in the U.S. to reduce that dependence through use of the extensive coal and natural gas resources as well as the development of technology and infrastructure to better utilize biomass and other renewable resources. For biomass utilization, several routes are available: combustion, torrefaction, liquefaction and gasification. This project addressed materials issues related to combustion of biomass or by-products derived from biomass.

Experience in North America and Europe with conventional fuels has shown the vulnerability of superheater tubes to a variety of corrosion mechanisms, and the upper operating temperature is generally limited by the corrosion rate of the superheater tubes. The limit is generally associated with the melting point of deposits that accumulate on tubes, and potassium and chlorine components of these deposits reduce their first melting point temperature. An example of superheater tube degradation in a wood waste power boiler is shown on the left side of Figure 1 [1].

As the use of biomass fuels becomes more common and as the variety of fuel sources increases, additional corrosion problems are anticipated. Extensive use of other plant and animal materials as well as municipal waste and refuse derived fuel will likely add sulfur, chlorine, additional alkali metals, and, possibly heavy metals, to the list of elements in the fuel that can cause corrosion problems. An indication of the magnitude of the increase in corrosion rate around the deposit melting temperature is shown on the right side of Figure 1where the weight loss of a fairly corrosion resistant alloy, type 310 stainless steel, is shown as a function of temperature.

Energy prices are a critical component of manufacturing costs in North American process industries and these prices along with the increasing emphasis on greenhouse gas reduction are presenting a challenge to energy intensive industries that currently consume large amounts of fossil fuels. In response, companies are looking to non-traditional fuels based on biomass to help address these critical issues and allow them to remain competitive in a global marketplace.

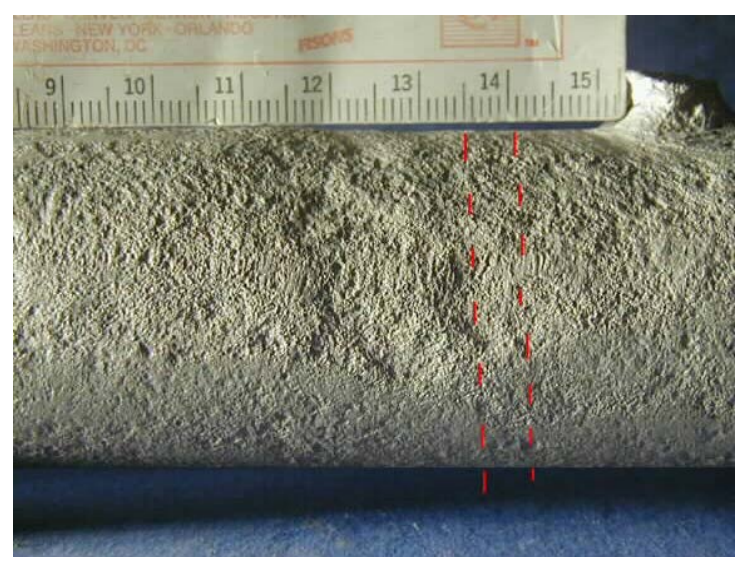

Fig. 1. Type $310 \mathrm{H}$ stainless steel tube exposed 36 months in a wood-fired power boiler. 


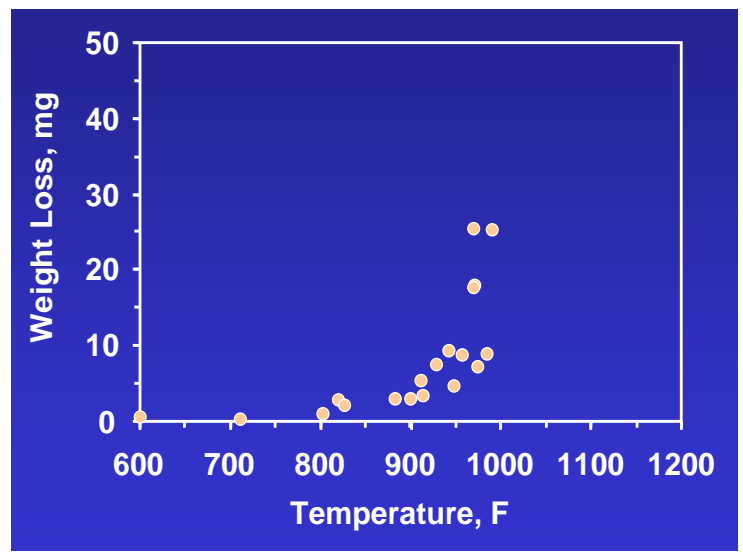

Figure 2 Corrosion rate as a function of temperature for type 310 stainless steel exposed to low melting temperature deposits.

However, relative to coal and natural gas, biomass-based fuels are extremely inhomogeneous and contain significant impurities, such as chlorides, alkali metals and heavy metals that deposit on heat transfer surfaces. While these deposits may reduce the overall energy efficiency of the boiler, their principal effect is to cause rapid corrosion of heat transfer surfaces that approach, or exceed, the first melting point of the deposits. As a consequence, boilers burning biomass have largely been limited to operating with superheater steam temperatures of less than $510^{\circ} \mathrm{C}\left(950^{\circ} \mathrm{F}\right)$ and steam pressures of less than $11 \mathrm{MPa}$ (1600 psi). Most existing biomass boilers in North America operate at substantially lower steam temperatures and pressures, particularly those utilized as waste utility boilers. In contrast, the most modern utility boilers burning coal are intended to operate at $26 \mathrm{MPa}(3800 \mathrm{psi})$ with $615^{\circ} \mathrm{C}\left(1140^{\circ} \mathrm{F}\right)$ superheated steam temperatures, and research programs are in-place to help design and build even more efficient boilers by the year 2015 .

While small, incremental gains in energy efficiency can be met by improving operation of existing biomass-fired boilers, much larger gains could be obtained by designing and building biomass boilers that operate with substantially higher pressures and superheater steam temperatures (HT/HP) than is the current practice. To gain this enhanced energy efficiency and retain operational reliability, challenging materials problems in the areas of high temperature strength and environmental degradation must be overcome, particularly at temperatures near or above the first melting point of the superheater tube deposits. Within the design envelope of existing biomass-based boilers, the use of higher chromium

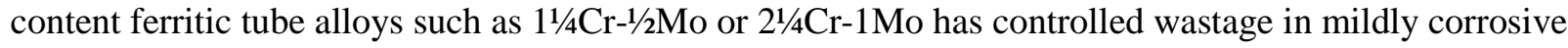
conditions at operating temperatures below the first melting point. Under more corrosive conditions at temperatures close to the first melting point of deposits, austenitic tube alloys such as $304 \mathrm{H}, 310 \mathrm{H}, 316 \mathrm{H}$, $321 \mathrm{H}$ and $347 \mathrm{H}$ have been used. For temperatures at or just above the first melting point of deposits, the iron-nickel-chromium alloys such as $800 \mathrm{H}, 800 \mathrm{HT}$ or nickel-chromium-molybdenum alloys like 625 have also been used, but with mixed success. However, no alloys have yet been found that would allow biomass-fueled boilers to approach the energy efficiency of coal or gas utility boilers.

This project provided a completely new approach with a potential for significant benefit. The research identified superheater materials and superheater designs that could survive molten or partially molten deposits and thus increase the energy derived from biofuels (and/or reduce other fuel requirements) as well as enabling use of more contaminated (more corrosive) fuels. Improved superheater materials could improve the energy efficiency of chemical plant boilers recovering heat from process wastes, municipalities producing electricity from garbage incineration and tire-derived fuel boilers as well as the forest products industry's biomass-fueled black liquor recovery boilers and hogged fuel boilers.

Currently, this represents a very significant market, and it most certainly is going to expand with the 
growing emphasis on decreasing the production of greenhouse gases and with the potential for increasing prices of imported fossil fuels.

The overall project sought to address environmental performance improvements of superheater tube materials for enhanced heat recovery, reliability and competitiveness in biomass-fueled steam generating systems. The challenge to obtaining increased energy efficiency was to clearly identify all operative corrosion mechanisms in the superheaters when operating at temperatures 100 Celsius degrees above current temperatures which likely means above the first melting point of the deposits, and then addressing solutions to each of these mechanisms in turn. This was achieved by a program that combined thermodynamic analyses, laboratory studies, and in situ probes to explore and expand the operating envelope of future biomass-fueled steam generating systems.

This project had the goal of recovering more energy from biomass fuels by operating superheater tubes with a maximum temperature 100 Celsius degrees higher than current maximum temperatures. To achieve this higher temperature the project considered the use of alternate superheater tube materials, alternate superheater designs, and/or techniques to remove from the gas stream the components causing tube degradation. In addition, a separate task addressed the financial benefits of operating boilers with higher superheater temperatures as well as the cost of the alternate technologies.

The studies conducted in this project were divided into four primary tasks. The first task consisted of conducting a critical review of the status of biomass combustion technologies and corrosion of superheater tube materials in biomass-fired boilers. Because of taxes and incentives being used in Europe to discourage greenhouse gas production and to encourage utilization of renewable fuels, a greater effort is being made there to utilize biomass resources. This includes development of new technologies and improvements on existing technologies. Consequently, team members visited many research and operating facilities and met with corporate staff members of utilities and equipment manufacturers to learn about and collect information on research efforts, evaluations of alternate materials and processes in operating systems and practical experience from unique systems.

A second task consisted of well-controlled laboratory studies to evaluate alternate superheater tube materials in environments simulating the conditions of particularly aggressive environments. An extensive testing program was defined using alloys selected by a team of the research partners, the alloy producers and the boiler manufacturers. The test environments were selected to simulate the environments in several types of biomass-fired boilers. The temperatures, times and environments (salt deposits and cover gases) were selected on the basis of the information collected during the aforementioned critical technology review as well as in consideration of the results from the analysis of deposits collected from sampling probes exposed in several biomass-fired boilers.

A more basic aspect of the laboratory testing program was a determination of the solubility of various alloy oxides $\left(\mathrm{Cr}_{2} \mathrm{O}_{3}, \mathrm{Al}_{2} \mathrm{O}_{3}, \mathrm{SiO}_{2}\right)$ in molten salts of approximately the same compositions as the deposits collected from one of the biomass boilers.

As part of a third task, deposit sampling probes were used to collect superheater deposits from three biomass boilers whose fuel had the potential to create particularly corrosive environments. Analysis of the deposits from these probes provided information for selection of the environments for the laboratory corrosion testing as well as information on the environments to which the corrosion probes were to be exposed.

Air-cooled, controlled temperature corrosion probes (like those developed and used in a previous project on superheater corrosion) [2] were used to measure corrosion rates on candidate materials in four boilers. The goal was to expose the corrosion probes to conditions such that the coolest samples were just below 
what was assumed to be the first melting temperature of the deposits, while other samples were at a temperature where the deposits were partially, but not fully, molten and the hottest samples were exposed under slagging conditions, e.g. with a goal of operating around 30 Celsius degrees above the temperature at which the deposits are fully molten. Corrosion probes were built from materials likely to be able to survive the test conditions, for example the most advanced alloy currently serving in superheaters and advanced $\mathrm{Na}_{2} \mathrm{SO}_{4} / \mathrm{NaCl}$-resistant gas turbine alloys that rely on different types of barrier oxides for corrosion protection (e.g. $\mathrm{Al}_{2} \mathrm{O}_{3}$-formers as well as $\mathrm{Cr}_{2} \mathrm{O}_{3}$-formers). Selection of candidate alloys was made in consultation with the advanced alloy manufacturers, other researchers as well as boiler fabricators and operators represented in the Industrial Partners.

In order to facilitate commercialization, another task in this project provided calculations to determine the extent to which the energy benefits of operating modified superheaters at much higher temperatures would pay for much more expensive tube materials, for alternate superheaters designs, or for the removal of the fuel contaminants that cause the low the first melting temperature of the deposits. The original idea was to develop software to calculate the energy benefits (or fuel savings) that could be achieved by increasing the steam outlet temperature of any given boiler. However, it was determined that suitable software already existed although it had not been used with the same objective in mind. Data on boiler operating parameters were collected from operators and designers of biomass boilers, and this information was used with the selected software to determine whether the savings that could be achieved by operating boiler superheaters at temperatures 50 or 100 Celsius degrees hotter. After inputting costs to replace superheater pendants, it was possible to determine the per foot cost that could be paid for superheater tubing made from advanced materials (for specified superheater service lives and specified future energy prices) that would be justified by increased steam temperatures. The software was also used to determine whether the cost of removing low melting temperature fuel constituents could be justified by increased thermal efficiencies available by raising the deposit first melting point temperature.

Results from each of these tasks are described in detail in the following sections. 


\section{RESULTS}

\subsection{ASSESSMENT OF ALTERNATE TECHNOLOGIES}

The information presented in this subsection was taken from three recent publications for which Sandy Sharp was the lead author [3-5].

\subsubsection{Design Modifications to Inhibit Superheater Corrosion}

Rather than trying to increase the efficiency of biomass boilers by operating with superheater tube temperatures above the melting temperature of fly ash deposits, European operators use conventional austenitic superheater tube materials such as Type 347HFG (UNS S34710), Sanicro 28 (UNS N08028) and AC66 (UNS S33228). They have explored many design modifications to reduce the corrosivity of the environment where the superheater tubes are installed and this review will discuss seven of these modifications. Many boilers remove ash deposits upstream of the superheater and/or remove the final superheater from the flue gas stream, a few operate with molten deposits dripping off the outer surface of the tubes, a few use rapidly-replaceable superheater units and at least two operate with superheater tube temperatures above the dew point of the corrosive ash deposits. We will discuss each of these design modifications in turn.

\subsubsection{Remove ash deposits upstream of the superheater by adding an empty pass}

Extending the length of the passage between the furnace and the superheater or adding a separate radiant pass (empty chamber) between them has two benefits. It allows more time for the completion of chemical reactions in the flue gas (e.g. to convert chlorides to lower melting temperature sulfates) and it allows undesirable ash components to fall out of the flue gases before they reach the superheater. This design is particularly appropriate in waste-fired boilers where the superheater would otherwise suffer severe fouling and corrosion.

Figure 3 shows a boiler with this type of radiant pass [6,7]. It is a Circulating Fluidized bed (CFB) boiler designed by Foster Wheeler for the Igelsta power plant of Söderenergi AB, located in Södertälje south of Stockholm, Sweden and started up in March 2010. It is designed to co-fire either mixtures of biomass (mainly wood residues) with up to $25 \%$ of recycled fuel pellets (i.e. municipal waste) or up to $70 \%$ recycled wood with other biomass. The Igelsta boiler has an output of $92 \mathrm{~kg} / \mathrm{s}$ (73,000 lbs/hour) of steam, at $90 \mathrm{bar}(1,305 \mathrm{psi})$ and $540^{\circ} \mathrm{C}\left(1,004^{\circ} \mathrm{F}\right)$. It produces $73 \mathrm{MW}$ of electricity and $219 \mathrm{MW}$ of district heating, with a plant efficiency of nearly $110 \%$ (LHV) or $>90 \%$ (HHV). To avoid fouling and corrosion the unit has:

- Its final superheater located in the recirculated fluidizing medium, rather than in the flue gas environment of the convective pass.

- An empty pass to increase residence time for the flue gases to cool and clean themselves before reaching the convective superheaters

- Water cannons on the sides of the empty pass to clean the walls of this empty pass and spring hammers to remove deposits from the convective superheaters

- Addition of sulfur granules [7] to raise the first melting temperature (FMT) of the superheater ash

- Hanging austenitic superheaters that are easily replaceable through the roof

To control the emissions from this unit, ammonia is added to control $\mathrm{NO}_{\mathrm{x}}$, sodium bicarbonate to capture sulfur, activated carbon to capture mercury and a bag filter to capture dust. 


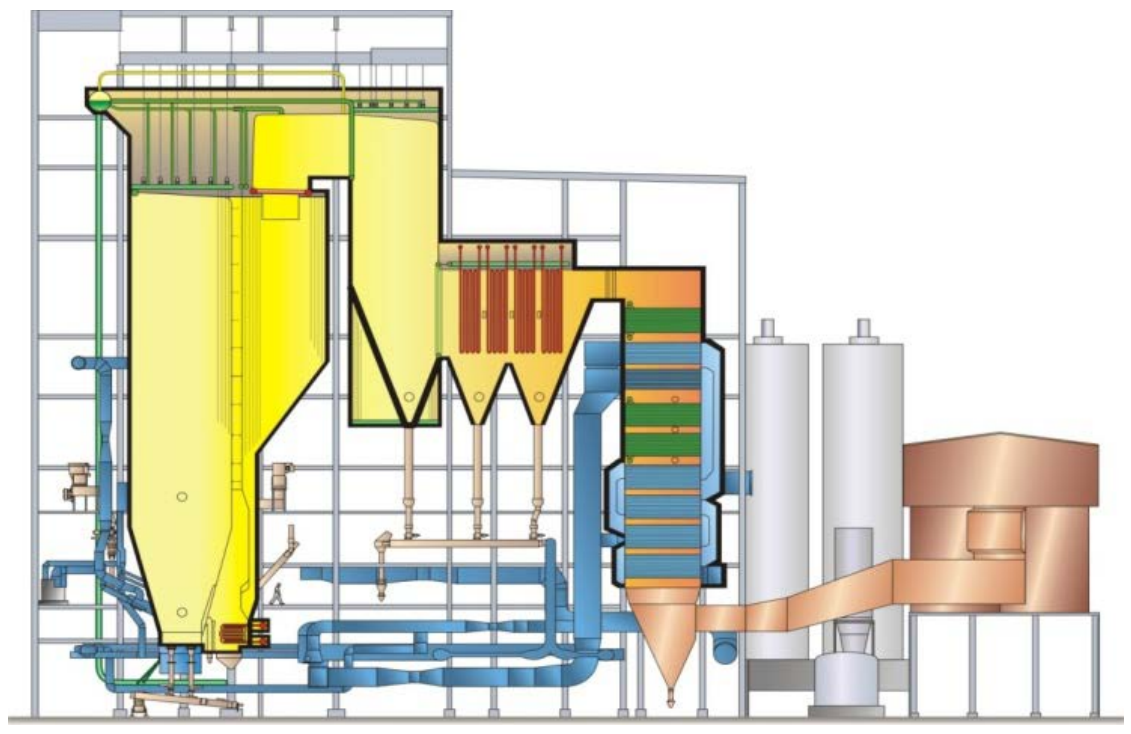

Fig. 3. Schematic drawing of Iglesta CHP boiler at, Södertälje, Sweden [6]

A similar empty “radiation pass" between the furnace and the superheater, designed into a waste-toenergy plant at Norrköping, Sweden has been described by Enestam, Lehtonen and Heikne [8].

\subsubsection{Remove ash deposits upstream of the superheater by adding a "Chlorine Trap"}

Another approach to removing ash deposits upstream of the superheater tubes was implemented after intensive field studies in a waste-to-energy boiler at the GKS power plant in Schweinfurt, Germany [9]. The arrangement of this boiler is shown schematically in Figure 4 [10]. It operates with steam parameters of 65 bars and $435^{\circ} \mathrm{C}\left(943 \mathrm{psi}\right.$ and $\left.815^{\circ} \mathrm{F}\right)$. The boiler faces substantial fouling and corrosion problems because its waste fuels contain high chloride concentrations. The fuel is fired on a grate. After reaching the top of the furnace the flue gases turn downwards through an empty pass like that described above in the Södertälje boiler. As the flue gases turn to flow upwards at the bottom of this empty pass they encounter a section of cool furnace screen tubes, shown schematically in Figure 5. Low melting temperature ash components that remain in the flue gases after the empty pass condense on the cool furnace screen tubes and form the massive deposits shown in Figure 6. Because these deposits are enriched in chlorine, the low temperature screen tube section has been named a "chlorine trap" by its inventor Ragnar Warnecke. The low temperature screen tubes operate at temperatures between 300 and $400^{\circ} \mathrm{C}$ ( 572 to $752^{\circ} \mathrm{F}$ ). Massive deposits accumulate with molten material on their outer surface. These deposits are removed by sootblowing only once each day. Operating personnel suggest that the molten ash on the fireside of the deposits may block the inward diffusion of chlorine-containing gases released by the sulfation of alkali metal chlorides in the flue gas stream and thus reduce the corrosion rate of the underlying tubes [11].

A similar shield of cool tubes was installed to protect the superheater of a CHP plant at Grenå, The Netherlands [13]. This plant has a capacity of $18 \mathrm{MW}$ of electricity and $60 \mathrm{MW}$ of heat. It burns coal containing up to $60 \%$ straw - or coal alone. The fuel is mixed in the boiler furnace with an inactive material (sand or ash) and combusts at a relatively low and uniform temperature $\left(850^{\circ} \mathrm{C}\right)$ to reduce $\mathrm{NO}_{\mathrm{x}}$ emissions and to allow desulfurization to take place in the furnace. Although firing straw would have produced rapid corrosion, co-firing straw with coal reduced corrosion to manageable rates except in the external ash cooler, which receives recycled "ash” (fluidizing medium) from the cyclones and contains the hottest superheaters (removed from the convective pass to avoid corrosion). Unfortunately, the recycled "ash" included unburned particles that contained enough chlorine to corrode the superheaters. 
Resulting design changes included keeping metal temperatures in the convective pass below about $450^{\circ} \mathrm{C}$ $\left(842^{\circ} \mathrm{F}\right)$. As at Schweinfurt, this was achieved by increasing the residence time between the furnace and the first superheater and by installing a low temperature evaporator tube bundle immediately ahead of the first superheater tubes in the convective pass. Heat recovered in this evaporator section helped to compensate for the restriction of heat transfer by thick refractory coatings on the waterwalls. The final superheater at Grenå was located outside the convective pass, as will be described in Section 7.

\subsubsection{In CFB boilers, move the final super heater out of the flue gas stream into the recirculated fluidizing medium or recirculated ash}

Fluidized bed boilers burn solid fuel particles suspended on upward-blowing air jets. The tumbling action within the fluidized bed provides excellent mixing and air for combustion. This quickly heats the fuel particles to the bed temperature and promotes the completion of combustion reactions. Fluidized bed boilers can typically burn a wide variety of fuels. Limestone particles can be added to the bed to react with $\mathrm{SO}_{\mathrm{x}}$ to reduce sulfur emissions and to improve conductive heat transfer to the wall tubes. Fluidized bed boilers are of two types, bubbling fluidized bed boilers and circulating fluidized bed boilers. Bubbling fluidized bed boilers (BFBs) are normally used to burn lower-quality fuels that contain substantial volatile matter. Operating them with sub-stoichiometric amounts of combustion air pyrolizes the fuel in the furnace prior to complete combustion. Most of the fluidizing medium remains in the

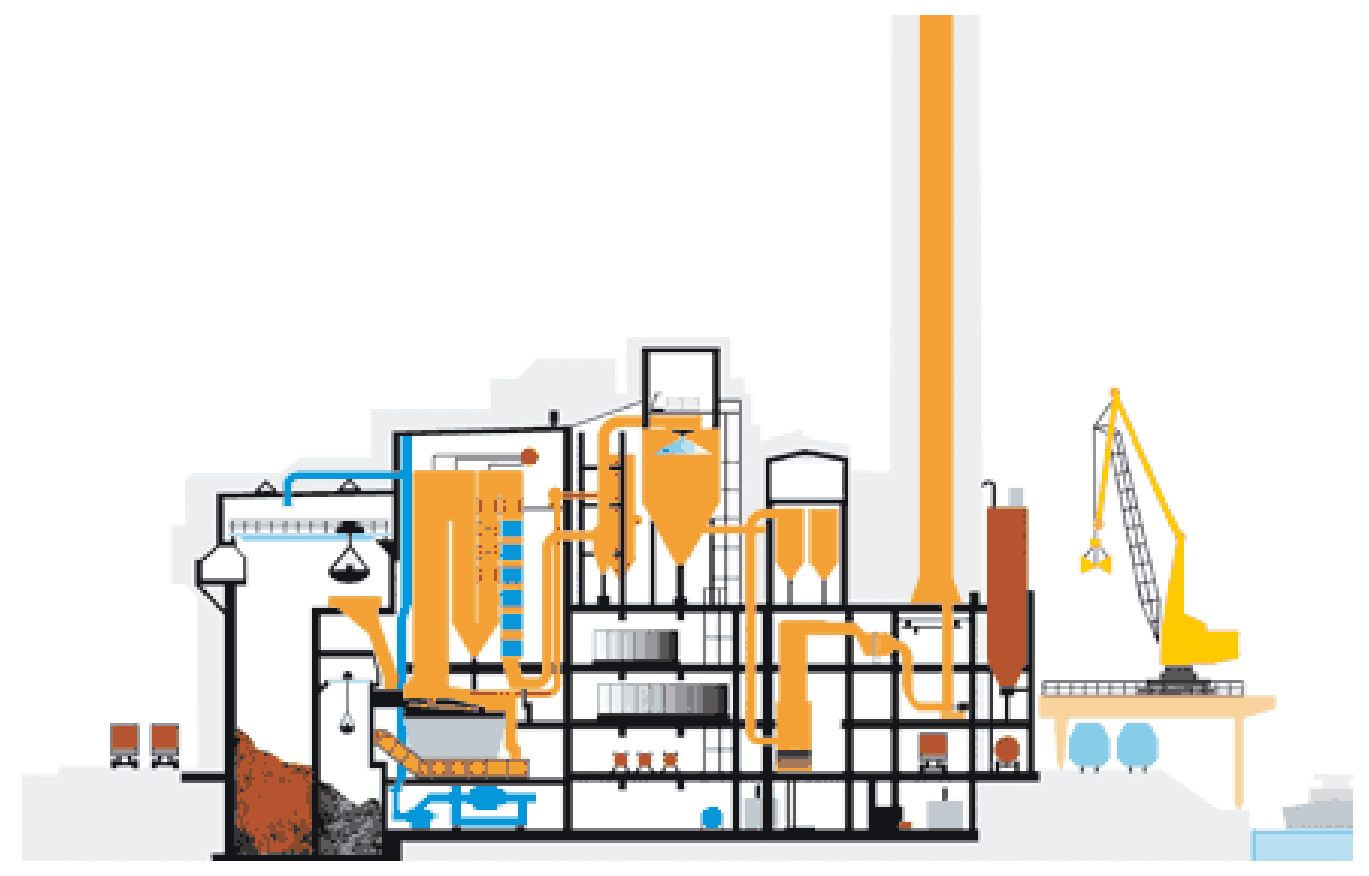

Fig. 4. General arrangement of Schweinfurt waste-to-energy boiler [10]

furnace. The inorganic ash that remains after the organic components are burned either falls into a hopper at the bottom of the furnace or is carried forward with the flue gases as fly ash particles. Some of this fly ash will be collected in hoppers under the economizer and air heater tubes and the rest will be removed by electrostatic precipitators or bag filters.

Circulating fluidized bed boilers (CFBs) are different. Their combustion gases propel fluidizing particles (e.g. sand) out of the furnace. The sand and the ash are separated by the difference in their specific 


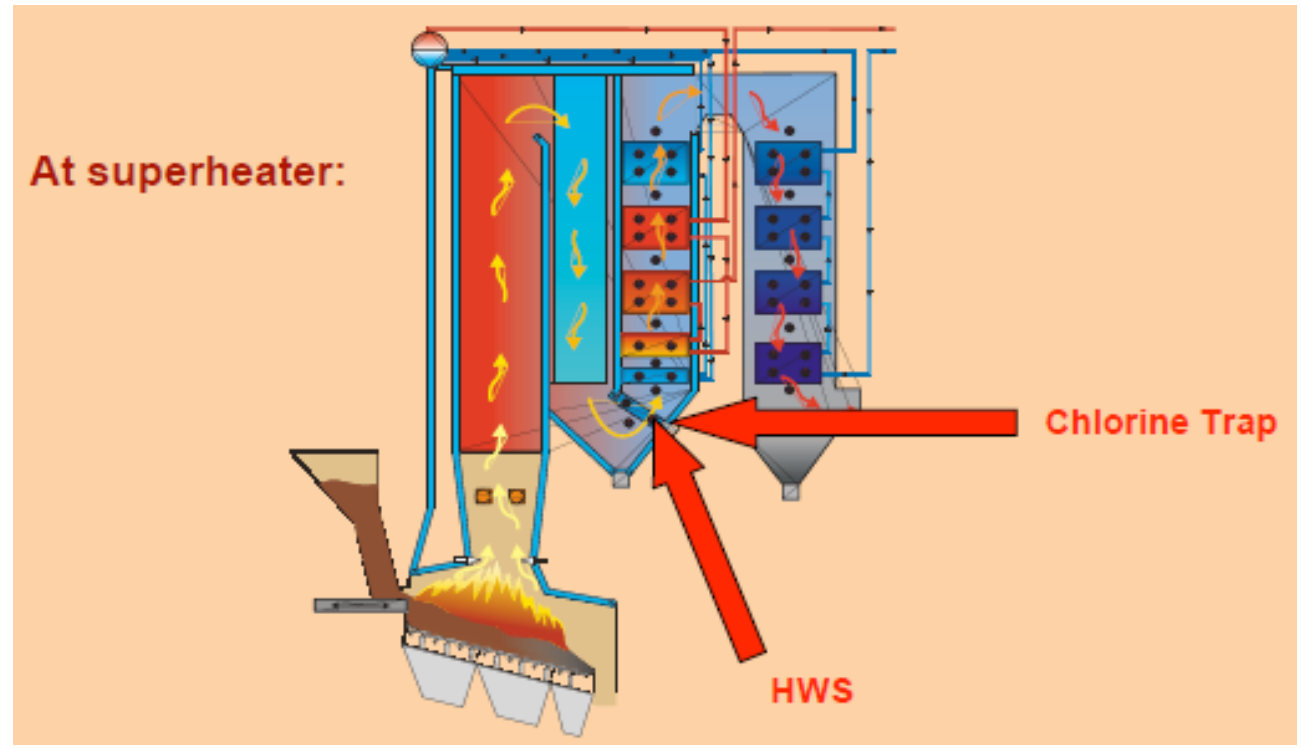

Fig. 5. “Chlorine trap” and Horizontal Wash System in Schweinfurt boiler [9]

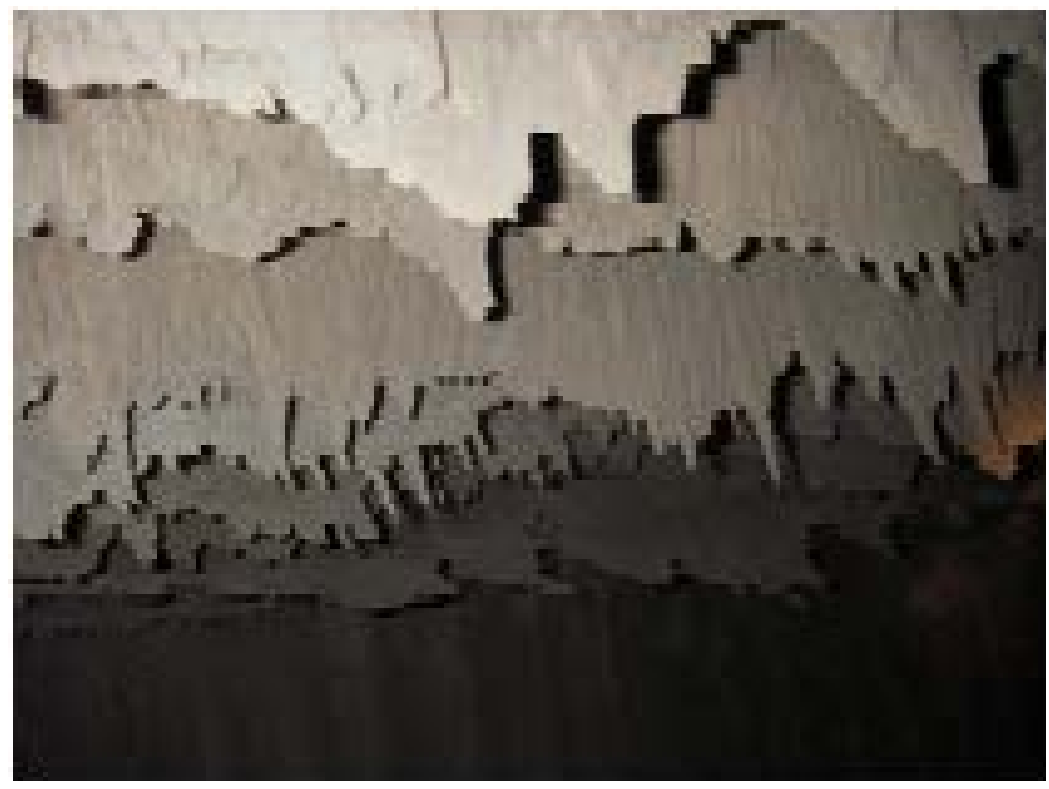

Fig. 6. Accumulation of low-melting temperature deposits on Schweinfurt low temperature screen tubes [12]

gravity and particle size. Most of the ash is carried forward into the convection section of the boiler with the flue gas while almost all the sand particles fall into a cyclone and are returned to the bottom of the furnace. The flue gases, prevented from recycling to the bottom of the furnace both by the pile of hot sand in the bottom of the cyclone and by a loop seal device, pass on through the convective passages of the boiler. Because the sand particles cool only very slightly before returning to the boiler, it is possible to locate the final superheaters in the recirculated fluidizing medium between the loop seal and the bottom of the boiler. Five to ten times more heat per unit area is transferred to these immersed superheater tubes than to tubes in a conventional superheater [14]. Also, the superheater tubes have much less exposure to alkali metal salts and corrosive gases like $\mathrm{HCl}$ and water vapor than they would have in the convective passage. CFB designs with the final superheater located between the loop seal and the furnace bottom have been commercialized in Foster Wheeler's INTREX design [15] and in Metso's CYMIC boilers [16], 
shown in Figures 7 and 8. Many of the most recently built biomass boilers use this approach to control superheater corrosion.

Erosion damage in these relocated superheaters is not rapid because the sand velocities are low. Nafari and Nylund [17] measured thinning rates of superheater tubes installed in the loop seal of a small woodfired CFB boiler in Nässjö, Sweden that produces 5MW of electricity plus $20 \mathrm{MW}$ of district heat. The steam temperatures at the inlet and outlet of the superheater were 470 and $540^{\circ} \mathrm{C}\left(878\right.$ and $\left.1004^{\circ} \mathrm{F}\right)$, and the authors anticipated that the tube surface temperatures would be 50 to 100 Celcius degrees (90 to 180 Fahrenheit degrees) higher than these values. Tube thinning rates increased with tube temperature, but tubes exposed for about 16 months showed no more wastage than tubes exposed for about 7 months. The corrosion products consisted of an inner layer of $\mathrm{Cr}$ and $\mathrm{Fe}$ oxides beneath an outer Fe-rich oxide.

Chlorides, potassium and sulfur accumulated near the alloy/scale interface. Average material losses on Esshete 1250 (UNS S21500) and Type 347H (UNS S34710) were comparable and just slightly greater than those on Alloy AC66 (UNS S33228), although AC66 showed the most severe internal oxidation.

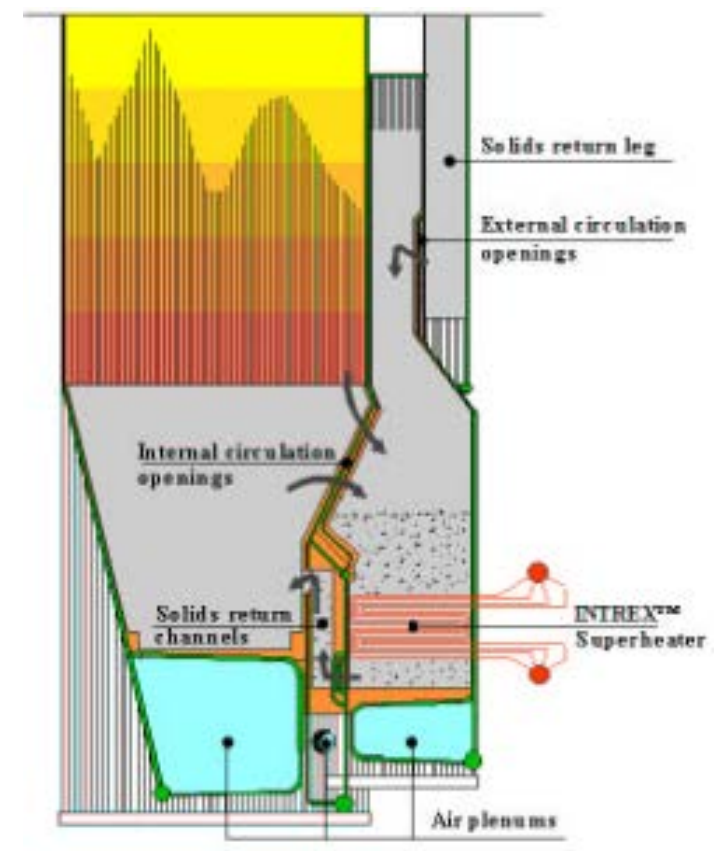

Fig. 7. Foster Wheeler INTREX loop seal superheater [15]

A second publication by Nafari and Nylund [18] reported additional tests of the same alloys and various coatings in the same loop seal location. Tube temperatures ranged from 510 to $550^{\circ} \mathrm{C}\left(950\right.$ to $\left.1022^{\circ} \mathrm{F}\right)$ and the loop seal ash contained 13\% Ca, 9\% K, 0.9\% Na, 800 ppm sulfate and 100 ppm chloride. Even the uncoated alloys suffered little corrosion during boiler operation. The fact that the degradation was no worse after two firing seasons than after one indicated that corrosion, rather than erosion, is the dominant deterioration mechanism. Austenitic steels suffered some internal oxidation and grain boundary attack. Although some coatings delaminated, 8 of the 17 coatings tested were unaffected by the exposure. Even the thickest oxides, on a $9 \% \mathrm{Cr}$ alloy, were only about $150 \mu \mathrm{m}(0.006 ")$ thick after about 7 months in service.

In boilers burning high-ash fuels, a bottom ash cooler can be added for additional heat recovery. A design by Lurgi Lentjes Energie, suitable for high ash fuels, moves the final superheater into the coolers that receive recycled CFB “ash” from the cyclones [13]. This is shown schematically in Figure 9. 


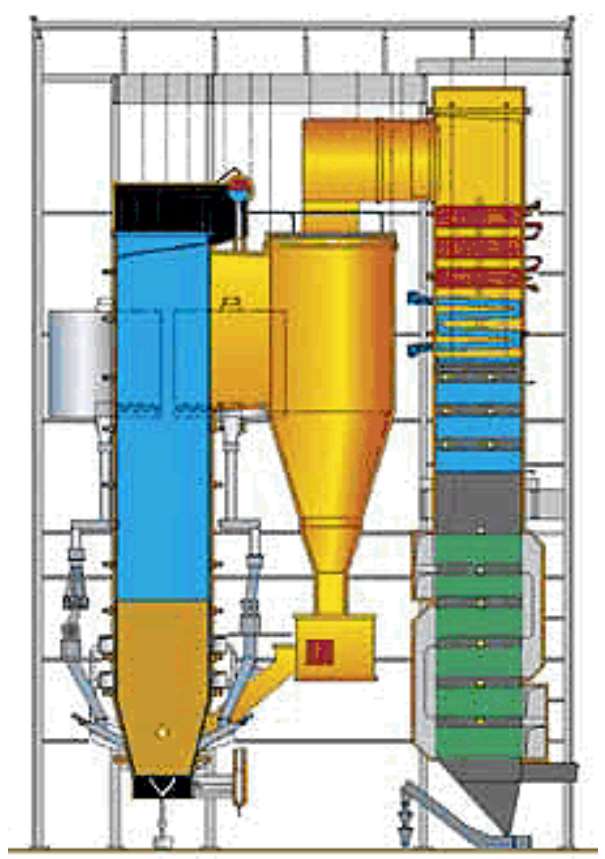

Figure 8: Metso CYMIC biomass boiler with loop seal superheater [16]

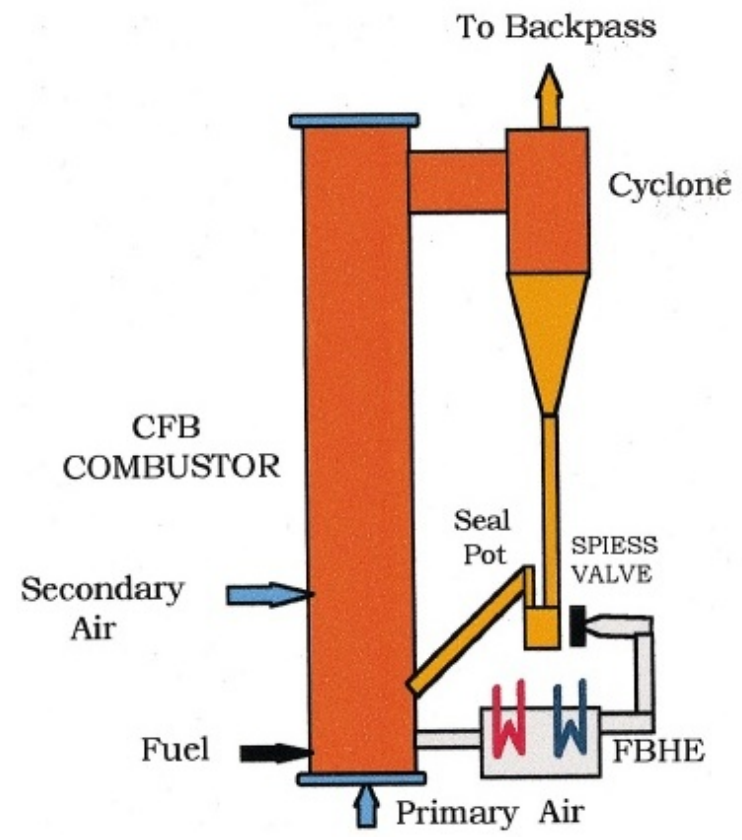

Fig. 9. Lurgi design for superheater in external "ash" cooler [19]

Using this type of external Fluidized Bed Heat Exchanger enabled the small-scale CHP plant in Grenå, Denmark to operate with a final steam temperature of $580^{\circ} \mathrm{C}\left(1076^{\circ} \mathrm{F}\right)$ while firing coal with straw containing up to $1 \%$ chloride, although the temperatures of superheaters within the convective path had to be restricted to $450^{\circ} \mathrm{C}\left(842^{\circ} \mathrm{F}\right)$ because of corrosion [13]. A pre-chamber was added to increase the time available to complete the removal of chlorides from unburned particles in recycled ash from this coal/straw-fired CFB. The solids separated by the cyclones are returned to the combustor via loop seals at the combustor exit temperature of 850 to $900^{\circ} \mathrm{C}\left(1562\right.$ to $\left.1652^{\circ} \mathrm{F}\right)$. The portion of the solids from the 


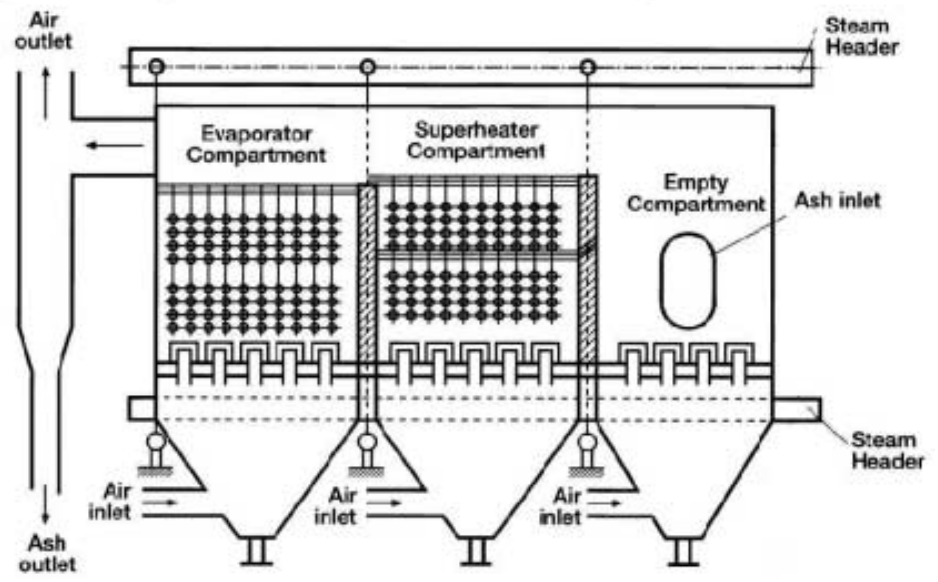

Fig. 10. Arrangement of Fluidized Bed Heat Exchanger in recirculated ash system [13]

seal pots that goes to the Fluidized Bed Heat Exchangers is returned to the combustor at 500 to $600^{\circ} \mathrm{C}$ (932 to $1112^{\circ} \mathrm{F}$ ). Changing the portion directed to the heat exchanger provides some additional control of the combustor temperature, which is useful for handling changing fuel compositions and low loads. The Lurgi design of external heat exchangers includes a fluidized empty chamber to increase the residence time and smooth the "ash" flow, followed by one or two heat exchanger chambers including the final superheater (Figure 10). The average "ash" residence time in these external superheaters varies between 3 and 20 minutes at full load operation [13].

\subsubsection{Move the final superheater out of the flue gas altogether and heat it with a less corrosive fuel}

In cases where a biofuel would produce particularly corrosive conditions on the superheater tubes some boiler designers have relocated the superheater tubes to a separate space outside the boiler cavity where they are heated by a less-corrosive fuel. As an example, we will consider the straw-fired boiler started up in 1998 at the Ensted power station of Sønderjyllands Højspændingsværk in the Danish city of Åbenrå [20]. Jensen and others showed that straw burning in this type of small grate boiler produced more rapid deposition and more severe corrosion than coal combustion [21]. Analysis of superheater deposits from the straw-fired boiler at Ensted found that underneath external iron oxides there was an intermediate layer of melted $\mathrm{KCl}$ with $\mathrm{Ca}$ - and Si-rich inclusions over an inner layer of iron oxides and potassium sulfate. Longer exposures produced thicker and denser inner layers of pure $\mathrm{KCl}$ and $\mathrm{K}_{2} \mathrm{SO}_{4}$. The authors concluded that a damaging cyclical corrosion mechanism called "active corrosion" occurred at the deposit/tube interface even when the deposit was several centimeters thick.

Because the straw burning was so corrosive, the maximum steam temperature in the Ensted biomass boiler had to be limited to $470^{\circ} \mathrm{C}$ and 210 bar (3,046 psi). However, the steam produced in the strawfired boiler was piped to an external superheater (Figure 11) where it was heated to the $542^{\circ} \mathrm{C}$ required for the steam turbine in a small furnace fired by much less corrosive wood chips. When steam raised by the biomass plant was connected in to the rest of the power plant (Figure 11), the overall plant efficiency was maintained at $40 \%$ - exceptional for this type of boiler. The two-unit boiler produces 37.5MW from its $78 \%$ straw $/ 22 \%$ wood chips fuel. The first boiler burns bales of straw on a water-cooled vibrating grate. The superheater portion feeds wood chips onto another vibrating water-cooled grate. The ash produced by biomass combustion is later spread as fertilizer on the farms where the trees were grown, as is done at Nässjö. 


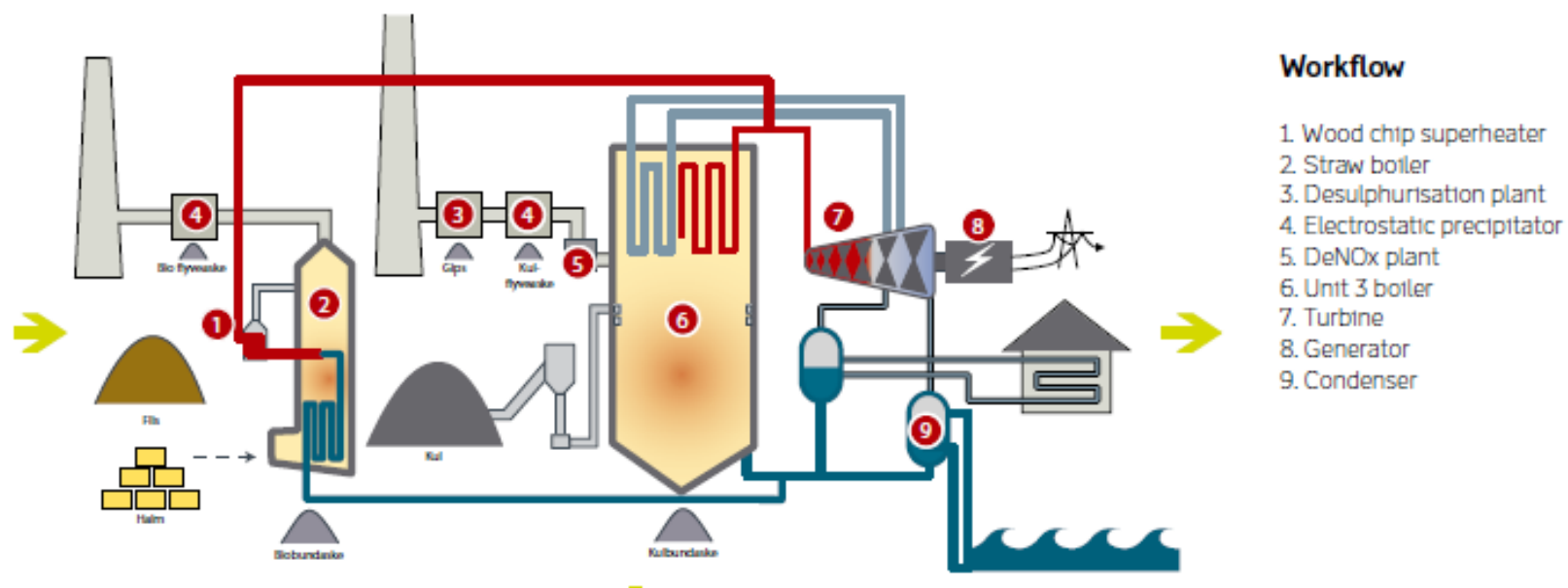

Fig. 11. Ensted EV3 biomass boiler with separate wood-fired superheater connected to steam system of coalfired unit [20].

\subsubsection{Design superheater units for very rapid replacement}

Another approach to enabling high steam conditions in boilers with corrosive superheater environments is to design the superheater units for rapid and simple replacement. This can enable a plant either to use lower cost alloys that have a limited life or to use high alloys that achieve a very high final steam temperature but also have a short life. An example is the CFB waste-to-energy boiler in E.ON's waste to energy (WTE) plant at Norrköping, Sweden. This boiler produces steam at about $450^{\circ} \mathrm{C}\left(842^{\circ} \mathrm{F}\right)$. Figure 12 shows the horizontal final superheater units, mounted in the loop seals downstream of each of the two cyclones, which were designed for easy replacement [8].

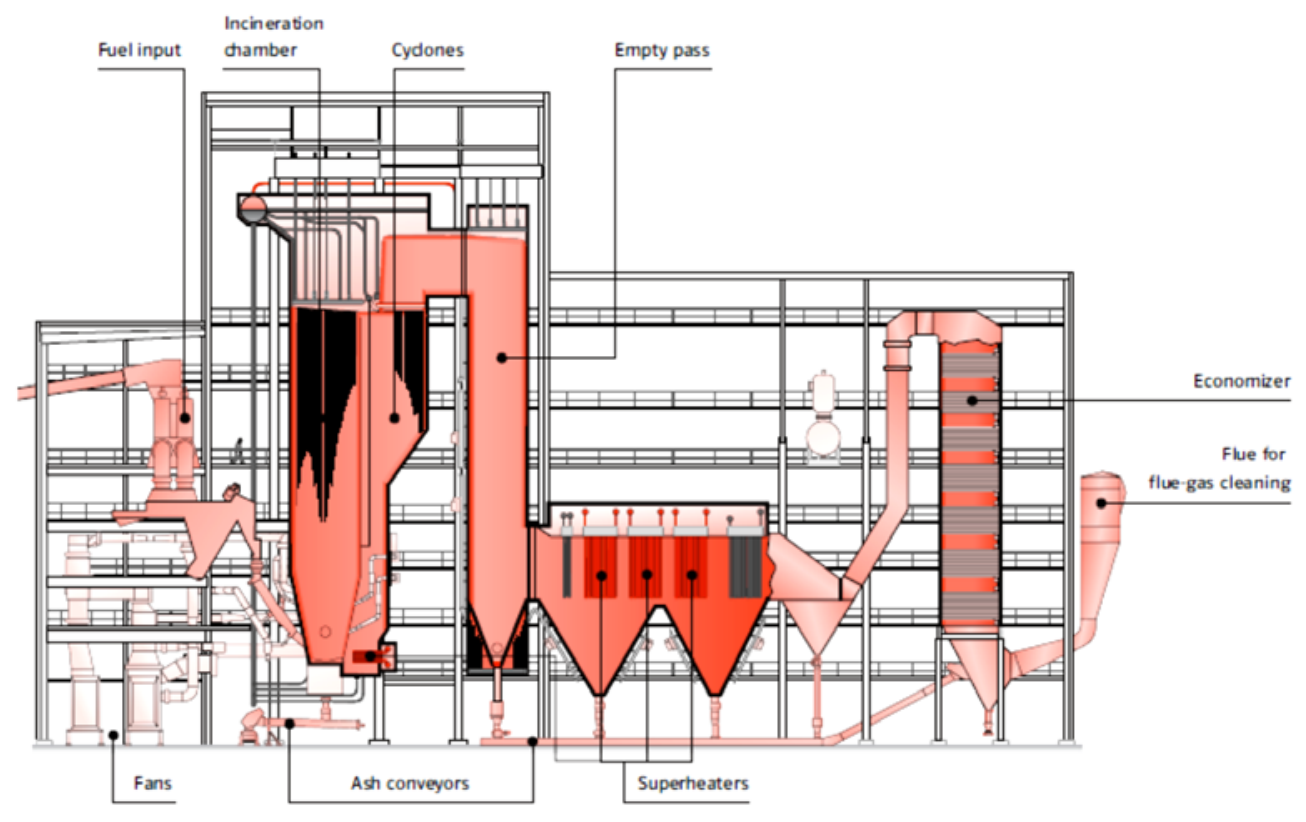

Fig. 12. Boiler 15 at E.ON Händelö waste-to-energy cogeneration plant, Norrköping, Sweden ([22]. 
Similarly, the heat exchanger units in the recirculated "ash" cooler of the coal/straw-fired boiler in Grenå, Denmark described above (Figure 10) were reported to be "designed for easy change at appropriate intervals" [13].

Another example of this approach is the $67 \mathrm{MW}$ waste-fired boiler operated by the City of Amsterdam [23], one of the largest waste-to-energy facilities in the world. This unit, shown in Figure 13, produces steam at $440^{\circ} \mathrm{C}\left(824^{\circ} \mathrm{F}\right)$ and $125 \mathrm{bar}(1,813 \mathrm{psi})$ and achieves an electrical efficiency of $30 \%$. Although the superheaters are located in the flue gas passage, they follow three empty passages (see Section 1 above) so that the flue gas temperature has time to cool and some entrained deposits have time to fall out before reaching the superheaters. The spacious furnace reduces flue gas velocities, reducing fouling rates. The superheaters are fabricated from heat resistant steel (15/16Mo3 and 13CrMo44) rather than corrosion-resistant alloys, but are designed to be replaced as a unit within 72 hours. One recent replacement was achieved in 48 hours, fire-to-fire.

A substantial corrosion monitoring program [24], including real-time electrochemical corrosion monitoring probes, indicates that current superheater corrosion rates in this unit are 0.1 to $0.2 \mathrm{~mm} /$ year (0.004 to 0.008 ” per year). The ability to change out the superheater in 48 hours would make even substantially higher corrosion rates tolerable.

\subsubsection{Operate superheater at a temperature above the dew point of corrosive ash deposit}

A novel approach to limiting superheater corrosion is to use composite superheater tubes with an insulating layer between the inner pressure-bearing layer and the outer corrosion-resistant layer. Metso has patented this method for increasing superheater surface temperatures above the dew point temperature of alkali chloride salts. Figure 14 shows the effects of increasing superheater tube surface temperatures on the concentrations of potentially corrosive species [25].

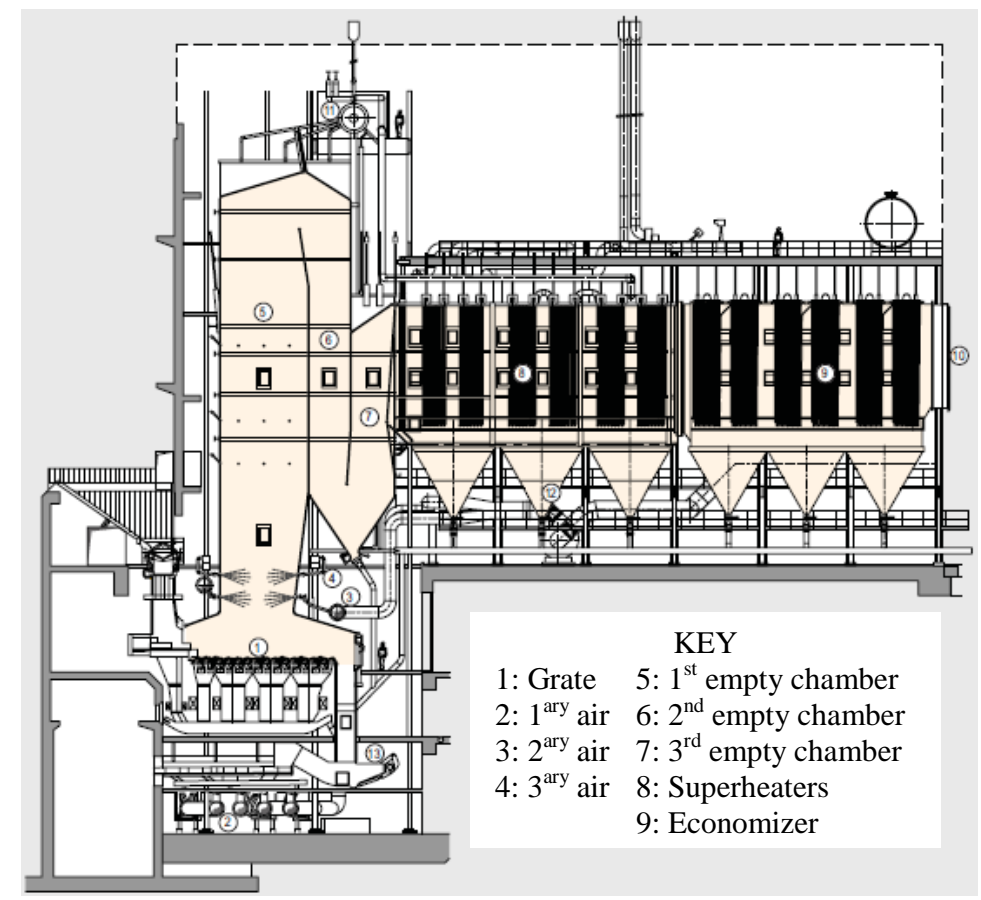

Fig. 13. City of Amsterdam waste-fired power plant [23]. 


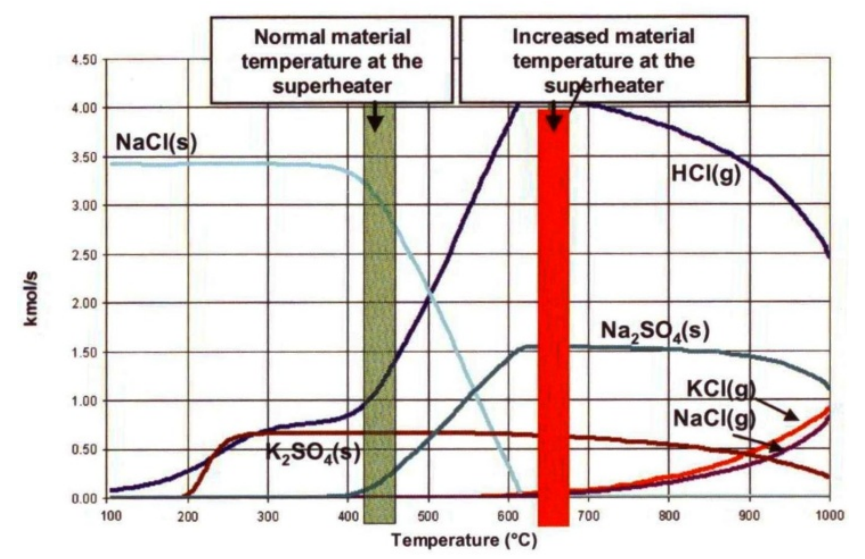

Fig. 14. Effects of increasing superheater tube temperature on concentrations of potential corrosives [25].

The data presented in Figure 14 indicate that alkali metal chlorides will not condense at the surface temperature of the superheater tubes containing an insulating layer $\left(660^{\circ} \mathrm{C} ; 1220^{\circ} \mathrm{F}\right)$. However, we cannot assume that alkali chlorides are non-corrosive above their dew point temperature. $\mathrm{KCl}$ vapors in a flue gas react with the $\mathrm{Cr}_{2} \mathrm{O}_{3}$ formed on the surface of corrosion-resistant tubes and form $\mathrm{K}_{2} \mathrm{CrO}_{4}$. Segerdahl and others reported that this caused local oxide failure on an $11 \% \mathrm{Cr}$ martensitic steel that led to the formation of non-protective $\mathrm{Fe}_{2} \mathrm{O}_{3}$ [26].

Petterson, Svensson and Johansson studied a corrosion-resistant superheater alloy (UNS N08028) at $600^{\circ} \mathrm{C}$ under conditions where the dew point temperature of $\mathrm{KCl}$ was $590^{\circ} \mathrm{C}$ [27]. $\mathrm{KCl}$ vapors reacted with $\mathrm{Cr}_{2} \mathrm{O}_{3}$ on the surface of the alloy, forming $\mathrm{K}_{2} \mathrm{CrO}_{4}$. Although this increased the oxidation rate, it did not cause a sudden failure (breakaway oxidation). The distribution of $\mathrm{K}_{2} \mathrm{CrO}_{4}$ on the alloy surface depended on the gas flow rate, indicating that the rate of chromate formation was limited by the rate of arrival of $\mathrm{KCl}$ at the surface. No alkali chlorides were found on the alloy surface.

To prevent this condensation, Metso developed a new type of composite tube containing an internal insulating layer [8] to raise the surface temperature above the dew point temperature of $\mathrm{NaCl}$. Figure 15 shows the thermally insulating layer between the pressure-bearing carbon steel tube and the outer corrosion-resistant stainless cladding. The equilibria presented in Figure 14 show that the increase in surface temperature changes the composition of the deposited ash from molten $\mathrm{NaCl}$ to $\mathrm{NaCl}$ and $\mathrm{KCl}$ vapors with $\mathrm{HCl}$ gas and solid $\mathrm{Na}_{2} \mathrm{SO}_{4}[25]$.

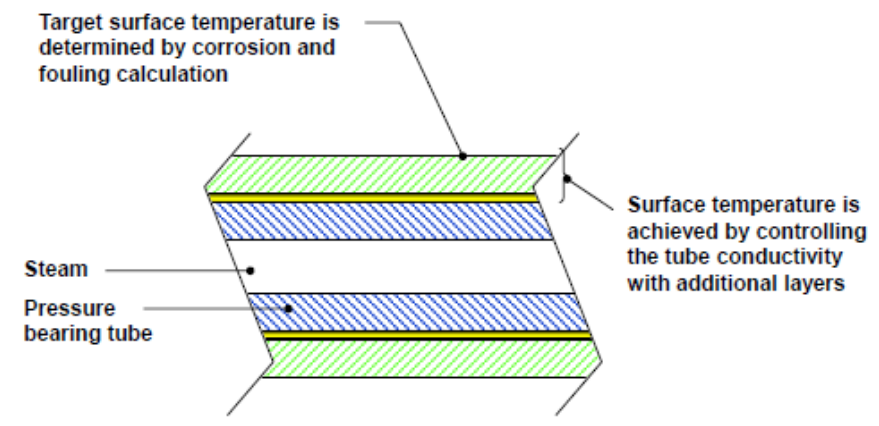

Fig. 15. Metso tube containing a thermally-insulating layer to raise its surface temperature above the dew point of $\mathrm{NaCl}$ vapor [28].

Skog and others reported that full-scale testing of these tubes has given "promising” results [25], and a publication by Enestam, Lehtonen and Heikne provides more information about this testing [8]. Enestam 
begins by listing design innovations implemented in E.ON’s CFB waste-to-energy boiler at Händelö, near Norrköping, Sweden, including:

Fuel residence time of 2 seconds at $850^{\circ} \mathrm{C}\left(1562^{\circ} \mathrm{F}\right)$ to promote complete combustion

Flue gases cooled in an empty "radiation pass" ahead of the lower temperature superheater sections

Final superheater located in the loop seal, as a fluidized bed heat exchanger

Tube banks designed for rapid replacement

Although the loop seal final superheater was made from "the best austenitic material", the waste fuel caused superheater corrosion that was traced to the condensation of alkali chlorides (primarily sodium chloride) on these tubes [8]. The corroded superheater tubes were replaced by tubes "that include a pressure bearing component and additional protective layers (Patent pending)" - evidently the tubes with the insulating layer described above. Although the higher surface temperature of the new final superheater tubes will reduce the heat transfer per unit area, this can be compensated for by adding additional heating surface in the tube bank design phase. Palonen and others [28] have reported that similar insulating composite tubes are installed in the final (loop seal) superheater in a CFB power boiler at the Stora Enso paper mill in Langerbrugge, Belgium.

\subsubsection{Operate superheaters with molten deposits}

It was noted in Section 2 that deposits on "chlorine trap" tubes in the Schweinfurt WTE boiler grow thick enough to be molten at the ash/flue gas interface. It seems possible that this molten layer provides protection to the underlying tube by slowing the delivery of corrosive species to the tube surface [11]. Žbogar, Frandsen and others studied the shedding of fireside ash deposits from superheater tubes in a straw-fired grate boiler at Avedøre in Denmark [29]. They used video recording, measured probe mass gain and probe heat uptake. The Avedøre 2 unit, which can burn natural gas, oil, straw and wood pellets, operates with a high flue gas temperature $\left(900-1100^{\circ} \mathrm{C} ; 1652-2012^{\circ} \mathrm{F}\right)$ a high steam temperature $580^{\circ} \mathrm{C}$ (and a low deposit melting temperature. The main shedding mechanism in this boiler is the flow of molten material off the outer surface of the deposit. The rate at which these deposits are shed depends on the percentage of molten material in the deposit and therefore on the flue gas temperature.

Results from Maribø and Avedøre 2 power plants in Denmark show that the presence of molten phases on the fireside surface of a superheater deposit does not in itself cause a major corrosion problem. Corrosion is controlled by the environment and temperature at the tube surface.

Thermographic measurements by Montgomery and others [30] in the Maribø Sakskøbing boiler confirmed the insulating properties of biomass ash deposits by showing that the superheater surface temperatures increased substantially when the tubes were covered with deposits. The effects of increased flue gas temperature are complex because they can simultaneously affect the thickness, composition and morphology of the deposit and the degree of deposit sulfation. When the surface temperature of the deposit exceeded $950^{\circ} \mathrm{C}\left(1,742^{\circ} \mathrm{F}\right)$ molten deposits ran off them. Later, test sections of candidate alloys were installed in the superheaters of straw-fired CHP boilers at both Maribo Saskøbing and Avedøre 2 [30]. Tube samples removed from the boilers were covered with deposits of $\mathrm{KCl}, \mathrm{K}_{2} \mathrm{SO}_{4}$ and some iron oxide. Such oxides as remained on the tube surfaces were porous and spalled easily. The outer portion was an iron-rich oxide. The inner portion was an iron-chromium-rich oxide. Chromium was preferentially attacked where it was accessible at grain boundaries in the tube surface. The authors concluded that the overall corrosion reaction was "active oxidation" (a cyclical corrosion mechanism involving the formation of iron chloride at the tube surface). Tube thickness data projections suggested that the average worst case tube thickness loss after 100,000 hours (11.5 years) service in the hottest superheater bank would be about $3.9 \mathrm{~mm}(0.15$ ”). Note that, despite the presence of molten phases on the 
outside of the ash deposits, the annualized thinning rate of Type 347H (UNS S34709) tubes was a tolerable $0.34 \mathrm{~mm}$ per year (0.013” per year).

\subsubsection{Process Modifications to Inhibit Superheater Corrosion}

\subsubsection{Dilution of corrosive biofuels with less corrosive fuels}

The simplest way to reduce superheater corrosion caused by fuel contaminants is to dilute the corrosive biomass with a less-corrosive fuel such as a clean coal or wood pellets. In countries where biofuel combustion is mandated, other fuels may be co-fired to achieve this dilution. Small amounts of biomass added to existing coal-fired boilers typically do not cause corrosion, although they may present materials handling issues. Thus, without new policies to reduce U.S. carbon dioxide emissions and further limit other gaseous emissions, coal is likely to retain its position as the primary fuel for U.S. power stations, co-fired with small amounts of biomass where this is economically attractive.

Kilgallon, Simms and Oakey have reported that mixing 20\% wheat straw with wood or with coal produced flue gas compositions well within the ranges predicted for firing different coals [31]. They concluded that adding up to $20 \%$ of biomass into a coal fuel would cause superheater corrosion rates similar to those produced by firing $100 \%$ coal or $100 \%$ wood.

\subsubsection{Leaching of corrosives from biofuels}

Fuels that contain more alkali and chlorine release more $\mathrm{HCl}, \mathrm{KCl}$, and $\mathrm{NaCl}$ when they burn. Dayton and others [32] have shown that water leaching typically removes $>80 \%$ of the potassium and sodium and $>90 \%$ of the chlorine from biomass fuels. It removes smaller proportions of sulfur and phosphorus. Therefore washing biomass fuels with water reduces or eliminates the release of corrosive alkali metal salts and chlorides when the fuels are later burned. Bench scale measurements of the volatile inorganic species evolved during the combustion of leached and unleached rice straw, wheat straw, switchgrass, power plant wood fuel, fuel crop banagrass and sugarcane bagasse confirmed that leaching could mitigate undesirable effects of biomass combustion ash.

In related research, Jensen and others [33] used water leaching to extract potassium and chlorine from straw fuels after pyrolyzing them at $550^{\circ} \mathrm{C}\left(1022^{\circ} \mathrm{F}\right)$ for subsequent co-firing with coal. In this case the primary goal was to remove potassium that would otherwise deactivate SCR catalysts used for $\mathrm{NO}_{\mathrm{x}}$ reduction. Potassium and residual chlorine were than leached out of the char by counter-current washing. In later work [34], the same authors made a more detailed study of this extraction of potassium and chlorine from the pyrolysis char. Three forms of potassium were dissolved in turn. The first 35-58\% dissolved very rapidly, followed by a slow release that was strongly influenced by particle size, water temperature, char type and water $\mathrm{KCl}$ content. The last $5-10 \%$ of the potassium could not be removed by water leaching.

\subsubsection{Use of additives that convert chloride ash deposits to sulfates}

Co-firing corrosive biomass fuels with high sulfur fuels not only dilutes the corrosive fuel but also converts salts that would form alkali chloride fuel ash deposits into alkali sulfates. Johansson and others studied fine fly ash particles $(<1 \mu \mathrm{m})$ formed in a CFB boiler [35]. Adding sulfur to the biomass fuel changed the fly ash particles from mostly $\mathrm{KCl}$ to mostly $\mathrm{K}_{2} \mathrm{SO}_{4} \cdot \mathrm{K}_{2} \mathrm{SO}_{4}$ deposits are much less corrosive than $\mathrm{KCl}$ [25], primarily because of their higher melting temperature $-770^{\circ} \mathrm{C}\left(1418^{\circ} \mathrm{F}\right)$ compared to $1069^{\circ} \mathrm{C}\left(1956^{\circ} \mathrm{F}\right)$ for $\mathrm{KCl}$. In related work they found that adding kaolin or co-firing with sewage sludge also increased the concentration of coarse $(>1 \mu \mathrm{m})$ fly ash particles and reduced the deposition rate on ash collection probes. 
Skog and others [25] have described the addition of $\mathrm{SO}_{2}$ to a $75 \mathrm{MW}$ waste-fired boiler at Händelö (near Norrköping, Sweden) to produce reactions of the type

$$
2 \mathrm{KCl}(\mathrm{s})+\mathrm{SO}_{2}(\mathrm{~g})+1 / 2 \mathrm{O}_{2}(\mathrm{~g})+\mathrm{H}_{2} \mathrm{O} \rightarrow \mathrm{K}_{2} \mathrm{SO}_{4}(\mathrm{~s})+2 \mathrm{HCl}(\mathrm{g})
$$

Additions of $\mathrm{SO}_{2}$ calculated to convert all the alkali chlorides in the superheater into alkali sulfates increased the $\mathrm{S} / \mathrm{Cl}$ ratio in the deposit. Although alkali chloride formation was not entirely suppressed, the $\mathrm{SO}_{2}$ additions eliminated the destruction, by chromate formation, of the chromium-rich protective oxide on stainless steel in tests at $550^{\circ} \mathrm{C}\left(1022^{\circ} \mathrm{F}\right)$. Without the $\mathrm{SO}_{2}$ addition, chromate formation was detected even on alloy Sanicro 28. The results also indicate that the $\mathrm{HCl}$ vapor was less corrosive to the superheater tubes than the $\mathrm{KCl}$ or $\mathrm{NaCl}$ deposits.

In 2002 the Swedish-based utility Vattenfall AB patented the use of reagents such as $\left(\mathrm{NH}_{4}\right)_{2} \mathrm{SO}_{4}$, $\mathrm{NH}_{4} \mathrm{HSO}_{4}, \mathrm{H}_{2} \mathrm{SO}_{4}$ and $\mathrm{FeSO}_{4}$ [36] for avoiding corrosion and fouling in boilers firing chlorine-containing fuels. Most subsequent Vattenfall publications about this approach focused on results obtained with ammonium sulfate. The system, marketed as ChlorOut ${ }^{\circledR}$ [37], uses the concentration of alkali vapors and fine particles in the flue gases measured by an on-line surface ionization technique [38] to control the addition of ammonium sulfate. The alkali sensor can measure concentrations as low as about $1 \mathrm{ppb}$ and as high as about $10 \mathrm{ppm}$. The ammonium sulfate decomposes to produce $\mathrm{SO}_{3}$ that converts the alkali chlorides to sulfates:

$$
\left(\mathrm{NH}_{4}\right)_{2} \mathrm{SO}_{4} \rightarrow \mathrm{SO}_{3}+2 \mathrm{NH}_{3}+\mathrm{H}_{2} \mathrm{O}
$$

A study by Vattenfall and others [39] exposed a range of alloys in long-term superheater probe tests in two wood-fired boilers with and without sulfating additives. One test boiler was the $540^{\circ} \mathrm{C}\left(1004^{\circ} \mathrm{F}\right)$ steam CHP unit in Nyköping and the other was a $98 \mathrm{MW}, 480^{\circ} \mathrm{C}\left(896^{\circ} \mathrm{F}\right)$ steam, bark-fired boiler at Munksund, also in Sweden. The results showed that the ammonium sulfate additions reduced the $\mathrm{KCl}$ levels not only in the flue gases but also in fly ash deposits on superheater tubes and specifically at the tube/scale interface. The additives substantially reduced the deposition rates and halved the corrosion rates of superheater materials.

An independent evaluation of the ChlorOut ${ }^{\circledR}$ technology was performed by Broström and others [40]. The tests were performed in a 96MW(thermal)/ 25MW(electricity) circulating fluidized bed (CFB) boiler burning bark with a chlorine-containing waste. Test probes showed that spraying ammonium sulfate into the flue gases reduced the $\mathrm{KCl}$ concentration from more than $15 \mathrm{ppm}$ to about $2 \mathrm{ppm}$, decreased ash deposition rates and decreased corrosion rates. When ammonium sulfate was added, the deposit contained significantly more sulfur and almost no chlorine, confirming that the additive was sulfating $\mathrm{KCl}$ to $\mathrm{K}_{2} \mathrm{SO}_{4}$.

Aho and others have studied the alkali-capturing power of aluminum and ferric sulfates in a pilot-scale fluidized bed biomass reactor [41] and patented the use of these compounds for sulfation [42]. They note that many other competing reactions can take place in addition to the simple sulfation of alkali chlorides by $\mathrm{SO}_{3}$ released by sulfate salts. Water-soluble sulfates can decompose over a wide range of temperatures and the rate at which they release $\mathrm{SO}_{3}$ can be catalyzed or inhibited by other species. The $\mathrm{S} / \mathrm{Cl}$ ratio required for complete sulfation of chloride ashes depends not only on the chloride concentration in the ash, but also on the concentrations of species such as $\mathrm{Ca}$ and $\mathrm{Mg}$ oxides that compete with alkali chlorides to react with the available $\mathrm{SO}_{3}$ and on the concentration of alkali hydroxides, which can consume $\mathrm{SO}_{3}$ as well as convert $\mathrm{HCl}$ produced by sulfation reactions back to alkali chlorides [41]. Although a greater volume of ferric sulfate than of aluminum sulfate is required to achieve sulfation, ferric sulfate is less expensive and more soluble in water unless the $\mathrm{pH}$ is lowered to increase the 
solubility of aluminum sulfate. While ferric and aluminum sulfate additions can convert chloride fly ash particles into less-corrosive sulfates, they do not offer the additional $\mathrm{NO}_{\mathrm{x}}$ emission reduction provided by ammonium sulfate which releases ammonia gas when decomposing. The sulfation reactions do not usually have a substantial effect on $\mathrm{SO}_{2}$ emissions, although $\mathrm{HCl}$ emissions increase slightly.

A thermodynamic study of the effects of ammonium sulfate additions published by Becidan and others confirmed the benefits of this treatment. Thermodynamic equilibria were used to study the primary and interactive effects of sodium, potassium, sulfur and chlorine in municipal waste incinerators [43]. The effectiveness of ammonium sulfate additives was studied with the same model to investigate direct and interactive effects of alkali ( $\mathrm{Na}$ and $\mathrm{K}$ ) species and of trace metals that form very low melting temperature salts (i.e. $\mathrm{Pb}$ and $\mathrm{Zn}$ ).

\subsubsection{Use of additives that convert alkali salts to silicates}

Coda and others [44] studied the vaporization of chlorine species and the formation of alkali deposits during combustion of biomass and waste in pilot-scale BFB reactors that simulated the particle residence times in full-scale boilers. The fuels burned (softwood and bark, paper mill sludge and blends of wood with agricultural waste or plastic waste) had low sulfur concentrations (i.e. $<0.5 \mathrm{wt}$. \%), but their chlorine and potassium concentrations ranged widely (0.02-3.2 w/o for $\mathrm{Cl}$ and 0.07-3.1 w/o for $\mathrm{K}$ ). $\mathrm{Cl}$ was found in the fly ash samples but not in the furnace bed ash. The addition of Al-containing materials - bauxite and fly ash from a pulverized coal plant - increased the $\mathrm{HCl}$ in the flue gas and reduced the concentration of $\mathrm{Cl}$ in the fly ash. Al-Si-based additives such as kaolin (hydrous 40:60 wt\% $\mathrm{Al}_{2} \mathrm{O}_{3} \cdot \mathrm{SiO}_{2}$ ) reacted with alkali chlorides to form alkali aluminum silicates found in coarse fly ash particles. In contrast, limestone additions (which, after being calcined, react with $\mathrm{SO}_{2}$ in the boiler to form calcium sulfate) increased the chlorine concentration in coarse flue gas particles.

Henriksen, Blum and Larsen studied the effects of silica and kaolinite additions on superheater corrosion in the external ash cooler of the Grenå CFB boiler which co-fires straw and coal [13]. Probes installed in the loop seal, which had a similar environment to that in the ash cooler, showed that this corrosion was caused by chlorine. Corrosion rates were lower in the ash cooler than in the convective pass, probably because most of the corrosive ash particles had been removed in the cyclone. Side stream experiments in a pilot plant indicated that the rate at which $\mathrm{KCl}$ arrived at the test probe fell when silica or kaolinite was blown in to the test chamber. Increasing the residence time to give the additives more time to react reduced the $\mathrm{KCl}$ flux by two orders of magnitude. The authors quoted preliminary data suggesting that oil-contaminated soil could provide a cheap and efficient substitute for these more expensive additives.

Davidsson, Steenari and Eskilsson studied the effects of kaolin additions to the loop seal of a 35MW CFB boiler fired with forest residues [45] and concluded that these additions reduced superheater deposition and corrosion. As the kaolin passed through the boiler, it removed alkali and raised the agglomeration temperature of the bed material. The authors concluded that alkali aluminum silicates had been formed because the additives increased the alkali concentration in the fly ash but decreased the solubility of alkali in the fly ash. The high melting temperature of alkali silicates would make them unlikely to form sticky deposits on superheater tubes. In a separate effect, a small portion of the kaolin remained in the furnace bed as a thin layer on the sand particles where it reduced furnace ash agglomeration.

\subsubsection{Discussion}

-Advanced European biomass boilers use a combination of design modifications, process modifications and corrosion-resistant alloys to maximize their steam temperature, and therefore their fuel efficiency. This approach typically begins with a boiler design optimized for biomass fuels. Such designs can include 
-Include at least one empty (radiation) pass to ensure that flue gas reactions such as sulfation go to completion and that flue gases cool to temperatures tolerable by the superheater materials. In some boilers this cooling is achieved by installing an economizer immediately upstream of the first superheater. -Install low temperature screen tubes immediately ahead of the superheaters where low melting temperature ash constituents can condense

-Remove the final superheater from the convection pass to the recirculated fluidizing medium or the recirculated ash system in a CFB boiler, or out of the boiler envelope altogether where it can be heated by a less-corrosive fuel

-Design the superheater tube banks for easy and very rapid replacement

Other design modifications that claim success in multiple full-scale applications include collecting low melting temperature ash constituents from the flue gas on to rarely cleaned cool tubes ahead of the superheater and using composite superheater tubes that contain an internal insulating layer to raise their fireside temperature above the dew point of corrosive potassium chloride in the ash.

The most profound of these developments is that of removing the final superheater from the flue gas passage. Separating the superheater from most of the corrosive flue gases and their entrained particles enables substantially higher steam temperatures to be achieved within the corrosion resistance of conventional alloys. If the final superheater remains in the flue gas passage, the steam temperature must usually be restricted to $450-470^{\circ} \mathrm{C}\left(842-878^{\circ} \mathrm{F}\right)$. However, if the superheater is moved to the loop seal, the steam temperature can be raised to at least $540-580^{\circ} \mathrm{C}\left(1,004\right.$ to $\left.1,076^{\circ} \mathrm{F}\right)$. This substantially increases the boiler efficiency.

In addition to using a boiler design suitable for the biomass fuel, European practice is to make additional efforts to reduce the corrosivity of the biomass combustion environment. Process modifications widely used for this purpose include

-Dilute corrosive biomass fuels with less-corrosive fuels

-Co-fire corrosive biomass with a high sulfur fuel that will convert corrosive (low melting temperature) alkali chloride deposits to (higher melting temperature) alkali sulfates -Use sulfate-bearing additives to convert alkali chlorides to alkali sulfates -Use silicate or aluminosilcate additives to convert corrosive alkali salts to (high melting temperature) alkali silicates or alkali aluminum silicates that pass through the convective pass as coarse fly ash particles.

After having used appropriate design and process modifications, the maximum steam temperature can be set to achieve the lowest life-cycle cost of produced energy. A critical part of this decision is the choice of alloy for the final superheater. This review of European technology shows that design and operational modifications practiced in Europe enable biomass-fired boilers to operate with substantially higher steam temperatures and therefore substantially higher efficiencies than U.S. biomass boilers. All these technological advances are available for implementation in U.S. biomass boilers. Even higher steam efficiencies might be achievable by using chemical additives to inhibit corrosion by materials recycled through the loop seal with the fluidizing particles, e.g. by sulfating alkali chlorides and absorbing $\mathrm{SO}_{\mathrm{x}}$.

The most corrosion-resistant alloys for biomass superheaters are typically FeCrNi alloys containing between $20 \%$ and $28 \% \mathrm{Cr}$. Although many of these alloys contain other additions, there is no coherent theory of the alloying required to resist the combination of high temperature salt deposits and flue gases that is found in biomass boiler superheaters. A major challenge in choosing a superheater alloy is that, although the environment at a superheater tube surface is initially that of the first-to-arrive deposits, the environment and temperature at the tube surface typically change as the deposits mature. 
It is widely thought that superheater tube alloys cannot survive in contact with molten deposits. However, although molten deposits are more corrosive than frozen deposits, increasing superheater tube temperatures through the first melting point of fly ash deposits does not appear to produce a step increase in corrosion rate. The corrosion rate typically begins to accelerate at temperatures significantly below the first melting temperature.

In this section we have mentioned several biomass boilers that operate with superheater deposits so thick that the fireside surface of their ash deposits is molten. It is important to note the presence of molten species on the outside of a tube deposit does not imply that molten deposits are in contact with the tube surface.

\subsubsection{Conclusions}

-Design and operational modifications practiced in Europe enable biomass-fired boilers to operate with substantially higher steam temperatures and therefore substantially higher efficiencies than U.S. biomass boilers. Even higher fuel efficiencies might be achievable by using chemical additives to reduce corrosion by flue gas constituents carried through the loop seal with the fluidizing material.

-The technological improvements that enable higher energy efficiency when firing biomass fuels are available to U.S. energy companies. The most important design advance is the removal of the final superheater from the flue gas/ fly ash environment, which enables substantial increases in steam temperature and consequent increases in boiler efficiency.

-Several advanced boilers are operating superheaters with molten material on the outside of the ash deposits without experiencing excessive corrosion.

In a subsequent paper, Sharp and associates reviewed the corrosion of superheater tubes in boilers burning biomass fuels [4]. Sharp first addressed issues in black liquor recovery boilers then he reviewed the issues with other types of biomass-fired boilers. That work is described in the next section.

\subsubsection{Superheater Corrosion Produced By Biomass Fuels}

Industrial boilers could, in principle, fire renewable biomass fuels instead of fossil fuels like natural gas, coal, and fuel oil. However, biomass fuels often contain elements such as chlorine, potassium, sodium and sulfur that deposit in ash on the superheater tubes that heat the steam to its maximum temperature. Because many components of these ash deposits and the surrounding flue gases are corrosive, operators have historically limited the temperatures of biomass boiler superheater tubes substantially below those of fossil-fuel-fired boilers to avoid accelerated corrosion. Unfortunately, lower steam temperatures reduce the energy derived from the fuel and produce boiler efficiencies far below those of advanced fossil-fuelfired boilers. A previous report [3] reviewed improvements in biomass boiler design and operation developed in European countries that signed the 1997 Kyoto Protocol. Advanced European biomass boilers combine design modifications, process changes and corrosion-resistant alloys to achieve substantially higher steam temperatures and efficiencies than U.S. biomass boilers. In order to gain an understanding of tube material considerations used in designing and fabricating boilers used in Europe, the role of corrosion-resistant alloys in increasing superheater temperatures was reviewed.

The energy extracted from a boiler fuel depends on the difference between the maximum and minimum steam temperatures in the steam cycle. The maximum steam temperature is typically limited by the corrosion resistance or strength of the boiler tube alloy. The minimum temperature is set by the condenser conditions. Superheater temperatures in coal-fired boilers have historically been limited to about $565^{\circ} \mathrm{C}$ $\left(1,049^{\circ} \mathrm{F}\right)$ and condenser temperatures to about $30^{\circ} \mathrm{C}\left(85^{\circ} \mathrm{F}\right)$. Although this offers a theoretical maximum fuel efficiency of about $63 \%$, the best coal-fired power stations achieve efficiencies of only about $45 \%$. 


\subsubsection{Energy Sources}

Plant-derived biomass fuels store carbon only for months or years, unlike fossil fuels, which store carbon for millions of years. Carbon dioxide removed from the air by the next crop of fuel plants balances the carbon dioxide released by the burning of the previous generation of plants. This capture-and-release cycle cannot be duplicated with fossil fuels. Although the harvesting and delivery of biomass uses a little electricity for harvesting, baling or chipping operations and a little petroleum-based fuel for transportation, making energy by burning recently-grown biomaterials is much more nearly carbon neutral than making energy by burning fossil fuels.

Biomass fuels available in the US include agricultural wastes, forest and wood plant residuals, as well as energy crops [46]. Because municipal wastes contain a significant proportion of biomass, they are often categorized as biomass fuels also. Without the incentives and penalties established to reduce $\mathrm{CO}_{2}$ emissions that have been enacted in Europe, US utilities continue to pursue a lowest-cost approach to electricity generation that relies primarily on fossil fuels. Consequently, available data show that only $8 \%$ of the total energy consumed in the US in 2010 was generated from renewable sources [47]. In contrast, Europe generated $11.6 \%$ of its 2009 power consumption from renewables and plans to increase this to $20 \%$ by 2020.

\subsubsection{Alloys Resistant to High Temperature Corrosion}

It was noted above that high temperature corrosion limits the efficiency of biomass-fueled boilers. If superheater temperatures produce unacceptably high corrosion rates on carbon steel, boiler designers turn to alloys that form more protective oxides. Stott [48] has documented the role of common alloying additions in high temperature alloys based on iron, nickel and cobalt. Chromium is generally the most important of these alloying elements. It reacts with oxygen in the flue gas to form a protective oxide $\left(\mathrm{Cr}_{2} \mathrm{O}_{3}\right)$ that provides reasonable corrosion protection in air or oxygen at temperatures up to about $900^{\circ} \mathrm{C}$ $\left(1,652^{\circ} \mathrm{F}\right)$. At higher temperatures the $\mathrm{Cr}_{2} \mathrm{O}_{3}$ tends to volatilize in the presence of water vapor. Therefore alloys designed to serve at higher temperatures often contain aluminum or silicon as well as chromium. Such alloys protect themselves by forming $\mathrm{Al}_{2} \mathrm{O}_{3}$ or $\mathrm{SiO}_{2}$. Although binary $\mathrm{Fe}-\mathrm{Al}$, Ni-Al or Co-Al alloys need to contain $6-12 \%$ aluminum to form continuous $\mathrm{Al}_{2} \mathrm{O}_{3}$ scales, $\mathrm{Fe}-\mathrm{Cr}$ alloys need less. $\mathrm{An} \mathrm{Fe}-15 \% \mathrm{Cr}$ alloy can establish an $\mathrm{Al}_{2} \mathrm{O}_{3}$ layer with the addition of only 3-4\% aluminum. Additions of silicon to Fe$\mathrm{Cr}$ alloys form internal $\mathrm{SiO}_{2}$ particles that grow and coalesce into a continuous layer. For example Fe-15$30 \% \mathrm{Cr}-\mathrm{Si}$ alloys initially form $\mathrm{Cr}_{2} \mathrm{O}_{3}$, but this gives way to an outer layer of iron oxides over an inner $\mathrm{Cr}_{2} \mathrm{O}_{3}$ scale with a healing layer of $\mathrm{SiO}_{2}$ at the alloy/oxide interface. Stott points out that the differential expansion stresses that cause oxide spallation during thermal cycling are more severe on austenitic than on ferritic alloys and that $\mathrm{Al}_{2} \mathrm{O}_{3}$ tends to spall more than $\mathrm{Cr}_{3} \mathrm{O}_{3}$. Strengthening elements such as Ti, Mo and $\mathrm{Nb}$ have little effect on the corrosion resistance of $\mathrm{Cr}_{2} \mathrm{O}_{3}$-forming alloys [48].

\subsubsection{Corrosion of Recovery Boiler Superheater Materials}

Black liquor recovery boilers generate steam from the combustion of organic materials dissolved out of wood chips by pulping liquors. Inorganic materials in the black liquor either flow out of the furnace bottom as a stream of molten $\mathrm{Na}_{2} \mathrm{~S}$ and $\mathrm{Na}_{2} \mathrm{CO}_{3}$, or are carried through the boiler as fly ash. Although the most corrosive constituents of the ash are generally alkali chlorides and carbonates, it has not been possible to develop unique rankings for recovery boiler superheater alloys because the tube surface environment depends not only on the pulping process but also on the waste streams recycled into the liquor system. The corrosion resistance of recovery boiler superheater tube materials typically increases with the chromium content of the alloy. Alloys used [49] include: carbon steel (no added Cr), UNS K11587 (1\% Cr - T11), UNS K21590 (2.25\% Cr steel - T22), UNS S30409 and UNS S34709 (19\% Cr 
stainless steels - Type 304H and Type 347), UNS S31000 (25\% Cr - Alloy 310) and UNS N08028 (27\% Cr - Alloy 28).

Crowe and Youngblood [50] have pointed out that the ferritic steels UNS K11587 (T11) and UNS K21590 (T22) are only useful at temperatures substantially below the first melting temperature (FMT) of superheater ash deposits. Using higher alloys, corrosion in recovery boiler superheaters is manageable while exit steam temperatures remain below about $450^{\circ} \mathrm{C}\left(842^{\circ} \mathrm{F}\right)$ [51]. Higher steam temperatures require austenitic stainless steels. At steam temperatures close to or just above the FMT, iron-nickelchromium alloys such as UNS N08810 (Alloy 800H) and nickel-chromium-molybdenum alloys such as UNS N06625 (Alloy 625) have been used [52], although the corrosion rate increases dramatically at the FMT.

Figure 2 presents corrosion data from probe tests by Estes [53] indicating that the corrosion rate of UNS S310009 (Alloy 310) coupons in a recovery boiler superheater increased 4- or 5-fold as a result of a 3-6 Celsius degree (5-10 Fahrenheit degree) increase in metal temperature.

As a result of the acceleration in corrosion rate that occurs near and above the FMT, most recovery boiler operators establish steam temperature limits that keep the temperature of fireside ash deposits comfortably below their melting point [51, 53-56]. Kish noted that all North American recovery boiler steam temperatures are below $500^{\circ} \mathrm{C}\left(932^{\circ} \mathrm{F}\right)$ [57].

Because austenitic stainless steel superheater alloys would be vulnerable to waterside stress-corrosion cracking if chloride-contaminated feedwater entered them under upset conditions, some mills have installed composite superheater tubes with a high alloy outer layer extruded over a pressure-bearing carbon steel inner tube. Pulp mills confident they will eliminate chloride contamination have installed less-expensive solid tube materials like UNS S34709 (Alloy 347H).

Vakkilainen and Pohjanne [58] recently reviewed alloys to consider for recovery boiler superheaters operating at temperatures of up to $520^{\circ} \mathrm{C}\left(932^{\circ} \mathrm{F}\right)$. Their candidates include UNS S34709 and S31009 (Alloys 347H and 310), UNS S32238 (Alloy AC-66), Sumitomo alloy HR2M®, UNS S31042 (Alloy $310 \mathrm{HCbN}$ ), Nippon alloy YUS 170®, UNS 08028 (Alloy 28), Sanicro alloys 63® and 67® and Sumitomo Super 625®. Vakkilainen and Pohjanne suggest UNS 08028 (Alloy 28) or UNS N06625 (Alloy 625) for the highest temperatures.

Although the maximum steam temperature in Scandinavian recovery boilers is now about $480^{\circ} \mathrm{C}\left(896^{\circ} \mathrm{F}\right)$, Mäkipää and others [55] have suggested that 25\% chromium alloys could serve at temperatures of up to about $525^{\circ} \mathrm{C}\left(977^{\circ} \mathrm{F}\right)$. Their laboratory and field tests evaluated alloys such as UNS 34709 (Alloy 347H), UNS S32238 (Alloy AC-66), UNS 08028 (Alloy 28), Sumitomo HR-11N®, UNS N06045 (Alloy 45TM), Alloy YUS 170®, UNS N06625 (Alloy 625) and Alloy 67®. The most resistant alloys in alkali chloride environments were nickel-based alloys like UNS N06625 (Alloy 625). Alloys containing a few percent of molybdenum suffered localized corrosion, apparently from molten chlorides. The authors noted that, because water vapor promotes the volatilization of chromium species from alloy surfaces, [59] the operation of recovery boiler sootblowers may increase corrosion rates on high-chromium superheater alloys.

Nippon Alloy MN25R ${ }^{\circledR}$ (Type 309LMoN) was developed for increased strength at high temperatures and increased intergranular corrosion resistance in recovery boiler superheater environments [60]. It contains $25 \% \mathrm{Cr}$ and is claimed to be suitable for temperatures of up to $540^{\circ} \mathrm{C}\left(1004^{\circ} \mathrm{F}\right)$ [61].

Skrifvars, Westén-Karlsson, Hupa and Salmenoja recently reported laboratory test data for 6 recovery boiler superheater alloys [62]. These alloys UNS K21590 (T-22), UNS K90901 (T-91), the 6\% Mn alloy 
UNS S21500 (Esshete 1250®), UNS 08028 (Alloy 28), HR11N® and Alloy 63®) were pre-oxidized in air for 24 hours at $200^{\circ} \mathrm{C}\left(392^{\circ} \mathrm{F}\right)$. Mixtures of $\mathrm{Na}_{2} \mathrm{SO}_{4}, \mathrm{~K}_{2} \mathrm{SO}_{4}$ and $\mathrm{NaCl}$, chosen to have FMTs ranging from 522 to $884^{\circ} \mathrm{C}\left(972\right.$ to $\left.1623^{\circ} \mathrm{F}\right)$, were applied to each alloy for one-week tests at 450 to $600^{\circ} \mathrm{C}(842$ to $1112^{\circ} \mathrm{F}$ ). Pure $\mathrm{Na}_{2} \mathrm{SO}_{4}$ deposits corroded only the lowest alloy UNS K21590 (T-22). However, when as little as 0.3 w/o chlorine was added, corrosion appeared below the FMT of the synthetic ash on UNS K21590, K90901 and S21500 (T-22, T-91 and Alloy 1250®). 1.3 w/o chlorine initiated corrosion below the FMT on UNS 08028 (Alloy 28). Substituting 10\% of the $\mathrm{KCl}$ with $\mathrm{NaCl}$ in the $0.3 \mathrm{w} / \mathrm{o}$ chlorine salt produced much thicker corrosion products. Because the test environment did not contain water vapor, these data are likely to underestimate corrosion in real environments where water vapor promotes the volatilization of chromic oxide. In related work, Backman, Hupa and others [63] showed that increasing the proportion of molten phases in salt layers of constant chloride concentration produced higher corrosion rates both on a 1\% Cr, 0.5\% Mo steel and on UNS 31009 (Alloy 310).

A second paper by Skrifvars, Westén-Karlsson, Hupa and Salmenoja [64] reported that differences between the corrosion resistance of alloys UNS K21590, S21500 and N06625 (T-22, Alloy 1250® and Alloy 625) under synthetic alkali chloride deposits were apparent within one-week laboratory tests. Chlorine-free $\mathrm{Na}$ and $\mathrm{K}$ salts did not corrode any of these steels. The effects of chloride additions depended on whether or not they depressed the FMT below the surface temperature of the test sample. At temperatures above the FMT, deposits containing Na and K chlorides corroded all the steels. Chloridecontaining salts also corroded UNS K21590 and S21500 (T-22 and Alloy 1250®) at temperatures below the FMT. The presence of porous iron oxide deposits on the outside of the oxide layer and on salt particles suggested that iron had volatilized from the alloy, possibly as iron chloride. At $575^{\circ} \mathrm{C}$, indications of condensed chromium and nickel oxides were also found in tests on UNS 06625 (Alloy 625) which was the most corrosion-resistant of the alloys tested.

\subsubsection{Summary}

The corrosivity of kraft recovery boiler superheater environments varies according to the associated pulp manufacturing process, because many of the most corrosive species arrive in waste streams recycled into the black liquor. It has been known since the early 1980s that recovery boiler superheater tubes corrode rapidly in contact with molten deposits and that the best-performing alloys are usually high-chromium austenitic stainless steels and nickel-chromium-molybdenum alloys. In light of the hazards associated with recovery boiler operation, operators typically keep the final steam temperature at least 30 Celsius (50 Fahrenheit) degrees below the FMT. Experience suggests that it is more cost-effective to raise the FMT of the deposits by purging chlorides out of the system than to install high alloys and run with superheater temperatures close to a lower FMT.

\subsubsection{Corrosion Mechanisms in Biomass Boiler Superheater Environments}

\subsubsection{Corrosives in biomass fuels}

Tillman and others [65] note that the corrosion problems caused by biomass fuels generally arise from the chlorine and alkali metals (specifically $\mathrm{K}$ and $\mathrm{Na}$ ) they contain. With the exception of wood and a handful of other fuel crops, biomass fuels contain significantly higher concentrations of chlorine than coal. [65] Field crops, with the exception of nut shells, pits and switchgrass, contain more chlorine than woody materials. Tables of typical chlorine and moisture concentrations in 20 biomass fuels [66] showed that chlorine concentrations, expressed as $\mathrm{lb} / 10^{6} \mathrm{Btu}$, ranged from 0.012 for willow, poplar and almond shells to 0.894 for rice straw and 0.923 for corn stover. All the biomass fuels contained more chlorine than coal samples from 9 representative US coalfields. 
Salmenoja and Mäkelä’s overview of superheater corrosion in biomass boilers [67] also identified $\mathrm{Cl}_{2}$, $\mathrm{HCl}$ and alkali chlorides as the dominant corrosives. Hiltunen, Barišić and Coda Zabetta [68] concluded that alkali salts released by biomass fuels, in particularly alkali chlorides, cause superheater corrosion both by lowering the FMT of superheater ash and by releasing chlorine when they react with sulfur compounds to form sulfates. Alkali salts can form low melting temperature eutectics with other ash materials or can themselves be molten on the tube surface, depending on the superheater temperature. $\mathrm{KCl}$ is more corrosive than $\mathrm{NaCl}$ and has a lower melting temperature. As in recovery boilers, the presence of molten phases at the tube surface causes accelerated corrosion. So biomass boiler operators similarly keep tube temperatures well below the FMT of fireside deposits to avoid rapid corrosion. The release of chlorine by the sulfation of ash deposits can produce active corrosion which will be discussed later.

Pinder's 2008 summary of materials challenges in biomass combustion [69] emphasized the value of achieving good energy efficiency in biomass combustion. Except in Denmark, conversion efficiencies have generally been low and steam temperatures limited because of fouling and corrosion concerns. Pinder pointed out that even the most energy-efficient straw-burning plants in Sweden achieve conversion efficiencies of only about $29 \%$ and are restricted to superheater temperatures of $540^{\circ} \mathrm{C} / 92 \mathrm{bar}$ $\left(1,004^{\circ} \mathrm{F} / 1,334 \mathrm{psi}\right)$, compared with current targets for coal-fired plants of $650^{\circ} \mathrm{C} / 300 \mathrm{bar}\left(1,202^{\circ} \mathrm{F} / 4,350\right.$ psi).

Ten years of research at Chalmers University of Technology, summarized by Johansson, Skog and others, $[25,70]$ indicate that alloys that rely on $\mathrm{Cr}_{2} \mathrm{O}_{3}$ for corrosion protection are vulnerable to failure by fluxing and by vaporization.

\subsubsection{Fluxing of otherwise-protective $\mathrm{Cr}_{2} \mathrm{O}_{3}$}

Alkali chlorides can react with the $\mathrm{Cr}_{2} \mathrm{O}_{3}$ that would otherwise protect the alloy surface by forming alkali metal chromates:

$$
\mathrm{Cr}_{2} \mathrm{O}_{3}(\mathrm{~s})+4 \mathrm{KCl}(\mathrm{s})+2 \mathrm{H}_{2} \mathrm{O}(\mathrm{g})+3 / 2 \mathrm{O}_{2}(\mathrm{~g}) \rightarrow 2 \mathrm{~K}_{2} \mathrm{CrO}_{4}(\mathrm{~s})+4 \mathrm{HCl}(\mathrm{g})
$$

If the rate of this fluxing reaction exceeds the rate of supply of chromium from the bulk of the alloy, the $\mathrm{Cr}_{2} \mathrm{O}_{3}$ scale gives way to an unprotective $(\mathrm{Fe}, \mathrm{Cr})_{3} \mathrm{O}_{4}$ spinel beneath an outer layer of $\mathrm{Fe}_{2} \mathrm{O}_{3}$ [25]. The inward penetration of chlorine-containing gases though the spinel forms $\mathrm{FeCl}_{2}$, which migrates outward towards the higher oxygen partial pressures at the ash/gas interface, where it decomposes to $\mathrm{Fe}_{2} \mathrm{O}_{3}$ and $\mathrm{Cl}_{2}$. The $\mathrm{Cl}_{2}$ penetrates back through the porous oxide to form more metal chlorides at the alloy surface, completing a cycle first called active oxidation by Lee and McNallan [71] and later studied in detail by Grabke and co-workers [72]. The difference between the oxidizing environment at the gas/scale interface and the reducing environment at the tube/scale interface is illustrated by experiments by Salmenoja and Mäkelä [67]. HCl produced by biomass combustion did not corrode superheater tubes in oxidizing environments where the tube temperature was below $600^{\circ} \mathrm{C}\left(1,112^{\circ} \mathrm{F}\right)$. However, in reducing (low oxygen partial pressure) conditions, corrosion of biomass boiler superheater tubes, indicated by metal chloride formation, began at about $450^{\circ} \mathrm{C}\left(842^{\circ} \mathrm{F}\right)$.

Pettersson, Svensson and Johansson [73] also showed that the KCl-induced corrosion of UNS S30400 (Type 304 stainless steel) in an $\mathrm{O}_{2}-\mathrm{H}_{2} \mathrm{O}$ environment accelerated rapidly with increasing temperature within the range $400-600^{\circ} \mathrm{C}\left(752-1,112^{\circ} \mathrm{F}\right)$. At $600^{\circ} \mathrm{C}\left(1,112^{\circ} \mathrm{F}\right)$ the addition of $\mathrm{KCl}$ increased the corrosion rate more than an order of magnitude [74]. Pettersson, Svensson and Johansson also compared the corrosivity of $\mathrm{KCl}, \mathrm{K}_{2} \mathrm{CO}_{3}$ and $\mathrm{K}_{2} \mathrm{SO}_{4}$ towards UNS S30400 (Type 304) [59]. KCl deposits caused rapid attack in laboratory tests [75] during the first 24 hours of exposure. The corrosion products were outward-growing sesquioxides - Fe-rich $\left(\mathrm{Fe}_{0.9}, \mathrm{Cr}_{0.1}\right)_{2} \mathrm{O}_{3}$ on Type 304 and mixed $\left(\mathrm{Fe}_{0.5}, \mathrm{Cr}_{0.5}\right)_{2} \mathrm{O}_{3}$ on UNS 
N08028 (Alloy 28) - over inward-growing (Fe,Cr,Ni) ${ }_{3} \mathrm{O}_{4}$ spinels. The formation of $\mathrm{K}_{2} \mathrm{CrO}_{4}$ allowed rapid corrosion when chromium oxides gave way to non-protective iron-rich oxides. The chlorine in the $\mathrm{KCl}$ was converted to gaseous HCl. Although UNS N08028 (Alloy 28) contained a sufficient reserve of chromium to form a healing $\mathrm{Cr}_{2} \mathrm{O}_{3}$ layer where $\mathrm{KCl}$ deposits had been applied, Petterson and her coauthors pointed out that the continuous supply of $\mathrm{KCl}$ in an operating biomass boiler would present a much more severe challenge to this alloy [75]. Short-term thermogravimetric tests in $\mathrm{O}_{2}+\mathrm{H}_{2} \mathrm{O}$ at $600^{\circ} \mathrm{C}$ $\left(1,112^{\circ} \mathrm{F}\right)$ showed that fluxing is also produced by $\mathrm{K}_{2} \mathrm{CO}_{3}$ :

$$
1 / 2 \mathrm{Cr}_{2} \mathrm{O}_{3} \text { (solid) }+\mathrm{K}_{2} \mathrm{CO}_{3} \text { (solid) }+3 / 4 \mathrm{O}_{2} \text { (gas) } \rightarrow \mathrm{K}_{2} \mathrm{CrO}_{4} \text { (solid) }+\mathrm{CO}_{2} \text { (gas) }
$$

The amount of $\mathrm{K}_{2} \mathrm{CrO}_{4}$ formed did not account for all the chlorides or carbonates that were introduced, [59] suggesting that $\mathrm{KCl}$ and $\mathrm{K}_{2} \mathrm{CO}_{3}$ may also be lost by vaporization. In the presence of water, solid $\mathrm{K}_{2} \mathrm{CO}_{3}$ vaporizes as $\mathrm{KOH}$, which may itself cause corrosion.

In contrast, $\mathrm{K}_{2} \mathrm{SO}_{4}$ does not react with $\mathrm{Cr}_{2} \mathrm{O}_{3}$ to form $\mathrm{K}_{2} \mathrm{CrO}_{4}$ [76]. This difference in reactivity is exploited in many approaches to control superheater corrosion by increasing the molar ratio of available sulfur to chlorine in order to convert corrosive potassium chloride to less reactive potassium sulfate:

$$
2 \mathrm{KCl} \text { (solid) }+\mathrm{SO}_{2} \text { (gas) }+1 / 2 \mathrm{O}_{2} \text { (gas) }+\mathrm{H}_{2} \mathrm{O} \text { (gas) } \rightarrow \mathrm{K}_{2} \mathrm{SO}_{4}+2 \mathrm{HCl} \text { (gas) }
$$

The practical use of sulfating additions for corrosion control has been discussed in our previous paper [3]. Although the release of chlorine by sulfation reactions on the tube surface causes active corrosion where the $\mathrm{Cr}_{2} \mathrm{O}_{3}$ barrier has failed, [68] the release of $\mathrm{HCl}$ into the flue gas by upstream sulfation reactions is not sufficient to cause active oxidation. Folkeson, Johansson and Svensson [77] showed that adding $\mathrm{HCl}$ vapor to moist oxygen-nitrogen mixtures accelerated the oxidation of UNS S31009 (Alloy 310) at $500^{\circ} \mathrm{C}$ $\left(932^{\circ} \mathrm{F}\right)$ but did not show the concentration of chlorides at the scale/metal interface that is characteristic of active oxidation.

Although $\mathrm{K}_{2} \mathrm{SO}_{4}$ deposits did not accelerate the corrosion of UNS S30400 (Type 304) by reacting with $\mathrm{Cr}_{2} \mathrm{O}_{3}, \mathrm{~K}_{2} \mathrm{CO}_{3}-\mathrm{K}_{2} \mathrm{CrO}_{4}$ and $\mathrm{K}_{2} \mathrm{CO}_{3}-\mathrm{K}_{2} \mathrm{SO}_{4}$ eutectics have relatively low melting temperatures - as low as 788 and $658^{\circ} \mathrm{C}\left(1,450\right.$ and $\left.1,216^{\circ} \mathrm{F}\right)$, respectively [59].

\subsubsection{Vaporization of otherwise-protective $\mathrm{Cr}_{2} \mathrm{O}_{3}$}

Oxide breakdown can also be caused by volatilization of $\mathrm{Cr}_{2} \mathrm{O}_{3}$. High temperatures, humid atmospheres and rapid gas flow remove $\mathrm{Cr}_{2} \mathrm{O}_{3}$ as a chromium oxy-hydroxide vapor:

$$
\mathrm{Cr}_{2} \mathrm{O}_{3} \text { (solid) }+2 \mathrm{H}_{2} \mathrm{O} \text { (gas) }+3 / 2 \mathrm{O}_{2} \text { (gas) } \rightarrow 2 \mathrm{CrO}_{2}(\mathrm{OH})_{2} \text { (gas) }
$$

Paul, Clark and Eckhardt reported this type of corrosion rate increase when adding 2 v/o of water vapor to a simulated coal-fired combustion environment [78]. If the rate of volatilization of chromium exceeded the rate of resupply from the bulk of the alloy, the $\mathrm{Cr}_{2} \mathrm{O}_{3}$ scale failed and was replaced by an unprotective $(\mathrm{Fe}, \mathrm{Cr})_{3} \mathrm{O}_{4}$ spinel beneath an outer layer of $\mathrm{Fe}_{2} \mathrm{O}_{3}$.

Pettersson and others [75] compared the volatilization behavior of UNS N08028 (Alloy 28) and UNS S30400 (Type 304). Both alloys formed protective, chromium-rich oxides in dry oxygen at $600^{\circ} \mathrm{C}$ $\left(1,112^{\circ} \mathrm{F}\right)$. However, adding water vapor caused rapid oxidation of UNS S30400 (Type 304), but not of UNS 08028 (Alloy 28). The greater availability of chromium in UNS 08028 (Alloy 28) apparently delivered chromium to the surface fast enough to maintain the protective $\mathrm{Cr}_{2} \mathrm{O}_{3}$. However, the limited availability of chromium in UNS S30400 (Type 304) to replace $\mathrm{Cr}_{2} \mathrm{O}_{3}$ lost by chromate formation or chromic acid volatilization produced a thick layer of $\mathrm{Fe}_{2} \mathrm{O}_{3}$ over an unprotective $(\mathrm{FeCrNi})_{3} \mathrm{O}_{4}$ spinel [59]. 
The non-protective spinel could be penetrated by chlorine species, and active oxidation ensued. Because the imperfect structure in grain boundaries accelerates the delivery of reactive elements where grain boundaries intersect an alloy surface, [75] the UNS S30400 (Type 304) corroded preferentially in the center of surface-breaking grains.[59] This also accelerated the formation of $\mathrm{K}_{2} \mathrm{CrO}_{4}$ above surface grain boundaries in UNS N08028 (Alloy 28).

Note that, at superheater temperatures, fluxing caused by even small concentrations of $\mathrm{KCl}$ and $\mathrm{K}_{2} \mathrm{CO}_{3}$ is typically much more damaging than volatilization caused by environments containing oxygen and water vapor.

\subsubsection{Corrosion of Biomass Boiler Superheater Materials}

Coleman, Simms, Kilgallon and Oakey[79] reported laboratory testing of potential superheater tube materials for boilers burning fast-growing energy crops that contain high concentrations of $\mathrm{K}$ and $\mathrm{Cl}$. Five alloys were studied: 1\% Cr steel (UNS K11597; T11), 2.25\% Cr steel (UNS K40712; T23), 9\% Cr steel (UNS K90901; T91), 12\% Cr steel (UNS S41000, i.e. X20CrMoV121 or Type 410), a stainless steel, UNS S34710 (Type 347HFG) and a nickel-base alloy, UNS N06625 (Alloy 625). 1000-hour tests were carried out at temperatures between 450 and $600^{\circ} \mathrm{C}$ (between 842 and $1,112^{\circ} \mathrm{F}$ ) with synthetic gas compositions and deposits (refreshed by re-coating) simulating biomass combustion conditions.

Corrosion was assessed by thermogravimetry and by dimensional metrology. The best performing alloy in all the tests was the nickel-based UNS N06625 (Alloy 625). It formed a protective $\mathrm{Cr}_{2} \mathrm{O}_{3}$ scale. The iron-based Alloy UNS S34710 (Type 347HFG) also produced a $\mathrm{Cr}_{2} \mathrm{O}_{3}$-rich scale, but suffered localized and internal corrosion in many of the exposure conditions. Alloys containing less chromium showed much more damage. In gaseous environments, higher $\mathrm{S} / \mathrm{Cl}$ ratios produced higher damage rates, suggesting that increased amounts of $\mathrm{SO}_{3}$ stabilized the molten deposit (by sulfation reactions that released chlorine, caused active oxidation and formed low melting temperature chloride deposits) as well as being directly corrosive. The molten deposits increased the corrosion rates [80].

Field testing of candidate materials for biomass boiler superheaters by Mäkipää, Baxter, Sroda and Oksa showed that whenever corrosion was found, the ash deposits were sulfated [81]. The authors concluded that $\mathrm{HCl}$ released in these sulfation reactions was causing active oxidation [71].

Pinder [69] reported that UNS S34709 (Type 347H) superheater tubes in a UK straw-fired power station need to be replaced every 5 years, but that reducing the steam temperature by $10^{\circ} \mathrm{C}\left(18^{\circ} \mathrm{F}\right)$ would nearly triple their service life.

Pettersson, Flyg and Viklund [82] tested the corrosion resistance of superheater alloys in a synthetic gas mixture established by the European PREWIN network to simulate waste incinerators. $2 \%$ and $9 \% \mathrm{Cr}$ steels (UNS K21590 and K90901), stainless steel UNS 30400 (Type 304) and high temperature alloy UNS S30815 (Outokumpu Alloy 253MA ${ }^{\circledR}$ ) were evaluated in 960-hour exposures at 550 and $700^{\circ} \mathrm{C}$ $\left(1,022\right.$ and $\left.1,292^{\circ} \mathrm{F}\right)$ under $\mathrm{KCl}-\mathrm{K}_{2} \mathrm{SO}_{4}$ deposits in $13 \% \mathrm{CO}_{2}, 5 \% \mathrm{O}_{2}, 15 \% \mathrm{H}_{2} \mathrm{O}, 0.02 \% \mathrm{HCl}$ environments. The eutectic temperature of this salt mixture is $690^{\circ} \mathrm{C}\left(1,274^{\circ} \mathrm{F}\right)$. UNS S30815 (Alloy 253MA ${ }^{\circledR}$ ) was the best performer. The authors concluded that its $1.5 \% \mathrm{Si}$ had formed a partial layer of $\mathrm{SiO}_{2}$ at the alloy/scale interface that limited the formation of metal chloride reaction products.

Salmenoja and Mäkelä [67] surveyed ash deposits on biomass boiler superheater tubes. These deposits had FMTs as low as $530^{\circ} \mathrm{C}\left(986^{\circ} \mathrm{F}\right)$. Molten phases produced superheater corrosion rates exceeding $10 \mathrm{~mm} /$ year (nearly 0.4 ” per year) [83].

Many modern biomass boilers use CFB designs in which the superheater is located in the recirculated fluidizing medium. Our previous paper [3] noted that this reduces the exposure of the superheater to alkali 
metal salts and corrosive flue gases. Nafari and Nylund [17] measured erosion-corrosion of loop seal superheater tubes in a 30MW CFB boiler fired with coal and forest residues at Nässjö, Sweden. Thinning rates increased with tube temperature. Steam inlet and outlet temperatures were 470 and $540^{\circ} \mathrm{C}(878$ and $1,004^{\circ} \mathrm{F}$ ), and the authors suggested that the tube surface temperatures would be 50 to 100 Celsius degrees (90 to 180 Fahrenheit degrees) higher than these values. The corrosion products consisted of an inner layer of $\mathrm{Cr}$ and Fe oxides beneath an outer Fe-rich oxide. Chloride was present at the alloy/scale interface, with K and S. Average material losses on UNS S21500 (Alloy 1250®) and on UNS S34709 (Type $347 \mathrm{H}$ ) were comparable and were slightly greater than on UNS S32238 (Alloy AC-66), although the UNS S32238 showed more severe internal oxidation.

Later work by the same authors presented additional results from the same superheater with tube temperatures between 510 and $550^{\circ} \mathrm{C}\left(950\right.$ and $\left.1,022^{\circ} \mathrm{F}\right)$ [18]. The loop seal ash contained $13 \%$ Ca, $9 \%$ $\mathrm{K}, 0.9 \% \mathrm{Na}, 800 \mathrm{ppm}$ sulfate and $100 \mathrm{ppm}$ chloride. Even the uncoated alloys suffered little corrosion during boiler operation. The fact that the degradation was no worse after two firing seasons than after one indicated that corrosion, rather than erosion, was the dominant deterioration mechanism. Although recirculated fluidizing particles are abrasive, their velocity is low and erosion is not normally a problem. The thickest oxides, on a 9\% Cr alloy, were only about $150 \mu \mathrm{m}(0.006$ ") thick after about 7 months in service. Austenitic steels suffered some internal oxidation and grain boundary attack. Although some coatings delaminated, 8 of the 17 coatings tested were unaffected by the exposure.

\subsubsection{Protective coatings}

Both robotically-applied weld overlay and thermally-sprayed coatings have been used to protect biomass boiler superheater tubes from corrosion. The most widely used overlay material in waste-to-energy (WTE) boilers is UNS N06625 (Alloy 625). The maximum service temperatures recommended for these coatings range from $400-420^{\circ} \mathrm{C}\left(750-790^{\circ} \mathrm{F}\right)$ [84] to $540^{\circ} \mathrm{C}\left(1004^{\circ} \mathrm{F}\right)$ [85]. Pinder noted that UNS N06625 (Alloy 625) overlay provided the best protection in a boiler firing straw and waste wood where high alloy austenitic steels suffered severe localized and internal attack.[69] For recovery boiler environments, Vakkilainen and Pohjanne have suggested applying weld overlay coatings of UNS S31009 (Type 310) or UNS N06052 (Alloy 52) [58].

With regard to thermally-sprayed coatings, Uuistalo and others reported that a high-chromium, nickelbased HVOF coating (Ni-57CrMoBSi) showed good resistance in an erosion-corrosion rig simulating a CFB combustor even when chlorides were added [86]. Chromized coatings and chromium carbide coatings did not survive. Because large platelets in thermal spray coatings are difficult to dislodge by erosive particles, the authors concluded that HVOF thermal spray coatings for these applications ought to be dense with a large splat size.

Tuurma and a large group of co-workers [87] recently evaluated the use of corrosion-resistant coatings in a biomass boiler. They found no visible corrosion on thermally sprayed HVOF coatings containing 16\%, $25 \%$ and $27 \% \mathrm{Cr}$ after one year's service on superheater tubes in a WTE boiler. Like Uuistalo, Tuurma concluded that the performance of these coatings depends on their application quality, coating adhesion and coating density. Amorphous coatings and fused-in-place coatings cracked before the test was complete.

\subsubsection{Corrosive impurities in demolition wood}

Demolition wood is a low-cost biomass fuel, but it sometimes contains lead and/or zinc impurities that form extremely low melting temperature ashes which cause rapid corrosion on low alloy tube materials. Much of the research on corrosion by lead and zinc impurities has been done for municipal waste incinerators. Spiegel [88] showed that, if $\mathrm{HCl}$ is present in the flue gases, temperatures above about 
$400^{\circ} \mathrm{C}\left(752^{\circ} \mathrm{F}\right)$ can convert $\mathrm{ZnSO}_{4}$ and $\mathrm{PbSO}_{4}$ to volatile chlorides even if the partial pressure of $\mathrm{SO}_{2}$ is relatively high. These volatile chlorides condense on fly ash particles and on superheater tubes, forming molten or sticky deposits or eutectics like $\mathrm{KCl}-\mathrm{ZnCl}_{2}$. Spiegel reported that these molten chloride eutectics caused rapid corrosion on UNS K21590 (T-22) tubes [88]. In contrast, UNS S32238 (Alloy AC-66) formed $\mathrm{PbCrO}_{4}$ and $\mathrm{ZnCr}_{2} \mathrm{O}_{4}$ at $600^{\circ} \mathrm{C}$, although the presence of an inner spinel layer and chlorides at the alloy/scale interface indicated active oxidation. However, when the temperature was reduced to $500^{\circ} \mathrm{C}\left(932^{\circ} \mathrm{F}\right)$, its corrosion rate was only two or three times higher than in a simple oxidizing environment.

Otero and others [89] simulated a waste incineration environment with a molten eutectic of $52 \% \mathrm{PbCl}_{2}$ $48 \% \mathrm{KCl}$. The corrosion rate on UNS N09910 (Incoloy 800) decreased with time, suggesting that a protective reaction product was thickening, but the rate on a $12 \mathrm{CrMoV}$ ferritic steel did not [90].

Li, Niu and Wu [91] described laboratory studies of the corrosion of several Fe-based alloys and of pure $\mathrm{Fe}, \mathrm{Cr}$ and $\mathrm{Ni}$ at $450^{\circ} \mathrm{C}\left(842^{\circ} \mathrm{F}\right)$ beneath $\mathrm{ZnCl}_{2}-\mathrm{KCl}$ deposits in flowing $\mathrm{O}_{2}$. Alloys tested included carbon steel, a 5CrMo steel (UNS K90901, T91), UNS S31009 (Type 310) and Kubota alloy HP®. Adding a $55 / 45$ (mole fraction) mixture of $\mathrm{ZnCl}_{2} / \mathrm{KCl}$ (melting temperature only $250^{\circ} \mathrm{C}\left(482^{\circ} \mathrm{F}\right)$ ) accelerated the corrosion of all these alloys by forming thick and porous oxides enriched in chlorine at the alloy/scale interface. Corrosion resistance increased with the nickel content of the alloy and decreased with the chromium content because high-Cr alloys produced less-adherent corrosion products. The authors [91] suggested that the molten salts had fluxed the oxide (i.e. reacted with $\mathrm{Cr}_{2} \mathrm{O}_{3}$ to form $\mathrm{ZnCr}_{2} \mathrm{O}_{4}$ and $\mathrm{FeCl}_{2}$ ). They also pointed out that loss of $\mathrm{ZnCl}_{2}$ from the molten salt eutectic by volatilization of $\mathrm{ZnCl}_{2}$ or by $\mathrm{ZnCr}_{2} \mathrm{O}_{4}$ formation could raise the FMT above the experimental temperature. Thus, unless a fuel supply continuously supplied $\mathrm{ZnCl}_{2}$ to a tube surface, the ash would gradually change from $\mathrm{ZnCl}_{2}$ to $\mathrm{KCl}$, raising the FMT and slowing the corrosion.

Pan, Zeng and Niu [92] later studied the corrosion of 9\% and 11\% Cr steels and UNS S30400 (Type 304) stainless steel under $\mathrm{ZnCl}_{2}-\mathrm{KCl}$ deposits at $400-500^{\circ} \mathrm{C}\left(752-932^{\circ} \mathrm{C}\right)$ in a reducing $\mathrm{CO}_{2}-2 \% \mathrm{H}_{2}-0.5 \% \mathrm{HCl}$ gas mixture. This work and a subsequent study [93] confirmed that alloys containing more chromium showed greater corrosion resistance in reducing environments. However, even UNS S30400 (Type 304) had unacceptable corrosion resistance under a $\mathrm{ZnCl}_{2}-\mathrm{KCl}$ deposit at temperatures between 400 and $500^{\circ} \mathrm{C}$ (752 and $932^{\circ} \mathrm{F}$ ), and showed active oxidation.

Bankiewicz, Yrjas and Hupa [94] studied the performance of UNS K21590 (T-22), UNS S34709 (Type 347) and UNS N08028 (Alloy 28) in synthetic salt mixtures simulating deposits in furnaces burning wastes containing zinc $\left(\mathrm{K}_{2} \mathrm{SO}_{4}, \mathrm{~K}_{2} \mathrm{SO}_{4}-\mathrm{KCl}\right.$ and $\left.\mathrm{K}_{2} \mathrm{SO}_{4}-\mathrm{ZnCl}_{2}\right)$. The FMT of the $\mathrm{K}_{2} \mathrm{SO}_{4}-\mathrm{ZnCl}_{2}$ salt mixtures was about $400^{\circ} \mathrm{C}\left(752^{\circ} \mathrm{F}\right)$ and the test temperatures were between 350 and $500^{\circ} \mathrm{C}$ (between 662 and $932^{\circ} \mathrm{C}$ ). UNS N08028 (Alloy 28) performed well, except at $600^{\circ} \mathrm{C}\left(1,112^{\circ} \mathrm{F}\right.$ ) which produced oxide thicknesses of 12-30 $\mu \mathrm{m}$ (0.0005-0.001”) on UNS S34709 and N08028 (Type 347 and Alloy 28). Tests in chloride salts produced active oxidation, and pitting attack on N08028 (Alloy 28).

Related corrosion studies by Ruh and Spiegel [95] investigated the corrosion of $\mathrm{Fe}$, Ni and $\mathrm{Cr}$ beneath a eutectic mixture of $50 \% \mathrm{KCl}, 50 \% \mathrm{ZnCl}_{2}$. Iron chloride is soluble in this eutectic, so $\mathrm{FeCl}_{2}$ diffuses through the molten deposit to be oxidized at the deposit/gas interface in the active oxidation cycle. In contrast, nickel and chromium have very limited solubility in the molten eutectic. Because chromium dissolves in the melt as chromate, it would appear that superheater tube materials in boilers burning fuels that can contain zinc should not rely on chromium to form protective oxides, but on aluminum or silicon instead [95].

$\mathrm{Li}$ and Spiegel [96] studied the performance of $\mathrm{Fe}-\mathrm{Al}$ and $\mathrm{Ni}-\mathrm{Al}$ alloys in simulated Zn-contaminated wood environments at 400 to $450^{\circ} \mathrm{C}\left(752\right.$ to $\left.842^{\circ} \mathrm{F}\right)$. Corrosion resistance increased with increasing $\mathrm{Al}$ 
content in binary Fe-Al alloys containing 10 to $45 \% \mathrm{Al}$ and in Ni-Al alloys. The alloy that showed the least mass loss was a $50 \% \mathrm{Ni}-50 \% \mathrm{Al}$ alloy. Although $\mathrm{Al}$-free materials corroded by an oxide fluxing mechanism, alloys of intermediate $\mathrm{Al}$ content reacted with $\mathrm{ZnCl}_{2}$ to form volatile $\mathrm{AlCl}_{3}$ (melting temperature only $\left.178^{\circ} \mathrm{C}\left(352^{\circ} \mathrm{F}\right)\right)$ and metallic $\mathrm{Zn}$. This metallic $\mathrm{Zn}$ reacted with the Al-rich surface of $45 \% \mathrm{Al}$ alloys to form an $\mathrm{Al}-\mathrm{Zn}$ eutectic.

\subsubsection{Modeling of superheater corrosion rates in biomass boilers}

Two European boiler suppliers and a UK consortium have developed models to predict fouling and corrosion in biomass boilers. These programs are used not only to select tube materials for new boilers but also to predict where corrosion is likely to appear first in a particular boiler firing a particular fuel mixture.

Foster Wheeler's model [97,98] is designed to be used by experts as an advisory tool. Its first module evaluates the probability of agglomeration and fouling promoted by the formation of low melting temperature compounds by alkali ( $\mathrm{Na}$ and $\mathrm{K}$ ) and alkaline earth (Ca and $\mathrm{Mg}$ ) salts and inhibited by the removal of these compounds by reaction with kaolinate materials. The second module assesses the release of chlorine from the fuel and its capture by sulfur oxides or kaolinite minerals. If the fouling tendency is low, corrosion rates will be low, but if the fouling tendency is high, corrosion rates will depend on how much chlorine is released by the fuel. The corrosion module uses fuzzy logic to estimate the corrosion rate produced by a particular fuel on a particular alloy at a particular temperature using a data base of over 10,000 fuel materials and over 1,000 operational tests with austenitic and nickel-based tube materials in about 150 CFB boilers. An example of the use of this model cited by Coda Zabetta and others [97,98] refers to a boiler firing mixtures of coal, rice husks and eucalyptus bark. Corrosion rates estimated for two extreme fuel mixtures (a low proportion of rice husks and high proportion of eucalyptus bark and the reverse ratio) correlated reasonably well with tube thinning rates measured in an operating boiler.

Metso Power has developed its own predictive model. Enestam, Niemi and Mäkelä report that this tool, called STEAMAX, [99] estimates the corrosivity of fuel mixtures and recommends maximum steam temperatures for candidate tube materials. From the analysis of a proposed fuel or fuel mixture, thermochemical equilibrium calculations predict the melting behavior of the fuel ash. Species considered include $\mathrm{C}, \mathrm{H}, \mathrm{N}, \mathrm{O}, \mathrm{S}, \mathrm{Cl}, \mathrm{Ca}, \mathrm{Mg}, \mathrm{Na}, \mathrm{K}, \mathrm{Al}, \mathrm{Si}, \mathrm{Fe}, \mathrm{P}, \mathrm{Pb}$ and $\mathrm{Zn}, 12$ solid compounds, 2 solid solutions, 2 liquid solutions and a gas phase. As in the Foster Wheeler program, corrosivity is estimated from the amount of chlorine in the flue gas at different temperatures and boiler locations. The maximum allowable temperature for given tube alloys is estimated from an empirical database based on superheater data from 20 biomass-fuelled and black liquor recovery boilers. The risk of corrosion by a molten deposit is estimated from the difference between the tube surface temperature and the FMT of the ash. The program recommends a maximum operating temperature for individual candidate alloys, considering solid chlorine-induced corrosion, gas phase chlorine-induced corrosion and molten phase corrosion. UK models of fireside corrosion in coal-fired boilers have been extended by Kilgallon, Simms and Oakey to predict rates of corrosion in biomass-fired boilers [31]. Their model applies to UNS S41000 (i.e. Alloy X20CrMoV121 - Type 410), UNS S34710 (Type 347HFG) and UNS N06625 (Alloy 625) in superheater conditions. The fuel is coal with up to $20 \%$ of biomass. Data from a matrix of 1,000 hour corrosion tests were used to develop an empirical model. The tests were made in various mixtures of $\mathrm{KCl}, \mathrm{K}_{2} \mathrm{SO}_{4}$ and pulverized coal fly ash based on deposit compositions found in Danish biomass-fuelled and co-fired boilers. The deposits were re-applied to the coupons every 100 hours. The gas atmospheres consisted of more and less oxidizing mixtures of $\mathrm{O}_{2}, \mathrm{CO}_{2}, \mathrm{H}_{2} \mathrm{O}, \mathrm{CO}, \mathrm{SO}_{2}$ and $\mathrm{HCl}$. The model shows effects of deposit composition $\left(\mathrm{K}^{+}, \mathrm{Cl}^{-}\right.$and $\mathrm{SO}_{4}{ }^{2-}$ ), gas composition $\left(\mathrm{SO}_{\mathrm{x}}\right.$ and $\left.\mathrm{HCl}\right)$ and the test temperature 560 or $600^{\circ} \mathrm{C}$ $\left(1,040\right.$ or $\left.1,112^{\circ} \mathrm{F}\right)$. Measured corrosion damage correlated quite well with predicted corrosion damage, although the model was not verified using a data set different to that on which it had been trained. 


\subsubsection{Summary}

Despite the economic benefits of increased superheater temperatures in biomass boilers, little systematic research has been done to indicate which alloys would be the best choice for extreme steam conditions. The corrosion resistance of superheater alloys in biomass boilers depends on their maintaining a protective surface layer of $\mathrm{Cr}_{2} \mathrm{O}_{3}$. If this oxide is fluxed by alkali salts, or volatilized, faster that it can be re-formed by chromium diffusing from the bulk of the alloy, the resulting non-protective oxides will be penetrated by chlorine species that cause further acceleration of the corrosion rate by active oxidation. Iron-based alloys containing at least $25 \% \mathrm{Cr}$ and nickel-based alloys typically perform best and additions of silicon have been shown to be beneficial. Some alloys that have performed well also contain additions of rare earth metals.

Alkali salts are generally the most aggressive components in biomass fuels. They can cause corrosion directly by fluxing the $\mathrm{Cr}_{2} \mathrm{O}_{3}$ and they can reduce the ash FMT, either causing agglomeration and fouling or forming corrosive molten deposits. Lead and zinc impurities in demolition wood are very corrosive, primarily because they form very low melting temperature ash components.

Even where corrosion data are available, their use to select cost-effective alloys for superheater tubes in particular boilers is difficult for at least three reasons. First, the operator might decide to burn a different fuel years after the tube materials were chosen. Second, although laboratory test data may be available, inconsistencies between methods used by different laboratories make it difficult to develop general conclusions from different data sets. Third, it is difficult to make quantitative comparisons of field data from different sources because boiler tube environments and temperatures are rarely well-characterized.

\section{Corrosion of Superheater Materials in Boilers Co-Firing Biomass with Coal}

In the absence of policies to promote the use of renewable fuels for power generation, coal will remain the lowest cost, easy-to-burn fuel for US utilities. Corrosion problems are manageable at steam temperatures that offer conversion efficiencies up to $50 \%$. Coals containing corrosive contaminants such as alkali chlorides and sulfates are diluted with less problematic fuels to avoid corrosion problems. ${ }^{1}$ As superheater temperatures are increased to maximize energy recovery from coal fuels, it appears that high temperature creep limits may be reached before corrosion limits are reached. Wood is co-fired with coal either to dilute corrosive impurities in the coal or to take advantage of incentives that promote the use of renewable fuels.

\section{Co-firing wood with coal}

The issues involved when converting a large coal-burning power plant to co-fire biomass have been reviewed by Fuller, Maier and Scheffknecht.[100] This review includes a detailed case study of a 250 MW coal-fired plant in Ghent, Belgium that modified its fuel milling system and burner locations to cofire up to $100 \%$ wood pellets. The wood firing did not produce substantial operational problems. Corrosion tests of candidate alloys at metal temperatures between 640 and $670^{\circ} \mathrm{C}\left(1,184\right.$ and $\left.1,238^{\circ} \mathrm{F}\right)$ in Swedish boilers co-firing biomass with coal and firing 100\% biomass have been reported by Henderson and others [101]. Corrosion rates were generally higher when burning 100\% biomass than when co-firing coal with the biomass. Alloys with the highest chromium content generally showed the lowest corrosion rates, although there were some exceptions. For example, the manganese additions in UNS S21500 (Alloy $1250 \AA$ ) seemed particularly beneficial.

\section{Co-firing straw with coal}

In Denmark, straw is widely burned as an energy fuel in large and efficient boilers. Frandsen has made detailed studies of the combustion chemistry of straw co-fired with coal.[102,103] Although straw fuels contain high concentrations of chlorine, Tillman and his co-authors reported [65] that co-firing 10\% of 
straw in a Danish power station produced little, if any, corrosion attributable to chlorine. At $20 \%$ cofiring, the corrosion rate increased by a factor of 2 or 3, but was still considered manageable. The authors suggested that good mixing and careful deposit control might permit higher straw substitution in coalfired plants.

Anderson and others [104] described ash formation in a 150 MW pulverized coal utility boiler converted to burn $20 \%$ (on an energy basis) of straw. Fe-rich deposits formed during coal combustion gave way to Ca- and Si-rich deposits when straw was co-fired. Because of good mixing during the combustion processes, no chlorine was found in combustion deposits, indicating that active oxidation had been avoided. Potassium from the straw reacted with Al silicates to form harmless, high-melting-temperature potassium aluminum silicates.

To simulate superheater conditions in straw-fired boilers, Nielsen, Frandsen and Dam-Johansen [105] coated ferritic boiler tubes and UNS S34709 (Type 347) tubes with synthetic ( $\mathrm{KCl}$ and/or $\mathrm{K}_{2} \mathrm{SO}_{4}$ ) and real deposits, and exposed them for between 1 week and 5 months under a synthetic flue gas at $550^{\circ} \mathrm{C}$.

Sulfation reactions released $\mathrm{Cl}_{2}$ and $\mathrm{HCl}$, causing rapid active oxidation of the tubes. Also, $\mathrm{KCl}$ formed a low melting temperature eutectic with $\mathrm{K}_{2} \mathrm{SO}_{4}$ and various iron compounds at the tube surface that caused rapid corrosion when the tube surface temperature exceeded the FMT.

Liu, Maier and Hein [106] studied the kinetics of fireside corrosion in ashes formed from the combustion of straw, wood and lignite coals in a $0.5 \mathrm{MW}$ pulverized fuel boiler. The test gas environment contained $\mathrm{HCl}, \mathrm{H}_{2} \mathrm{O}, \mathrm{SO}_{2}, \mathrm{O}_{2}$ and $\mathrm{N}_{2}$. A ferritic $2 \frac{1}{4} \%$ Cr alloy (UNS K30736, T-24), a ferritic-martensitic $12 \% \mathrm{Cr}$ alloy (UNS K91271, T122) and an austenitic 20\% Cr-25\% Ni alloy (UNS S31009, Nippon NF709®) all suffered active oxidation that began as pitting corrosion. The corrosion morphologies produced on ferritic, martensitic and austenitic boiler steels were described in a second paper [107]. The low $\mathrm{Cr}$ content of the ferritic steels allowed the formation of thick and porous corrosion products. The $12 \% \mathrm{Cr}$ martensitic steel suffered isolated corrosion in alloy grain centers. The $20 \% \mathrm{Cr}$ austenitic stainless steel suffered deep grain boundary attack under chlorine-rich deposits at $650^{\circ} \mathrm{C}\left(1,202^{\circ} \mathrm{F}\right)$. The morphology of corrosion was related to carbide attack. Carbides in the austenitic steel were segregated to the grain boundaries, while carbides in the martensitic steel were finely-dispersed.

\section{Summary}

Co-firing up to about $20 \%$ of clean wood in a pulverized coal utility boiler offers benefits of renewable power without significant operational or corrosion challenges. Although straw contains high concentrations of chlorine, 10 or $20 \%$ of straw can be co-fired with coal with manageable increases in corrosion rate. Higher substitutions of corrosive fuels, such as rice straw, corn stover, or demolition wood introduce severe corrosion problems that are typically addressed by chemical additives or by lowering steam temperatures [3]. 


\subsection{LABORATORY CORROSION STUDIES}

\subsubsection{Introduction}

Biomass is increasingly looked on as a cost-effective, environmentally friendly alternative to coal and petroleum-based fuels in the generation of energy. However, relative to coal and fuel oils, biomass-based fuels are inhomogeneous and they also contain significant impurities, such as chlorides, alkali metals and heavy metals that deposit on heat transfer surfaces. While these deposits may reduce the overall energy efficiency of the boiler, their principal effect is to cause rapid corrosion of heat transfer surfaces that approach, or exceed, the first melting point of the deposits. As a consequence, boilers burning biomass have largely been limited to operating with superheater steam temperatures of less than $510^{\circ} \mathrm{C}\left(950^{\circ} \mathrm{F}\right)$ and steam pressures of less than $11 \mathrm{MPa}(1600 \mathrm{psi})$. The bulk of existing biomass boilers in North America operate at substantially lower steam temperatures and pressures, particularly those utilized as waste utility boilers. A laboratory-based program was designed to evaluate candidate alloys for superheaters operating temperatures substantially higher than currently used in practice for biomass and chemical recovery boilers.

\subsubsection{Experimental Procedure}

\subsubsection{Overview}

A test matrix was developed to evaluate materials in simulated superheater deposit environments based on the analysis of deposits from the three operating boilers used in the program - one recovery boiler and two biomass-fired boilers. A total of 25 tests were completed over the course of the program, ranging in length from 100 to 1000 hours (Table 1). Complete experimental details can be obtained from the final program report [108] and a recent publication [109]; what follows is a brief synopsis of the important details.

Table 1. The test matrix for the laboratory program. Cover gas for all experiments contained $5 \% \mathrm{O}_{2}, 10 \% \mathrm{CO}_{2}, 20 \% \mathrm{H}_{2} \mathrm{O}$, bal. $\mathrm{N}_{2}$. Makeup of Alloy Sets is shown in Table II

\begin{tabular}{|c|c|c|c|c|c|c|}
\hline & \multirow[b]{3}{*}{ Hours } & \multicolumn{5}{|c|}{ Simulated Deposits } \\
\hline & & \multicolumn{3}{|c|}{ RB } & \multirow{2}{*}{$\begin{array}{c}\text { PB1 } \\
650^{\circ} \mathrm{C}\end{array}$} & \multirow{2}{*}{$\begin{array}{c}\text { PB2 } \\
650^{\circ} \mathrm{C}\end{array}$} \\
\hline & & $510^{\circ} \mathrm{C}$ & $530^{\circ} \mathrm{C}$ & $625^{\circ} \mathrm{C}$ & & \\
\hline \multirow[t]{4}{*}{ Alloy Set 1} & 100 & $\mathrm{~T} 1$ & - & $\mathrm{T} 5$ & T9 & $\mathrm{T} 13$ \\
\hline & 200 & $\mathrm{~T} 2$ & - & $\mathrm{T} 6$ & $\mathrm{~T} 10$ & T14 \\
\hline & 500 & $\mathrm{~T} 3$ & - & $\mathrm{T} 7$ & $\mathrm{~T} 11$ & $\mathrm{~T} 15$ \\
\hline & 1000 & $\mathrm{~T} 4$ & $\mathrm{~T} 17$ & $\mathrm{~T} 8$ & $\mathrm{~T} 12$ & $\mathrm{~T} 16$ \\
\hline Alloy Set 2 & 1000 & $\mathrm{~T} 20$ & $\mathrm{~T} 24$ & $\mathrm{~T} 21$ & $\mathrm{~T} 22$ & $\mathrm{~T} 23$ \\
\hline Alloy Set 3 & 1000 & $\mathrm{~T} 27 *$ & T28* & T29* & & \\
\hline
\end{tabular}

\subsubsection{Test temperatures}

The principal established for selecting the test temperatures was to set a target for metal temperature of $100 \mathrm{C}^{\circ}$ higher than the current maximum operating superheated steam temperature for the type of boiler. This was anticipated to provide a challenging, but realistic stretch target for alloys and new boiler design. 
Since tube surface temperatures are higher than the steam temperature in service, this implies less than $100 \mathrm{C}^{\circ}$ increase in steam temperature.

In the case of the recovery boiler, a very few boilers world-wide operate with superheater steam temperatures of $525^{\circ} \mathrm{C}$, and so the maximum test temperature was chosen to be $625^{\circ} \mathrm{C}$. Additional tests were conducted at $510^{\circ} \mathrm{C}$ - a temperature below the first melting temperature (FMT) of the synthetic deposit, and $530^{\circ} \mathrm{C}$ - just above the FMT of the deposit. Some European wood-fired boilers operate with $550^{\circ} \mathrm{C}$ superheated steam [3], so the maximum test temperature for those tests was chosen to be $650^{\circ} \mathrm{C}$. The FMT for the bark-fired power boiler deposits was greater than $700^{\circ} \mathrm{C}$. This is much higher temperature than the boilers could reasonably be expected to operate, even during upset conditions. Consequently, no tests were carried out at the FMT of the biomass boiler deposits.

\subsubsection{Deposit chemistry}

The synthetic salts used for the bark-fired boiler tests were based on analyses of deposits from air-cooled probes installed in the model biomass-fired boilers [110]. One was considered to be very aggressive, with high levels of chloride and potassium, while the other was representative of a much cleaner fuel. The recovery boiler salt composition was tailored to provide a salt with a FMT of $525^{\circ} \mathrm{C}$. It is the same as that used in previous work by FPInnovations and was based on analyses of superheater deposits in several boilers, including the recovery boiler from the pulp mill used as the host for the long-term corrosion probe work [110]. Figure 16 shows the composition of the simulated deposits as elemental mole fraction.

Batches of the salts were made in bulk using ACS reagent grade salts when available. The mixtures of compounds were placed into a porcelain milling jar and tumbled with high purity alumina balls for 45-60 minutes. The resultant powder was passed through a 100 mesh screen and the FMT checked by Differential Thermal Analysis (DTA) before being accepted for use.

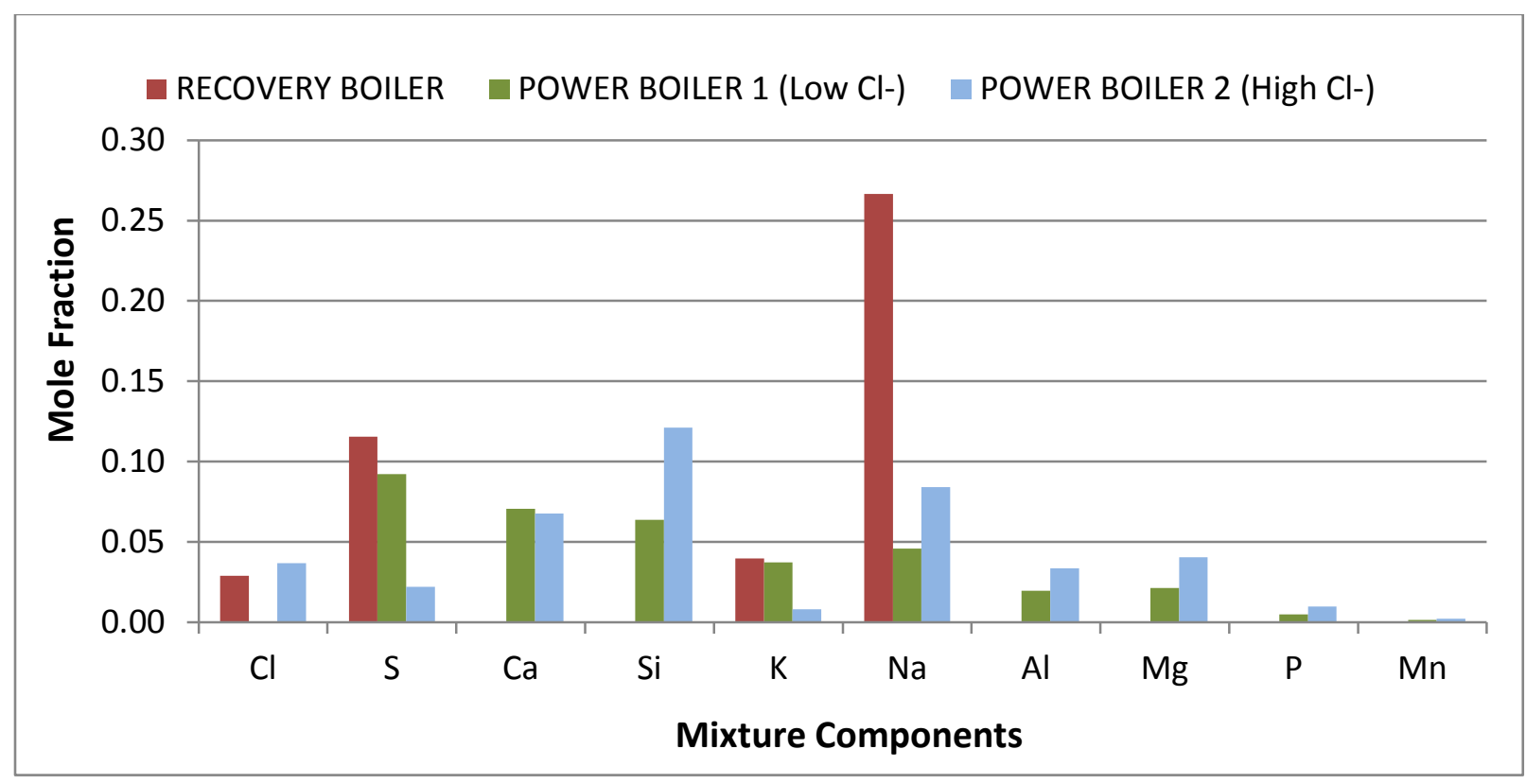

Fig. 16. Graphic representation of the three salt compositions used in this work.

\subsubsection{Cover gas composition}

The gas mixture used for all but three tests was 5 vol\% $\mathrm{O}_{2}, 10$ vol\% $\mathrm{CO}_{2}$ and 20 vol\% $\mathrm{H}_{2} \mathrm{O}$. The balance was $\mathrm{N}_{2}$. A small amount of $\mathrm{SO}_{2}(50 \mathrm{ppm})$ was added to the cover gas for the final three tests. The flow of 
each gas, except for water vapour, was controlled by a mass flow controller (MFC). The total of 200 standard $\mathrm{cm}^{3}$ produced a linear flow rate of $5 \mathrm{~cm} / \mathrm{m}$ through the furnace tube. The accuracy of the controllers was $\pm 3-5 \%$ of the setpoint, depending on the gas and capacity of the MFC. The flow of distilled water was controlled by a precision peristaltic pump, and the water was added directly into the gas inlet end of the furnace tubes. Tests showed that the water vaporized before reaching the tube wall. The water flow varied as the pump tubes aged and had to be monitored daily and adjusted on occasion. Analysis of the daily water usage data showed the volume $\% \mathrm{H}_{2} \mathrm{O}$ normally ranged between \pm 5 vol $\%$ of the setpoint.

\subsubsection{Alloys}

The choice of alloys was based on consultations with boiler manufacturers and alloy suppliers participating in this project as industrial partners, as well as consideration of the literature and experience with these alloys in other types of service. The alloys are listed in Table 2 by Alloy Set - each set being the alloys exposed together in a single test. Nominal composition of the alloys is shown in Table 3, along with the single letter code adopted for use in all documentation.

Table 2. Alloys used in each alloy set. Due to limited space for data in tables and graphs, codes are used throughout the report to represent the alloys

\begin{tabular}{|c|c|c|c|c|}
\hline Code & Alloy & Alloy Set 1 & Alloy Set 2 & Alloy Set 3 \\
\hline A & Esshete 1250 & $\mathrm{X}$ & & $\mathrm{X}$ \\
\hline $\mathrm{B}$ & $310 \mathrm{H}$ & $\mathrm{X}$ & $\mathrm{X}$ & $X$ \\
\hline $\mathrm{C}$ & Sanicro 28 & $X$ & & \\
\hline $\mathrm{D}$ & HR120 & $\mathrm{X}$ & $\mathrm{X}$ & $\mathrm{X}$ \\
\hline $\mathrm{E}$ & 602CA & $\mathrm{X}$ & & $\mathrm{X}$ \\
\hline EP & 602CA pre-oxidized & $X$ & $\mathrm{X}$ & \\
\hline $\mathrm{F}$ & HR214 & $X$ & & \\
\hline FP & HR214 pre-oxidized & $X$ & & \\
\hline $\mathrm{G}$ & A33 & & $\mathrm{X}$ & \\
\hline $\mathrm{H}$ & AC66 & & $\mathrm{X}$ & $\mathrm{X}$ \\
\hline $\mathrm{I}$ & HR160 & & $\mathrm{X}$ & $X$ \\
\hline $\mathrm{J}$ & A59 & & $\mathrm{X}$ & \\
\hline K & A690 & & X & X \\
\hline
\end{tabular}

Peg coupons were produced from each alloy with dimensions $25 \mathrm{~mm}$ long by $5 \mathrm{~mm}$ diameter, with a 0.4 to 1.6 micron Ra ground finish. A notch was cut in one or both ends of each peg coupon to act as an indicator of coupon orientation relative to the direction of gas flow in the furnace. The coupons were cleaned and dried with blowing hot air. The diameter of each peg coupon was measured with a micrometer ( \pm 2.5 micron) at three points around either end and in the middle of the cylinder. These measurements were averaged for each location and used respectively as the "before exposure" diameters during post exposure analysis. The peg coupons were stored in plastic containers until use.

\subsubsection{Exposures}

Peg coupons were placed in alumina crucibles and synthetic salts packed around the circumference (Figure 17). The pegs were taller than the crucibles, and hence permitted exposure of each specimen to both the gas phase within the furnace (including corrosive vapours) and to coverage by a bed of synthetic salt. Twelve crucibles at a time (with at least two of each alloy) were placed onto an alumina "D" support 
platform, and placed in the centre of a horizontal tube furnace. Coupon orientation on the " $\mathrm{D}$ " was noted and remained consistent from test to test. More alloys were evaluated than space allowed in a single test, so sets of coupons were independently exposed to the same test conditions in some cases. Once the coupons were sealed in the furnace under flowing nitrogen, the temperature was ramped slowly to the

Table 3: Nominal composition of alloys evaluated in the test program

\begin{tabular}{|c|c|c|c|c|c|c|c|c|c|c|c|}
\hline $\begin{array}{l}\frac{n}{u} \\
\frac{\bar{y}}{5} \\
\end{array}$ & 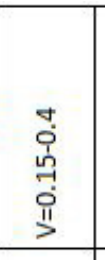 & $\begin{array}{l}0 \\
0 \\
0 \\
\text { II } \\
\end{array}$ & 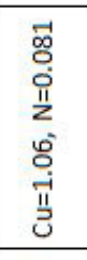 & 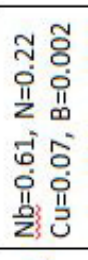 & 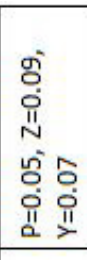 & 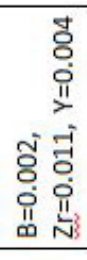 & 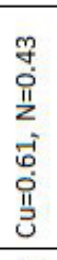 & 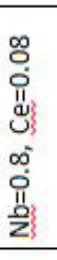 & & $\begin{array}{l}\text { a } \\
\text { oj } \\
\text { a } \\
\end{array}$ & $\begin{array}{l}\text { ப̇ } \\
\text { İ } \\
\text { J }\end{array}$ \\
\hline$u$ & & $\begin{array}{l}\text { ô } \\
\text { O̊ }\end{array}$ & $\stackrel{0}{0}$ & $\begin{array}{l}\text { J } \\
\text { O }\end{array}$ & नิ่ & $\stackrel{0}{0}$ & $\begin{array}{l}\text { â } \\
\stackrel{0}{0}\end{array}$ & $\stackrel{\circ}{\circ}$ & $\begin{array}{l}\text { 号 } \\
\text { O }\end{array}$ & $\begin{array}{l}\text { to } \\
\text { o. }\end{array}$ & ס̊ \\
\hline$F$ & & $\begin{array}{l}\overrightarrow{0} \\
\dot{v}\end{array}$ & & $\begin{array}{l}\overrightarrow{0} \\
\dot{0}\end{array}$ & 뭉. & 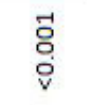 & & & $\stackrel{\infty}{0}$ & & \\
\hline in & $\tilde{c})$ & 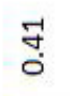 & ֻु & 㝵 & $\stackrel{\text { ח̊ }}{\circ}$ & $\stackrel{\circ}{\circ}$ & $\underset{\text { İ }}{\text { İ }}$ & స్ำ & 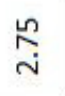 & $\underset{0}{0}$ & $\stackrel{n}{2}$ \\
\hline$\Sigma$ & ఝֶ. & กู & $\underset{i}{\stackrel{t}{S}}$ & ָ̊. & ֻั & సี & to. & $\stackrel{n}{\circ}$ & $\stackrel{\infty}{\circ}$ & ને & กี \\
\hline $\bar{\varangle}$ & & $\stackrel{\text { ֻ̊ }}{0}$ & & ò & $\stackrel{m}{\sim}$ & ঙ্লি & & ¿े. & & ஜू. & \\
\hline ○ & & ก̃ & & 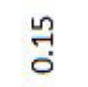 & & ö & & & ָ̃ & -10 & \\
\hline$\stackrel{\circ}{\Sigma}$ & $\dashv$ & 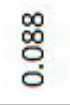 & 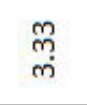 & 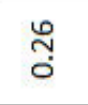 & & r. & g & & స్ & $\begin{array}{l}\text { กn } \\
\text { "n }\end{array}$ & \\
\hline ¿ & 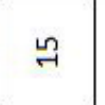 & 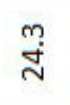 & 官 & 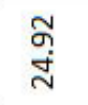 & 岕 & ت્નુ & m & 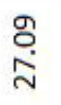 & $\stackrel{\infty}{\sim}$ & 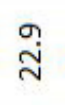 & $\stackrel{\infty}{\stackrel{\infty}{\sim}}$ \\
\hline $\bar{z}$ & 강 & ه̆ & ப் & $\stackrel{m}{\stackrel{m}{m}}$ & ָָ & $\underset{\frac{n}{2}}{\frac{n}{2}}$ & 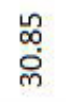 & $\begin{array}{l}\infty \\
\vec{m} \\
\vec{~}\end{array}$ & 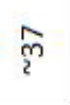 & 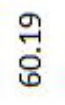 & $\stackrel{\mathscr{n}}{\mathrm{G}}$ \\
\hline$\stackrel{\sim}{\longleftarrow}$ & 6 & $\underset{\infty}{\bar{\infty}}$ & $\begin{array}{l}\bar{\varpi}\{ \\
\infty\end{array}$ & $\bar{\varpi}$ & $\stackrel{\circ}{\sigma}$ & $\begin{array}{l}\stackrel{\infty}{\infty} \\
\text { mi }\end{array}$ & ্ָঠు & $\begin{array}{l}\bar{\infty} \\
\infty\end{array}$ & $\stackrel{\mathscr{0}}{0}$ & $\stackrel{\circ}{\circ}$ & 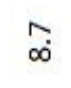 \\
\hline 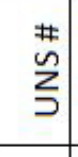 & 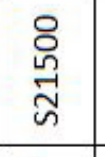 & $\begin{array}{l}\text { वे } \\
\text { ले } \\
\text { ભ }\end{array}$ & 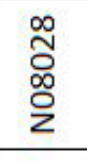 & $\begin{array}{l}\text { Iิ } \\
\text { o } \\
\text { Oे }\end{array}$ & 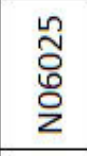 & 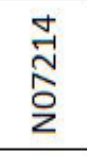 & 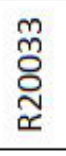 & $\underset{\sim ్ N}{\widetilde{N}}$ & 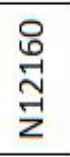 & 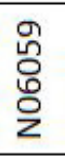 & 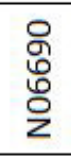 \\
\hline 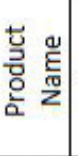 & 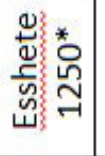 & $\underset{\mathrm{m}}{\mathrm{T}}$ & 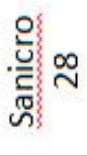 & $\begin{array}{l}\underset{\text { ㄱ. }}{\not{I}} \\
\underline{\underline{I}}\end{array}$ & 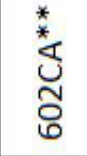 & 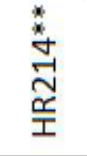 & $\stackrel{\tilde{q}}{q}$ & 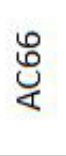 & 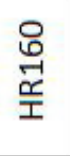 & 多 & $\begin{array}{l}\text { \& } \\
\text { \& }\end{array}$ \\
\hline $\begin{array}{l}\text { 山े } \\
\text { ठे }\end{array}$ & $\varangle$ & $\infty$ & $u$ & 0 & س & 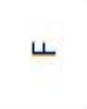 & (1) & $I$ & - & $\neg$ & $\check{x}$ \\
\hline
\end{tabular}


setpoint. When it was reached, the test gases and water were introduced into the furnace. At the conclusion, the coupons were allowed to cool in the furnace with flowing nitrogen as a cover gas.

\subsubsection{Analysis}

Coupons were photographed immediately on removal from the furnace, then carefully pried from the crucible with the salt layer as intact as possible. Six coupons at a time were fitted to a jig, and embedded in an epoxy metallographic mount for sectioning and cross-sectional polishing (Figure 18). Each mount was sectioned at a point above and below the level of the salts in the crucible. Sections were then drypolished to a 3 micron diamond finish and the surface of each coupon photographed at 10X magnification in an automated Zeiss AxioVision microscope. In total, more than 350 coupons were exposed in the test program - leaving some 700 surfaces to analyze. For coupons with more than 20 microns of corrosion, a customized image analysis program was used to segment the coupon into 24 arcs, and measure both the maximum metal loss and total-affected-metal (TAM) in each arc (Figure 19). Metal loss was determined at the interface between the scale and sound metal, while the TAM was defined as the average of the deepest visible penetration of corrosion into the interior of the coupon on the 24 arcs. The accuracy of the measurement was estimated to be \pm 3 microns.

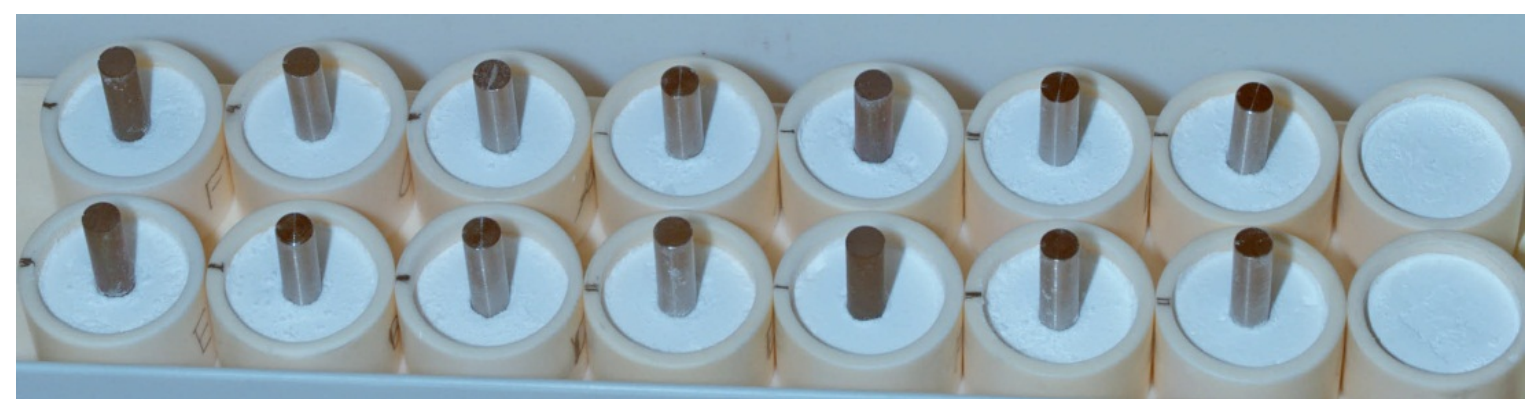

Fig. 17. Alloy Set 1 laid out in preparation for insertion to a furnace, showing the reproducibility of the initial salt packing and surface height. The pre-oxidized coupons in the third and last rows from the right are darker than the remaining as ground coupons. Blank "guard" pots placed at the gas inlet are also visible.

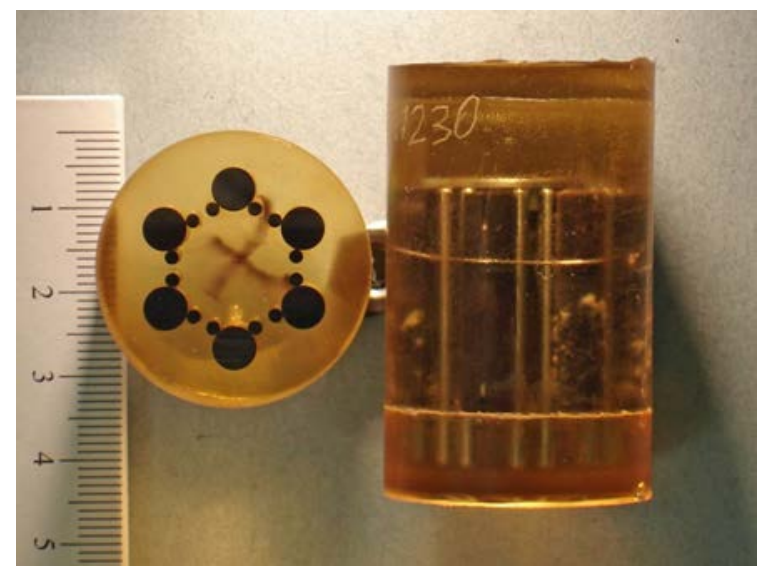

Fig. 18. Six coupons embedded in epoxy with their support pins. The mount on the right has not been machined square yet. The mount on the left has been dry sectioned.

\subsubsection{Results and Discussion}

\subsubsection{Overview}


An example of the general appearance of the coupons after exposure is shown in Figure 20. These coupons were exposed to the recovery boiler salts at $625^{\circ} \mathrm{C}$. Yellowing at the surface of the salts was observed in many tests, but to a far greater extent in the recovery boiler salts. EDX analysis of yellow and white salts confirmed that the yellow color was associated with chromium. Sodium chromate $\left(\mathrm{Na}_{2} \mathrm{CrO}_{4}\right)$ is an intense yellow salt that appears the most likely to have been formed. On several occasions, and for more than one alloy, it was noted that when one of a pair of coupons within a given test had corroded significantly more than the other, the salts had remained white for the corroded coupon and had yellowed for the more resistant.

The complex test environment presented many experimental challenges, both in the set up and operation, as well as for the analyses of the coupons afterwards. Throughout the test program, steps and checks were put in place to determine how consistent conditions were from test to test, and to enable data to be compared and normalized across tests. This was achieved by putting two baseline coupons of S31009 (alloy B) in the same locations of the furnace in every test, exposing duplicate coupons of every alloy, and duplicating some alloys (S31009 (alloy B), N06025 pre-oxidized (alloy E), S21500(alloy A)) between identical tests.

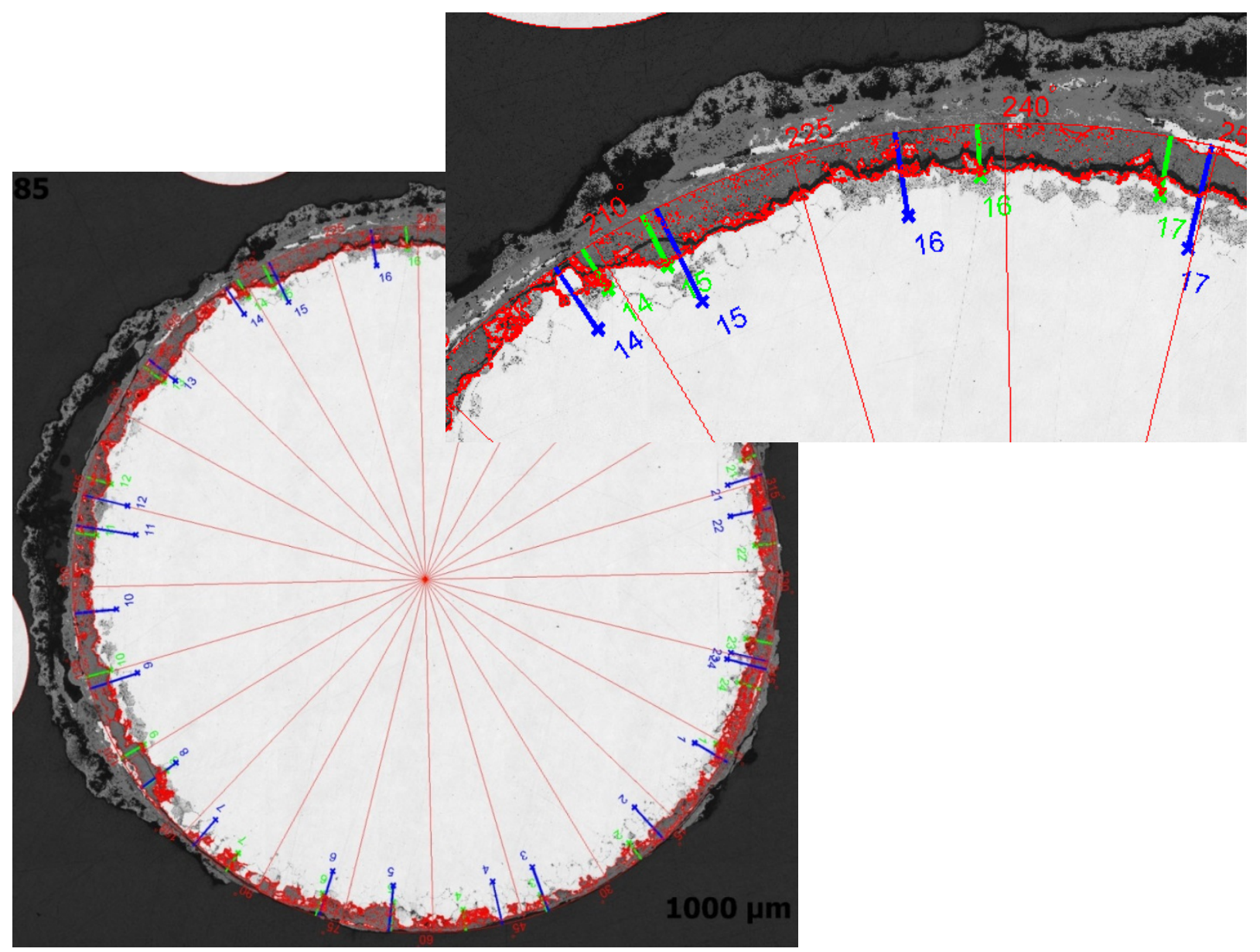

Fig. 19. A mosaic image of a cross-section after analysis. Inset shows top right corner in more detail. The outer red circle is the original circumference of the coupon. The green lines indicate the depth measured for metal loss, and the blue lines indicate the total affected metal measurement for each of the 24 arcs around the circumference. The average of the $\mathbf{2 4}$ total affected metal measurements is defined as the TAM of the coupon. 
It is clear from an examination of the data that conditions within the furnaces were not always identical, and neither were conditions in duplicate tests. Nonetheless, the data proved to be reasonably consistent within, as well as between tests. A few tests produced highly variable data that was almost certainly caused by artifacts in the test environment. The stochastic nature of corrosion was also demonstrated as greater variability was found in the shorter-term tests due to the randomness of initiation events on the coupons. Results in the longer-term tests were more uniform.

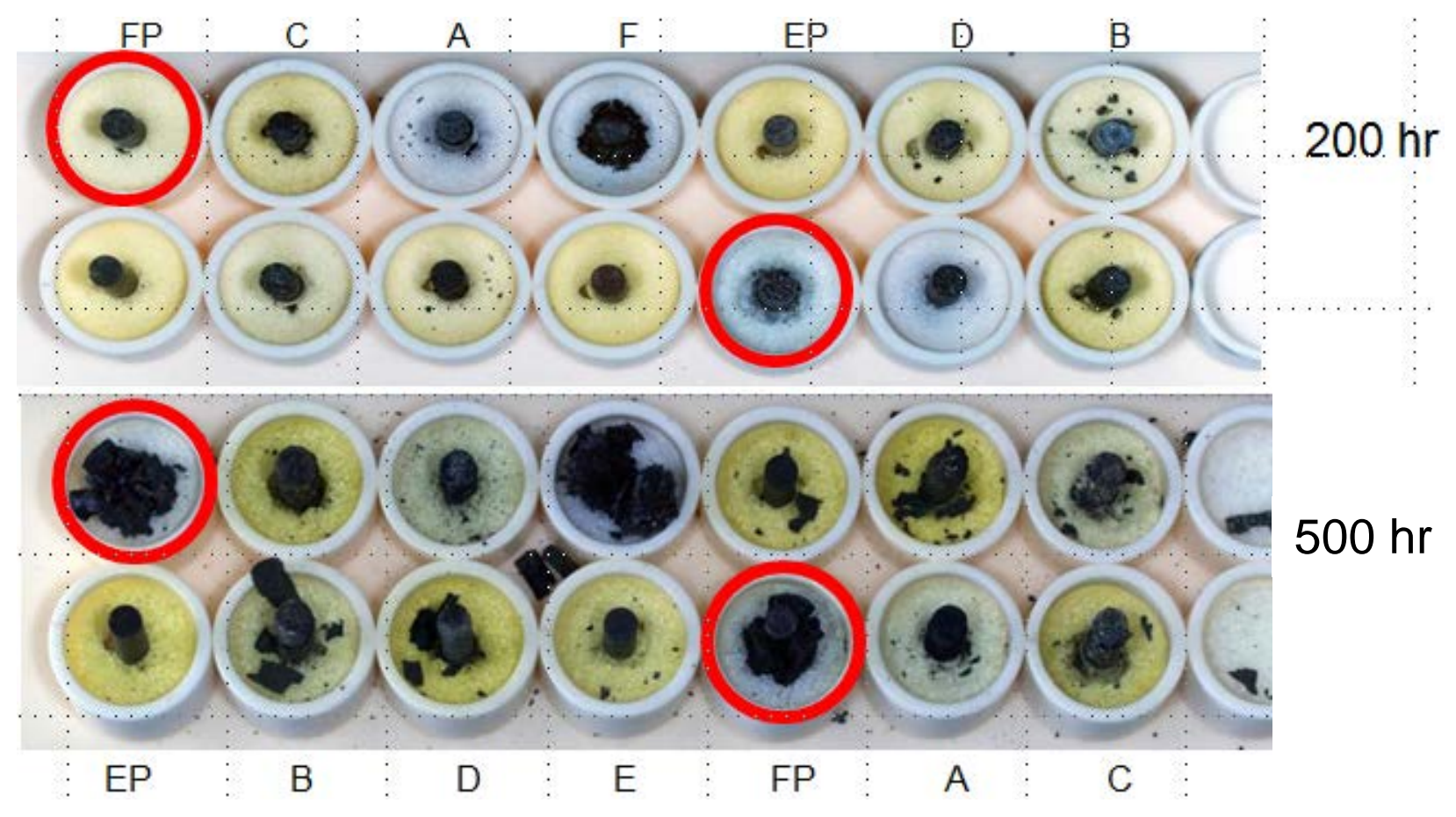

Fig. 20. Shows variation with salt color relating to corrosion of the coupon. Red circles indicate coupons of pre-oxidized HR214 (Alloy FP) in RB salts at $625^{\circ} \mathrm{C}$. Note that the only Alloy F coupon not to show substantial spalling is the one with the yellow-shaded salt.

A total of fifty S31009 (alloy B) coupons were exposed over the entire program, giving 100 sections to be analyzed (half in the vapour phase and half under-deposit). Data was analysed from the 50 individual S31009 sections for which the TAM was greater than 25 microns [108]. The standard deviation of the 24 TAM measurements around the circumference as a percent of their average was calculated for each coupon. It ranged from $7 \%$ to $62 \%$ above the salts with an average of $15 \%$, and from $5 \%$ to $30 \%$ below the salts with an average of 18\%. The overall average of the above for S31009 is 16\%.

For the balance of the alloys, the standard deviation for any given set of measurements in duplicate tests fell between 15 and 25\% of the average TAM for the alloy, consistent with the S31009 result. Only three materials fell outside of this range - those with the most severe corrosion and those with the least corrosion (Table 4).

\subsubsection{Power Boiler I (PB1) tests}

The PB1 salt was representative of deposits produced by clean, uncontaminated fuel. There was minimal corrosion on all coupons exposed to this salt, even for tests that lasted 1000 hours. The average TAM was far less than 25 microns for all coupons. 


\subsubsection{Power Boiler 2 (PB2) tests}

The PB2 salt was representative of deposits produced by fuel that is highly contaminated with chloride. Even so, the depths of corrosive attack on all coupons were much less than 25 microns after 100 hours. Only coupons from test exposures 200 hours and longer were subjected to the full standard analysis. Corrosion as a function of time is shown in Figure 21 while results for the 1000 hour tests are shown in Figure 22, plotted in order of increasing nickel content in the alloys. The most extensive corrosion in these tests occurred underneath the layer of salt; there was very little corrosion above the salt layer. There is also a clear correlation between increased resistance to corrosion and greater nickel content of the alloy. Conversely, there was no correlation when the same data was plotted as a function of chromium content. The results from the test conducted at $500{ }^{\circ} \mathrm{C}$ appear anomalous and a review of the data showed higher than average variation in TAM on several coupons. No reason for this variation was discovered.

Table 4. Standard deviation in average TAM for alloys for all the test environments. The data is separated into Vapor Phase and Under-Deposit results and sorted by the average of those results

\begin{tabular}{|c|c|c|c|c|}
\hline & & \multicolumn{2}{|c|}{ Std Dev as \% of Average TAM } & \\
\hline Code & Alloy & Vapour Phase & Under-Deposit & Average \\
\hline H & AC66 & $14 \%$ & $17 \%$ & $16 \%$ \\
\hline B & $310 H$ & $18 \%$ & $14 \%$ & $16 \%$ \\
\hline C & San28 & $18 \%$ & $20 \%$ & $19 \%$ \\
\hline A & Esshete 1250 & $24 \%$ & $20 \%$ & $22 \%$ \\
\hline J & A59 & - & $22 \%$ & $22 \%$ \\
\hline D & HR120 & $24 \%$ & $24 \%$ & $24 \%$ \\
\hline K & A690 & $26 \%$ & $23 \%$ & $25 \%$ \\
\hline EP & $602 C A$ pre-oxidized & $24 \%$ & $26 \%$ & $25 \%$ \\
\hline E & $602 C A$ & $34 \%$ & $32 \%$ & $32 \%$ \\
\hline F & HR214 & $38 \%$ & $28 \%$ & $33 \%$ \\
\hline FP & HR214 pre-oxidized & $42 \%$ & $29 \%$ & $33 \%$ \\
\hline I & HR160 & $29 \%$ & $38 \%$ & $34 \%$ \\
\hline \hline
\end{tabular}

\subsubsection{Recovery boiler tests}

Negligible corrosion was observed on the alloys in tests conducted at $510^{\circ} \mathrm{C}$ - the greatest TAM measured was only 17 microns for N06025 (alloy E). This temperature is below the FMT of the salt deposits. More substantial corrosion was observed at both higher temperatures, and two alloys completely disintegrated in the 1000 hour test at $625^{\circ} \mathrm{C}$. These were N07214 (alloy F) and N06059 (alloy I). Data for the $1000 \mathrm{hr}$ tests at $625^{\circ} \mathrm{C}$ is shown in Figure 23. The correlation between corrosion and nickel content is not apparent in these tests; nor does the corrosion correlate with chromium content of the alloys. Of significance in these tests was the observation that corrosion in the gas phase was nearly as severe as underneath the salt deposits. Especially in the vapour phase, internal penetration accounted for a larger proportion of the TAM. A measureable increase in corrosion was noted for many of the alloys when $\mathrm{SO}_{2}$ was added to the cover gas (Figures 24 and 25). 


\section{ABOVE SALTS}

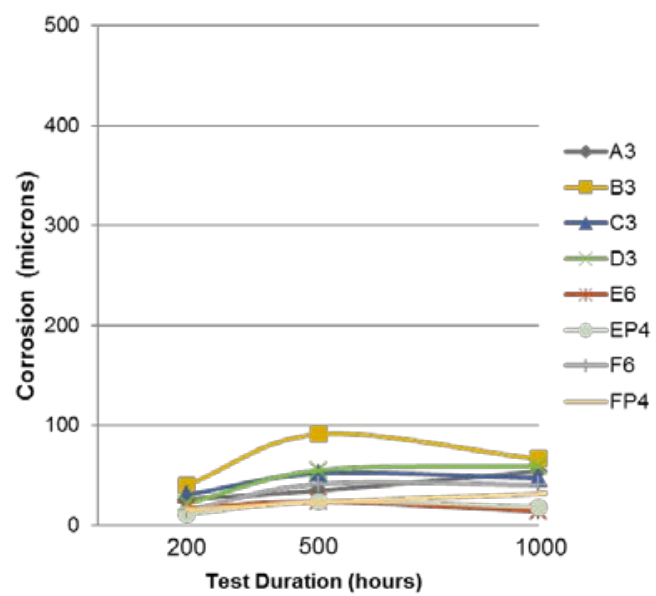

BELOW SALTS

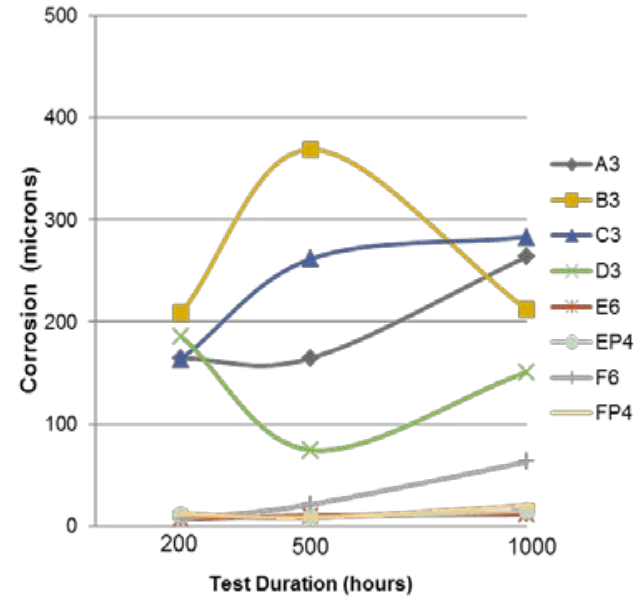

Fig. 21. Variation of average TAM with time in $\mathrm{PB} 2$ salts at $650{ }^{\circ} \mathrm{C}(\mathrm{T} 14, \mathrm{~T} 15, \mathrm{~T} 16)$, in microns.

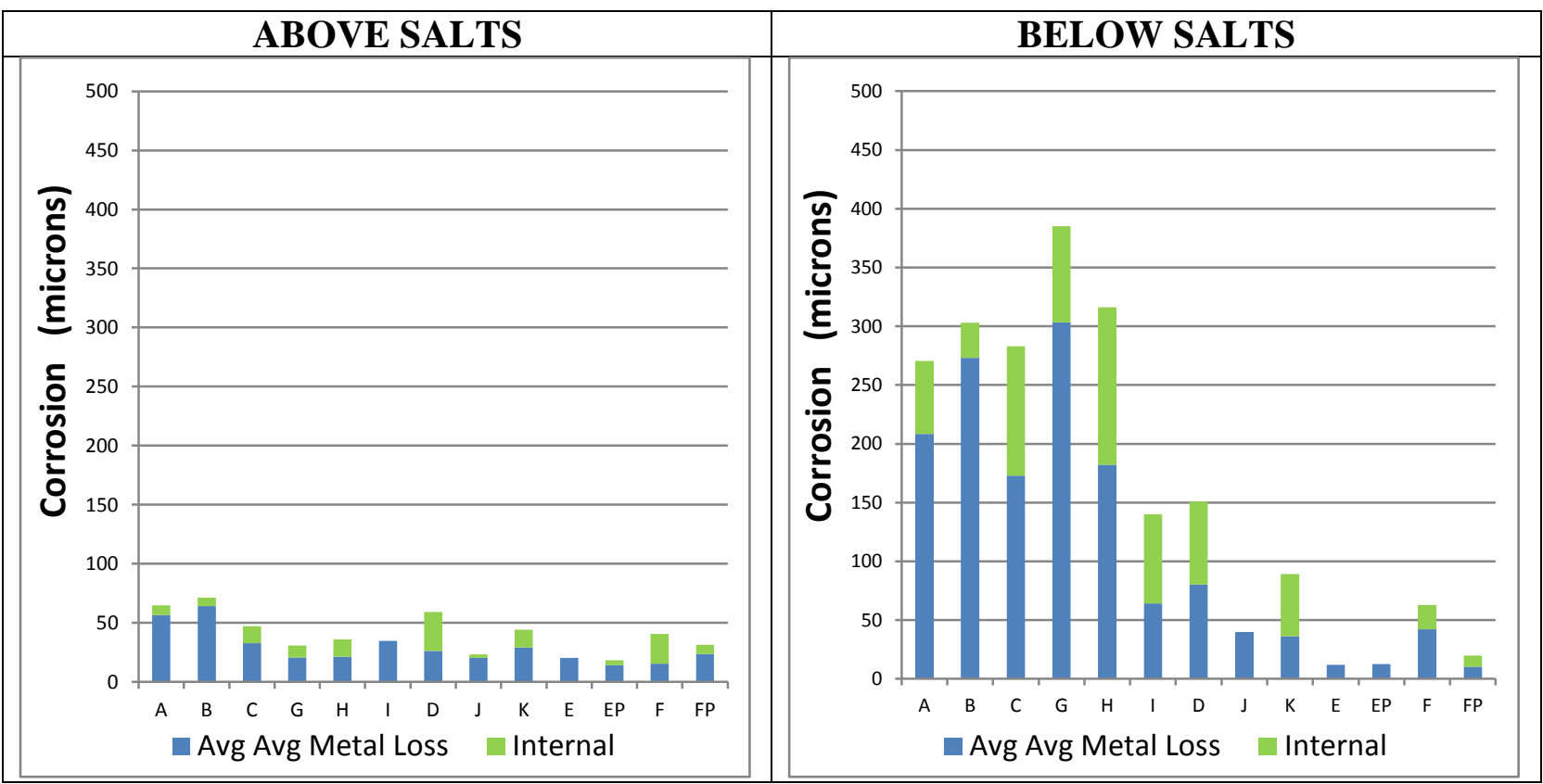

Fig. 22. Test data from alloys exposed to $\mathrm{PB} 2$ salts for $1000 \mathrm{hrs}$ at $650^{\circ} \mathrm{C}$. Alloys are listed in order of increasing nickel content left to right with the last four on the right being the alumina formers (E, EP, F, FP). Metal loss is blue portion of bar, TAM is green portion of bar. 


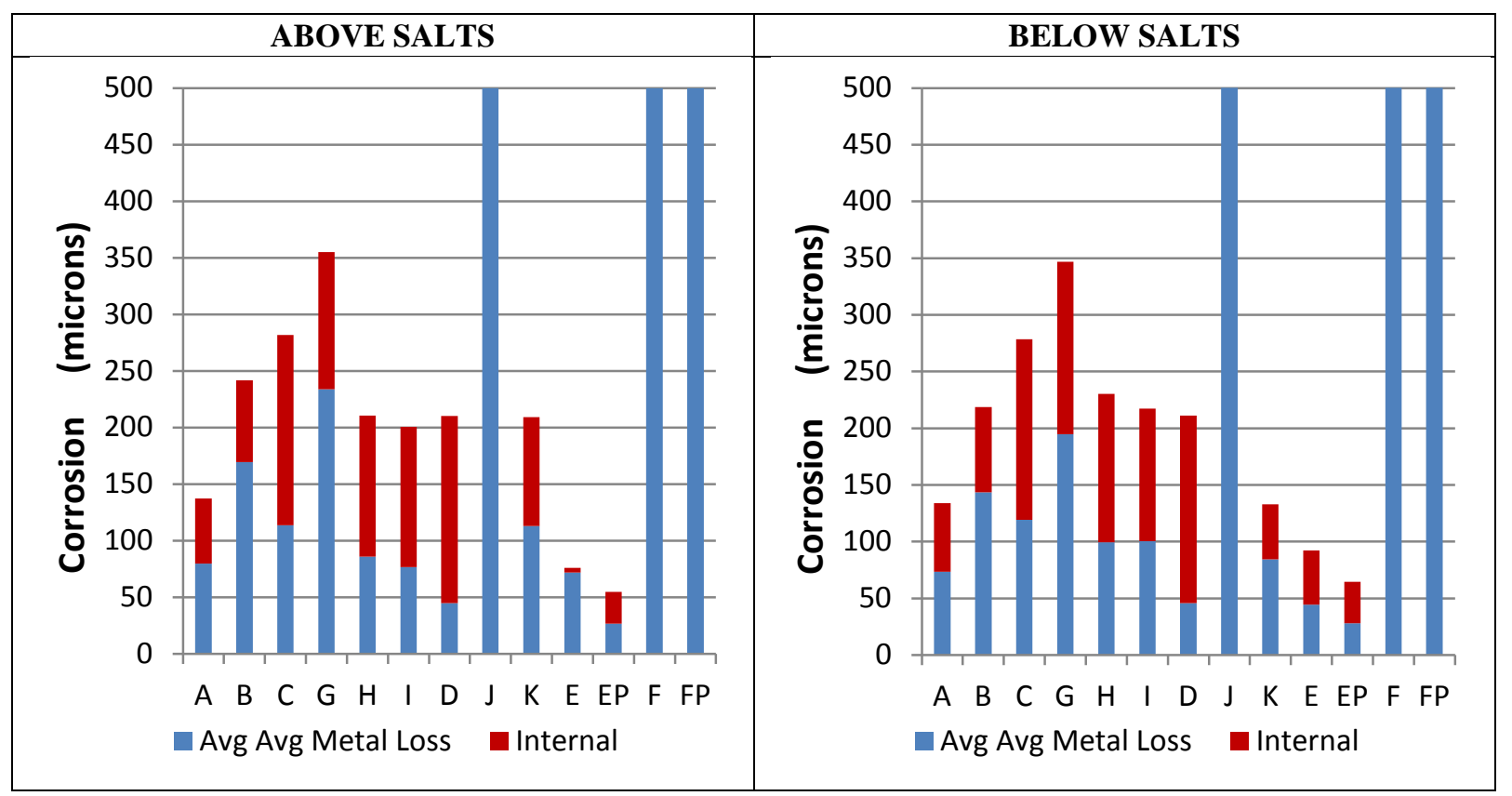

Fig. 23. Test data from alloys exposed to RB salts for $1000 \mathrm{hrs}$ at $625^{\circ} \mathrm{C}$. Metal loss is blue portion of bar, TAM is red portion of bar. The alloys are listed in order of increasing nickel content left to right with the alumina formers at the right (E, EP, F, FP).

\subsubsection{Alloy performance and ranking}

Evaluation of alloy performance was based on the results of $1000 \mathrm{hr}$ tests, and compared the average TAM from all coupons of the same alloy in each environment, as well as visual and microscopic observation of the coupons. An arbitrary scale was used to rank the alloys. An average TAM of less than 20 microns was considered acceptable, between 20 and 100 microns was intermediate, and greater than 100 was considered unacceptable performance. For reference, linear corrosion at 20 microns/1000 hrs would extrapolate to $1.8 \mathrm{~mm}$ over 10 years and 50 microns/1000 hrs would represent a loss of nearly 4.4 mm over a 10 year life. The ranking of alloys was different for each environment, and also varied by temperature in the same environment.

In the PB1 environment, all alloys performed well enough to fit into the acceptable category. In the PB2 environment at $650^{\circ} \mathrm{C}$, only two alloys fell into the acceptable performance range - N06025 (alloy E) and the pre-oxidized N07214 (alloy FP). N06059 (alloy J) was the only other alloy amongst the group to fit into the intermediate category for both above and below the deposit (Figure 26). A number of other alloys performed moderately well in the vapour space above the salts, but did much more poorly underneath the deposits. Most notable amongst these were R20033 (alloy G) and S33228 (alloy H). These two alloys were in the group of four alloys with the lowest nickel content. The other alloys in this group included S31009 (alloy B) and S21500 (alloy A), both of which also fared quite poorly in these tests.

In the recovery boiler environment at $510^{\circ} \mathrm{C}$, all alloys provided acceptable corrosion resistance. At $530^{\circ} \mathrm{C}$, the only alloy to provide acceptable service both above and below the salt level was N06059 (alloy J). A few other alloys - notably N06025 (alloy E \& EP) and N07214 (alloy F) were acceptable in the vapour space, but not beneath the salts. N06690 (alloy K) and N12160 (alloy I) fell into the intermediate category above the salts, and N06025 (alloy E) was the only alloy to fit into the intermediate category beneath the salts. The worst alloys in this service were S31009 (alloy B), S21500 (alloy A) and S33228 (alloy H). 


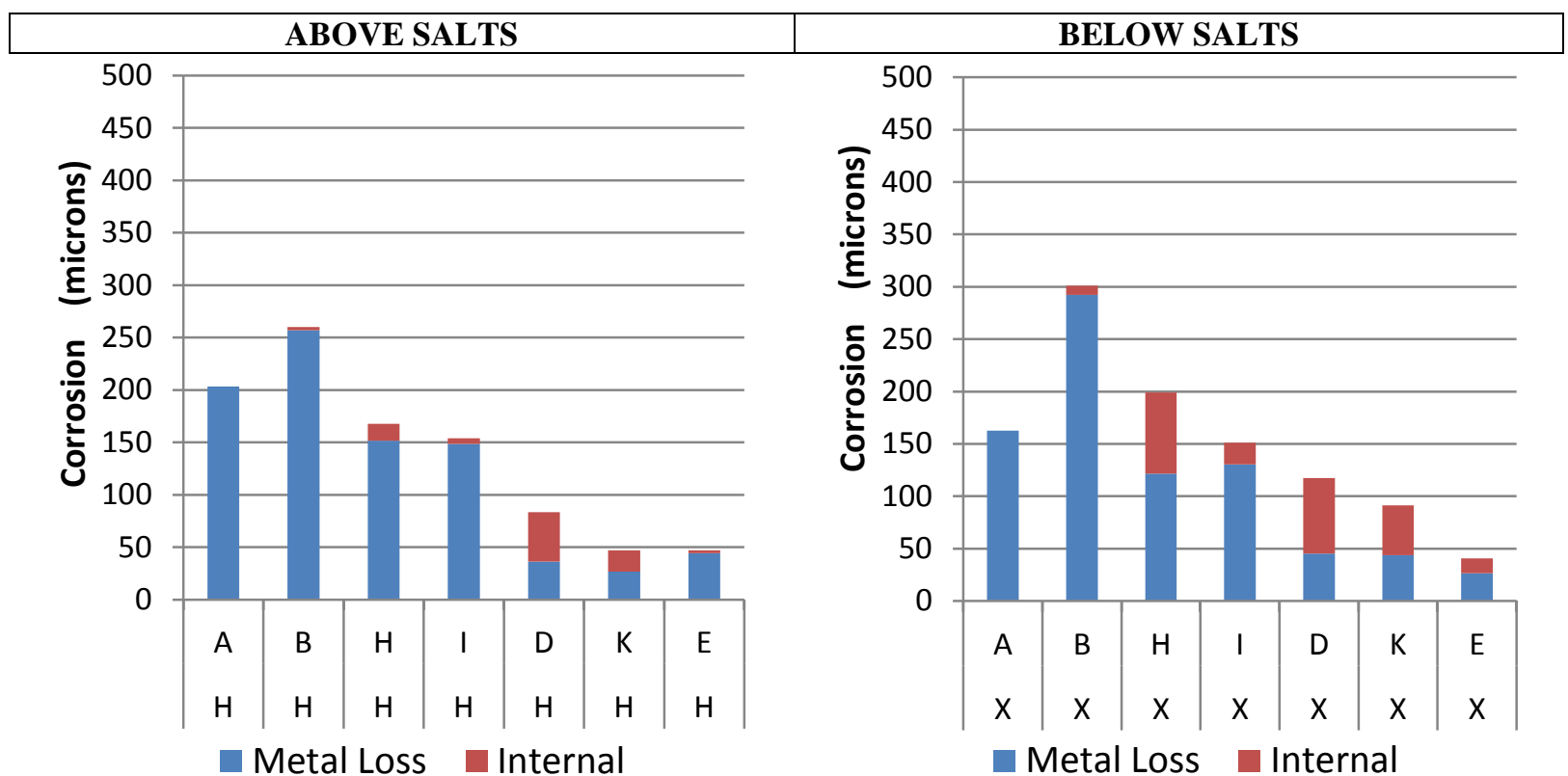

(a) $530{ }^{\circ} \mathrm{C}$

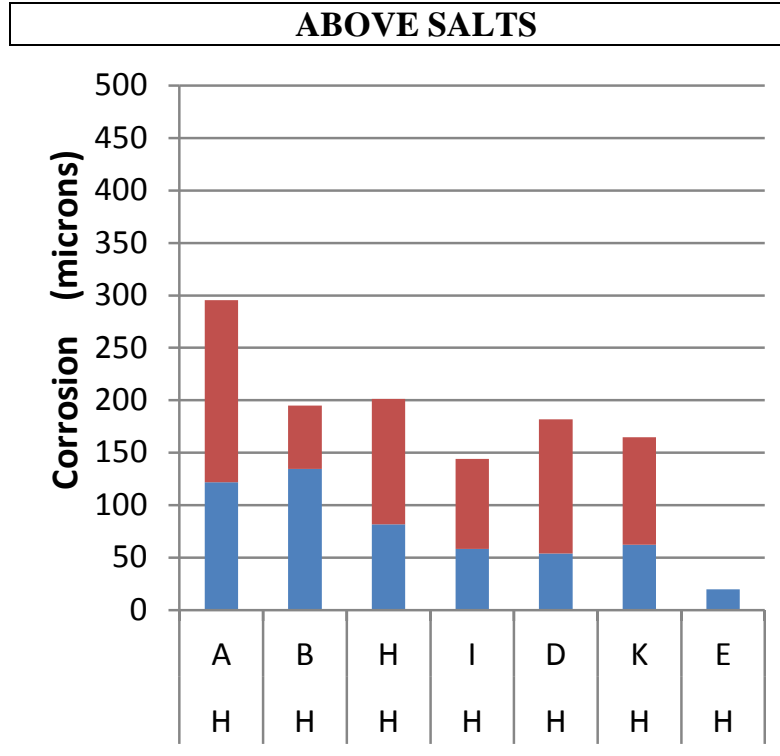

Metal Loss Internal

\section{BELOW SALTS}

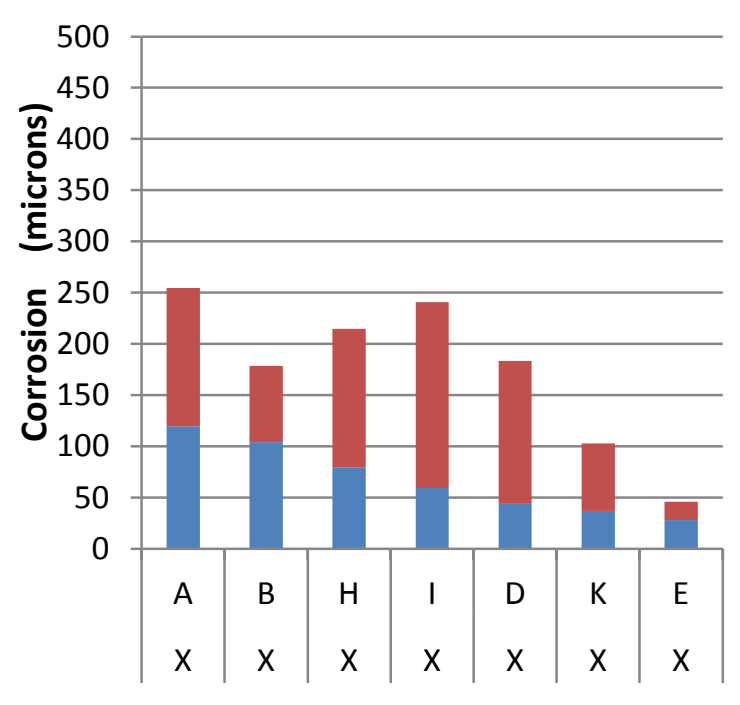

Metal Loss $\square$ Internal

(b) $625^{\circ} \mathrm{C}$

Fig. 24. Corrosion results for Alloy Set 3 after exposure to recovery boiler salts at (a) $530{ }^{\circ} \mathrm{C}$ and (b) $625^{\circ} \mathrm{C}$

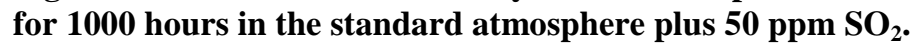




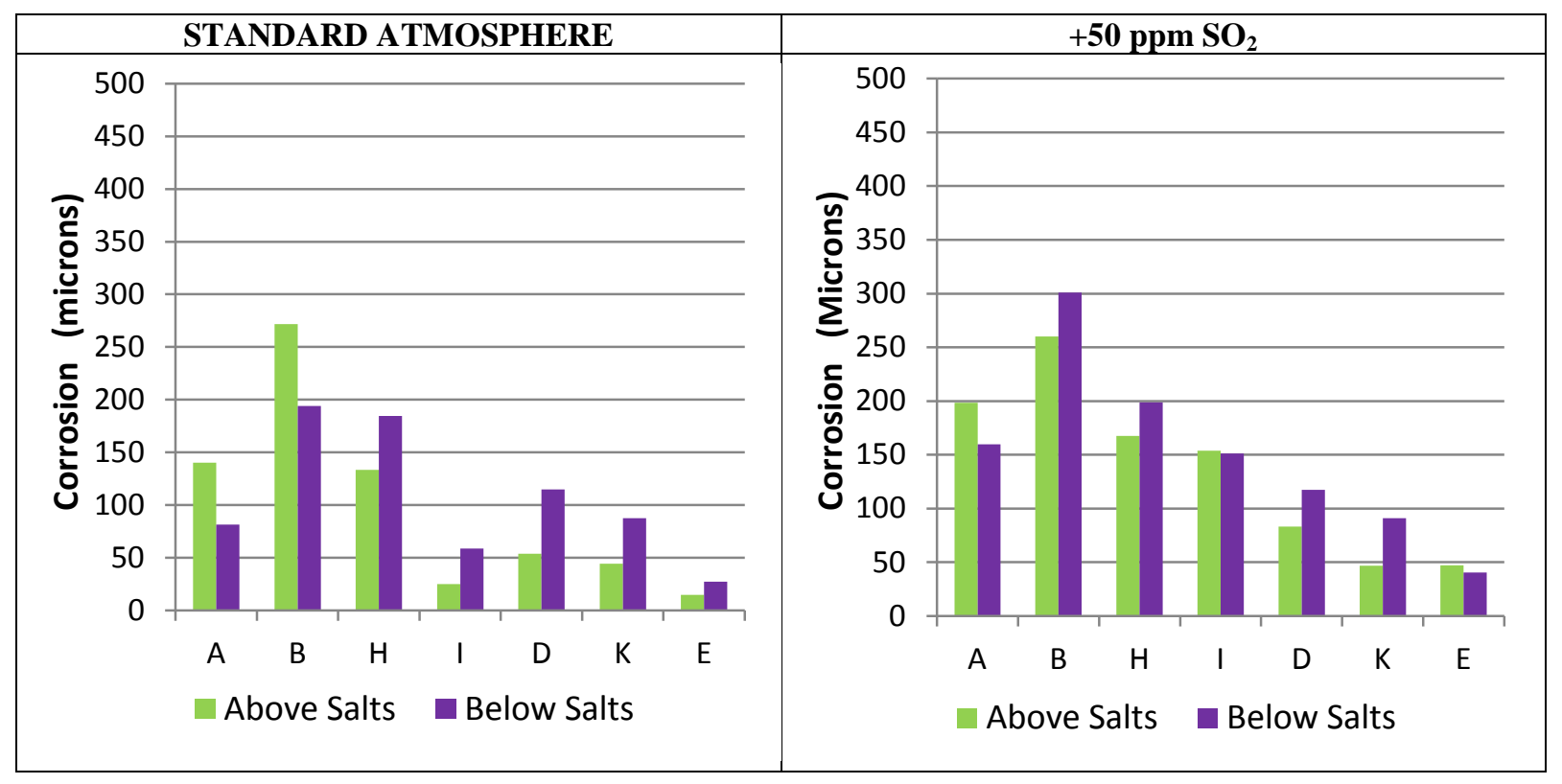

(a) $530{ }^{\circ} \mathrm{C}$

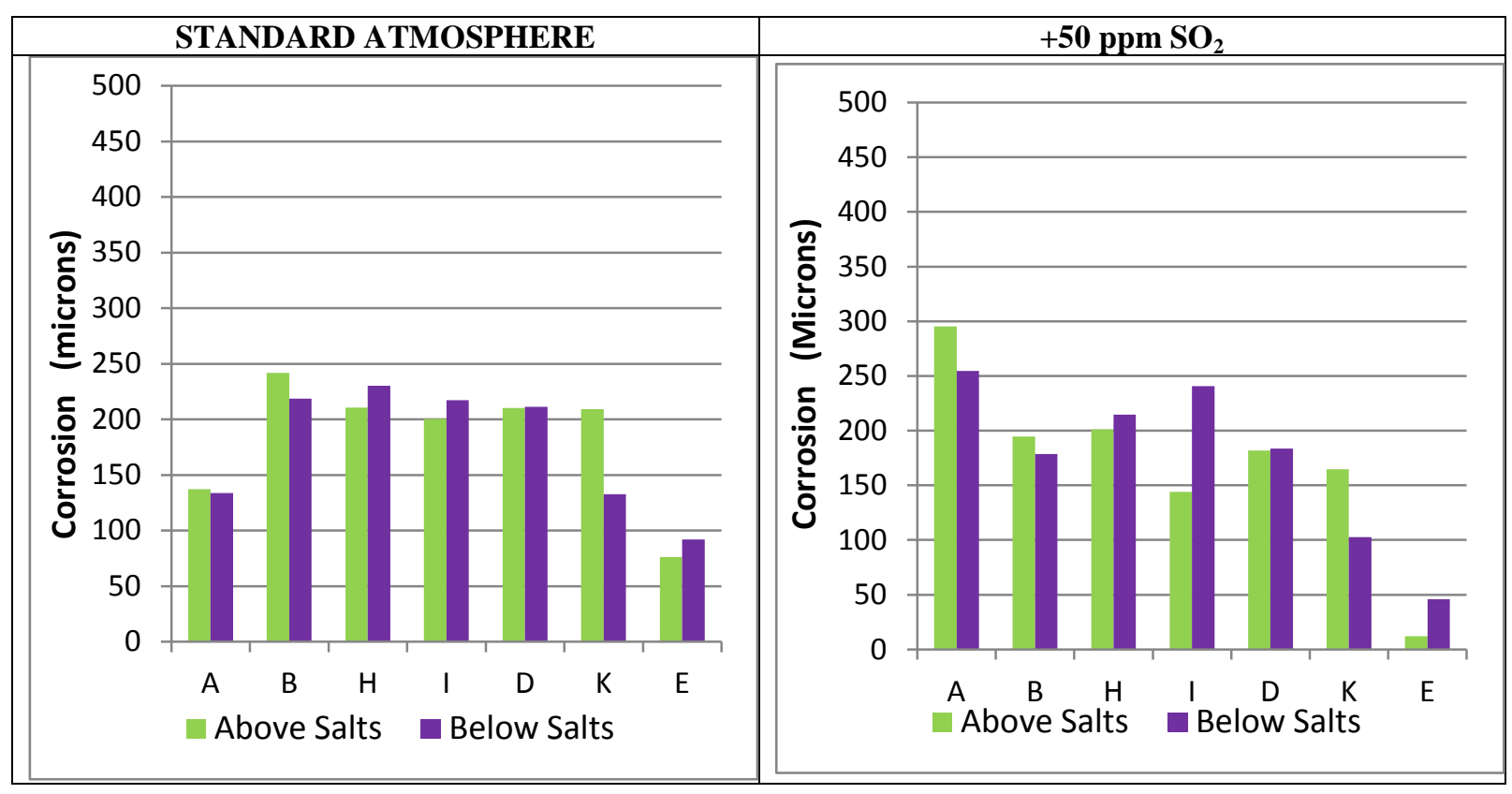

(b) $625^{\circ} \mathrm{C}$

Fig. 25. Comparison of average TAM for the alloys that were in recovery boiler 1000 hour tests, without and with the addition of $50 \mathrm{ppm} \mathrm{SO}_{2}$. (a) $530^{\circ} \mathrm{C}$; (b) $625^{\circ} \mathrm{C}$

As expected, the recovery boiler environment at $625^{\circ} \mathrm{C}$ was extremely aggressive and no alloy fit into either the acceptable or intermediate categories. Corrosion rates above and below the salt level were similar. N06025 (alloy E) was the best of the alloys, along with S21500 (alloy A) and N06690 (alloy K). Two alloys failed catastrophically in the recovery boiler environment at $650{ }^{\circ} \mathrm{C}-\mathrm{N} 06059$ (alloy J) and 
N07214 (alloy F). The failure of N06059 (alloy J) was unexpected, given its extremely good performance in the same environment at the lower temperature. This alloy stands out from the others due to the very high molybdenum content and it is likely that this is the contributing factor to the failure. N07214 (alloy F), in contrast, contains little molybdenum, but contains the second least amount of chromium (next to S21500 (alloy A)). Chromium is well known to enhance corrosion resistance in Kraft recovery environments, so the failure of N07214 (F) was not unexpected. In contrast, the relatively good performance of the S21500 (alloy A) coupons in this environment was surprising, given the low chromium content of this alloy. While it might be argued that the manganese content of this alloy imparted some level of protection, there remains the possibility that it too might have failed catastrophically had the test been prolonged.

The ranking of alloys in the $\mathrm{SO}_{2}$-containing cover gas were similar to the equivalent results in tests without $\mathrm{SO}_{2}$. Only 7 of the alloys were exposed in this environment, and they were chosen as the best of the previous tests. 602CA (alloy E) displayed by far the best corrosion resistance in this test. There appeared to be little difference in corrosion above or below the salt level. S21500 (alloy A) and S31009 (alloy B) were the worst of the limited set of alloys exposed to the $\mathrm{SO}_{2}$-containing environment. Given that the standard deviation of these experiments varies between 15-25 percent, the performance of the balance of the other alloys could be described as similar.

\subsubsection{Comparison to Field Data}

Laboratory experiments are typically well-controlled and provide more reproducible results than field exposures, where temperature, deposit flux and composition, and other critical parameters vary dramatically as a function of time. The intent of laboratory experiments is to provide comparable data in less time, with useful results. Oftentimes, they also fail to replicate critical aspects of the corrosive environment, and consequently under- or over-estimate the real rate of corrosion in-service. One unique aspect of this particular program is the strong linkage between field and laboratory tests $[110,111]$. The salt deposits chosen for the laboratory tests were meant to mimic the real deposits collected from the one recovery boiler and two power boilers boilers involved in the program. The equivalent field tests, in this case, typically ran for about 2000 hours.

Overall, the general trends between field and laboratory trials matched well in the case of the in situ recovery boiler trials. N07214 (alloy F), N08028 (alloy C) and S31009 (alloy B) all performed poorly in the field. These alloys were also amongst the worst performers in the laboratory trials, particularly the N07214 (alloy F) at higher temperatures. The alloys that performed best in the in situ probes were N12160 (alloy I) and S21500 (alloy A), both of which fared reasonably well in the laboratory tests as well. Although N06025 (alloy E) was clearly the best alloy in the laboratory tests, it did not fare as well at the higher temperatures in the field probe.

The correlations between laboratory and field results were less clear for the power boilers, because of the temperature differences. The laboratory trials were conducted at significantly higher temperatures than could be reached in the locations where the field probes were installed, and consequently, there is no directly comparable data. In the case of the PB1 tests (Port Mellon boiler in the field trials), the maximum exposure temperature did not exceed $480^{\circ} \mathrm{C}$ in the field probe. Overall, the conditions in this boiler were much less corrosive than was the case in the PB2 boiler (Crofton). This matches the laboratory experience. However, an interesting note is that the most rapid corrosion in the field trial in PB1boiler occurred at temperatures between 400 and $450^{\circ} \mathrm{C}$. This was attributed to the presence of $\mathrm{Zn}$ and $\mathrm{Pb}$ in the deposits, which form low-melting eutectic compounds at those temperatures. This is a good example of not replicating the critical corrosive environment in a laboratory test. These elements were not included in the synthetic salts, nor was the test temperature in the appropriate range for this corrosion mechanism. 
For the PB2 boiler, the maximum exposure temperature in the field was about $550^{\circ} \mathrm{C}$. The best performing alloys in the field were N08120 (alloy D) and S21500 (alloy A), neither of which did particularly well at the higher temperature laboratory tests. N06025 (alloy E) was also not a good performing alloy in the field trials, despite doing well in the laboratory tests.

Across all three boilers, corrosion in the field trials was roughly of the same order of magnitude, but somewhat higher than those measured in the laboratory experiments. This is a good correlation, given the longer exposure times in the field trials. Cyclic temperatures and heat flux are also known to be strong accelerators for corrosion in high temperature conditions, and neither of these was present in the laboratory experiments. The difference in corrosion behavior for N06025 (alloy E) between the laboratory and field trials was surprising and merits further investigation, given the good performance of this alloy in the laboratory.

\subsubsection{Summary and Conclusions}

A laboratory test was developed that allows for assessment and comparison of corrosion that occurs above and below deposits on the same coupon in simulated fireside superheater environments.

In these tests, the rate of corrosion in the gas phase of simulated power boiler environments was substantially lower than for corrosion that occurred underneath deposits. This observation may have strong practical implications for companies that practice risk-based inspection in biomass-fired boilers.

Under the test conditions employed, rates of corrosion above and underneath deposits were similar in a simulated Kraft recovery boiler environment.

In terms of best corrosion resistance, Alloy N06025 was ranked either first or second out of all the alloys evaluated in all laboratory test environments. The order of ranking of other alloys depended on the test environment, whether the corrosion was measured above or underneath the synthetic salt, and temperature.

In an environment simulating a chloride-contaminated biomass-fired boiler, the alloy ranking at $650^{\circ} \mathrm{C}$ from most corrosion resistant to least was (roughly equivalent performance alloys ranked together):

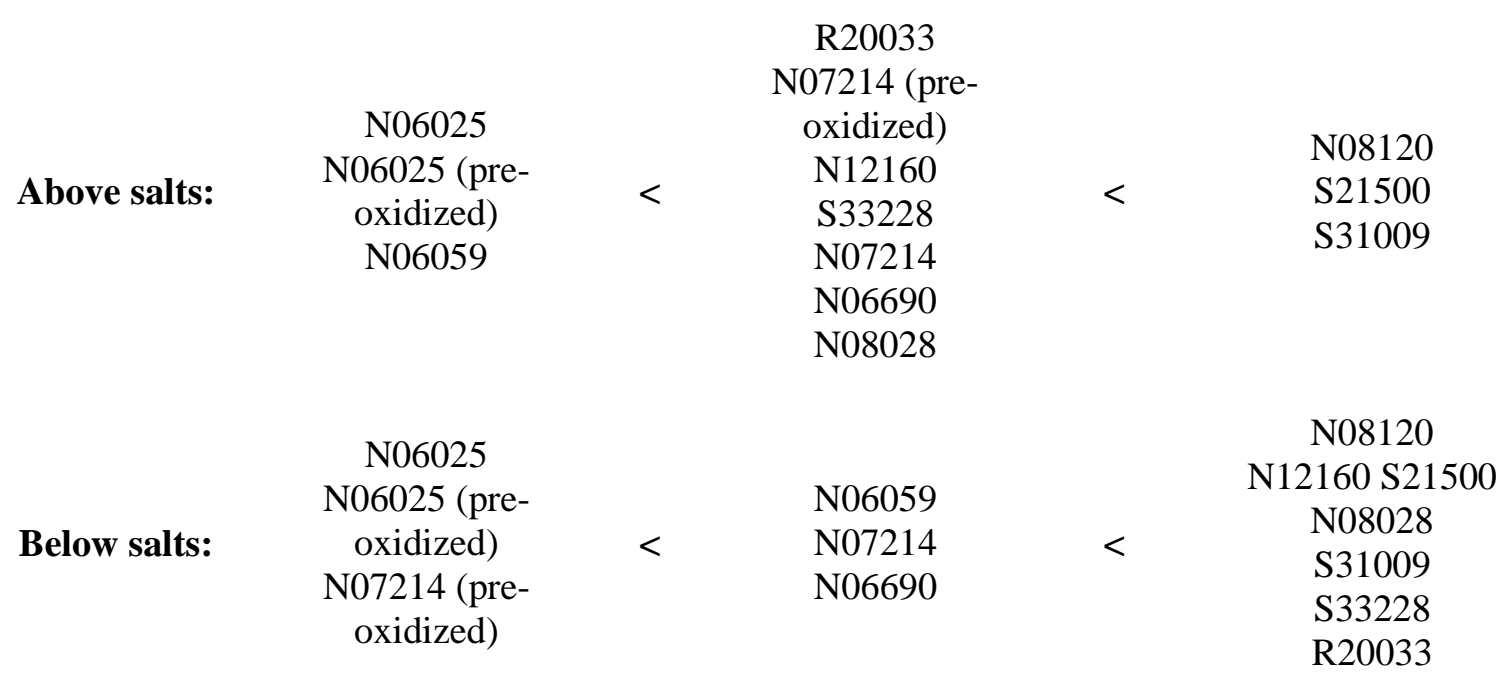

- In an environment simulating a kraft recovery boiler, the alloy ranking at $530^{\circ} \mathrm{C}$ from most corrosion resistant to least was(roughly equivalent performance alloys ranked together): 


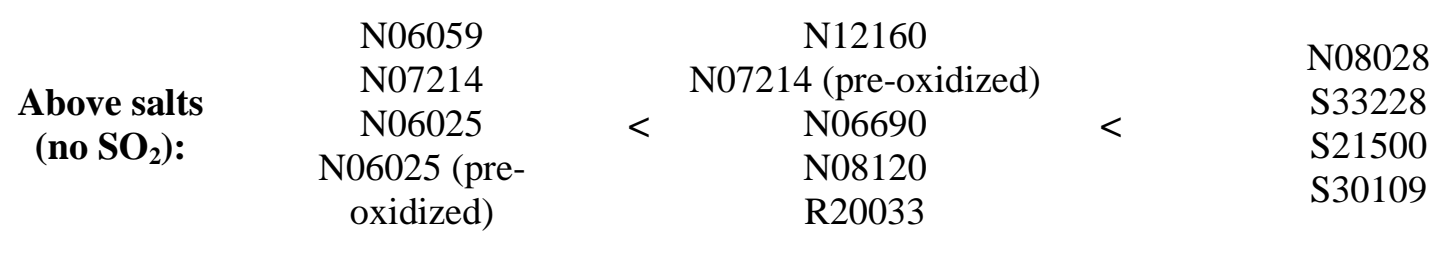

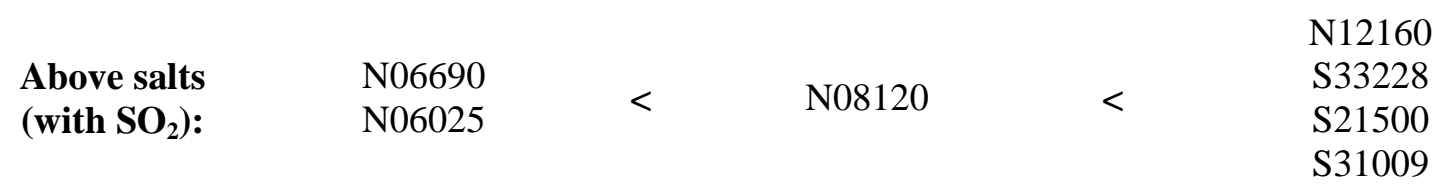

$\begin{array}{ccccc} & & \text { N12160 } & & \text { N07214 (pre-oxidized) } \\ \text { Below } & \text { N06059 } & \text { N06025 } & \text { N07214 } & \text { N08028 } \\ \text { salts } & \text { N06025 (pre- } & \text { S21500 } & \text { S31009 } \\ \text { (no SO } \text { S }_{2}: & \text { oxidized) } & & \text { N06690 } & \text { S33228 } \\ & & \text { R20033 } & & \end{array}$

\begin{tabular}{|c|c|c|c|c|c|}
\hline $\begin{array}{l}\text { Below } \\
\text { salts } \\
\text { (with } \\
\mathrm{SO}_{2} \text { ): }\end{array}$ & N06025 & $<$ & $\begin{array}{l}\text { N06690 } \\
\text { N08120 }\end{array}$ & $<$ & $\begin{array}{l}\text { N12160 } \\
\text { S21500 } \\
\text { S33228 } \\
\text { S31009 }\end{array}$ \\
\hline
\end{tabular}

- In an environment simulating a kraft recovery boiler with $625^{\circ} \mathrm{C}$ superheater tube temperature, all alloys were ranked as providing unacceptable performance. Based on these results, it is unlikely that a recovery boiler could be designed to operate at such a high temperature in the superheater. The alloy ranking at $625^{\circ} \mathrm{C}$ from most corrosion resistant to least was (roughly equivalent performance alloys ranked together):

\begin{tabular}{|c|c|c|c|c|c|}
\hline \multirow{7}{*}{$\begin{array}{l}\text { Above salts } \\
\left(\text { no } \mathrm{SO}_{2}\right):\end{array}$} & \multirow{7}{*}{$\begin{array}{l}\text { N06025 } \\
\text { N06025 (pre- } \\
\text { oxidized) } \\
\text { S21500 }\end{array}$} & \multirow{7}{*}{$<$} & N12160 & \multirow{7}{*}{$<$} & \multirow{7}{*}{$\begin{array}{c}\text { N06059 } \\
\text { N07214 } \\
\text { N07214 (pre-oxidized) }\end{array}$} \\
\hline & & & N06690 & & \\
\hline & & & N08120 & & \\
\hline & & & S33228 & & \\
\hline & & & S31009 & & \\
\hline & & & N08028 & & \\
\hline & & & R20033 & & \\
\hline \multirow{5}{*}{$\begin{array}{l}\text { Above salts } \\
\text { (with } \mathrm{SO}_{2} \text { ): }\end{array}$} & \multirow{5}{*}{ N06025 } & \multirow{5}{*}{$<$} & N12160 & \multirow{5}{*}{$<$} & \multirow{5}{*}{ S21500 } \\
\hline & & & N06690 & & \\
\hline & & & N08120 & & \\
\hline & & & S31009 & & \\
\hline & & & S33228 & & \\
\hline
\end{tabular}




$\begin{array}{ccccc} & \text { N06025 (pre- } & \text { N08120 } & & \\ \text { Below salts } & \text { oxidized) } & & \text { N12160 } & \\ \text { (no SO } \text { 2): } & \text { N06025 } & \text { S31009 } & \text { N06059 } \\ & \text { N06690 } & & \text { S33228 } \\ & \text { S21500 } & \text { N08028 } & & \text { N07214 } \\ & \text { R20033 } & & \text { N07214 (pre-oxidized) }\end{array}$

S31009

$\begin{array}{rrrr}\text { Below salts } & & & \mathrm{N} 08120 \\ \text { (with SO } \mathbf{S O}_{2} \text { ): } & \mathrm{N} 06025 & \mathrm{~N} 06690 & \mathrm{~S} 33228 \\ & & & \mathrm{~N} 12160 \\ & & & \mathrm{~S} 21500\end{array}$

\begin{tabular}{|c|c|c|c|c|c|c|c|c|c|c|c|c|c|}
\hline & \multicolumn{13}{|c|}{ PB2 $650^{\circ} \mathrm{C}$} \\
\hline \multirow{2}{*}{ 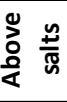 } & $\mathrm{E}$ & EP & $\mathrm{J}$ & $\mathrm{G}$ & $\mathrm{FP}$ & 1 & $\mathrm{H}$ & $\mathrm{F}$ & $\mathrm{K}$ & C & $D$ & $A$ & B \\
\hline & 18 & 18 & 23 & 31 & 31 & 35 & 36 & 41 & 44 & 47 & 59 & 65 & 71 \\
\hline & & & & & & & & & & & & & \\
\hline \multirow{2}{*}{ 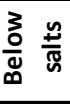 } & $\mathrm{E}$ & EP & FP & $\mathrm{J}$ & $\mathrm{F}$ & $\mathrm{K}$ & D & 1 & A & C & B & $\mathrm{H}$ & G \\
\hline & 10 & 12 & 20 & 38 & 63 & 89 & 151 & 154 & 271 & 283 & 303 & 316 & 385 \\
\hline
\end{tabular}

Fig. 26. The average TAM in microns for each alloy exposed to the $P B 2$ environment at $650{ }^{\circ} \mathrm{C}$. Alloy performance is color coded as acceptable (green), intermediate (yellow) and unacceptable (red).

\begin{tabular}{|c|c|c|c|c|c|c|c|c|c|c|c|c|c|c|c|c|c|c|c|c|c|}
\hline & \multicolumn{13}{|c|}{$\operatorname{RB} 530^{\circ} \mathrm{C}$} & & \multicolumn{7}{|c|}{$\mathrm{RB} 530^{\circ} \mathrm{C}+\mathrm{SO} 2$} \\
\hline \multirow{2}{*}{ 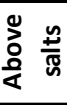 } & $\mathrm{J}$ & $\mathrm{F}$ & $E$ & EP & 1 & $\mathrm{FP}$ & $\mathrm{K}$ & $\mathrm{D}$ & $\mathrm{G}$ & C & $\mathrm{H}$ & $\mathrm{A}$ & B & \multirow{2}{*}{ 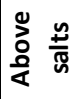 } & $\mathrm{K}$ & $E$ & $\mathrm{D}$ & 1 & $\mathrm{H}$ & $\mathrm{A}$ & $\mathrm{B}$ \\
\hline & 12 & 13 & 15 & 15 & 25 & 42 & 44 & 54 & 62 & 127 & 133 & 140 & 272 & & 47 & 47 & 83 & 154 & 168 & 198 & 260 \\
\hline & & & & & & & & & & & & & & & & & & & & & \\
\hline \multirow{2}{*}{ 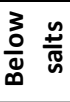 } & $\mathrm{J}$ & $\mathrm{E}$ & EP & 1 & $\mathrm{~F}$ & A & $\mathrm{K}$ & $\mathrm{G}$ & $\mathrm{D}$ & $\mathrm{FP}$ & C & $\mathrm{H}$ & $B$ & \multirow{2}{*}{$\frac{3}{0} \frac{n}{0}$} & $\mathrm{E}$ & $\mathrm{K}$ & $\mathrm{D}$ & 1 & A & $\mathrm{H}$ & $B$ \\
\hline & 14 & 27 & 39 & 59 & 61 & 81 & 87 & 99 & 115 & \begin{tabular}{|l|}
159 \\
\end{tabular} & 169 & 185 & 194 & & 41 & 91 & 118 & 151 & 160 & 199 & 301 \\
\hline
\end{tabular}

Fig. 27. The average TAM in microns for each alloy exposed to the recovery boiler environment at $530{ }^{\circ} \mathrm{C}$. Alloy performance is color coded as acceptable (green), intermediate (yellow) and unacceptable (red).

\begin{tabular}{|c|c|c|c|c|c|c|c|c|c|c|c|c|c|c|c|c|c|c|c|c|c|}
\hline & \multicolumn{13}{|c|}{$\mathrm{RB} 625^{\circ} \mathrm{C}$} & & \multicolumn{7}{|c|}{$\mathrm{RB} 625^{\circ} \mathrm{C}+\mathrm{SO} 2$} \\
\hline \multirow{2}{*}{ 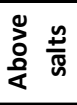 } & EP & $E$ & $A$ & 1 & $\mathrm{~K}$ & $\mathrm{D}$ & $\mathrm{H}$ & B & $\mathrm{C}$ & G & J & $\mathrm{F}$ & FP & \multirow{2}{*}{ 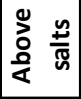 } & $E$ & I & K & D & $B$ & $\mathrm{H}$ & $A$ \\
\hline & 55 & 76 & 137 & 201 & 209 & 210 & 211 & 242 & 282 & 355 & 2000 & 2000 & 2000 & & 12 & 144 & 165 & 182 & 195 & 201 & 295 \\
\hline & & & & & & & & & & & & & & & & & & & & & \\
\hline \multirow{2}{*}{$\frac{3}{\Phi} \frac{n}{\Phi}$} & EP & $\mathrm{E}$ & $\mathrm{K}$ & A & D & 1 & B & $\mathrm{H}$ & C & G & $\mathrm{J}$ & $\mathrm{F}$ & FP & \multirow{2}{*}{ 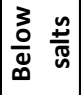 } & $E$ & $\mathrm{~K}$ & B & D & $\mathrm{H}$ & 1 & A \\
\hline & 65 & 92 & 133 & 134 & 211 & 217 & 219 & 230 & 278 & 347 & 2000 & 2000 & 2000 & & 46 & 103 & 179 & 184 & 215 & 241 & 255 \\
\hline
\end{tabular}

Fig. 28. The average TAM in microns for each alloy exposed to the recovery boiler environment at $625^{\circ} \mathrm{C}$. Alloy performance is color coded as acceptable (green), intermediate (yellow) and unacceptable (red). 


\subsection{SOLUBILITY OF METAL OXIDES IN MOLTEN SALT}

The presence of alkali metal salts, particularly chloride salts, is well recognized as a major factor in the degradation of superheater tubes and, consequently, a significant contributor to the limit on superheater steam outlet temperatures. These salts are an especially important consideration as temperatures approach the first melting point of the salts, and the solubility of the normally protective metal oxides in the salts becomes a concern. Consequently, a study of the solubility of metal oxides in a typical salt was initiated at Georgia Institute of Technology as a master's degree project under the supervision of Prof. Preet Singh. A thesis resulted from this project, and the following text has been taken from the paper presented by Joseph Meyer at the 2013 NACE Corrosion conference.

\subsubsection{Background}

The recovery boiler is an important part of the Kraft cycle that converts black liquor into green liquor and steam. The efficiency of the recovery boiler then determines the amount of recoverable white liquor and steam that is available to the mill for continued operations. The major limitation for converting the energy into steam efficiently is that the increased steam temperature may also increase the corrosion rate dramatically. Depending on the fuel used and the operating parameters, the first melting temperature (FMT) of the ash deposits on the superheater tubes is near $520^{\circ} \mathrm{C}$ while the steam temperature is limited to around $500^{\circ} \mathrm{C}$.[57] If the salt deposits melt, then the corrosion rate can increase 4-5 fold while the metal temperature increases as little as $3-6 \mathrm{C}^{\mathrm{O}}$ [4]. Using tube materials that contain more protective alloying elements might reduce the corrosion rate to an acceptable level even with higher steam conditions.

Molten salt corrosion is similar to aqueous corrosion in that the salt acts as an electrolyte that allows for quick diffusion of ions [112]. The salt behaves like water where it can be described as a combination of an acid and base (e.g. $\mathrm{Na}_{2} \mathrm{O}$ and $\mathrm{SO}_{3}$ for $\mathrm{Na}_{2} \mathrm{SO}_{4}$ and $\mathrm{H}^{+}$and $\mathrm{OH}^{-}$for $\mathrm{H}_{2} \mathrm{O}$ ). The activity or basicity of $\mathrm{Na}_{2} \mathrm{O}$ is similar to a pOH scale (where $\mathrm{pOH}$ is the base 10 logarithm of the activity of $\mathrm{OH}^{-}$ions in the solution) and how corrosive the salt is will be determined by its basicity [113]. Most oxides are amphoteric and will have an acidic or basic reaction with the salt according to its basicity.

The amount of corrosion is dependent on the solubility of oxide in the salt. As the solubility limit is reached, the oxide/salt reaction rate will begin to decrease to maintain equilibrium. An oxide with a low degree of solubility will be more protective because it will take less oxide dissolution to reach saturation than one with a larger solubility limit [112]. A plot of oxide solubility against the basicity of the salt will be is linear and has a slope that is easily determined theoretically. For example, if we consider the solubility of $\mathrm{NiO}$ in $\mathrm{Na}_{2} \mathrm{SO}_{4}$, Equations 7 and 8 show the reaction and slope for the acidic reaction and Equations 9 and 10 show the reaction and slope for the basic reaction [114].

Acidic reaction : $2 \mathrm{NiO}+\mathrm{Na}_{2} \mathrm{O}+1 / 2 \mathrm{O}_{2}(\mathrm{~g})=2 \mathrm{NaNiO}_{2}$

Slope: $\log \left(\mathrm{NaNiO}_{2}\right) / \log \left(\mathrm{Na}_{2} \mathrm{O}\right)=-1 / 2$ at fixed $\mathrm{P}_{\mathrm{O} 2}$ for this reaction

Basic reaction: $\mathrm{NiO}+\mathrm{Na}_{2} \mathrm{SO}_{4}=\mathrm{NiSO}_{4}+\mathrm{Na}_{2} \mathrm{O}$

Slope $=\log \left(\mathrm{NiSO}_{4}\right) / \log \left(\mathrm{Na}_{2} \mathrm{O}\right)=1$ (independent of the oxygen partial pressure)

The major interest is in determining the oxide concentration at the solubility minimum (where the acid/base reactions meet) and the value of basicity where minimum solubility for a particular oxide occurs. If the value of basicity at the solubility minimum is known and the slopes are verified experimentally, the solubility of an oxide under a given condition can be calculated and its solubility relative to other oxides can be calculated.

If multiple salts are present, the basicity will be controlled by the conjugate acid partial pressures [113]. Thus the basicity of $\mathrm{Na}_{2} \mathrm{SO}_{4}$ will be controlled by the partial pressure of $\mathrm{SO}_{3(\mathrm{~g})}$ while the basicity of $\mathrm{NaOH}$ will be is controlled by the partial pressure of water vapor. To evaluate the effects of multiple salts, 
the partial pressures of the conjugate acids all need to be controlled independently rather than just the activity of $\mathrm{Na}_{2} \mathrm{O}$. Simply changing the $\mathrm{Na}_{2} \mathrm{O}$ concentration would produce reactions with both conjugate acids.

Despite the usefulness of the solubility measurement, it does not take into account variations in the solubility of oxides through the thickness of a molten salt layer on an oxidized metal. The solubility is not expected to remain constant throughout the salt layer and can either increase or decrease between the metal oxide/salt and salt/flue gas interface. An increase in solubility with distance from the metal oxide (positive solubility gradient) would be preferred because after a given period of time, the salt adjacent to the oxide will become saturated with dissolved oxide [115]. A negative solubility gradient is a problem because it favors the diffusion of dissolved oxide away from the tube towards the salt/flue gas interface. As more oxide diffuses towards the flue gas, the oxide solubility will decrease and the oxide will begin to precipitate. Figure 29 shows a schematic of a negative solubility gradient where the precipitated oxide forms a diffuse film of non-protective particles at the salt/flue gas interface. The diffusion gradient is still maintained because the concentration of dissolved oxide near the tube is greater than away from the tube despite the precipitated oxide. Because the diffusion gradient may never be satisfied and the system may never reach an equilibrium, the corrosion reaction will then proceed until the all the tube metal is dissolved. Even if an oxide is considered protective based on its solubility, a negative solubility gradient will inevitably produce a high corrosion rate.

\subsubsection{Experimental}

Solubility measurements were taken by dissolving 1 gram of oxide in 200 grams of salt mixture. The salt was contained in an alumina double crucible to prevent leaks. A schematic of the experimental setup is given in Figure 30. Ultra-pure nitrogen gas was passed through the apparatus to fix the $\mathrm{Na}_{2} \mathrm{O}$ activity. A salt mixture of $73.9 \mathrm{wt} \% \mathrm{Na}_{2} \mathrm{SO}_{4}, 10.2 \mathrm{wt} \% \mathrm{KCl}, 11.5 \mathrm{wt} \% \mathrm{Na}_{2} \mathrm{CO}_{3}$, and $4.4 \mathrm{wt} \% \mathrm{~K}_{2} \mathrm{SO}_{4}$ was used. The salt composition was the same as the recovery boiler field study where superheater deposits were collected on a probe and analyzed at FPInnovations, Vancouver [111]. At the test temperature of $750^{\circ} \mathrm{C}$, the salt mixture was completely liquid.

There are advantages and disadvantages of using a temperature above the solid-liquid two phase region for this salt mixture in this experiment. The advantage was that the salt composition was fixed. Also, if the salt is completely liquid; it can help to alleviate any local changes in composition due to improper mixing. Other advantages include reduced sampling errors. If the tests were conducted at a lower temperature in the liquid-solid two phase region, the composition of the molten salt would depend on the temperature of the salt mixture. Temperature fluctuations could then change the composition during a test.

The oxide was added to the salt after the test temperature was reached to allow the salt to reach equilibrium with the atmosphere and to prevent the possibility of the basicity or solubility changing significantly with temperature. If the salt was not completely molten, the oxide would float on top of the salt and contaminate the samples removed for solubility measurements. Oxide added to the molten salt mixture would sink to the bottom of the crucible and undissolved oxide would remain there for the rest of the experiment. Another problem is that sampling when the salt is not completely molten; it is possible to catch solid salt in the sample. This would dilute the measurement because the solid salt would not contain any oxide. Lastly, accidentally adding too much oxide or using a temperature close to the FMT can freeze the salt and prevent sampling.

The disadvantage of using a temperature above the liquidus line is that is the results may not replicate what happens on the tube surface at temperatures near the FMT. The composition of the salt that melts first can be very different than the average composition of the mix. The solubility will change as the temperature increases and the composition moves. The basicity is a function of temperature like with $\mathrm{pH}$ 


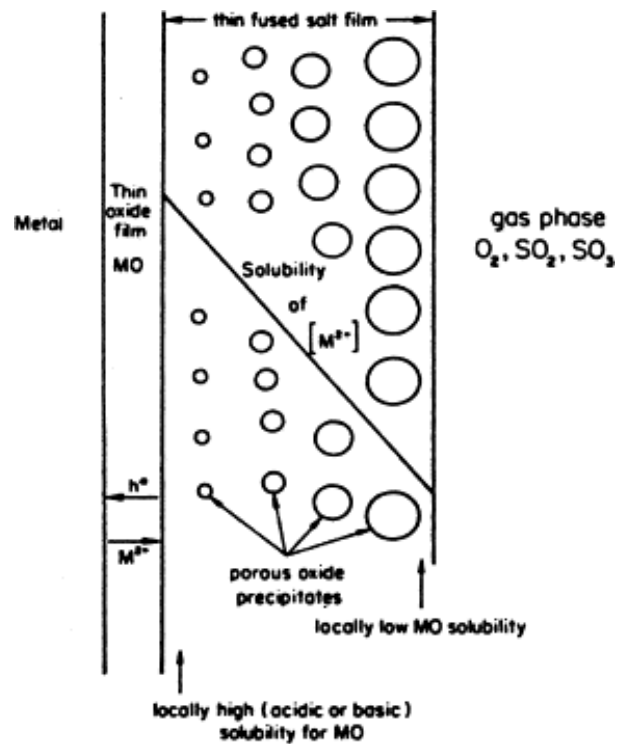

Fig. 29. Schematic of a negative solubility gradient throughout the molten salt that continually precipitates out to form an unproductive scale[112].

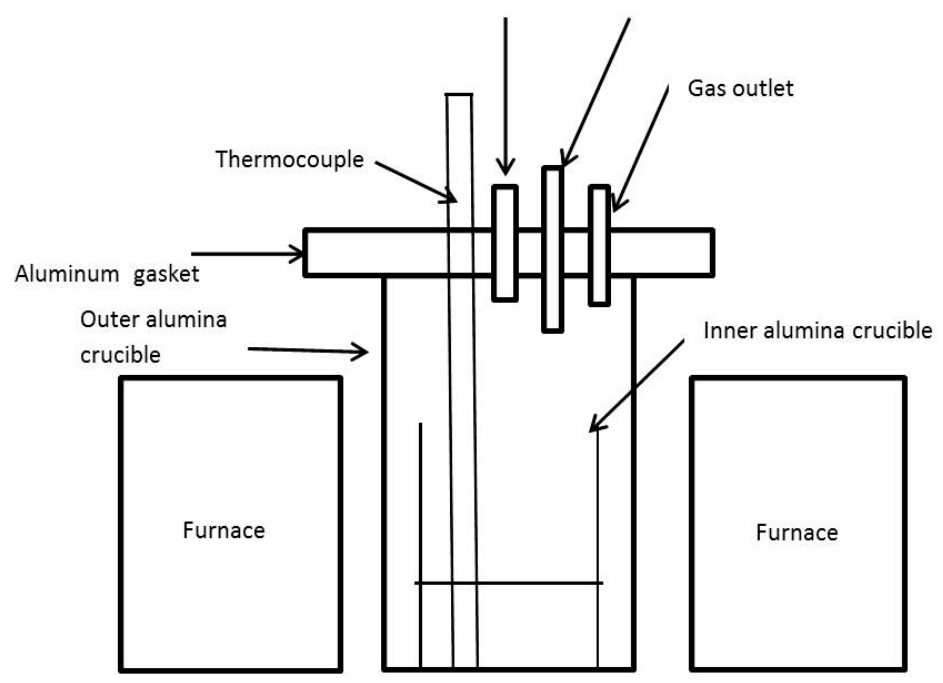

Fig. 30. Schematic of experimental apparatus.

in water. Even if the composition was somehow held constant, the solubility due to the basicity would vary even from the liquidus to the experimental temperature.

The salt was held at temperature for two days to allow for the salt to equilibrate with the atmosphere and the crucible. The crucible was made of alumina and significant concentrations of alumina were measured in every melt. After the oxide was added, care was taken to prevent disturbing the melt. An alumina rod was used to sample the melt and was inserted until it was approximately $1-2 \mathrm{~cm}$ from the bottom of the crucible to prevent oxide contamination. The salt removed on the alumina rod was allowed to cool before dissolving it into a known mass of water to prevent any changes in mass after sampling due to absorption of water vapor. The major concern of error is during sampling because it is difficult to guarantee the same sampling location and amount of melt for each measurement. If the solubility of the salt is location- 
dependent, it would be difficult to get a reliable measurement. Samples were taken every hour after the oxide was introduced up to 8 hours. This allowed enough time to find the saturation point and time to saturation for each oxide.

Every sample was analyzed by inductively coupled plasma - optical emission spectroscopy (ICP). The oxides evaluated were $\mathrm{Al}_{2} \mathrm{O}_{3}, \mathrm{Fe}_{2} \mathrm{O}_{3}, \mathrm{Cr}_{2} \mathrm{O}_{3}$, $\mathrm{NiO}$, and $\mathrm{SiO}_{2}$. $\mathrm{Fe}_{2} \mathrm{O}_{3}, \mathrm{Cr}_{2} \mathrm{O}_{3}$, and $\mathrm{NiO}$ are the oxides of the major alloying elements in stainless steels. $\mathrm{Al}_{2} \mathrm{O}_{3}$ and $\mathrm{SiO}_{2}$ were chosen to verify any effect the dissolved oxide from the crucible had on the experiment and they are also considered as protective oxides in some applications. ICP allows for parts per million to parts per billion resolutions and the amount of water added to the salt when it is dissolved helped to keep the concentration of dissolved oxide within operational range. Most of the samples measured were between 1ppm to 30ppm before dilution was taken into account. ICP only measures metal concentrations instead of molecules so if equal weights of $\mathrm{FeO}$ and $\mathrm{Fe}_{2} \mathrm{O}_{3}$ were dissolved in water, the Fe concentration would be higher in the $\mathrm{Fe}_{2} \mathrm{O}_{3}$ sample. This effect is limited to the experiments with $\mathrm{NiO}$ and $\mathrm{SiO}_{2}$. The other oxides were $\mathrm{M}_{2} \mathrm{O}_{3}$ compounds and not subject to this uncertainty.

\subsubsection{Results and Discussion}

From the results obtained from the present study, the oxides can be ordered from least soluble to most soluble in the synthetic superheater deposit as: $\mathrm{NiO}<\mathrm{Fe}_{2} \mathrm{O}_{3}<\mathrm{Cr}_{2} \mathrm{O}_{3}=\mathrm{Al}_{2} \mathrm{O}_{3}<\mathrm{SiO}_{2}$. Figure 31 shows the average solubility from 3 samples collected every hour for each oxide during the 8 hours of each experiment. All of the oxides reached saturation within 1-2 hours and did not vary in concentration by more than 1 order of magnitude except $\mathrm{SiO}_{2}$ which did so in 8 hours. The increased saturation time for $\mathrm{SiO}_{2}$ is likely due to how much more $\mathrm{SiO}_{2}$ had to dissolve compared to the other oxides. Based solely on the saturation curves, $\mathrm{Ni}$-based alloys that form continuous $\mathrm{NiO}$ oxides would be the most corrosionresistant. Considering that $\mathrm{Al}_{2} \mathrm{O}_{3}$ and $\mathrm{Cr}_{2} \mathrm{O}_{3}$ have similar solubility in this salt, alloys relying on $\mathrm{Cr}_{2} \mathrm{O}_{3}$ and on $\mathrm{Al}_{2} \mathrm{O}_{3}$ for corrosion protection should be roughly equivalent in corrosion resistance. Carbon steel seems to be an economical choice because $\mathrm{Fe}_{2} \mathrm{O}_{3}$ has an adequate amount of solubility and is the cheapest alloy. However, oxidation resistance of carbon steel under recovery boiler superheater conditions is not adequate. An important consideration is that saturation tests do not take into account the effects of changes in solubility in the salt. If a negative saturation gradient is present, then the saturation limit is irrelevant and $\mathrm{SiO}_{2}$ could actually be the most protective. Exposure tests under similar conditions can indicate if a negative solubility gradient is present, because a negative solubility gradient would have excessive corrosion despite an oxide's low solubility.

\subsubsection{Effect of presence of other oxides on solubility of alumina}

The dissolved alumina from the crucible was measured during the oxides test to see what effect the additional oxide could have on its solubility. If no effect exists then the solubility should be similar between the tests. An advantage of using ICP is that it can measure all of the elements in parallel and this analysis can be done without additional experiments. Figure 32 shows the changes of aluminum concentration during the tests. Considering the solubility tests in Figure 31, the alumina concentration should be between 100ppm and 1000ppm for all of the tests. Adding another oxide with the $\mathrm{Al}_{2} \mathrm{O}_{3}$ depressed the solubility of the $\mathrm{Al}_{2} \mathrm{O}_{3}$ to between 1 and $100 \mathrm{ppm}$. This is unusual because if the alumina reacted with another metal oxide it would either increase the solubility and/or decrease the time to saturation. This synergistic reaction occurs when one oxide undergoes an acidic reaction while the other a basic reaction. The reactions would use up or produce $\mathrm{Na}_{2} \mathrm{O}$ and thereby encourage the reaction. $\mathrm{A}$ possible reason for the depressed alumina solubility is that the dissolved alumina is reacting with something in the experiment like the added metal oxide or any dissolved species and precipitating out. 


\section{Average Solubility of Metal Oxides in Recovery Boiler Salt}

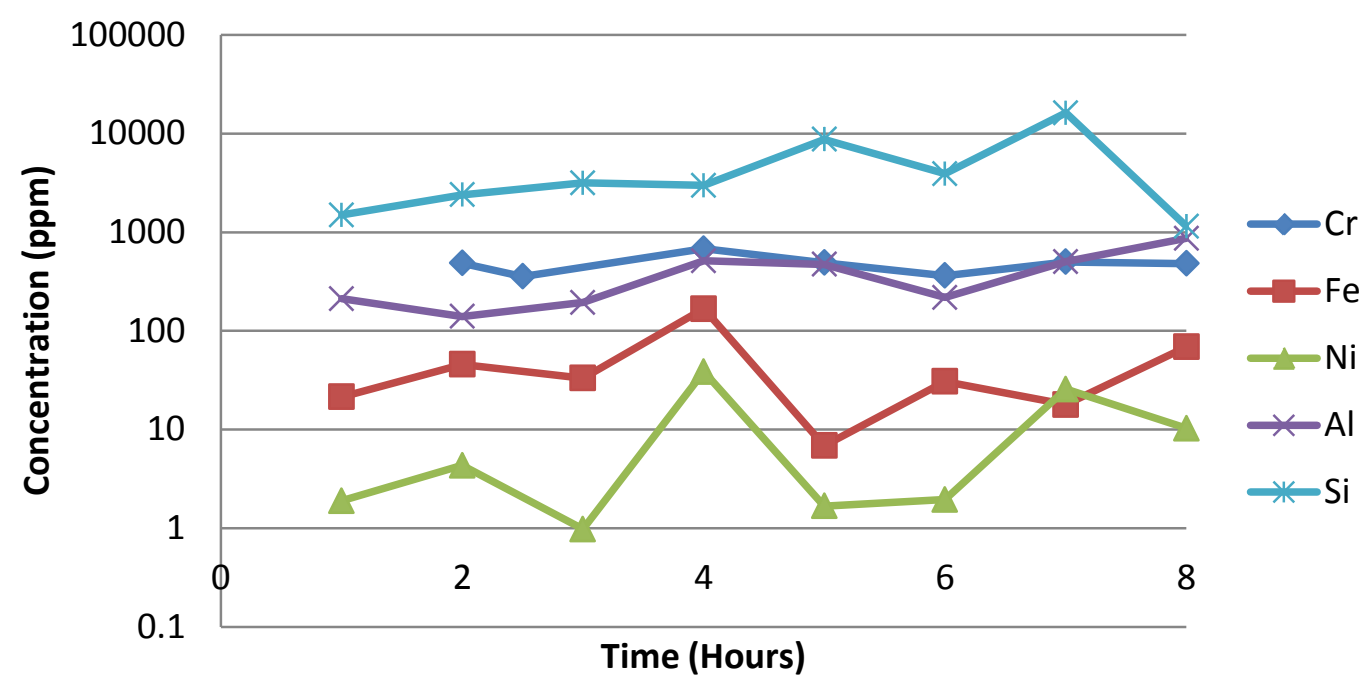

Fig. 31. Average solubility of metal oxides in a recovery boiler salt exposed for 8 hours at $750^{\circ} \mathrm{C}$

The crucible is fairly smooth and may not replenish the dissolved alumina as fast as it is precipitated. The best way to test this hypothesis would be to check the compounds formed in the salt to see if the alumina reacted with any of the other metal oxides. This would verify if any unexpected reactions are taking place.

It is important to consider the effects of multiple oxides on the surface of an alloy because commercial alloys can form combinations of multiple oxides. Also, oxides that form during boiler operation have a composition that varies with exposure time. A common effect, when the recovery boiler salt is not molten, is chromium depletion in the surface of the alloy where the protective chromium has been used up to form $\mathrm{Cr}_{2} \mathrm{O}_{3}$. If the $\mathrm{Cr}_{2} \mathrm{O}_{3}$ film fails, the chromium composition in the alloy surface may be insufficient to re-form a $\mathrm{Cr}_{2} \mathrm{O}_{3}$ film, so that a less protective $\mathrm{Fe}_{2} \mathrm{O}_{3}$ film is formed. If this effect is localized, then adjacent areas of the alloy might be covered with $\mathrm{Cr}_{2} \mathrm{O}_{3}$ and $\mathrm{Fe}_{2} \mathrm{O}_{3}$. Alternately, during maintenance, the oxide may fracture or scale off revealing new metal. In both cases, adjacent dissimilar oxides would be exposed, increasing or decreasing the corrosion rate.

A well-known issue with multiple oxides is a synergistic reaction that increases the corrosion rate in a given molten salt environment. Equations 7 and 9 indicate that one reaction produces $\mathrm{Na}_{2} \mathrm{O}$ while the other consumes it driving the reaction [116]. This effect only occurs when the basicity are between the solubility minimum for both oxides but cannot be overlooked. The data in Figure 31 suggest that it may be possible to reduce an oxide's solubility. From a design perspective, if the effect of multiple oxides is taken into account, it might be possible to avoid unexpected corrosion or boost an alloy's corrosion resistance.

\subsubsection{Conclusions from Molten Salt Solubility Studies}

Molten salt corrosion of alloys is controlled by thermodynamic and kinetic factors. Based on the acid/base reaction equilibrium $\mathrm{Na}_{2} \mathrm{O}$ concentration and oxide solubility are important factors in determining the thermodynamic effects of corrosion. Solubility is useful under a positive solubility gradient where molten salt corrosion is controlled by thermodynamics. A negative solubility gradient on the other hand is kinetics controlled and is not limited by solubility. The solubility of $\mathrm{NiO}, \mathrm{Fe}_{2} \mathrm{O}_{3}, \mathrm{Cr}_{2} \mathrm{O}_{3}, \mathrm{Al}_{2} \mathrm{O}_{3}$, and $\mathrm{SiO}_{2}$ in a mixture of $\mathrm{Na}_{2} \mathrm{SO}_{4}, \mathrm{KCl}, \mathrm{K}_{2} \mathrm{SO}_{4}$, and $\mathrm{Na}_{2} \mathrm{CO}_{3}$ indicates that $\mathrm{NiO}$ is the least soluble. $\mathrm{Cr}_{2} \mathrm{O}_{3}$ and $\mathrm{Al}_{2} \mathrm{O}_{3}$ 
had similar solubility while $\mathrm{SiO}_{2}$ had the greatest solubility of the group. $\mathrm{Fe}_{2} \mathrm{O}_{3}$ was shown to have the second-lowest solubility of the group but carbon steels may not have adequate oxidation resistance for superheater environments. However, this information should be used along with kinetic data to determine the most protective oxide and alloy for these conditions. If a negative solubility gradient exists, the most soluble oxide can become the most protective.

\section{Average Solubility of Alumina Mixed with other} Oxides in Recovery Boiler Salt

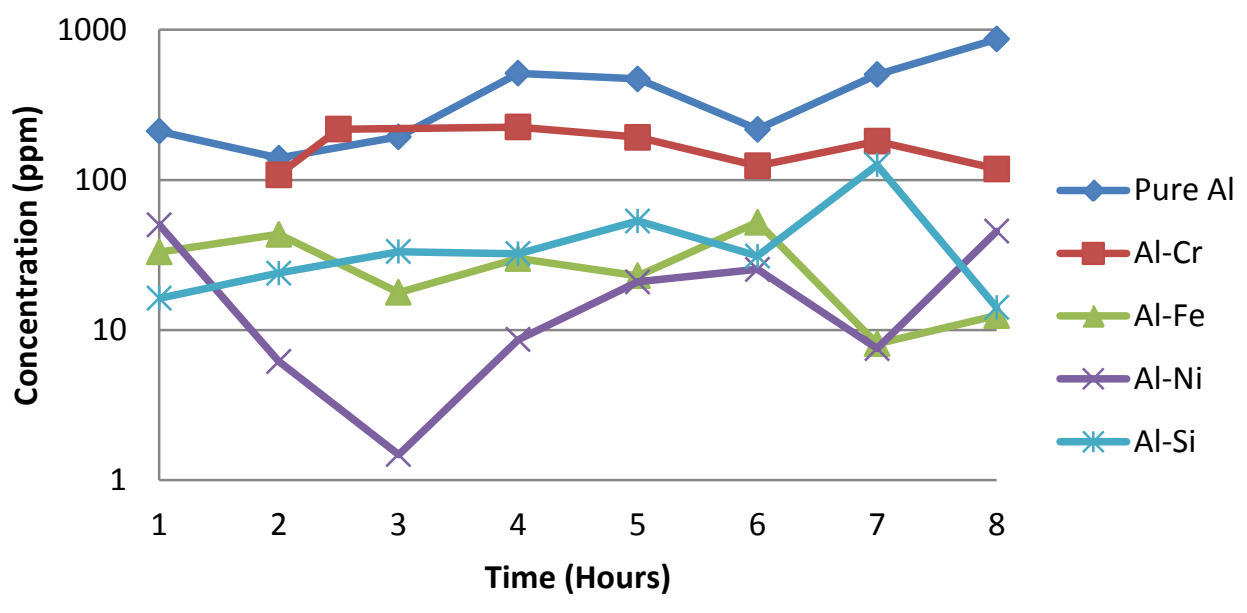

Fig. 32. Average solubility of alumina in the presence of an additional metal oxide during 8 hours of exposure. 


\subsection{FIELD CORROSION STUDIES}

As a complement to the laboratory corrosion studies, field studies with specially designed corrosion probes were used to measure the corrosion rates of alternate superheater tube alloys in four particularly aggressive biomass-fired boiler environments at temperatures as much as 100 Celsius degrees above the normal maximum superheater tube temperature.

Before exposing the corrosion probes, in order to get an indication of the composition of the superheater deposits, air-cooled sampling probes were exposed in three of the four environments. These sampling probes were exposed for a relatively short time - generally 7-10 days - and care was taken in recovering the deposits from the top and bottom surfaces of the probes. Results obtained from analysis of these deposits helped determine the test compositions for the laboratory studies.

In order to assess the performance of the selected alloys under the most severe environments that might be encountered during combustion of biomass, four boilers were selected as examples of what would be expected to be particularly hostile biomass boiler environments. These environments include a recovery boiler in Covington, Virginia, that processes black liquor derived primarily from hardwood thus yielding deposits particularly high in potassium content. A hogged fuel boiler in Crofton, British Columbia, that primarily burns bark obtained from seawater-floated logs was expected to have deposits that are high in chlorine content. Another hogged fuel boiler in Port Mellon, British Columbia, burns fuel consisting primarily of wood from beetle-killed pine trees, but also uses bark from seawater-floated logs and construction and demolition (C \& D) waste which together could result in superheater deposits containing some heavy metal as well as some chlorine. The fourth environment was a power boiler in Gadsden, Alabama, that normally burns coal but supplemented the coal with wood for the period of these studies. This resulted in an environment containing sulfur from the coal as well as the alkali metal salts from the wood. This paper summarizes the results from the four corrosion probes that were exposed in the boiler superheater areas of particularly hostile but significantly different boiler environments.

\subsubsection{Experimental Procedure}

\subsubsection{Deposit sampling}

Deposit sampling probes were exposed in the recovery boiler and the two hogged fuel boilers. The sampling probes in the two hogged fuel boilers were prepared, exposed and analyzed by the FPInnovations collaborators. The sampling probe exposed in the Covington boiler was air cooled and had ten thermocouples spaced every $15 \mathrm{~cm}$ (six inches) along the length of the probe. These thermocouples alternated between the "top" and "bottom" of the probe so temperatures measured on the bottom of the probe reflected the effects of radiant heating while temperatures measured on the top are more representative of the gas temperature. At the end of the approximately one week exposure period, the deposit sampling probe was removed from the boiler, allowed to cool and then wrapped with plastic wrap to keep the deposits in place on the surface of the probe. Once the probe was safely returned to Oak Ridge, samples of the deposits were removed from both the top and bottom of the probe for analysis.

\subsubsection{Corrosion probe design}

Each air-cooled corrosion probe was designed to contain 30 samples each $5.08 \mathrm{~cm}$ ( 2 inches) long fabricated from $1 \frac{1 / 2}{2}$ inch schedule 40 pipe or the equivalent. The samples were fabricated so that they were interlocking and each had a slot machined in the surface to accommodate a 1/16 inch diameter sheathed thermocouple. Temperatures were measured by twenty-four thermocouples so that four of every five samples had a thermocouple attached. These thermocouples were fed through the inner diameter (ID) of the corrosion probe. The corrosion sample design, which is shown in Figure 33, provides for 

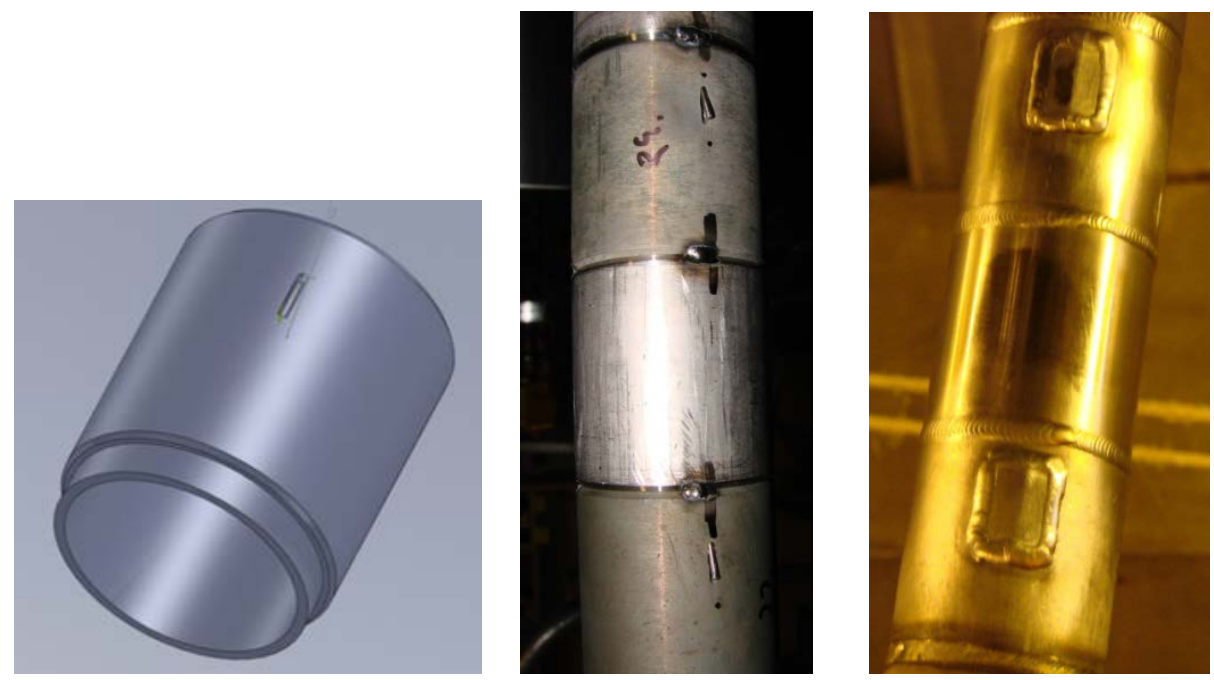

Fig. 33. Left) Schematic of the corrosion samples, center) Photo of samples tack welded with thermocouples protruding from the surface of the samples, and right) Photo of samples welded together and with shim stock welded in place to hold thermocouples on the surface of the samples.

about $1 \mathrm{~cm}$ of the thermocouple be in contact with the outer surface of the sample. This design was intended to minimize the cooling effect on the thermocouples of the air flowing through the probe thus making the measured temperature representative of the temperature of the outer surface of the samples. To assure that each thermocouple maintained full contact with the sample surface, a piece of $0.78 \mathrm{~mm}$ (0.031 inch) stainless steel shim stock was welded to the sample so that the shim stock held the thermocouple tightly against the sample. Pictures of the thermocouple arrangement without and with the shim stock are also included in Figure 33. Besides showing the shim stock that was welded in place over each thermocouple, this figure also shows the tack welds that were used to position and align the samples before application of the circumferential welds that rigidly connect adjacent samples. To provide additional support for the probe which extended at least 2.1 meters ( 7 feet) from the boiler wall, a $1 / 2$ inch diameter stainless rod ran the length of the probe inside the corrosion samples (along with the thermocouples). A stiff spring was placed between the rod and the outside base of the corrosion probe in order to allow for thermal expansion that was expected to differ between the array of welded samples and the stainless steel support rod that was cooled by the air flowing through the probe.

For the laboratory corrosion study, eleven alloys were exposed to synthetic environments similar to those encountered in the biomass-fired boilers. The three co-investigators and the project participants selected eight of these alloys plus 347H stainless steel for exposure in the corrosion probe. These alloys and their compositions are listed in Table 5. Nominal compositions are given for three of the alloys while the other compositions are from actual heat analyses. The selected alloys included two alumina-forming alloys as well as seven more traditional chromia-forming alloys. Alloy S31009 was chosen because it is currently used in the hottest areas of the Covington recovery boiler's superheater. Two other alloys (S21500 and S34709) were chosen because of good experience from similar superheater studies conducted in Europe. The two alumina-forming alloys were preoxidized at $1000^{\circ} \mathrm{C}$ to promote formation of the alumina layer while the chromia-forming alloys were not given any pretreatment. Prior to assembly into the corrosion probe, the wall thickness of each sample was measured in several locations around the circumference.

The thirty samples on each corrosion probe were arranged in a repeating pattern so that samples of all but two of the materials (N06690 and N12160) were exposed to a range of temperatures. Four samples of 
each of the other seven alloys were positioned so that one sample of each material was near the hotter end of the probe, one sample was near the cooler end and the other two samples of each material experienced intermediate temperatures. In addition to the effect resulting from a sample’s position on the corrosion

Table 5. Composition of alloys selected for exposure in the corrosion probes

\begin{tabular}{|l|l|l|l|l|l|l|l|l|l|l|l|l|}
\hline $\begin{array}{l}\text { Product } \\
\text { name }\end{array}$ & $\begin{array}{l}\text { UNS } \\
\text { number }\end{array}$ & Fe & Ni & Cr & Mo & Co & Mn & Al & Si & Ti & C & Others \\
\hline 310H SS & S31009 & Bal & 19.10 & 24.30 & 0.25 & & 1.17 & & 0.55 & & 0.045 & \\
\hline Haynes 214 & N07214 & 3.56 & Bal & 16.08 & & 0.03 & 0.21 & 4.22 & 0.12 & & 0.04 & $\begin{array}{l}\text { Y=0.004, } \\
\text { Zr }=0.011\end{array}$ \\
\hline $\begin{array}{l}\text { Sanicro } \\
28^{*}\end{array}$ & N08028 & 35 & 31 & 27 & 3.5 & & 1.8 & & 0.2 & & 0.01 & \\
\hline 602CA & N06025 & 9.60 & 62.20 & 25.30 & & & 0.02 & 2.30 & 0.03 & 0.10 & 0.170 & $\begin{array}{l}\text { Y=0.07, } \\
\text { Zr }=0.09\end{array}$ \\
\hline HR160 & N12160 & 0.63 & Bal & 28.00 & 0.27 & 30.20 & 0.48 & & 2.75 & 0.48 & 0.056 & \\
\hline $\begin{array}{l}\text { Inconel } \\
690^{*}\end{array}$ & N06690 & 9 & 62 & 29 & & & & & & & 0.02 & \\
\hline HR120 & N08120 & 36.26 & 36.68 & 24.74 & 0.07 & 0.11 & 0.68 & 0.16 & 0.73 & & 0.057 & $\mathrm{~N}=0.21$ \\
\hline $\begin{array}{l}\text { Esshete } \\
1250 *\end{array}$ & S21500 & 72 & 10 & 15 & 1 & & 6.3 & & 0.5 & & 0.1 & $\begin{array}{l}\mathrm{Nb}=1, \mathrm{~V}=0.25, \\
\mathrm{~B}=0.006\end{array}$ \\
\hline 347H SS & S34709 & Bal & 9.02 & 17.21 & & & 1.31 & & 0.57 & & 0.048 & \\
\hline
\end{tabular}

*Nominal values

probe, the temperature of a sample varied from "top" to "bottom" in that one side was heated by the incident gas, and in some cases radiant heat from the lower boiler, so, in one case, it was observed that one side was as much as 80 Celsius degrees hotter than the other side. The arrangement of samples on the corrosion probe and the identification of thermocouple locations are shown in Table 6, and Figure 34 shows a typical corrosion probe with alloy locations identified. Instrumentation for data collection and process control along with a computer were provided with the corrosion probe. A variable flow valve controlled air flow to the corrosion probe and the setting of the variable flow valve was determined by computer software which adjusted the flow to maintain the temperature of a particular thermocouple in a selected range. Generally, a thermocouple experiencing one of the highest temperatures was selected for this control function, and this was usually a thermocouple on the bottom side near the hot end of the probe. In addition to enabling the remotely-located operator to select the reference thermocouple, the computer's display panel also permitted the operator to select the control range for this thermocouple and the data collection rate.

Although the computer software permitted the operator to select the data collection rate, all four computers were set to record the temperature of each thermocouple once a minute during their entire operating periods. On a daily basis, the temperatures and valve setting data were transferred via a telephone connection from the on-site computer to a computer in Oak Ridge. Plots of each day's temperature data were made and evaluated to be certain there were no operational issues. About once a week, the temperature plots were sent to the boiler operators.

At the completion of the exposure, the probe was removed from the boiler with as little loss of the deposits as was possible. Once the probe had cooled, the portion of the probe with the thirty samples was wrapped tightly with plastic to retain as much of the deposits as possible. When the probe was received at the laboratory, the orientation was carefully noted, then samples of the deposits were collected and each metal sample was cut off the probe. An example of the thirty samples is shown in Figure 35. For the metallographic examination, a complete ring was cut from the approximate center of each sample and its orientation during exposure was noted. So that the exposed cross-section would be representative of the true thickness of the sample, every effort was made to make the cuts perpendicular to the axis of each 
sample. Any error introduced if cuts were not perpendicular would result in the remaining thickness being overestimated; thus any error would be on the conservative side. Using the micrographs from the metallographic examinations, the thickness of remaining unaffected metal was determined for the top and bottom of each sample. Scanning electron microscopy was used to determine the extent of subsurface degradation and to collect compositional information for the reaction products on and near the surface, particularly for the samples exposed at the highest temperatures.

Table 6. Arrangement of samples on the corrosion probe and location of thermocouples

\begin{tabular}{|c|l|c|c|}
\hline Position & UNS number/Alloy & TC \# (on top of sample) & $\begin{array}{c}\text { TC \# (on bottom of } \\
\text { sample) }\end{array}$ \\
\hline 1 & S31009/310H SS & 24 & 23 \\
\hline 2 & N07214/Haynes 214 & & 21 \\
\hline 3 & N08028/Sanicro 28 & 22 & \\
\hline 4 & N06025/602CA & & 19 \\
\hline 5 & N12160/HR160 & & 17 \\
\hline 6 & N06690/Inconel 690 & & \\
\hline 7 & N08120/HR120 & & 15 \\
\hline 8 & S21500/Esshete 1250 & & \\
\hline 9 & S34709/347H SS & & 13 \\
\hline 10 & S31009/310H SS & & \\
\hline 11 & N07214/Haynes 214 & & \\
\hline 12 & N08028/Sanicro 28 & & \\
\hline 13 & N06025/602CA & & \\
\hline 14 & N08120/HR120 & & \\
\hline 15 & S21500/Esshete 1250 & & \\
\hline 16 & S34709/347H SS & & \\
\hline 17 & S31009/310H SS & & \\
\hline 18 & N07214/Haynes 214 & & \\
\hline 19 & N08028/Sanicro 28 & & \\
\hline 20 & N06025/602CA & & \\
\hline 21 & N08120/HR120 & & \\
\hline 22 & S21500/Esshete 1250 & & \\
\hline 23 & S34709/347H SS & & \\
\hline 24 & S31009/310H SS & & \\
\hline 25 & N07214/Haynes 214 & & \\
\hline 26 & N08028/Sanicro 28 & & \\
\hline 27 & N06025/602CA & & \\
\hline 28 & N08120/HR120 & & \\
\hline 29 & S21500/Esshete 1250 & & \\
\hline 30 & S31009/310H SS & & \\
\hline & & & \\
\hline
\end{tabular}

\subsubsection{Results}

Results from examination of samples from the various corrosion probes are summarized in the following section. The order of presentation is the order in which the probes were inserted in the respective boilers.

\subsubsection{Covington recovery boiler deposit probe}

Figure 36 shows the average daily temperature of the ten thermocouples over the approximately eight day exposure period of the deposit sampling probe in the Covington recovery boiler. The measured temperatures ranged from about $300^{\circ} \mathrm{C}$ to about $600^{\circ} \mathrm{C}$ [111]. Analysis of the deposits using X-ray 
diffraction provided results which indicated the potassium-rich compound, $\mathrm{K}_{3} \mathrm{Na}\left(\mathrm{SO}_{4}\right)_{2}$, was among the components of the deposit [111].

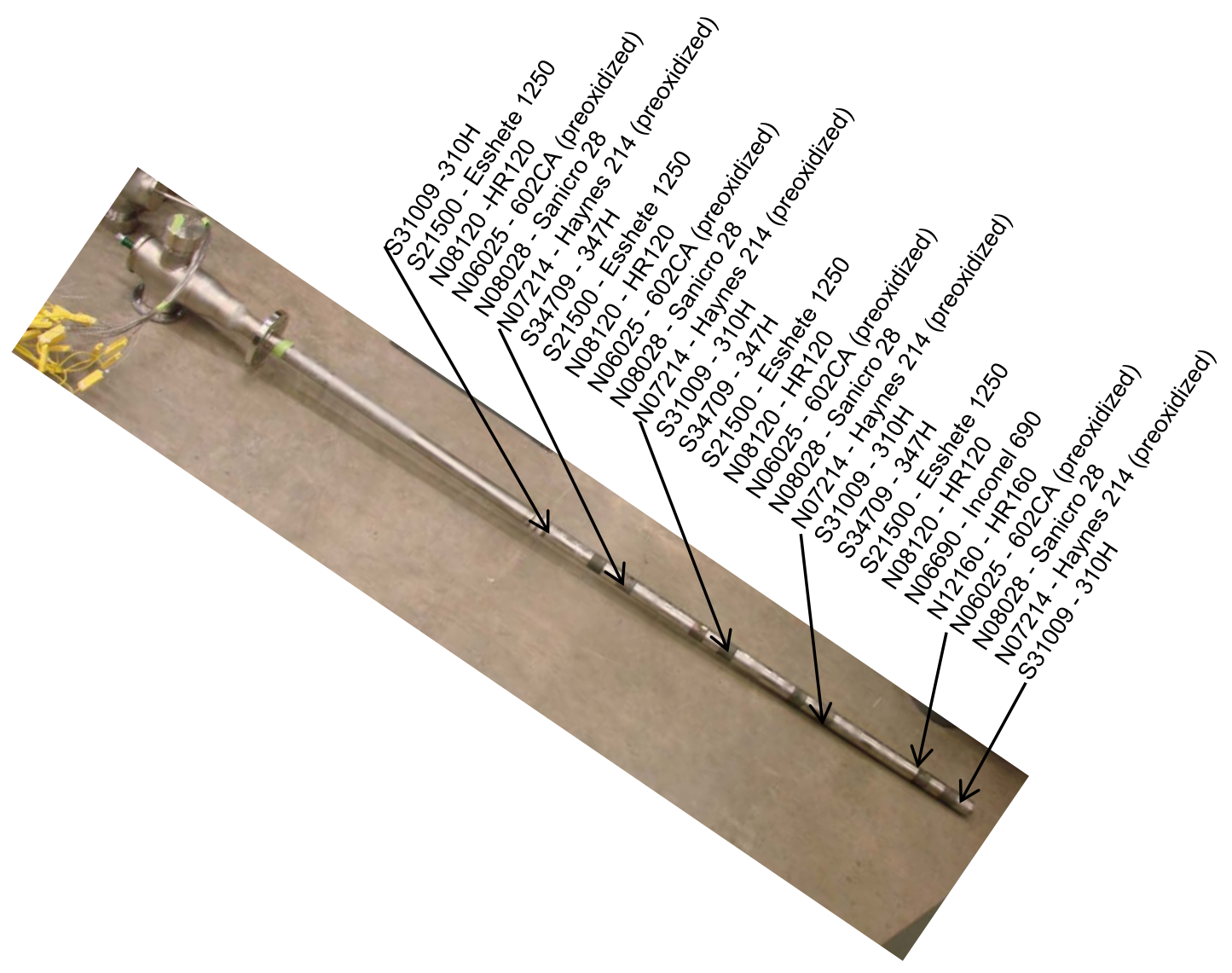

Fig. 34. Typical corrosion probe showing the arrangement of samples as they were assembled on the probe.

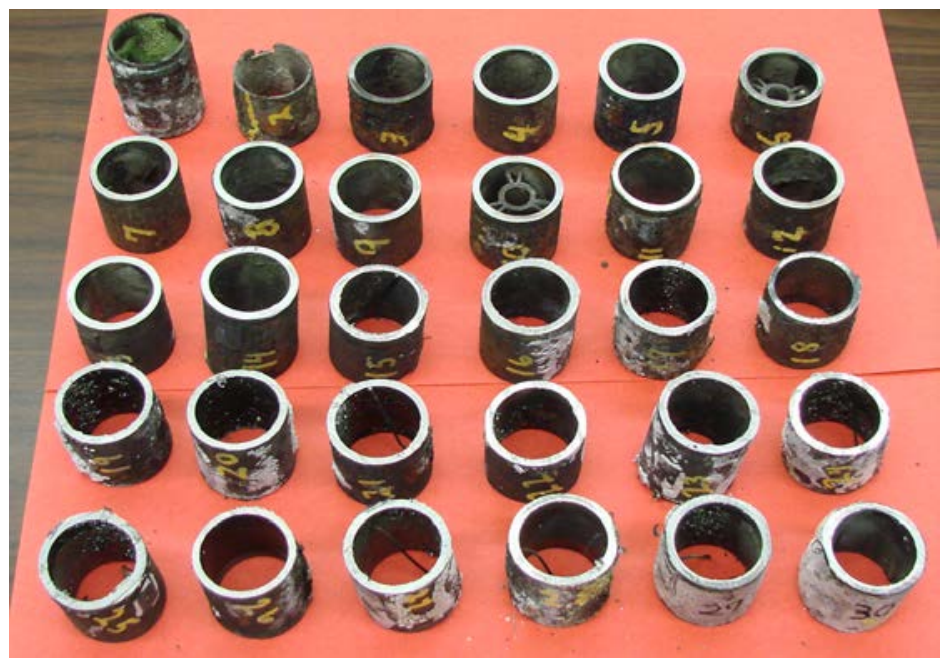

Fig. 35. Photo of the 30 samples removed from one of the corrosion probes. Samples \#6 and \#10 still contain the spacers used to position the support rod in the center of the probe. Several other samples still contain the remnants of the thermocouple that was attached to the outer surface of most samples. 


\subsubsection{Covington recovery boiler corrosion probe}

The deposit sampling probe and the corrosion probe were inserted through a port on the rear wall (the side opposite the bull nose and the smelt spouts) on the 14th floor of the boiler which was about 20 feet (6 meters) below the roof of the boiler. This location was high enough in the boiler that the temperature could be controlled in the desired range with a reasonable air flow, and, because this location was well away from the superheater tubes, there were no sootblowers in the vicinity to affect or disrupt the accumulation of deposits on the probe. As noted previously, deposits from the sampling probe exposed in the Covington boiler confirmed the presence of significant amounts of potassium in the deposits.

The corrosion probe was exposed for 2,000 hours (12 weeks), and the boiler operated under reasonably normal conditions for the great majority of that time. An example of the data collected for one day early in the exposure period is shown in Figure 37. Unfortunately, several thermocouples failed during the latter part of the exposure period, so temperatures shown for some thermocouples do not cover the full 2,000 hours. At the conclusion of the probe exposure, the arithmetic mean temperature for each thermocouple on each day was calculated, and these results are shown in Figure 38. From a plot of these average temperatures an estimate was made for the average top and bottom temperature for each sample. Clearly, during the 2,000 hour exposure the temperature of every sample varied considerably from the average value, so the meaning of exposure temperature is much different between the field exposures and the well-controlled laboratory tests.

In order to determine the performance of each alloy as a function of average exposure temperature and to compare the performance of all the alloys, the depth of affected material (a sum of thickness loss and extent of subsurface attack) was plotted versus the estimated average temperature. Results for all the alloys exposed in the Covington boiler are shown in Figure 39 and results for selected individual alloys are shown in Figure 40. These results show there are several alloys that did not perform very well in this environment at and above $570^{\circ} \mathrm{C}$ (N07214, N08028 and S31009) while N12160 and S21500 were among the better performers. Alloy N06025 showed a very low rate of material affected around $590^{\circ} \mathrm{C}$, but considerably higher rates at 560 and $615^{\circ} \mathrm{C}$.

As a means to compare the results of the corrosion probe exposure with actual boiler experience, it is important to note that S31009 has performed well under the current boiler operating conditions presumably at a tube temperature of about $470^{\circ} \mathrm{C}$. If it is assumed that the degradation rate observed at $470^{\circ} \mathrm{C}$ for S31009 exposed on the probe is acceptable, then it would seem reasonable that any alloy that demonstrates approximately the same rate at $570^{\circ} \mathrm{C}$ would be suitable for use at that temperature. On that basis, N12160 and S21500 would be expected to perform satisfactorily if used in a "high potassium" boiler operating with superheater tube temperatures around $570^{\circ} \mathrm{C}$.

\subsubsection{Crofton hogged fuel boiler}

As previously noted, the hogged fuel boiler in Crofton, British Columbia, was selected because bark from the seawater floated logs would result in a fuel with high chloride content. X-ray diffraction analysis of deposits collected from the surface of several corrosion probe samples showed a high concentration of $\mathrm{NaCl}$. Figure 41 shows the results of examination of several samples.

The corrosion probe in the Crofton boiler was inserted through a manway door in the superheater area less than an estimated 2 meters below a sootblower. Consequently, some cleaning of the tube surface possibly occurred on a fairly regular basis. The probe was exposed for a total of about 2160 hours, but the exposure was interrupted and the probe removed from the boiler because of a planned shutdown and water washing of the boiler about midway through the exposure period. 


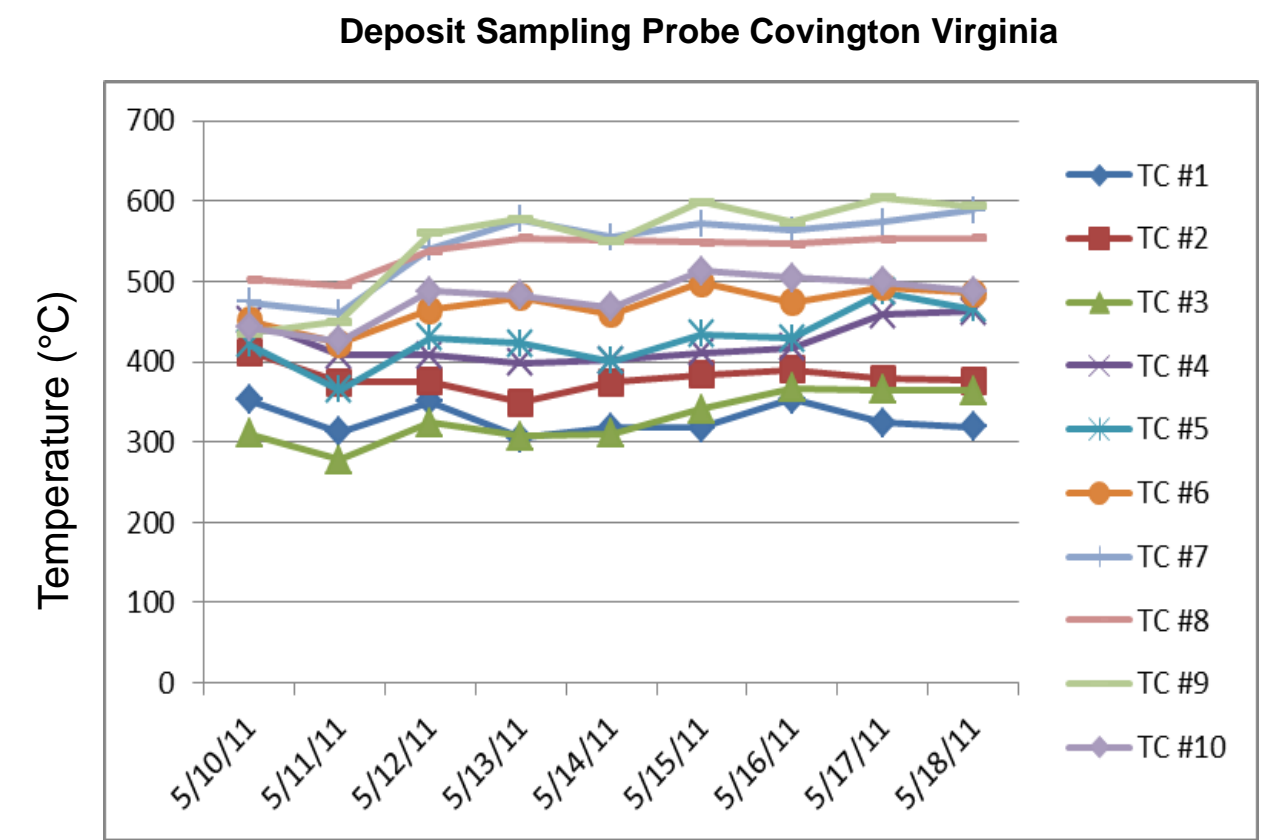

Fig. 36. Average daily temperatures for each of the ten thermocouples on the deposit sampling probe.

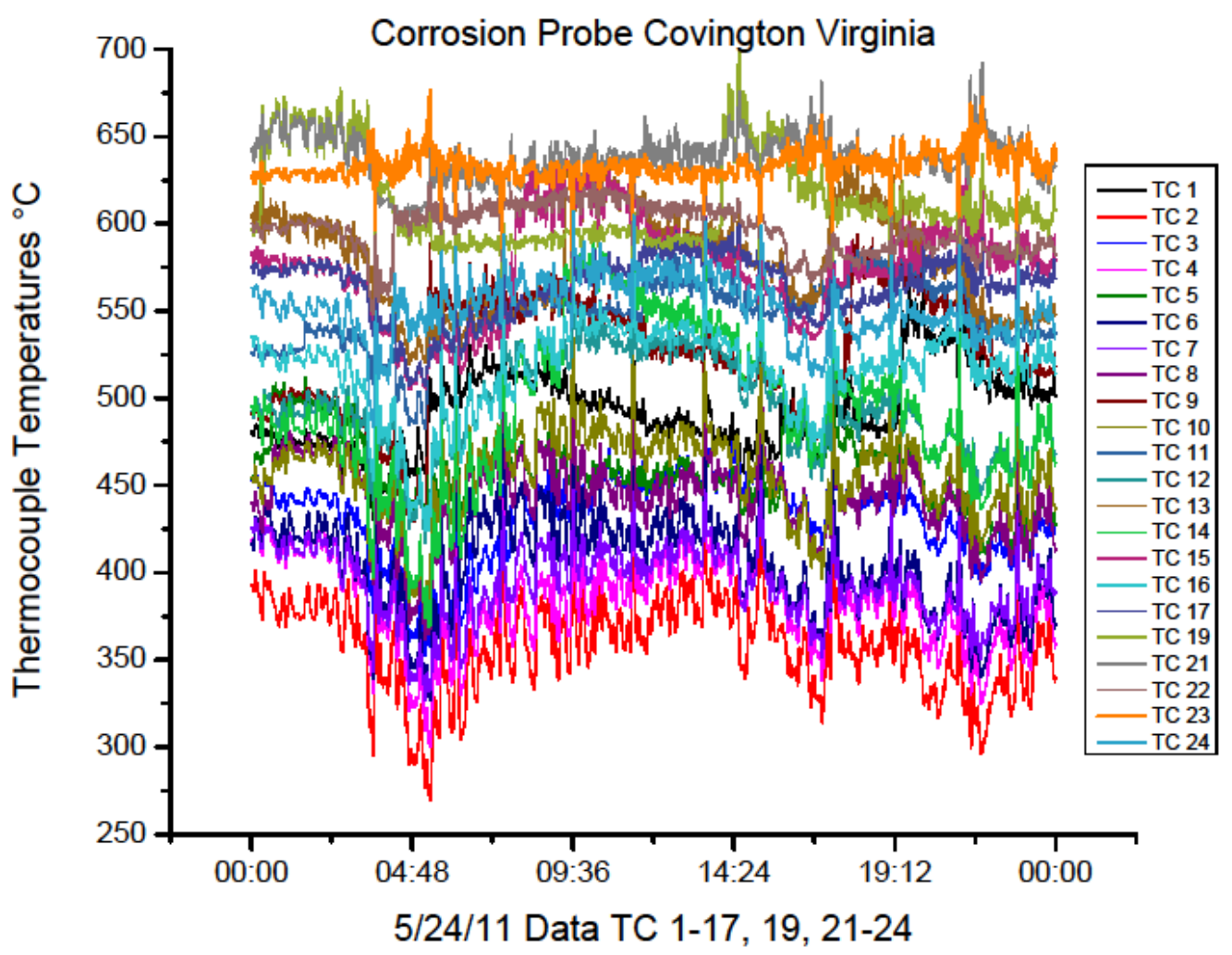

Fig. 37. Typical example of thermocouple temperatures from the corrosion probe exposed in the Covington recovery boiler. Note that the orange line shows the temperature of thermocouple \#23 which was being used to control the flow of cooling air and thus the probe temperature. 


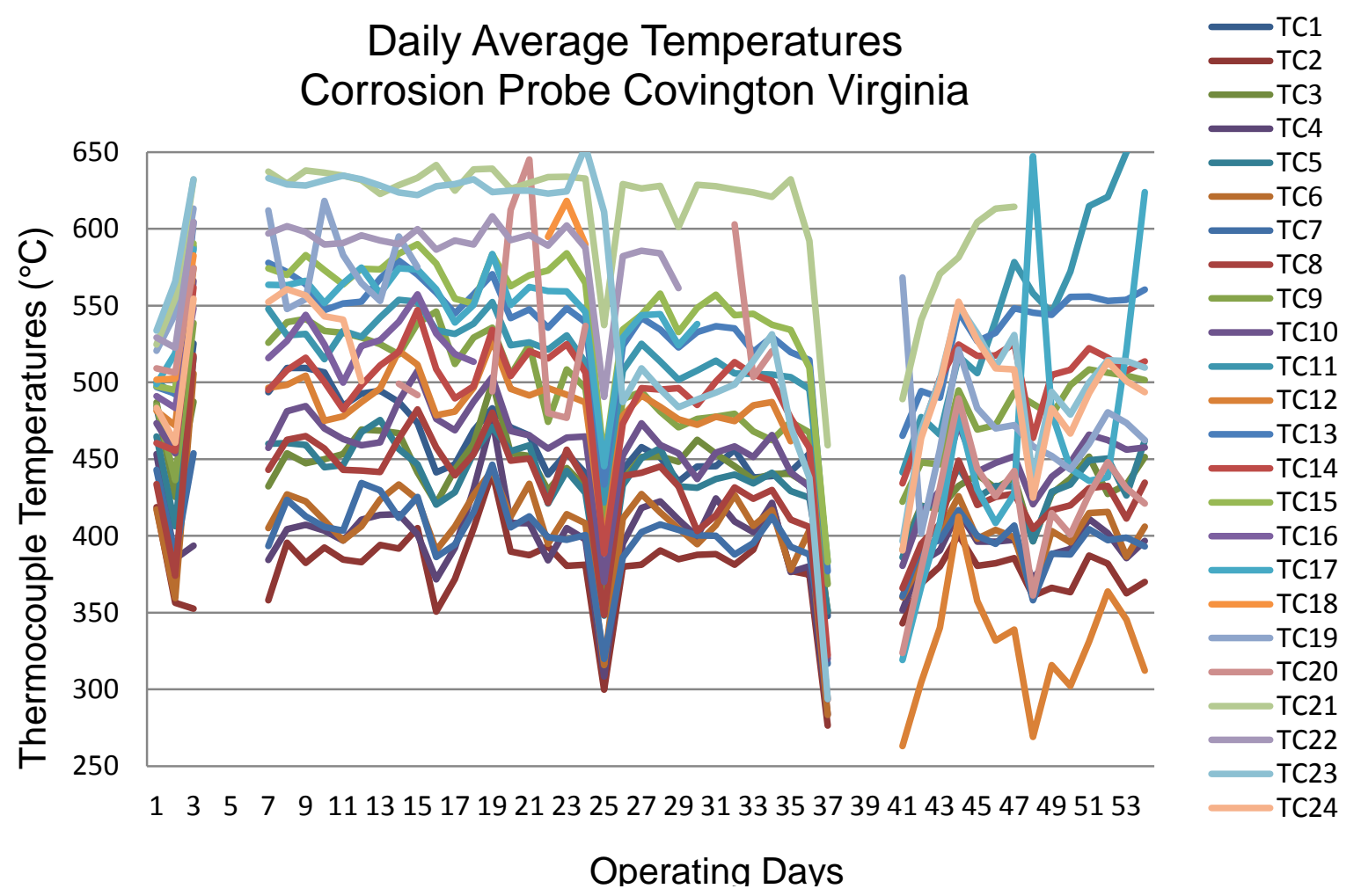

Fig. 38. Average daily temperatures of thermocouples in the Covington recovery boiler

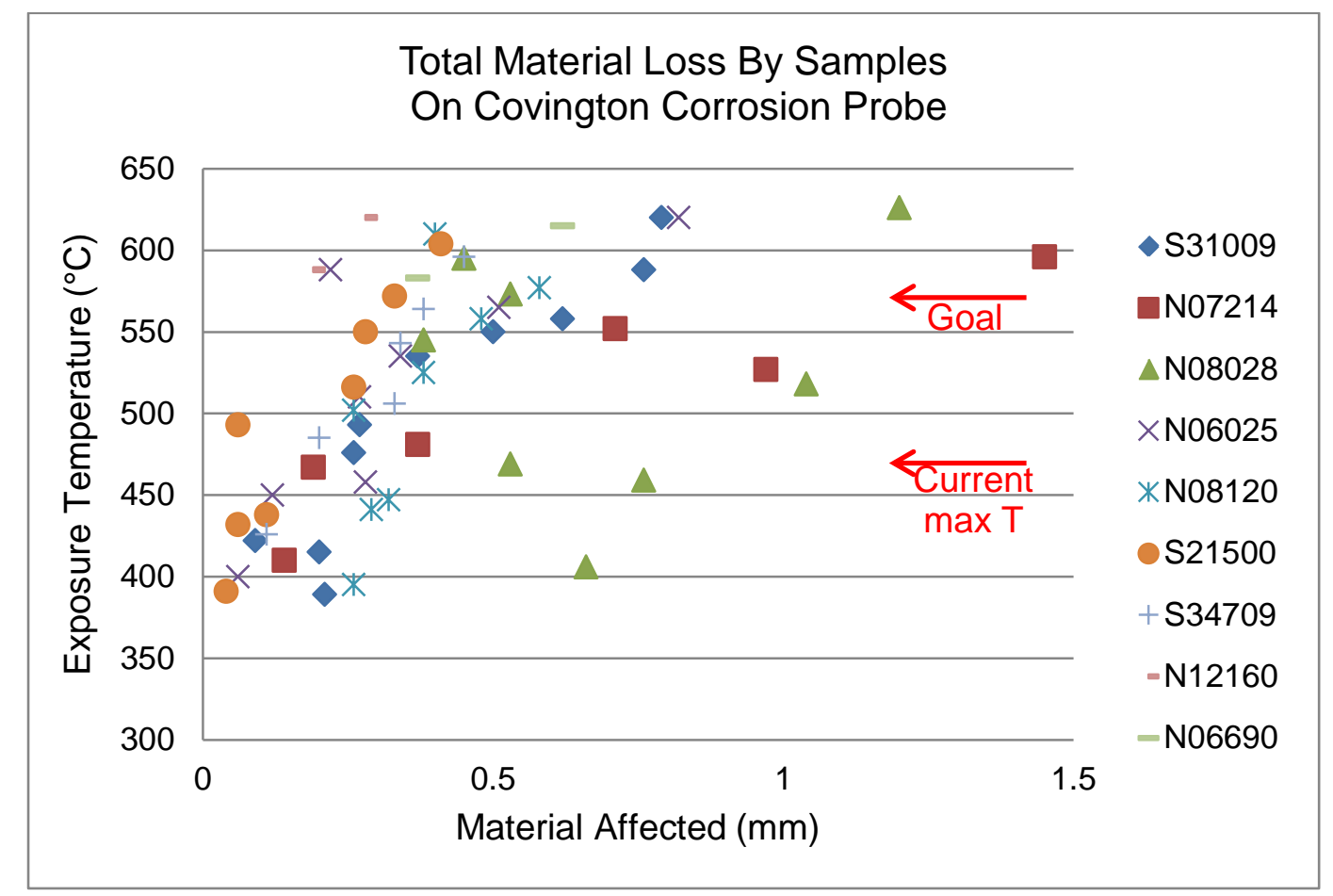

Fig. 39. Total affected material as a function of exposure temperature for samples exposed for 2,000 hours on the corrosion probe in the Covington recovery boiler. 

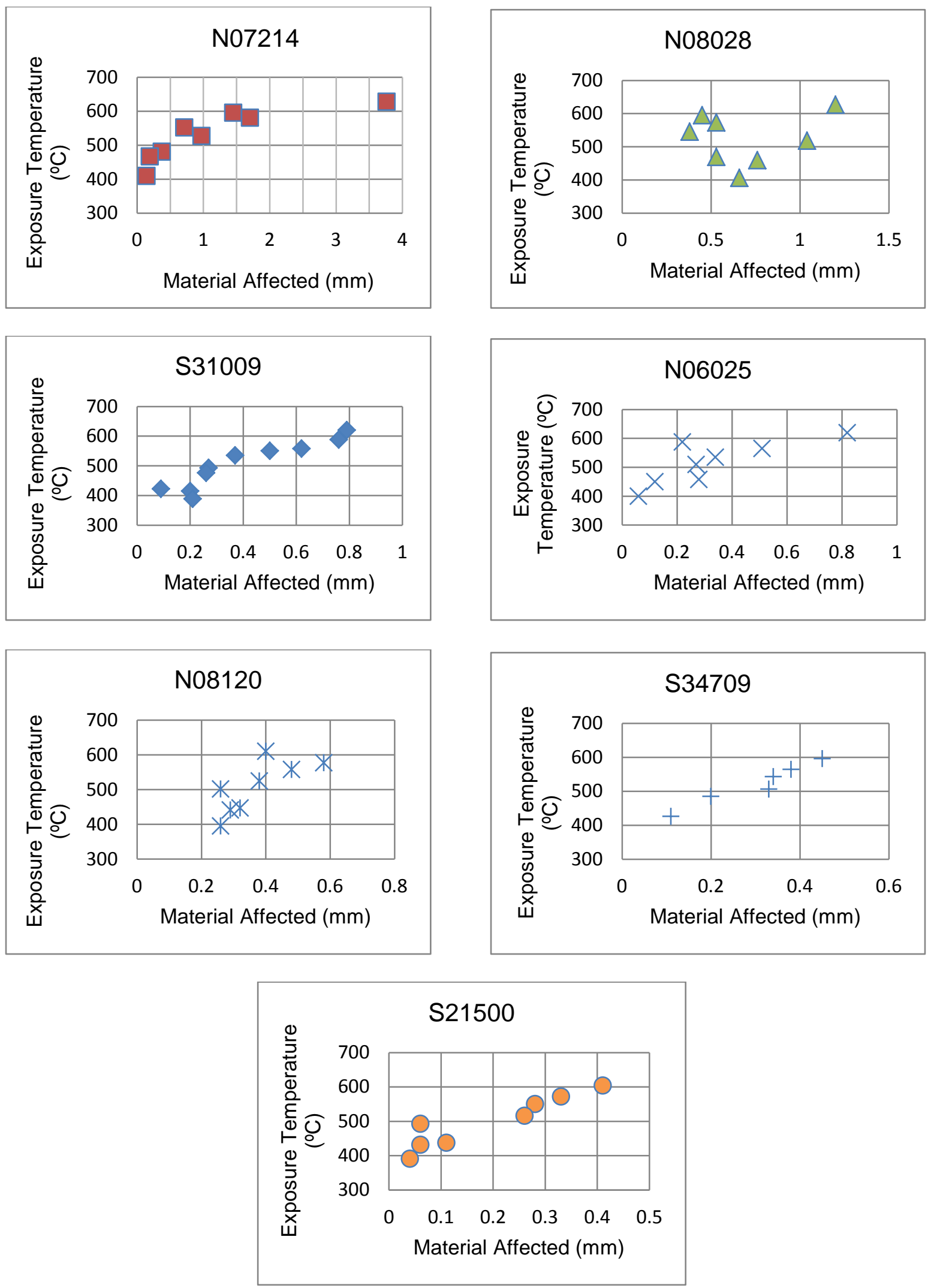

Fig. 40. Total affected material versus exposure temperature for individual alloys exposed for 2,000 hours on the corrosion probe in the Covington recovery boiler. 
1. 30 Bottom

2. 26 Bottom

3. 21 Bottom

4. 16 Bottom

5. 11 Bottom

6. 6 Bottom

7. 1 Bottom

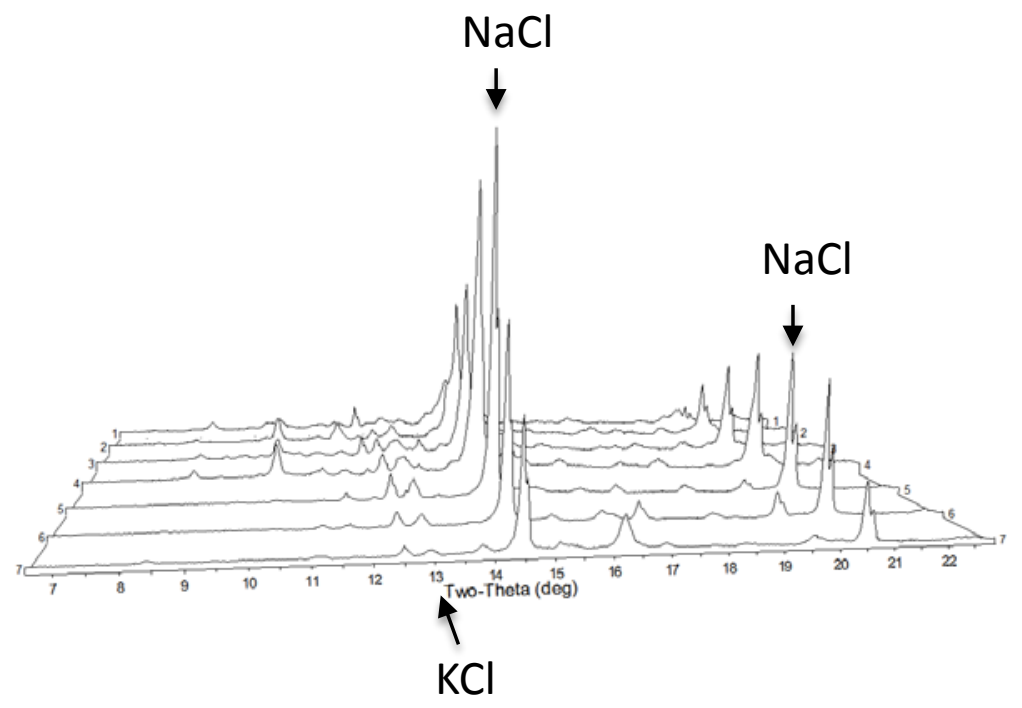

Fig. 41. Results of $X$-ray diffraction measurements of deposits collected from the bottom of 7 samples on the corrosion probe in the Crofton hogged fuel boiler.

Figure 42 shows the average daily temperatures for the 24 thermocouples on the corrosion probe that was exposed in the Crofton boiler. The computer software was set to control the flow of cooling air on the basis of the temperature of thermocouple \#24, but it is clear from Figure 42 that the temperature of thermocouple \#24 frequently dropped below the desired range. In these cases, the air flow was already reduced to a minimal level, so this resulted in the significant fluctuations in temperature shown in Figure 42. An average value for the temperature of each sample was calculated, but it should be recognized that each sample experienced significant variations around the calculated value.

Figure 43 shows the measured thickness of affected material versus exposure temperature for the samples exposed on the Crofton boiler probe. With the current maximum superheater tube temperature at about $415^{\circ} \mathrm{C}$, the goal was to identify the materials with the lowest degradation rate at $515^{\circ} \mathrm{C}$. This figure shows that most of the alloys had a fairly low degradation rate at $500^{\circ} \mathrm{C}$, but many of the alloys showed rapid increases in degradation at slightly higher temperatures. This pattern is more clearly shown in the plots for individual alloys displayed in Figure 44. The two alumina forming alloys, N07214 and N06025, along with N08028 showed this type of behavior while S34709, N08120 and S21500 didn’t appear to show such rapid increases when exposed to average temperature at and above $525^{\circ} \mathrm{C}$.

\subsubsection{Gadsden power boiler}

One of the boiler manufacturers participating in this project suggested that the coal fired boiler at Southern Company's power plant in Gadsden, Alabama, be considered for inclusion in the project because the boiler had previously been used for co-firing coal and biomass - both wood and switchgrass. After a description of the project was presented to power plant and administrative personnel, the power plant operators agreed to participate in the project and to operate the boiler continuously for an extended time with a blend of coal and wood. The original goal was to operate with up to $15 \%$ biomass, but that goal could not be achieved. The actual amount of biomass included in the coal-wood blend ranged from 8 to $15 \%$. 


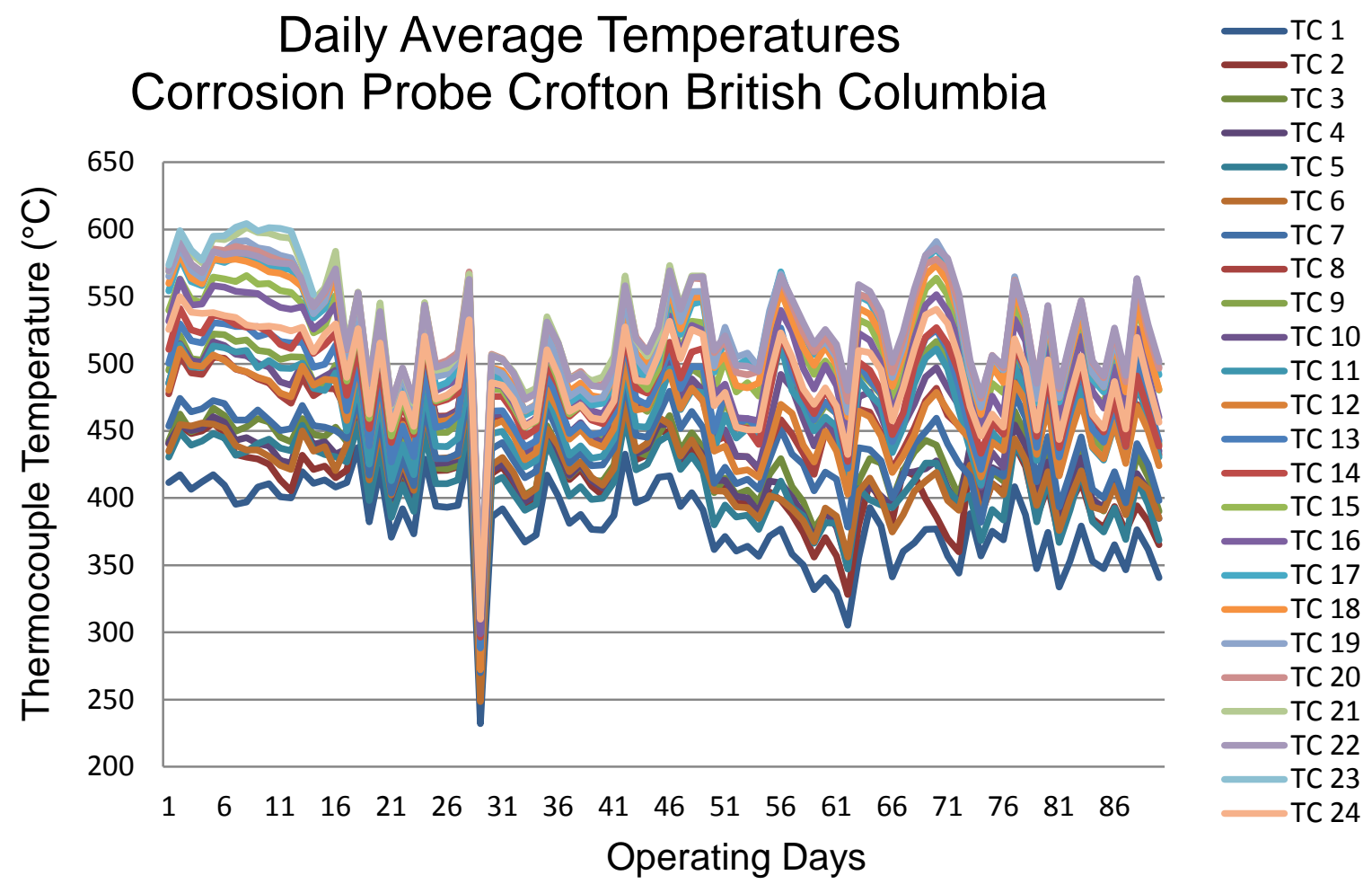

Fig, 42. Daily average temperature of thermocouples exposed about 2,160 hours on the corrosion probe in the Crofton hogged fuel boiler.

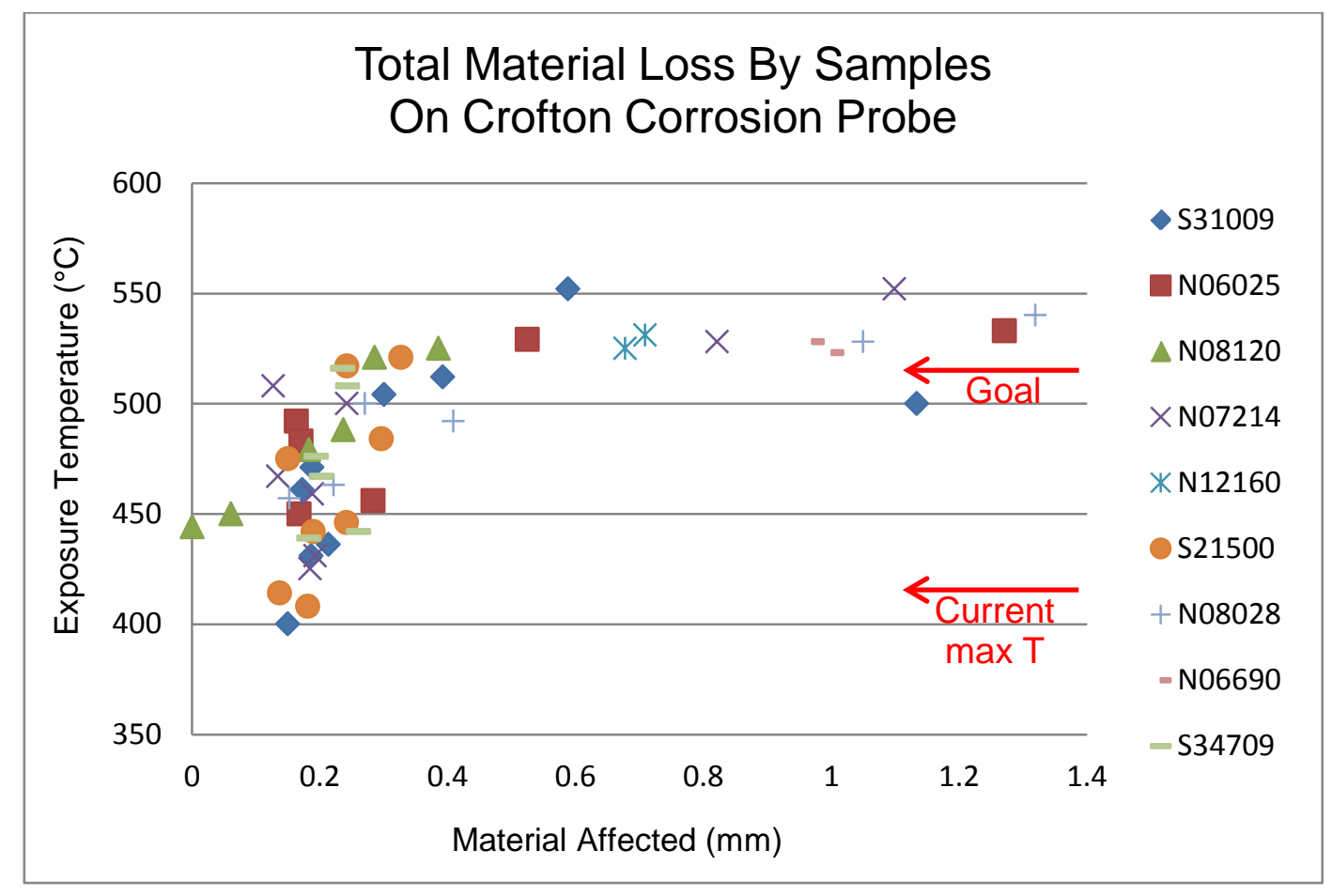

Fig. 43. Total affected material as a function of exposure temperature for samples exposed for 2,160 hours on the corrosion probe in the Crofton hogged fuel boiler. 

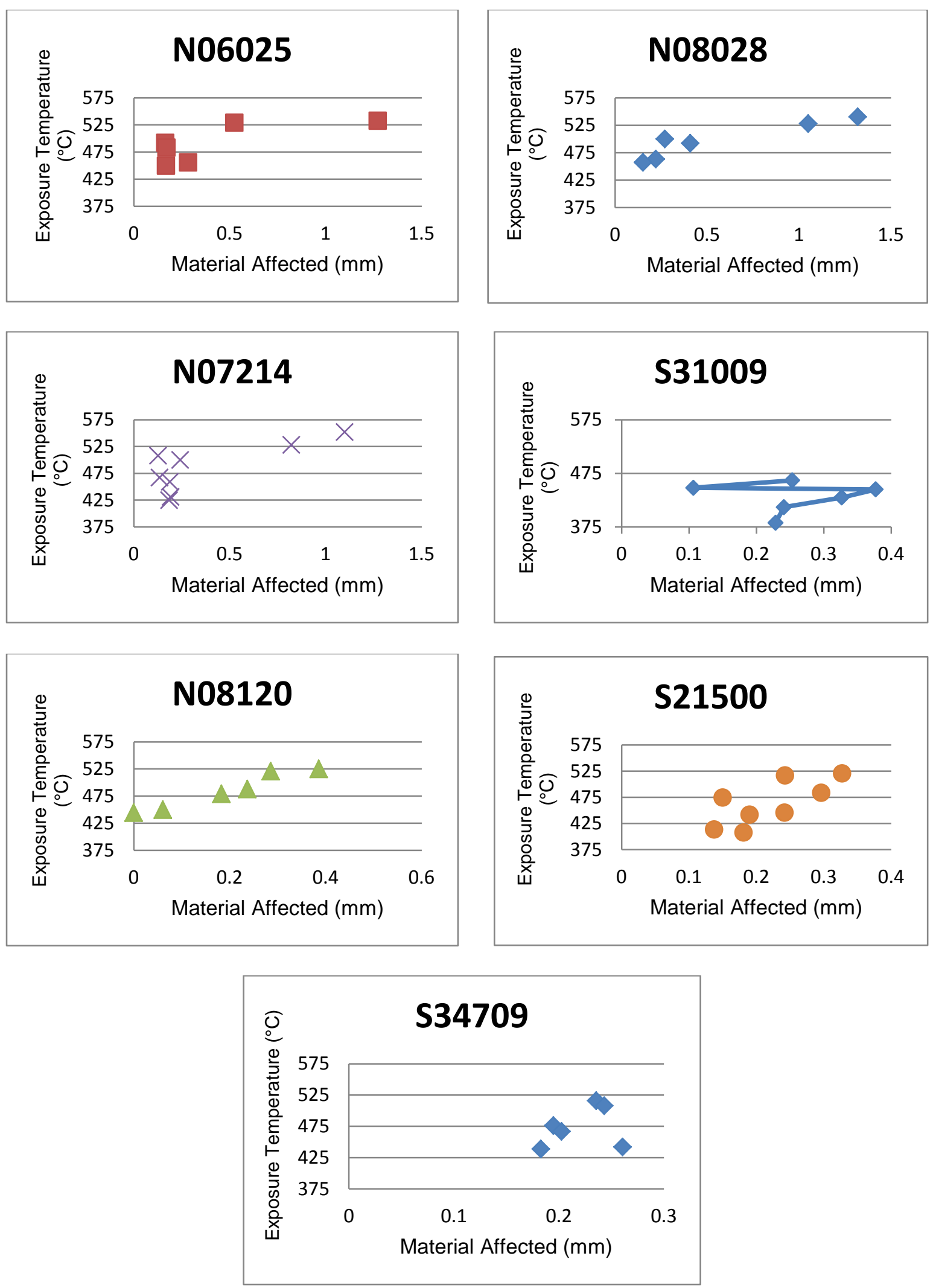

Fig. 44. Total affected material versus exposure temperature for individual alloys exposed for 2,160 hours on the corrosion probe in the Crofton hogged fuel boiler. 
This corrosion probe was inserted in a sootblower lane between superheater tube platens and is shown in Figure 45 just before it was removed. Deposits on the probe were a reddish color and were fairly limited in terms of the amount accumulated. Although there were a couple interruptions in boiler operation during the early stages of the exposure, as shown in Figure 46, the temperatures were far more constant than observed in the other three boilers that were studied. The total exposure period lasted for about 123 days, but the first several days were during a start up period when temperatures were low, and there were two short periods, clearly evident in Figure 46, where the boiler briefly cooled, in one case to near room temperature. The probe was actually exposed to normal operating conditions for about 106 days or 2,540 hours.

The average temperatures for the top and bottom of each sample were calculated from the daily average temperatures. From these calculations, it was evident that the tops of the samples were 60-80 Celsius degrees hotter than the bottom of the samples. This is not the pattern generally seen in superheater tubes, but the boiler operators confirmed that this was the pattern to be expected for this location.

After the probe and the supporting structure were returned to the lab, preparations were made to dispose of the portion of the probe that was just inside the boiler wall but did not include any samples. In making the routine but required check for evidence of radioactivity on the structure, it was found that low levels of lead and bismuth isotopes were present. These isotopes are decay products of uranium, and it is reasonable to assume that the low concentration of uranium in the coal resulted in deposition of these isotopes on the cooler portion of the corrosion probe. As a result, the nine samples on the cooler end of the probe could not be removed and examined. Deposits were removed from the samples on the hotter end of the corrosion probe, and the analyses identified mullite, quartz, cristobalite, hematite and magnetite as the major components.

The 21 samples that could be examined were sectioned in the customary way and the reduction in thickness determined as well as the subsurface attack. Results of those measurements are plotted as a function of exposure temperature in Figure 47. These results show that the degradation of the alloys in the coal-wood-fired environment was significantly less than seen for most of the alloys in the boilers fired exclusively with biomass. As can be seen from the figure, several alloys had losses in the 0.20 to 0.25 $\mathrm{mm}$ range for this exposure period.

\subsubsection{Port Mellon hogged fuel boiler}

The fourth probe was inserted in a hogged fuel boiler in Port Mellon, BC, with the expectation that the boiler would be, like the Crofton boiler, firing bark from seawater floated logs. However, the infestation of pine beetles resulted in a ready availability of beetle-killed pine trees. Consequently, at the time of the corrosion probe exposure, the mill was using wood from beetle-killed pine trees, bark from seawater floated logs along with occasional barge loads of C \& D waste from Vancouver. The latter of these three sources of biomass may have ultimately contributed some unexpected, but very interesting, results.

This boiler was converted to a fluidized bed system and this delayed insertion of the corrosion probe, so this was the last of the exposures to be started. Once the probe was inserted there was a problem with the variable flow valve that made it impossible to reduce the flow of cooling air to less than the fully open position. This made it impossible to control the probe temperature, and consequently, these temperatures stayed well below the desired level. Eventually, the variable flow valve was replaced, and this permitted better control of the temperature. However, the site available for insertion of the probe was less than 30 $\mathrm{cm}$ (12 inches) above the bullnose, and this proximity to a water cooled surface apparently prevented the probe temperatures from reaching the desired levels. The average daily temperatures are shown in Figure 48, and it is obvious that the temperatures stayed low until about the $70^{\text {th }}$ day when the variable flow valve was replaced. Even after the valve replacement, for many days the highest temperatures were not 


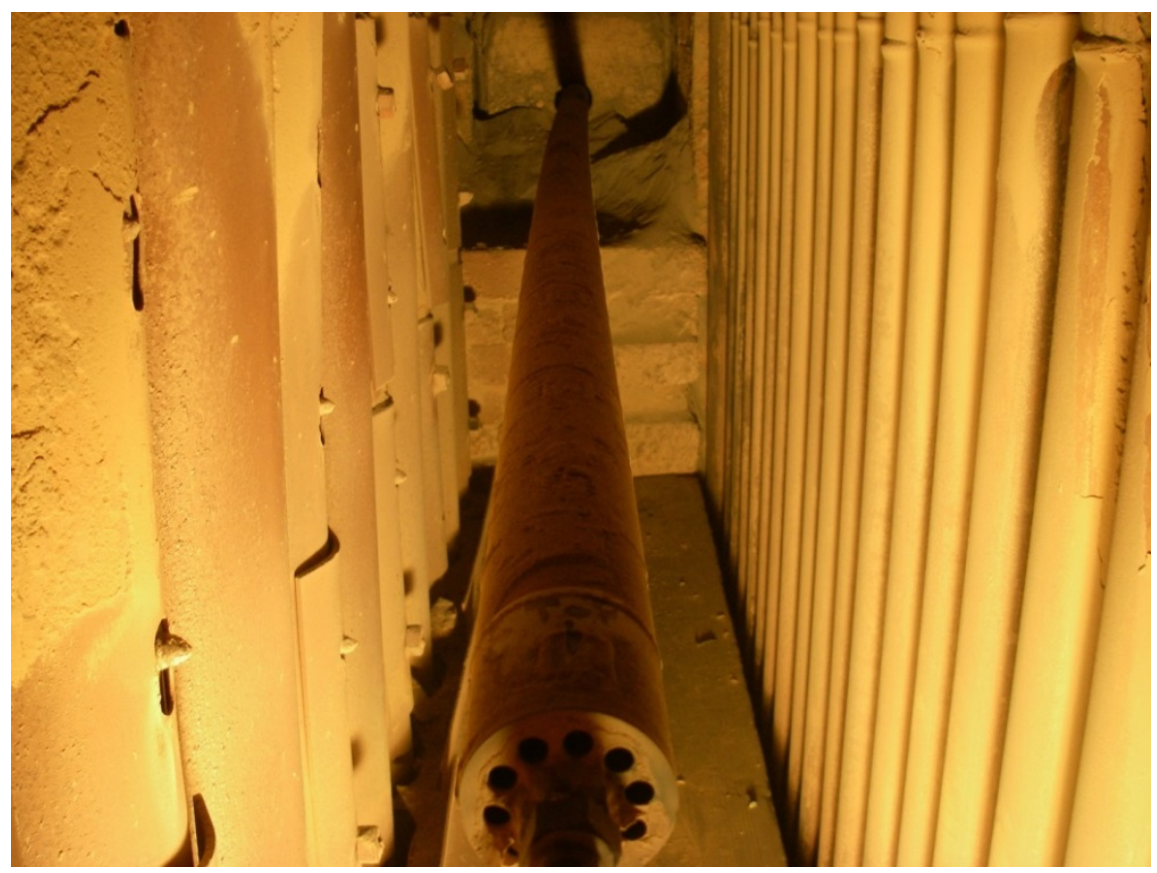

Fig. 45. Photo of the corrosion probe in the Gadsden power boiler just prior to its removal (photo courtesy of Billy Zemo, Southern Company).

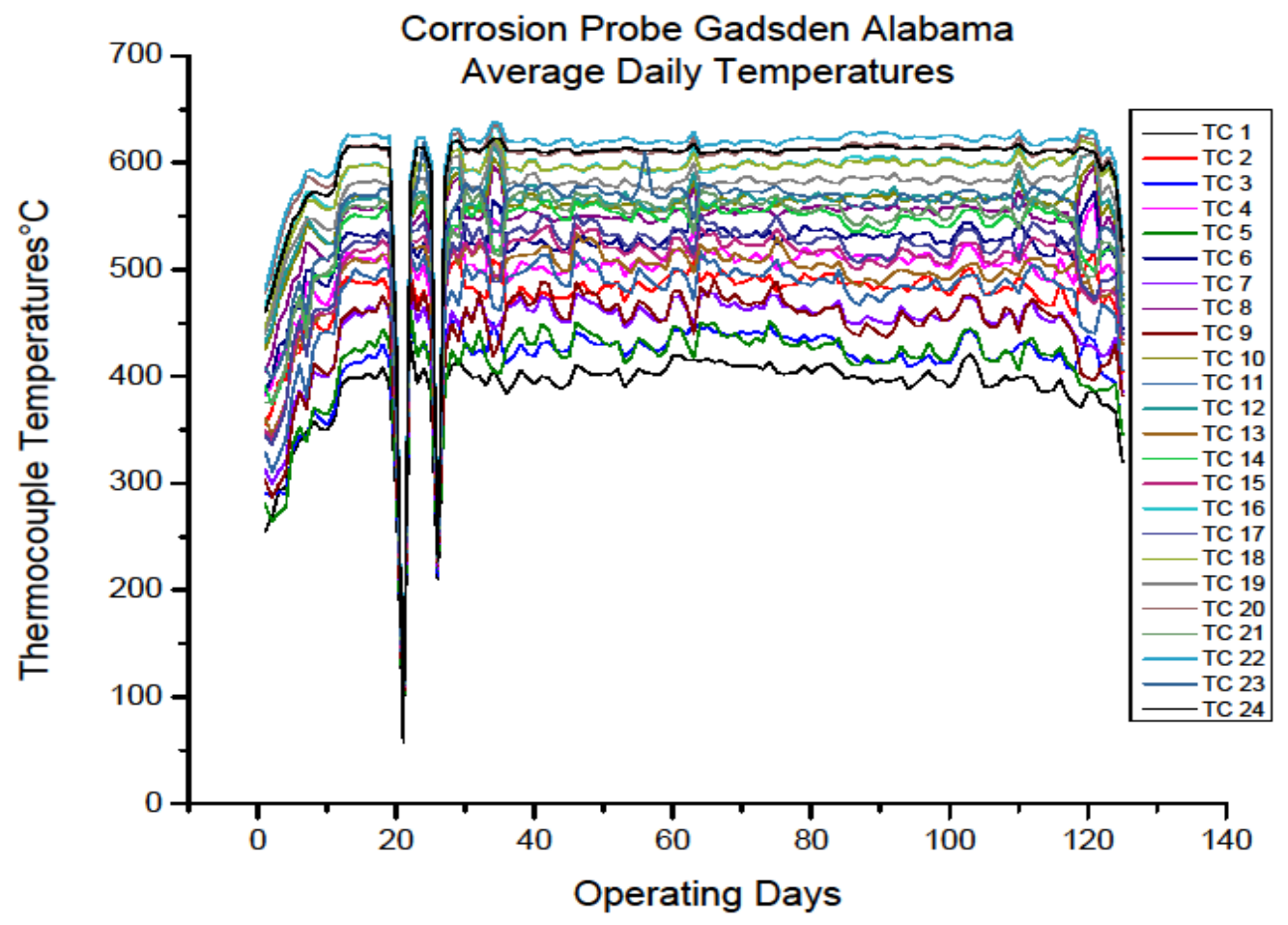

Fig. 46. Average daily temperatures of thermocouples on the corrosion probe exposed about 2, 540 hours in the coal and wood co-fired Gadsden power boiler. 


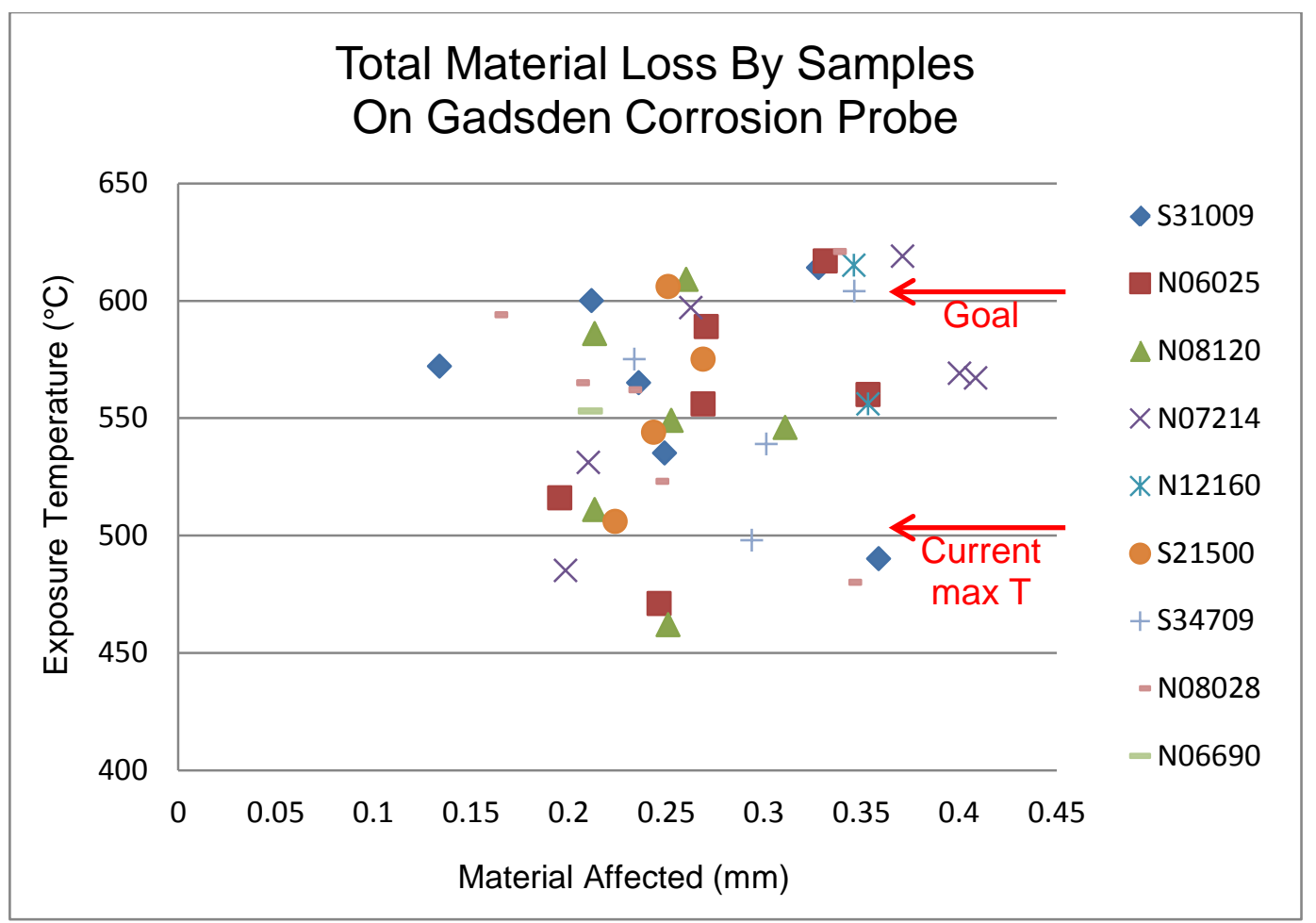

Fig. 47. Total affected material as a function of exposure temperature for samples exposed for 2,540 hours on the corrosion probe in the Gadsden power boiler.

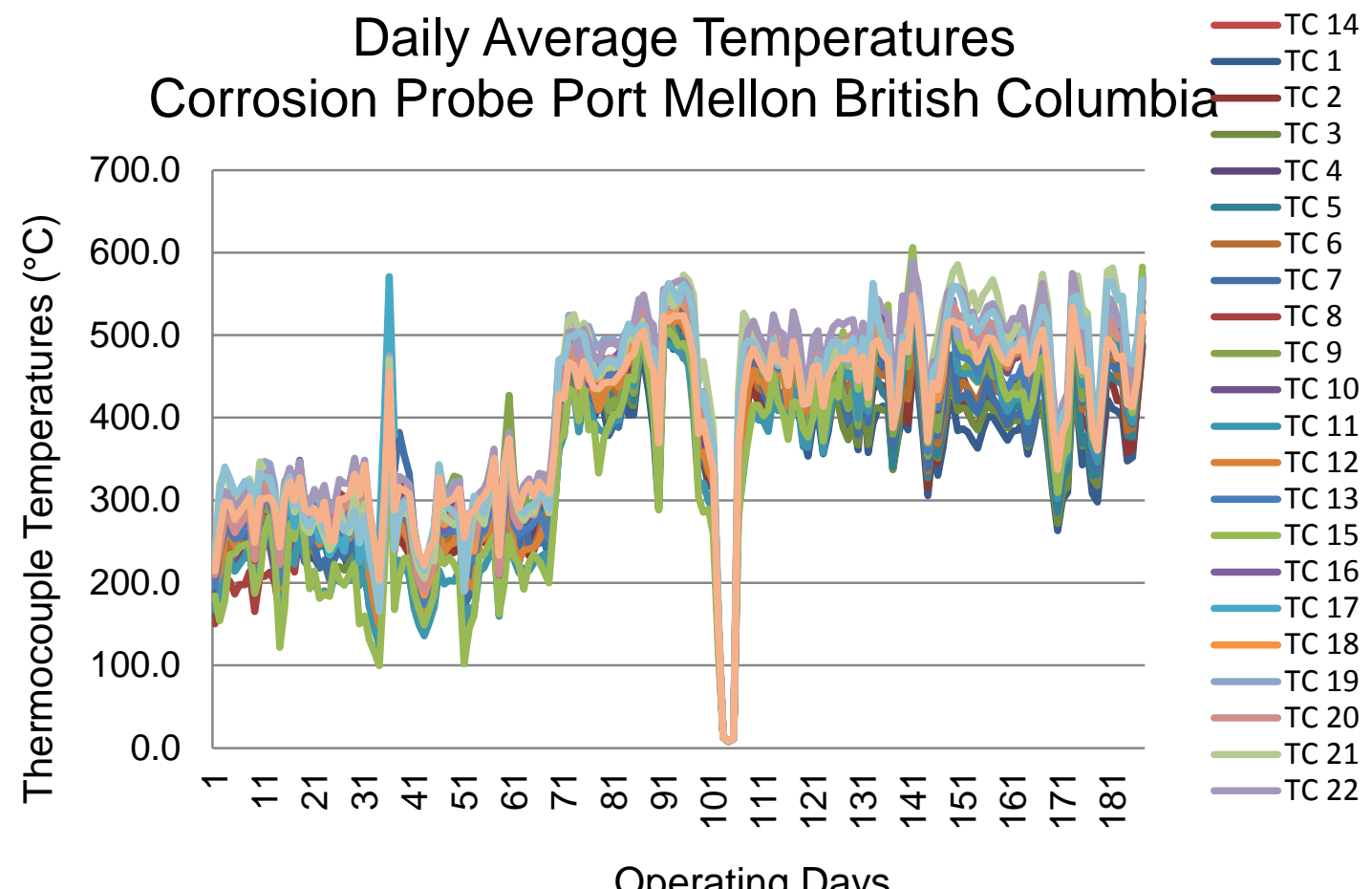

Fig. 48. Average daily temperatures of thermocouples on the corrosion probe exposed about 2,830 hours in the Port Mellon hogged fuel boiler. 
much above $500^{\circ} \mathrm{C}$. This resulted in not having sufficient data to predict degradation rates at and above $500^{\circ} \mathrm{C}$. The exposure time at the higher temperature levels was about 118 days or about 2830 hours.

Figure 49 shows the depth of affected material versus temperature for the various samples exposed in the Port Mellon boiler. In addition to the fact that the highest temperatures were lower than desired, it was particularly of interest to note that most of the alloys showed a higher than expected degree of degradation in the $400-430^{\circ} \mathrm{C}$ temperature range. Note the data points inside the red oval in Figure 49. The deviation from the expected degradation pattern is more evident in the plots in Figure 50 which show the variation in affected material versus temperature for six of the alloys exposed in this boiler.

In an effort to determine why higher rates of degradation were seen at relatively low temperatures, more thorough analysis were undertaken on deposits collected from the samples exposed in the particular temperature range. Both X-ray diffraction and Raman scattering were used to try to identify components of the deposits that might be responsible for low melting point compounds that might cause accelerated degradation in a fairly low temperature range. Results of the X-ray and Raman studies indicate the presence of $\mathrm{Zn}$ (II) and/or $\mathrm{Pb}$ (II) either one of which could form relatively low melting point compounds. A more detailed review of the analysis results of the deposits collected from the sampling probe exposed by FPInnovations revealed zinc concentrations on the order of $0.2 \%$ and lead concentrations of about a third that level [117]. Studies conducted in Finland at Åbo Akademi have shown that heavy metal salts or oxides containing zinc and/or lead can cause accelerated corrosion of superheater tube alloys like 21/4Cr$1 \mathrm{Mo}$ steel and $347 \mathrm{H}$ stainless steel [118]. Based on this information, it appears likely that the higher degree of degradation seen in the $400-430^{\circ} \mathrm{C}$ range on the corrosion probe samples is due to the presence of these heavy metals that almost certainly were introduced into the boiler in the $\mathrm{C} \& \mathrm{D}$ waste. It will be of interest to learn if the lower temperature superheater tubes and the tubes in the bull nose of the Port Mellon boiler experience accelerated corrosion.

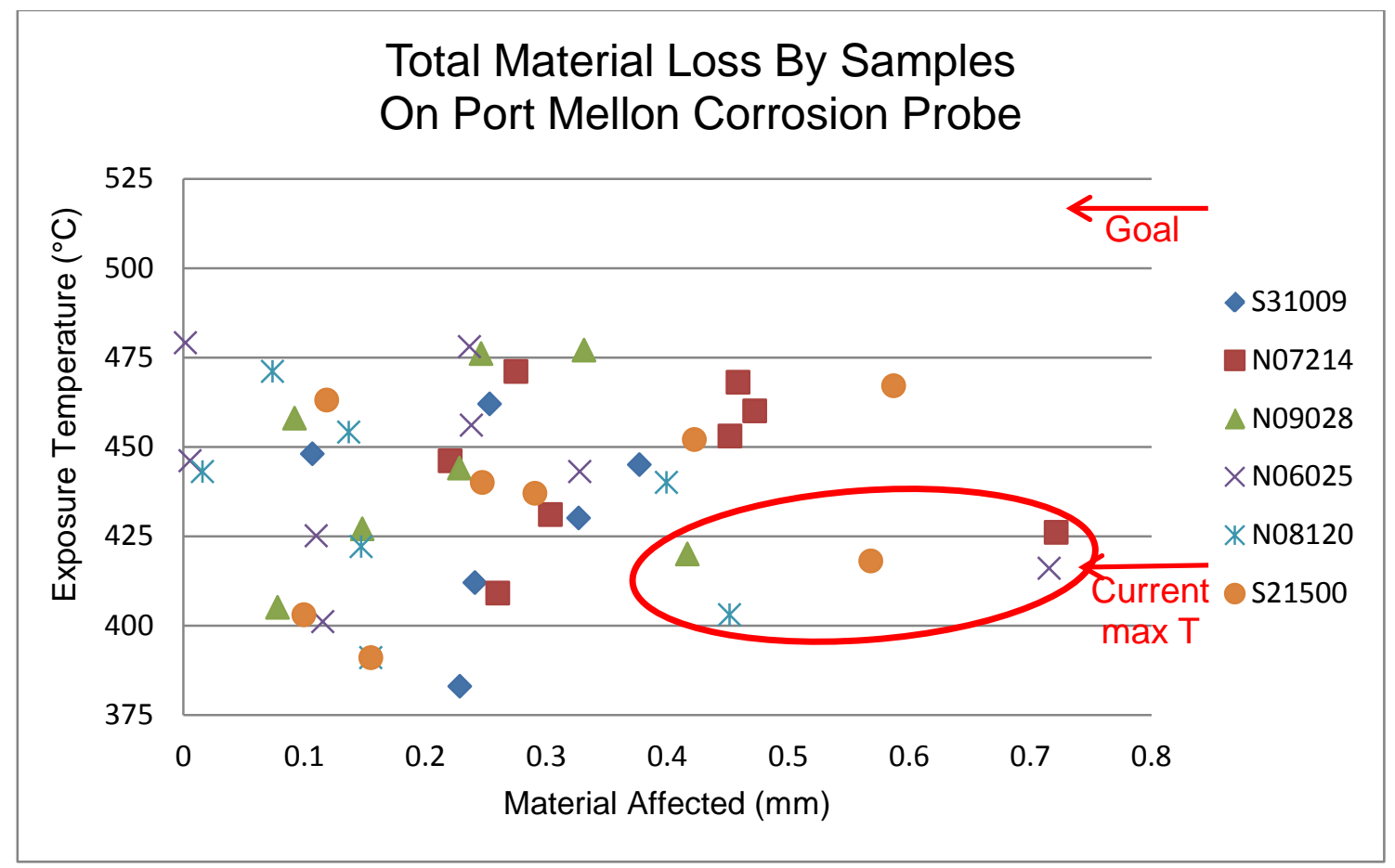

Fig. 49. Total affected material as a function of exposure temperature for samples exposed about $\mathbf{2 , 8 3 0}$ hours on the corrosion probe in the Port Mellon hogged fuel boiler. 

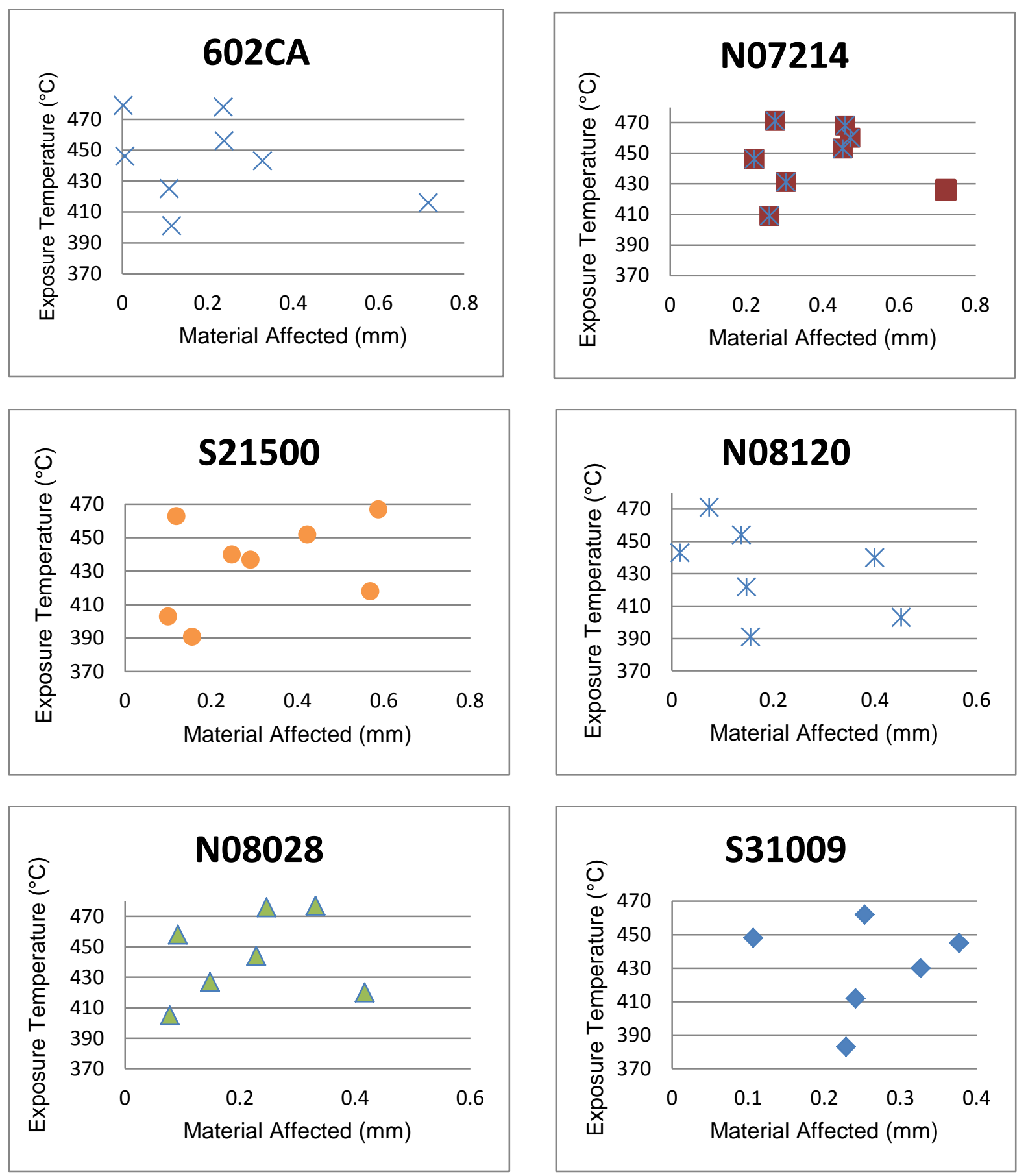

Fig. 50. Total affected material versus exposure temperature for individual alloys exposed for 2,830 hours on the corrosion probe in the Port Mellon hogged fuel boiler. Note the higher amount of material lost in the 400$430^{\circ} \mathrm{C}$ temperature range for most alloys.

\subsubsection{Summary}

Four corrosion probes each containing a total of 30 metallic samples of 9 different alloys were each exposed in a boiler firing biomass. Three of the boilers were selected because of the extreme environment that was expected in each, and the fourth was chosen because it burned a mixture of coal and biomass. 
The temperatures measured by the 24 thermocouples on each probe showed very significant variations during the exposures that had durations of at least 2,000 hours.

In the potassium-rich environment of the Covington probe two alloys (N06690 and S21500) seemed to demonstrate corrosion resistance that would suggest they would likely perform satisfactorily in a potassium-rich environment at a temperature 100 Celsius degrees above current operating temperatures.

For the chloride-rich environment of the Crofton boiler, essentially all alloys showed fairly low degradation rates when exposed at temperatures below about $500^{\circ} \mathrm{C}$, but the six alloys that had samples exposed above about $525^{\circ} \mathrm{C}$ all showed greatly accelerated rates above that temperature. Both alumina forming alloys (N06025 and N07214) performed very well below about $510^{\circ} \mathrm{C}$, but, as noted, both alloys had much higher rates above $525^{\circ} \mathrm{C}$.

The environment of the Gadsden probe likely showed small variations as the amount of wood varied, but that variation was probably considerably less than that of the environment in the other boilers studied because of the expectation of consistent steam production from this power boiler. All samples exposed in the Gadsden boiler showed relatively low degradation rates, possibly because of the absence of significant amounts of alkali metals and chlorides.

The presence of zinc and/or lead in the environment of the Port Mellon boiler was not expected when the exposure sites were selected, but this provided some very interesting results. Essentially all the alloys (except S31009) showed higher degradation rates in the $400-430^{\circ} \mathrm{C}$ range, and this very likely can be attributed to the presence of $\mathrm{Zn}$ and/or $\mathrm{Pb}$ in the deposits. Even though the average sample temperatures on this corrosion probe were well below the desired range, enough information was collected to note that degradation rates for almost all alloys tended toward higher values even at 40 or more Celsius degrees below the temperature goal.

It is generally expected that the corrosion resistance of an alloy will improve with increasing chromium content. However, that was not a pattern that fits the results of the corrosion probe studies. Alumina forming alloys are sometimes an alternative to chromia forming alloys because of an improved resistance in some aggressive environments, but the alumina forming alloys did not consistently perform well on these corrosion probes. It is worth noting that the alumina forming alloys often perform better at considerably higher temperatures, and the temperatures to which the probes were exposed may not have been high enough to get the best features of the alumina forming alloys. 


\subsection{ECONOMICS}

The 1997 Kyoto Protocol set the goal of stabilizing greenhouse gas concentrations in the atmosphere at a level that would avoid dangerous climate change by obliging industrialized countries to reduce such emissions. European countries that ratified this protocol have adopted systems of incentives and penalties to reduce greenhouse gas emissions. Many have developed and implemented technologies that improve the efficiency with which steam and power can be generated from biomass fuels. Biomass fuels are attractive for power generation because they are renewable and almost carbon-neutral. However, the combustion of biomass produces superheater ashes that contain corrosive elements like chlorine, potassium and sodium. When climate change and renewable fuels were of less concern, outlet steam temperatures of biomass-fueled boilers were kept low to avoid fireside corrosion of superheater tubes and/or pluggage in the convective sections. Such temperature limitations restricted the power that could be generated from biomass fuels.

As part of the project to evaluate corrosion mitigation strategies that would enable biomass-fueled boilers to operate with higher superheater steam temperatures this task analyzed the economic impacts of higher superheater temperatures in biomass-fueled boilers [119]. Boiler performance and process conditions were estimated using proprietary thermodynamics-based plant simulation software. We present financial calculations of the benefits of increased superheated steam temperatures based on the analysis of steam and power production in five example boilers burning biomass. These financial benefits are compared with the additional costs of alloys that could resist corrosion at the higher superheater temperatures. Where the financial benefits exceed these costs, using more corrosion-resistant alloys to enable higher steam temperatures offers a net financial benefit to the boiler operator. Second, we compare the financial benefits of higher steam temperatures with the cost of fuel treatments or additives [3] applied to reduce the concentration of corrosives in the superheater ash. Third, we compare the financial benefits with the cost of boiler redesign, e.g. of constructing a circulating fluidized bed (CFB) boiler with the superheater in the loop seal [3] instead of in the convective pass.

\subsubsection{Calculation Methods}

The primary tool used for these calculations is a thermodynamic software program developed by the second author of this paper. This program, called StmPowr ${ }^{\circledR}{ }^{1}$, models Combined Heat and Power (CHP) systems that supply process steam to an adjacent plant (or sell it for district heating) and simultaneously generate electricity for plant use or external sale. For example, in a pulp and paper mill, a typical steam turbine would supply high-, medium- or low-pressure steam to dry paper, evaporate water from black liquor and heat process units such as pulp digesters. It would also generate electrical power.

StmPower ${ }^{\circledR}$ calculates the net electrical power and process steam generated from a Rankine cycle power plant. Almost all power plants use the Rankine cycle as their heat engine. This cycle has four components. First, the working fluid (boiler feedwater) is pressurized by a pump. The high pressure water is heated at constant pressure to become a dry saturated vapor (steam). This dry steam expands through a steam turbine, generating power and lower pressure process steam. The remaining turbine exhaust steam is condensed immediately or later to a saturated liquid. The working fluid (condensate) is recirculated and heated to become boiler feedwater, continuing through a closed condensate - boiler feedwater - steam loop.

Required inputs to the software model include the rate of fuel input, the fuel characteristics (elemental composition, gross heating value, and temperature) and process and equipment parameters for various

\footnotetext{
${ }^{1}$ Available from Table Mountain Consulting, 1024 Tucker Gulch Drive, Golden, CO 80403; http://tmcjimfred.com/TMCLLC/Welcome.html
} 
unit operations that will be described below. The software uses the flow rate, temperature and pressure of the inlet steam and turbine efficiency parameters to predict the temperature, pressure and flow rates of the steam extracted from the turbine and the power generated. Figure 51 shows the configuration and the process mass and energy streams included in the model. The StmPowr ${ }^{\circledR}$ software calculates the flow rates and conditions of the process streams that cross the process boundary (red dashed line) in this figure.

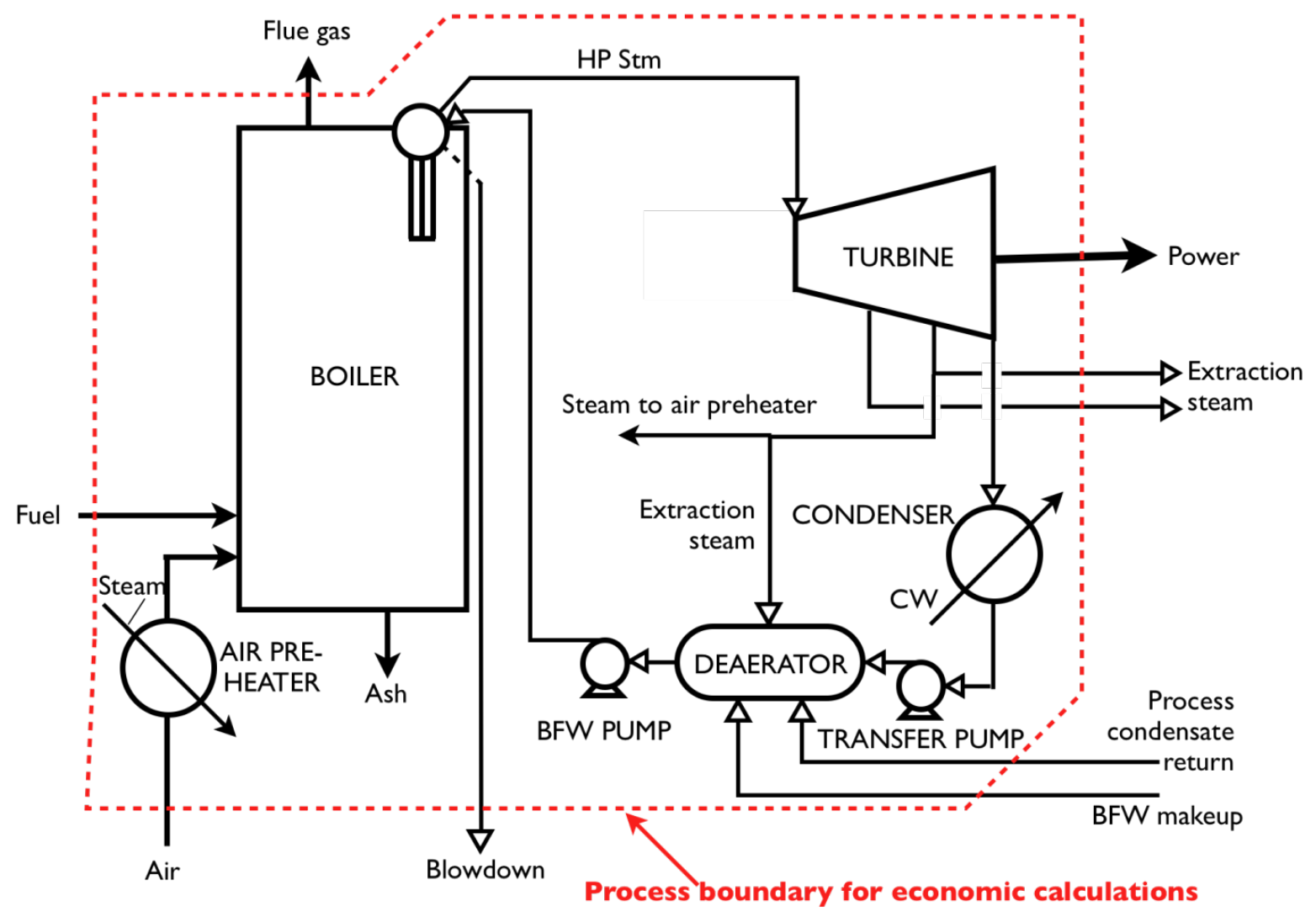

Fig. 51. Process mass and energy streams included in the software model.

The Rankine cycle analyzed by the StmPower ${ }^{\circledR}$ model consists of seven unit processes:

Boiler

Steam turbine

Exhaust steam surface condenser

Condensate transfer pump

Deaerator

Boiler feedwater pump

Combustion air preheater

We will discuss each of these unit processes in turn.

\subsubsection{Components of the Steam Power Cycle Calculation Module}

\subsubsection{Boiler}

The boiler sub-module calculates the net rate of high-pressure steam generation at specified steam conditions ( $\mathrm{T}, \mathrm{P})$ and other specified parameters from the fuel input rate, as shown in Table 7 . The steam rate calculation is based on the heat loss method $(120,121)$. 
Table 7: Components of boiler sub-module

\begin{tabular}{|l|l|l|}
\hline Specified input conditions & Specified exit conditions & Calculated parameters \\
\hline $\begin{array}{l}\text { Fuel input rate and temperature, gross } \\
\text { heating value of dry fuel, fuel moisture } \\
\text { content and elemental composition }\end{array}$ & $\begin{array}{l}\text { Temperature and pressure } \\
\text { of the superheated steam } \\
\text { produced }\end{array}$ & $\begin{array}{l}\text { Thermal efficiency of } \\
\text { boiler }\end{array}$ \\
\hline $\begin{array}{l}\text { Combustion air input rate, temperature and } \\
\text { moisture content }\end{array}$ & Blowdown rate & $\begin{array}{l}\text { Rate of generation of } \\
\text { high pressure, } \\
\text { superheated steam }\end{array}$ \\
\hline Boiler feedwater temperature and pressure & & $\begin{array}{l}\text { Boiler feedwater input } \\
\text { rate }\end{array}$ \\
\hline $\begin{array}{l}\text { Internal steam used for air heating and } \\
\text { sootblowing (pressures, temperatures and } \\
\text { flows) }\end{array}$ & Flue gas exit composition \\
\hline $\begin{array}{l}\text { Correlation between flue gas exit } \\
\text { temperature and fuel input rate }\end{array}$ & Ash output rate \\
\hline
\end{tabular}

\subsubsection{Steam Turbine}

The steam turbine sub-module calculates the power generated by the calculated flow of superheated steam generated by the boiler. The turbine operates at its own specified isentropic efficiency. The power generated is calculated from the temperature, pressure steam and flow rate of the steam flowing to the turbine, the temperatures, pressures and flow rates of process steam extracted from the turbine and the temperature, pressure and flow rate at the turbine exhaust, as shown in Table 8.

Table 8: Components of the steam turbine sub-module

\begin{tabular}{|l|l|l|}
\hline Specified input conditions & Specified exit conditions & Calculated parameters \\
\hline $\begin{array}{l}\text { Flow rate of high pressure } \\
\text { superheated steam to the } \\
\text { turbine inlet }\end{array}$ & $\begin{array}{l}\text { Pressures and flow rates of } \\
\text { process steam extracted from the } \\
\text { turbine }\end{array}$ & $\begin{array}{l}\text { Power generated for the steam } \\
\text { conditions specified }\end{array}$ \\
\hline $\begin{array}{l}\text { Temperature and pressure of } \\
\text { steam delivered to the turbine }\end{array}$ & & $\begin{array}{l}\text { Temperatures of process steam } \\
\text { extracted from the turbine }\end{array}$ \\
\hline $\begin{array}{l}\text { Isentropic efficiency of the } \\
\text { turbine }\end{array}$ & & \\
\hline
\end{tabular}

\subsubsection{Exhaust Steam Condenser}

For condensing turbines, this sub-module calculates the cooling water flow required to condense the exhausted steam at its specified temperature, pressure and flow rate as summarized in Table 9. This condensate returns to the deaerator for reuse as boiler feed water.

Table 9: Components of exhaust steam condenser sub-module

\begin{tabular}{|l|l|l|}
\hline Specified input conditions & Specified exit conditions & Calculated parameters \\
\hline $\begin{array}{l}\text { Temperature, pressure and flow } \\
\text { rate of turbine exhaust steam }\end{array}$ & $\begin{array}{l}\text { Temperature and pressure of } \\
\text { condensate }\end{array}$ & $\begin{array}{l}\text { Flow of cooling water required to } \\
\text { condense exhausted steam }\end{array}$ \\
\hline $\begin{array}{l}\text { Temperature and pressure of } \\
\text { steam extracted to the deaerator }\end{array}$ & $\begin{array}{l}\text { Inlet temperature of cooling } \\
\text { water }\end{array}$ & $\begin{array}{l}\text { Outlet temperature of cooling } \\
\text { water }\end{array}$ \\
\hline $\begin{array}{l}\text { Feed water make-up rate and } \\
\text { temperature }\end{array}$ & \multicolumn{2}{|l}{} \\
\hline
\end{tabular}




\subsubsection{Condensate transfer pump}

The condensate transfer pump moves the condensate from the turbine steam condenser sump to the deaerator. Components of the sub-module are shown in Table 10.

Table 10: Components of condensate transfer sub-module

\begin{tabular}{|l|l|l|}
\hline Specified input conditions & Specified exit conditions & Calculated parameters \\
\hline $\begin{array}{l}\text { Temperature, pressure and flow } \\
\text { rate of condensate from the } \\
\text { condensate sump }\end{array}$ & Deaerator pressure & $\begin{array}{l}\text { Power required by condensate } \\
\text { transfer pump }\end{array}$ \\
\hline Pump and motor efficiency & & \\
\hline
\end{tabular}

\subsubsection{Deaerator}

Boiler makeup feedwater is added to the condensate in the deaerator. This combined feedwater is heated to the saturation temperature at the deaerator pressure by steam extracted from the turbine. The components of the deaerator sub-module are listed in Table 11.

Table 11: Components of the deaerator sub-module

\begin{tabular}{|l|l|l|}
\hline Specified input conditions & Specified exit conditions & Calculated parameters \\
\hline $\begin{array}{l}\text { Temperature, pressure and flow } \\
\text { rate of condensate return to } \\
\text { deaerator }\end{array}$ & Boiler feedwater temperature & $\begin{array}{l}\text { Flow rate of steam extracted } \\
\text { from the turbine to the deaerator } \\
\text { at the specified temperature and } \\
\text { pressure }\end{array}$ \\
\hline $\begin{array}{l}\text { Temperature and flow rate of } \\
\text { boiler feedwater make-up }\end{array}$ & \\
\hline $\begin{array}{l}\text { Temperature, pressure and flow } \\
\text { rate of steam used for deaerator } \\
\text { heating }\end{array}$ & & \\
\hline
\end{tabular}

\subsubsection{Boiler Feedwater Pump}

The boiler feedwater pump raises the pressure of the boiler feedwater from the pressure in the deaerator up to the boiler inlet pressure, as shown in Table 12.

Table 12: Components of the boiler feedwater pump sub-module

\begin{tabular}{|l|l|l|}
\hline Specified input conditions & Specified exit conditions & Calculated parameters \\
\hline $\begin{array}{l}\text { Temperature, pressure and flow } \\
\text { rate of boiler feedwater flow } \\
\text { from deaerator }\end{array}$ & $\begin{array}{l}\text { Pressure of feedwater at boiler } \\
\text { inlet }\end{array}$ & $\begin{array}{l}\text { Power required by boiler } \\
\text { feedwater pump }\end{array}$ \\
\hline $\begin{array}{l}\text { Efficiency of the feedwater } \\
\text { pump and motor }\end{array}$ & & \\
\hline
\end{tabular}

\subsubsection{Combustion air preheater}

The combustion air preheater is a heat exchanger that uses turbine extraction steam to heat the outside air from ambient temperature to the temperature required for fuel combustion, as summarized in Table 13.

Table 13: Components of the combustion air sub-module

\begin{tabular}{|l|l|l|}
\hline Specified input conditions & Specified exit conditions & Calculated parameters \\
\hline
\end{tabular}




\begin{tabular}{|l|l|l|}
\hline $\begin{array}{l}\text { Temperature and pressure of } \\
\text { steam extracted from turbine to } \\
\text { heat combustion air }\end{array}$ & $\begin{array}{l}\text { Temperature of combustion air } \\
\text { entering boiler }\end{array}$ & $\begin{array}{l}\text { Required flow rate of steam } \\
\text { extracted from turbine to heat } \\
\text { combustion air }\end{array}$ \\
\hline $\begin{array}{l}\text { Temperature of ambient air } \\
\text { entering preheater }\end{array}$ & & \\
\hline
\end{tabular}

\subsubsection{Boiler Systems Analyzed}

To determine the magnitude of the economic costs and benefits of higher superheater steam conditions, we asked industrial collaborators in the project to supply data from typical biomass-fueled boilers.

Calculations were made with data from five boilers - two recovery boilers and three boilers burning hogged wood. Hogged fuel is produced from waste bark or wood that has been processed by a disintegrator, or hog, that processes the wood into chips or shreds of practically uniform size. The boilers used for the calculations are as follows. Data for Recovery Boiler B were supplied by a boiler manufacturer as part of a software model of a recovery boiler in a typical pulp mill where process steam is extracted from the turbine. The steam data for Recovery Boiler M came from a WinGEMS ${ }^{2}$ software model of a 1000 oven-dried tons per day unbleached pulp mill with a recovery boiler operating at 1450 psi. These two recovery boilers produced power outputs of 52 and 53.6 MW with conventional steam conditions.

All the biomass boilers were real units. Biomass Boiler $\mathrm{C}$ operates on the Pacific Coast and is fired by hogged fuel produced from sea-floated logs. Biomass Boiler $\mathrm{H}$ also operates on the Pacific Coast, but fires about 2/3 beetle-killed pine, about $1 / 3$ sea-floated logs and a small amount of wood from construction waste. Biomass Boiler $\mathrm{M}$ is a biomass boiler recently converted to bubbling fluidized bed operation by a boiler manufacturer. It burns hogged wood.

Figure 52 illustrates the difference between the two types of steam turbine that are used in the calculations that will follow. Condensing CHP turbines are shown schematically in Figure 52(a). Steam used to turn

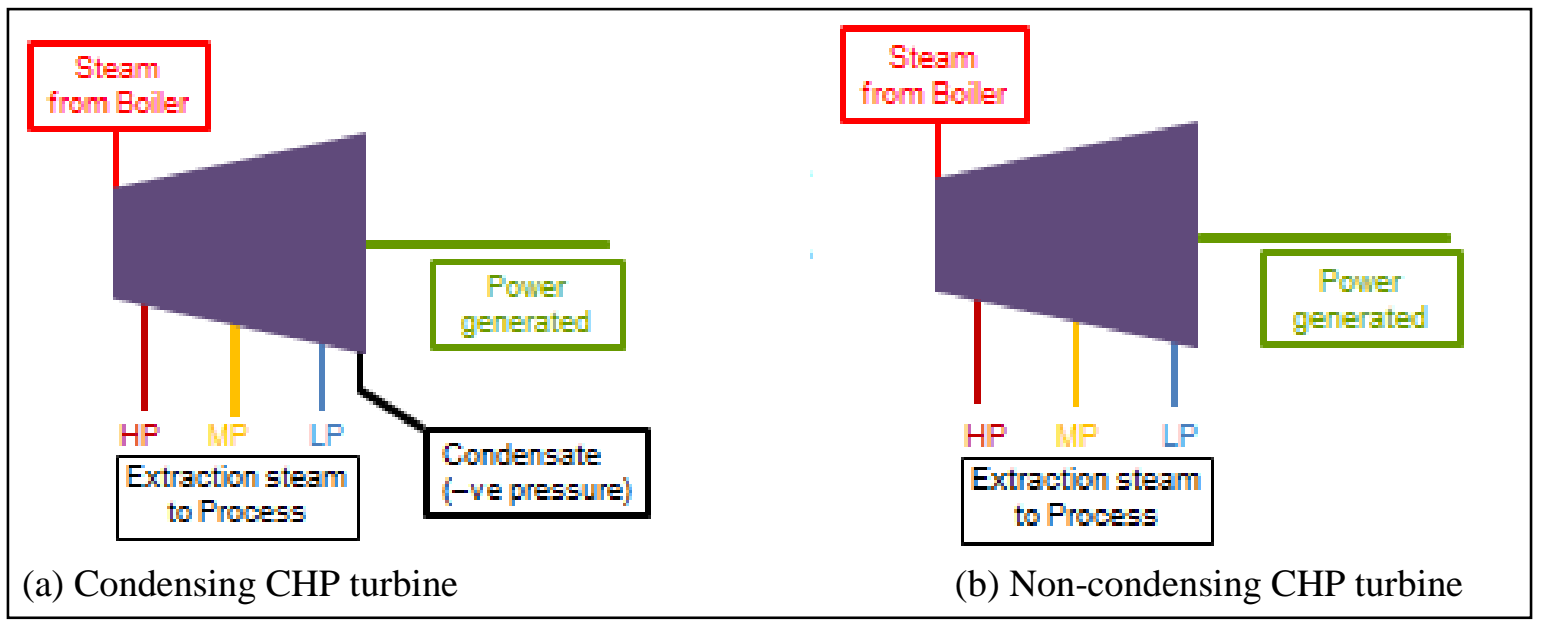

Fig. 52. Types of steam turbine used in calculations of costs and benefits of increasing superheater steam temperature.

the rotor is extracted at high, medium and low pressures (or sometimes at only two pressures). Any remaining steam is then condensed in water-cooled tubes in a surface condenser. Non-condensing (back-

\footnotetext{
${ }^{2}$ Now available as Metso Process Simulator from Metso Automation USA, Norcross, GA.
} 
pressure) turbines, shown schematically in Figure 52(b), extract all the steam used to turn the turbine rotor as process steam to be used in an adjacent plant.

Both of the example recovery boilers deliver their steam to condensing turbines while all three wood-fired boilers deliver their steam to non-condensing turbines. Condensing turbines use all the steam supplied by the boiler to turn the turbo-generator rotor and generate power. Steam that has passed through the full length of the turbine is condensed on water-cooled tubes in a surface condenser. This condensation decreases the volume of the steam by about 1,800 times and creates a vacuum in the condenser. Surface condensers can produce pressures of 90 to 100 kilopascals (13 to 14.5 psi) below atmospheric pressure. Creating this vacuum allows the steam supplied by the boiler to expand much more, producing a larger enthalpy change through the turbine and increasing the turbine efficiency. For this reason, utility boilers, where efficiency is of primary importance, always use condensing turbines. Note that the vacuum pressure developed by the surface condenser depends on the temperature of the cooling water, which could be subject to seasonal changes, and on the partial pressures exerted by non-condensable gases accumulated in the feedwater. Because the turbine efficiency increases as the condenser vacuum increases, accumulated non-condensable gases should be stripped out and the condensing temperature should be kept as low as possible. The steam condensate, stripped of non-condensable gases, is returned to the boiler as feed water.

The simplest non-condensing (back-pressure) steam turbine would extract all the steam used to drive the turbo-generator rotor as process steam at a series of decreasing pressures. "Back-pressure" simply indicates that the steam is extracted at pressures above atmospheric. The process steam flows are extracted at the pressure(s) required by the process operations regardless of the load on the turbine. This is achieved by controlling the steam flows at the extraction points. The extraction pressures are chosen to suit the particular process steam requirements of the plant where the boiler is located. The extracted steam can be used in an adjacent process plant (e.g. a pulp and paper mill or chemical plant) or for district heating. The steam condensate is later augmented by make-up boiler water, deaerated and returned to the boiler.

Once saturated steam has been generated in a boiler, relatively little additional fuel energy is required to raise its temperature and pressure to the superheat required to provide more efficient power generation. Therefore if a process plant already needs a substantial amount of process steam, adding a noncondensing turbine offers a simultaneous supply of relatively inexpensive power without the need for the substantial volumes of cooling water that would be required to operate a surface condenser in a condensing turbine. However, the capacity of a turbine to generate power falls substantially when process steam is extracted at appreciable pressure instead of being expanded into a vacuum in a surface condenser.

The biomass-fueled boilers studied in the current project all produce a combination of heat and power (CHP). All of them provide process steam to an adjacent plant and all of them generate power. All are once-through turbines that do not take advantage of the efficiencies of reheating the steam in the boiler between various turbine stages.

\subsubsection{The Thermodynamic Basis for the Increasing Value of Steam with Increasing Temperature}

The principle that underlies the work described in this paper is that the availability of energy in steam increases as the temperature of the steam increases. Availability, also called available energy, is a thermodynamic property like enthalpy. Gibbs introduced this concept in 1873 [122] by defining "capacity for entropy" as the amount by which the entropy of a body can be increased without changing the energy of the body or increasing its volume. For steam, the available energy is the maximum amount 
of mechanical work that can be obtained from it in an ideal engine by bringing it to the temperature and pressure of a reference atmosphere without allowing heat to pass into it or out of it, i.e.:

Available energy = Enthalpy of steam $-($ Entropy of steam) $x$ (Temperature of surroundings)

More rigorously:

where:

$$
\mathrm{a}=\mathrm{h}-\mathrm{T}_{0} \mathrm{~S}
$$

$\mathrm{a}=$ specific available energy, $\mathrm{kJ} / \mathrm{kg}$

$\mathrm{h}=$ specific enthalpy, $\mathrm{kJ} / \mathrm{kg}$

$\mathrm{T}_{0}=$ absolute temperature of the surroundings, ${ }^{\circ} \mathrm{K}$

$\mathrm{s}=$ specific entropy, $\mathrm{kJ} / \mathrm{kg}$

Consider the effect of increasing temperature on the steam parameters in this equation. Figure 53 shows that, as the temperature of a unit mass of steam at constant pressure increases, its specific enthalpy increases. Figure 54 shows that the specific entropy of the steam also increases with the steam temperature at constant pressure.

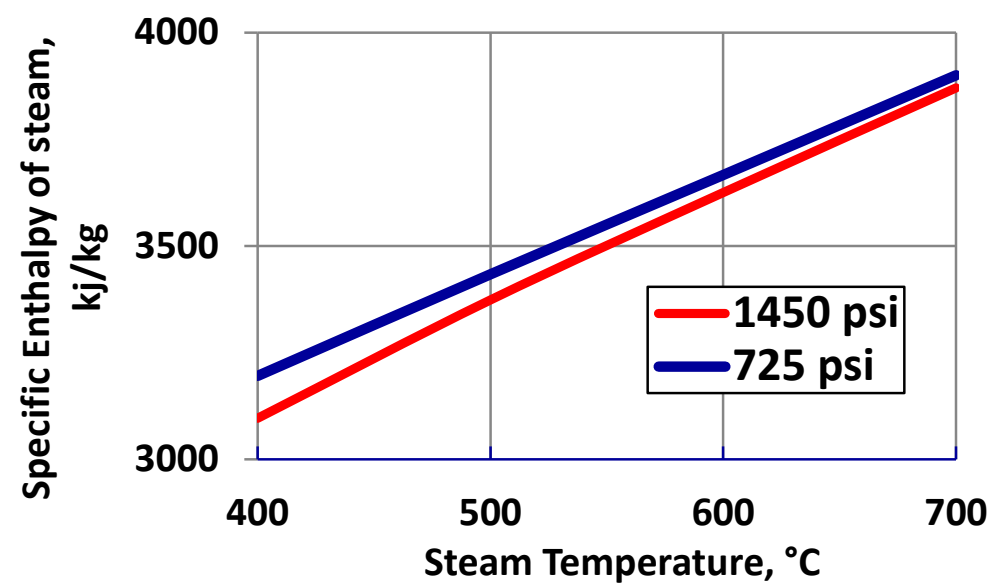

Fig. 53. Increase of specific enthalpy of steam with temperature at 50 and 100 bars pressure (725 and 1450 psi).

The availability of energy from the steam increases with increasing temperature because the specific enthalpy of steam increases proportionally more with temperature than does the specific entropy of steam. This conclusion is demonstrated in Figure 55, which shows the temperature dependence of the specific available energy of steam at boiler pressures of 50 bars (725 psi) and 100 bars (1,450 psi) within the temperature range of interest in this work. These data lead to the practical conclusion that, for a turbine to derive the most energy from the steam produced by a boiler fuel, the boiler should be designed to produce steam at the highest temperature that its superheater metallurgy allows.

It is important to note that the volume of a given mass of steam heated by burning a given amount of fuel to heat will fall as the final temperature of the steam increases. In the data presented in Figure 54, raising the steam temperature from $500^{\circ} \mathrm{C}$ to $600^{\circ} \mathrm{C}$ without changing the fuel input to the CHP plant reduces the volume of steam produced by $6.6 \%$ at a pressure of 50 bars (725 psi) and by $7.2 \%$ at a pressure of 100 bars (1450 psi). Whether or not this reduction in steam volume presents a problem in plant operation will depend on the process steam requirements and the turbine design. In a condensing turbine, the smaller 


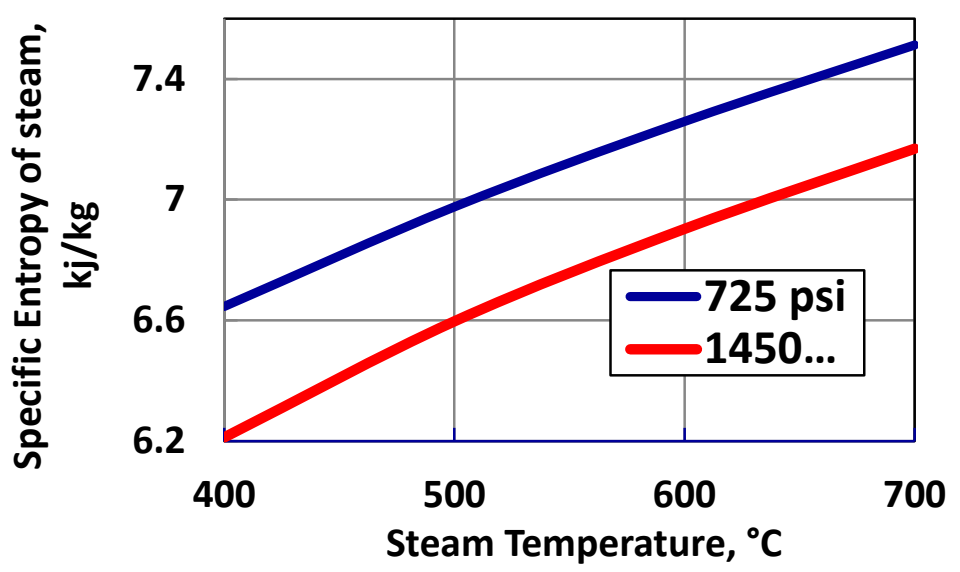

Fig. 54. Increase of specific entropy with temperature at 50 and 100 bars pressure (725 and 1450 psi).

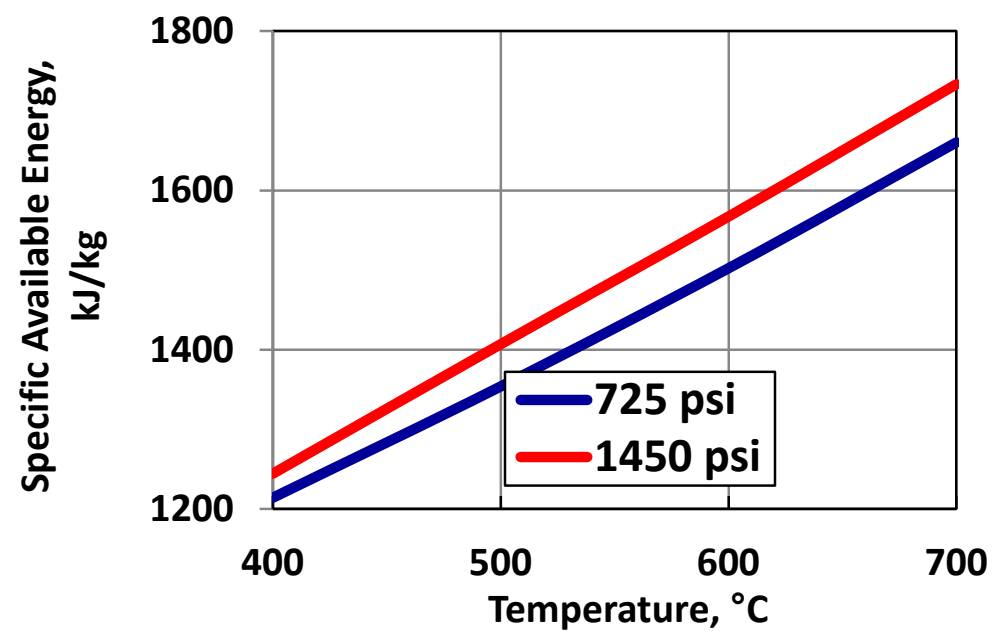

Fig. 55. Increase in specific available energy in steam with increasing steam temperature at constant pressure.

volume of steam produced at a higher temperature could, in principle, be redistributed among the extraction stages by controlling the steam flows at the extraction points. However, in a back-pressure turbine, it may not be possible to maintain the process steam flows if the steam volume is reduced by heating the steam to a higher final temperature.

Table 14 lists the steam parameters for the two recovery boilers and the three wood-fired boilers studied in the economic calculations. The boiler parameters were supplied by project partners. Three of these example boilers used for the calculations were also used for field tests to measure the corrosion resistance of candidate alloys in higher temperature superheater environments.

The steam extraction temperatures used in the calculations were recalculated from the extraction pressures using standardized turbine stage efficiencies to determine the entropy of the steam extracted. The condensate temperatures were adjusted to those of saturated condensate at atmospheric temperature. These calculations used the procedures proposed by Ulrich [123], although similar calculation procedures are presented in other engineering thermodynamics and process design texts. The turbine stage efficiencies used for the recovery boiler calculations were provided by an Industrial Partner [124] and the 
turbine stage efficiencies used for the biomass boiler calculations were estimated from data presented by Ulrich (Reference 123, page 87).

Table 14 Steam system parameters for the five boilers studied

\begin{tabular}{|c|c|c|c|c|c|}
\hline \multirow{2}{*}{ Boiler type and identifier code } & \multicolumn{2}{|c|}{ Recovery Boiler } & \multicolumn{3}{|c|}{ Biomass (wood)-Fired Boiler } \\
\hline & $\mathrm{B}$ & $\mathrm{M}$ & $\mathrm{C}$ & $\mathrm{H}$ & $\mathrm{M}$ \\
\hline Steam Production, kg/sec & 91.8 & 101.68 & 119.7 & 59.98 & 60.48 \\
\hline Steam Pressure, bar & 61.22 & 99.66 & 41.84 & 89.63 & 89.63 \\
\hline Steam Temperature, ${ }^{\circ} \mathrm{C}$ & 465.6 & 471.1 & 399.0 & 482.2 & 480.0 \\
\hline HP Steam Pressure, bar & N/A & N/A & N/A & N/A & 28 \\
\hline HP Steam Temperature, ${ }^{\circ} \mathrm{C}$ & N/A & N/A & N/A & N/A & 328.2 \\
\hline HP Steam Enthalpy, kJ/kg & 2933.74 & 2838.42 & 3132.56 & 3146.11 & 3069.18 \\
\hline HP Steam Extraction Flow, kg/sec & 0 & 0 & 0 & 0 & 15.12 \\
\hline MP Steam Pressure, bar & 12.75 & 12.75 & 11.22 & 12.75 & 12.75 \\
\hline MP Steam Temperature, ${ }^{\circ} \mathrm{C}$ & 247.8 & 190.86 & 335.2 & 330.2 & 287.4 \\
\hline MP Steam Enthalpy, kJ/kg & 2923.63 & 2814.46 & 3124.03 & 3110.13 & 3016.76 \\
\hline MP Steam Extraction Flow, kg/sec & 8.82 & 39.31 & 15.12 & 15.00 & 6.05 \\
\hline LP Steam Pressure, bar & 5.10 & 5.10 & 4.15 & 4.15 & 4.15 \\
\hline LP Steam Temperature, ${ }^{\circ} \mathrm{C}$ & 152.60 & 152.60 & 177.1 & 175.9 & 167.9 \\
\hline LP Steam Enthalpy, kJ/kg & 2768.81 & 2756.43 & 2811.52 & 2808.91 & 2791.51 \\
\hline LP Steam Extraction Flow, kg/sec & 63.76 & 48.26 & 104.58 & 44.99 & 39.31 \\
\hline Exhaust Steam Pressure, bar & 0.14 & 0.14 & N/A & N/A & N/A \\
\hline Exhaust Steam Temperature, ${ }^{\circ} \mathrm{C}$ & 100 & 100 & N/A & N/A & N/A \\
\hline Exhaust Steam Enthalpy, kJ/kg & 2715.63 & 2711.29 & - & - & - \\
\hline Exhaust Steam Flow, kg/s & 19.22 & 14.11 & 0 & 0 & 0 \\
\hline Condensate Flow, kg/s & 72.58 & 87.57 & 119.7 & 59.98 & 60.48 \\
\hline Condensate Pressure, bar & 18 & 18 & 1.24 & 1.24 & 1.24 \\
\hline Adj. Condensate Temperature, ${ }^{\circ} \mathrm{C}$ & 108.5 & 108.5 & 100 & 100 & 100 \\
\hline \multicolumn{6}{|l|}{ Intrinsic turbine stage efficiencies: } \\
\hline High pressure stage & 0.890 & 0.890 & \multirow{4}{*}{0.813} & \multirow{4}{*}{0.813} & \multirow{4}{*}{0.813} \\
\hline Medium pressure stage & 0.459 & 0.459 & & & \\
\hline Low pressure stage & 0.887 & 0.887 & & & \\
\hline Exhaust stage & 0.650 & 0.650 & & & \\
\hline
\end{tabular}

\subsubsection{Economic Calculations}

Many different approaches could be taken to calculations of the effects of increasing the outlet steam temperatures of a biomass-fueled boiler. Different sets of constraints could be applied to evaluate the effects of specific local factors such as changing needs for process steam, opportunities to sell high-priced power or a decision to install a new high-efficiency turbine. The purpose of the current project was to estimate the economic benefits that would accrue to a boiler operator if a biomass-fueled boiler could be operated with substantially higher exit steam temperatures. To make these estimates, calculations were made with the data from Table 14. The value of the increased steam and power production that would be obtained by increasing the steam temperature by 50 and by 100 Celsius degrees was calculated for each of the five example boilers, using the following assumptions: 
The existing turbine could operate with the higher temperature steam

The heat produced by the combustion of the fuel would be unchanged when the final steam temperature was increased

The product of specific steam enthalpy and steam flow would be unchanged when the final steam temperature was increased

The amount of steam extracted from the turbine to meet process heating requirements would remain unchanged when the final steam temperature was increased

We will first review the results of calculations made with these assumptions and later discuss the uncertainties associated with these assumptions.

Table 15 shows the value of the increased power that would be produced in the two example recovery boilers that would accrue to the owners of these boilers if they could increase the exit steam temperature by 50 or 100 Celsius degrees above the current operating temperature. Because the value of electrical power varies both with location and with time, the value of the additional power generated was calculated for power prices of both \$40/MWh and \$80/MWh. Current power prices typically lie within this range.

Table 15: Value of increased energy production in the two example recovery boilers

\begin{tabular}{|l|l|l|}
\hline \multirow{2}{*}{ Type of boiler and identifier } & \multicolumn{2}{|c|}{ Recovery Boiler } \\
& B & M \\
\hline Condition/data & & \\
\hline Current power generation & $52.0 \mathrm{MW}$ & $53.6 \mathrm{MW}$ \\
\hline Power generated with $50^{\circ} \mathrm{C}$ higher steam temperature & $56.4 \mathrm{MW}$ & $60.8 \mathrm{MW}$ \\
\hline Additional power generated & $+4.4 \mathrm{MW}$ & $+7.2 \mathrm{MW}$ \\
\cline { 2 - 3 } & $+8.4 \%$ & $+13.4 \%$ \\
\hline Value of this additional power @\$40/MWh & $+\$ 1.54 \mathrm{~m} / \mathrm{y}$ & $+\$ 2.52 \mathrm{~m} / \mathrm{y}$ \\
\hline Value of this additional power @\$80/MWh & $+\$ 3.08 \mathrm{~m} / \mathrm{y}$ & $+\$ 5.05 \mathrm{~m} / \mathrm{y}$ \\
\hline Power generated with $100^{\circ} \mathrm{C}$ higher steam temperature & $59.0 \mathrm{MW}$ & $66.3 \mathrm{MW}$ \\
\hline Additional power generated & $+7.0 \mathrm{MW}$ & $+12.7 \mathrm{MW}$ \\
\cline { 2 - 3 } & $+13.4 \%$ & $+23.7 \%$ \\
\hline Value of this additional power @\$40/MWh & $+\$ 2.45 \mathrm{~m} / \mathrm{y}$ & $+\$ 4.45 \mathrm{~m} / \mathrm{y}$ \\
\hline Value of this additional power @ $\$ 80 / \mathrm{MWh}$ & $+\$ 4.91 \mathrm{~m} / \mathrm{y}$ & $+\$ 8.90 \mathrm{~m} / \mathrm{y}$ \\
\hline
\end{tabular}

In related work, three types of virtual turbine were studied to evaluate the effects of higher steam conditions in Recovery Boiler M. In the first case, the turbine generator was optimized for the original (conventional) steam conditions and was therefore less efficient at the higher steam temperatures. In the second case it was assumed that the turbine generator used for higher steam conditions was optimized for these conditions, i.e. that the turbine efficiency remained constant as the steam conditions were increased. In the third case a reheater was added between the high pressure and medium pressure turbine extractions. These calculations showed that increasing the isentropic efficiencies of the various turbine stages towards the maximum attainable efficiency increases the amount of power generated as much as increasing the steam temperature. This shows the value of using a steam turbine designed for higher steam conditions when redesigning a boiler to produce higher temperature steam.

Table 16 shows the value of the increased power that would be produced in the three example wood-fired boilers assuming that the isentropic efficiency of the steam turbine was maintained at the higher input steam temperature.

Table 17 summarizes the calculated economic benefits of increased exit steam temperatures in all five example boilers under the previously-stated assumptions. These results indicate that very substantial 
economic benefits would accrue if biomass boilers could be designed to operate with higher superheater steam temperatures.

Table 16: Value of increased power that could be produced by raising exit steam temperatures by 50 and by 100 Celsius degrees in the three example wood-fueled boilers.

\begin{tabular}{|c|c|c|c|}
\hline \multirow{2}{*}{ Type of boiler and identifier } & \multicolumn{3}{|c|}{ Wood-fired Boiler } \\
\hline & \multicolumn{2}{|l|}{$\mathrm{C} \quad \mathrm{H}$} & M \\
\hline \multicolumn{4}{|l|}{ Parameter } \\
\hline Current power generation & 42.8MW & $27.5 \mathrm{MW}$ & $27.4 \mathrm{MW}$ \\
\hline Power generated with $50^{\circ} \mathrm{C}$ higher steam temperature & 51.2MW & 31.3MW & 31.0MW \\
\hline \multirow{2}{*}{ Additional power generated } & $+8.4 \mathrm{MW}$ & $+3.8 \mathrm{MW}$ & $+3.6 \mathrm{MW}$ \\
\hline & $+19.6 \%$ & $+13.8 \%$ & $+13.1 \%$ \\
\hline Value of this additional power @\$40/MWh & $+\$ 2.94 \mathrm{~m}$ & $+\$ 1.33 \mathrm{~m} / \mathrm{y}$ & $+\$ 1.26 \mathrm{~m} / \mathrm{y}$ \\
\hline Value of this additional power @\$80/MWh & $+\$ 5.87 \mathrm{~m}$ & $+\$ 2.66 \mathrm{~m} / \mathrm{y}$ & $+\$ 2.52 \mathrm{~m} / \mathrm{y}$ \\
\hline $\begin{array}{l}\text { Reduced volume of steam generated with } 50^{\circ} \mathrm{C} \text { higher steam } \\
\text { temperature }\end{array}$ & $3.22 \mathrm{~kg} / \mathrm{s}$ & $2.18 \mathrm{~kg} / \mathrm{s}$ & $2.2 \mathrm{~kg} / \mathrm{s}$ \\
\hline Power generated with $100^{\circ} \mathrm{C}$ higher steam temperature & 58.8MW & 34.9MW & 34.3MW \\
\hline \multirow[t]{2}{*}{ Additional power generated } & $+16.0 \mathrm{MW}$ & $+7.4 \mathrm{MW}$ & $+6.9 \mathrm{MW}$ \\
\hline & $+37.3 \%$ & $+26.9 \%$ & $+25.1 \%$ \\
\hline Value of this additional power @\$40/MWh & $+\$ 5.59 \mathrm{~m} / \mathrm{y}$ & $+\$ 2.59 \mathrm{~m} / \mathrm{y}$ & $+\$ 2.41 \mathrm{~m} / \mathrm{y}$ \\
\hline Value of this additional power @\$80/MWh & $+\$ 11.18 \mathrm{~m} / \mathrm{y}$ & $+\$ 5.17 \mathrm{~m} / \mathrm{y}$ & $+\$ 4.82 \mathrm{~m} / \mathrm{y}$ \\
\hline $\begin{array}{l}\text { Reduced volume of steam generated with } 100^{\circ} \mathrm{C} \text { higher steam } \\
\text { temperature }\end{array}$ & $8.09 \mathrm{~kg} / \mathrm{s}$ & $4.15 \mathrm{~kg} / \mathrm{s}$ & $4.2 \mathrm{~kg} / \mathrm{s}$ \\
\hline
\end{tabular}

Table 17: Summary of calculated value of additional power generated by raising exit steam temperatures by 50 and 100 Celsius degrees

\begin{tabular}{|c|c|c|c|c|c|}
\hline \multirow{2}{*}{ Parameter } & \multicolumn{2}{|c|}{ Recovery Boilers } & \multicolumn{3}{|c|}{ Biomass Boilers } \\
\hline & $\mathrm{B}$ & $\mathrm{M}$ & $\mathrm{C}$ & $\mathrm{H}$ & $\mathrm{M}$ \\
\hline \multicolumn{6}{|l|}{$+50^{\circ} \mathrm{C}$ steam } \\
\hline Increased value @\$40/MWh & $+\$ 1.54 \mathrm{~m}$ & $+\$ 2.52 \mathrm{~m} / \mathrm{y}$ & $+\$ 2.94 \mathrm{~m} / \mathrm{y}$ & $+\$ 1.33 \mathrm{~m} / \mathrm{y}$ & $+\$ 1.26 \mathrm{~m} / \mathrm{y}$ \\
\hline Increased value@\$80/MWh & $+\$ 3.08 \mathrm{~m}$ & $+\$ 5.05 \mathrm{~m} / \mathrm{y}$ & $+\$ 5.87 \mathrm{~m} / \mathrm{y}$ & $+\$ 2.66 \mathrm{~m} / \mathrm{y}$ & $+\$ 2.52 \mathrm{~m} / \mathrm{y}$ \\
\hline \multicolumn{6}{|l|}{$+100^{\circ} \mathrm{C}$ steam } \\
\hline Increased value @\$40/MWh & $+\$ 2.45 \mathrm{~m} / \mathrm{y}$ & $+\$ 4.45 \mathrm{~m} / \mathrm{y}$ & $+\$ 5.59 \mathrm{~m} / \mathrm{y}$ & $+\$ 2.59 \mathrm{~m} / \mathrm{y}$ & $+\$ 2.41 \mathrm{~m} / \mathrm{y}$ \\
\hline Increased value@\$80/MWh & $+\$ 4.91 \mathrm{~m} / \mathrm{y}$ & $+\$ 8.90 \mathrm{~m} / \mathrm{y}$ & $+\$ 11.18 \mathrm{~m} / \mathrm{y}$ & $+\$ 5.17 \mathrm{~m} / \mathrm{y}$ & $+\$ 4.82 \mathrm{~m} / \mathrm{y}$ \\
\hline
\end{tabular}

The magnitude of the increased power generated at higher temperatures in these calculations is similar to that published by groups in Sweden [125] and Denmark [126]. Stålenheim and Henderson [125] have presented similar plots of the increase of electrical efficiency with final steam temperature at various steam pressures in advanced steam cycle units. Kamuk ([126] commented that the electrical efficiency of biomass-fueled boiler systems is typically limited to about 35\%, compared to about $49 \%$ for coal fired boiler systems, because of superheater corrosion. She also noted that achieving higher steam conditions is the key to raising electrical efficiency.

The most attractive route to achieving higher steam temperatures appears to be to identify new superheater alloys or composite tube materials that can resist corrosion and creep in the flue gas and fuel ash environment around superheater tubes in biomass boilers. If suitable tubing were installed in the hottest portions of a biomass-fueled boiler's superheater, the boiler owner would make a net profit if the additional cost of this tubing did not exceed the value of the additional steam generated. For example, if 5 meters of high alloy tubing were installed in each of ten superheater loops in 45 platens (for a total of 2,250 meters) and served for 5 years before being replaced, tubing costs of less than $\$ 5,378$ to $\$ 24,911$ 
per meter would more than pay for a 100 Celsius degree increase in steam temperature. Current costs of superheater tubing are about two orders of magnitude lower than the lowest of these estimates of the justifiable cost. To gain the full financial advantage of tubes designed for a five-year replacement life, it would be useful to also design the superheater for rapid replacement. It was noted in an earlier publication [3] that the superheater of a 67 MW waste-fired boiler operated by the City of Amsterdam, which had been designed for rapid replacement, was recently replaced in 48 hours, from fire-to-fire.

A second route to enabling higher steam conditions would be to chemically treat the biomass fuel to remove corrosive components before or during combustion. This could involve diluting a corrosive biomass fuel with a less-corrosive fuel, leaching corrosives out of biofuels. ${ }^{3}$ or using additives (such as ammonium sulfate or $\mathrm{SO}_{2}$ ) that convert alkali chlorides to less corrosive sulfates, or additives such as kaolin (40-60 wt\% $\mathrm{Al}_{2} \mathrm{O}_{3} \cdot \mathrm{SiO}_{2}$ ) that convert alkali salts to less-corrosive silicates. More details about these approaches is available [3]. If the corrosivity of the biomass fuel could be reduced by pre-treatment or by combustion additives, the fuel processing would have to cost less than $\$ 2,420,000$ to $\$ 11,210,000$ per year to justify the increased value of the power generated by producing steam 100 Celsius degrees hotter than current values.

Other approaches to enabling higher steam conditions that have been implemented in Europe [3] involve re-designing biomass-fueled boilers to maximize the service life of superheater tubes by separating the superheater tubes from the corrosive fly ash (either by adding an empty pass between the furnace and the superheater or by condensing the fly ash on low temperature tubes in a "Chlorine Trap"), by increasing the superheater temperature above the dew point temperature of corrosive components of the fly ash, by moving the superheater of a circulating fluidized bed boiler (CFB) out of the flue gas passage into the recirculated fluidizing medium and by using an external superheater fired by a less-corrosive fuel. With the current abundance and relatively low cost of natural gas in the United States, this last approach appears particularly attractive. To justify the financial benefit of the increased power production provided by a 100 Celsius degree steam temperature increase within 5 years, the capital costs of boiler design changes would have to be less than $\$ 12,000,000$ to $\$ 56,000,000$. The magnitude of these financial gains associated with increased steam temperatures appears to justify substantial boiler redesign or fuel treatment.

\subsubsection{Issues Raised By Simplifying Assumptions}

We will now review the credibility of the simplifying assumptions that were used to calculate the potential benefits of increased steam conditions. The first assumption, that the existing turbine could handle the higher temperature steam, is probably not true. Steam turbines have designs and materials of construction optimized for particular steam conditions and the calculations described above for Recovery Boiler $\mathrm{M}$ indicate that the efficiency of an existing turbine would be substantially lower if it operated with a steam temperature 100 Celsius degrees higher than its design conditions. Substantial infusions of capital could be required to simultaneously upgrade both biomass-fueled boilers and their turbines to take advantage of the increased power generation potential of hotter steam. However we have shown above that the value of the additional steam generated would more than justify the cost of any foreseeable corrosion-resistant alloy tubing and that the increased cost of a turbine designed to handle higher temperature steam could probably be paid off by the value of the additional steam generated in one or two years. New biomass-fueled boilers are being built every year and will very likely be designed for efficient combustion and efficient steam generation, following the approaches discussed here.

\footnotetext{
${ }^{3}$ Although water leaching is claimed to remove $>80 \%$ of the potassium and sodium and $>90 \%$ of the chlorine from some biomass fuels, the process is not yet economic because of the cost of subsequent drying of the fuel (1).
} 
The second assumption in the calculations is that the heat produced by the combustion of the fuel remains unchanged. This assumption appears reasonable. The firing of the fuel in the furnace and the volume of water supplied to the boiler would not be changed, but the steam would be heated to a higher final temperature in the superheater. The final steam temperature would be raised by extracting more heat in the superheater, most likely by redesigning the superheater to add more heat transfer surface. Increasing the heat transfer surface in the superheater would require installing additional tube platens or extending the existing platens. Although the costs of this type of rebuild are highly plant-specific, the financial calculations suggest that these capital costs could be paid for by two to five years of additional power production. The third assumption - that the product of the steam enthalpy and the steam flow would be unchanged - is closely related to the second. This assumes that the amount of heat transferred to the steam is unaffected by raising the final temperature of the steam. This assumption also seems reasonable.

The fourth assumption in the calculations is that the amount of steam extracted from the turbine for process heating would remain constant. The provision of process steam is a critical function of CHP turbine generators. However, we noted above that raising the final temperature of steam in a boiler reduces the total volume of the steam produced. In condensing turbines, it may be possible to adjust the extraction flows so as to maintain the existing requirements for process steam while reducing the steam flow to the surface condenser. Table 18 shows calculations of the steam flows in the turbines used by Recovery Boilers $\mathrm{B}$ and $\mathrm{M}$ as the temperature of the steam delivered by the boiler is raised by 50 and by 100 Celsius degrees above current operating conditions. The total volume of steam produced falls by $6.6 \%$ in boiler B and by $7.2 \%$ in boiler $\mathrm{M}$ as the temperature is raised by 100 Celsius degrees.

Fortunately, for both of these boilers, it would be possible to maintain the flows of medium and low pressure steam from the turbine by reducing the volume of steam exhausted to the surface condenser (Table 25).

Table 18: Calculations of redirected steam flows in the steam turbines of Recovery Boilers $B$ and $M$ as the inlet steam temperature is raised by 50 and by 100 Celsius degrees.

\begin{tabular}{|l|c|l|l|l|l|l|}
\hline \multirow{2}{*}{$\begin{array}{l}\text { Recovery } \\
\text { Boiler }\end{array}$} & Case & \multicolumn{6}{|l|}{ Steam Flow, kg/sec } \\
\cline { 2 - 7 } & & $\begin{array}{l}\text { HP } \\
\text { Extraction }\end{array}$ & $\begin{array}{l}\text { MP } \\
\text { Extraction }\end{array}$ & $\begin{array}{l}\text { LP } \\
\text { Extraction }\end{array}$ & Exhaust & Total \\
\hline B & Current operation & 0 & 8.82 & 63.76 & 19.22 & 91.80 \\
\hline B & $+50^{\circ} \mathrm{C}$ steam & 0 & 8.82 & 63.76 & 16.04 & 88.62 \\
\hline B & $+100^{\circ} \mathrm{C}$ steam & 0 & 8.82 & 63.76 & 13.12 & 85.70 \\
\hline M & Current operation & 0 & 39.31 & 48.26 & 14.11 & 101.68 \\
\hline M & $+50^{\circ} \mathrm{C}$ steam & 0 & 39.31 & 48.26 & 10.27 & 97.84 \\
\hline M & $+100^{\circ} \mathrm{C}$ steam & 0 & 39.31 & 48.26 & 6.82 & 94.39 \\
\hline
\end{tabular}

The three wood-fueled boilers in this study all use non-condensing, back-pressure turbines. These have no exhaust flow to make up for the reduced volume of hotter steam that would be produced if their final steam temperature was increased. The steam flow calculations for these turbines presented in Table 19 are similar to those for the condensing recovery boiler turbines in Table 18. As with the recovery boilers, the total volume of steam produced falls as the final steam temperature is raised. This would reduce the total steam flow by $6.76 \%$ in boiler $\mathrm{C}$, by $6.93 \%$ in boiler $\mathrm{H}$ and by $6.94 \%$ in boiler $\mathrm{M}$. The steam flows from the various turbine extraction points would be correspondingly reduced. Although a pulp and paper mill that has implemented substantial energy savings since its non-condensing turbine was installed might be able to operate with these reduced flows of process steam, this will generally not be possible. However, three other approaches could be used to maintain the volumes of process steam while still obtaining the benefits of increased power generation. Probably the most economic would be to attemperate the steam either by a water spray or by passing some of it through a heat exchanger cooled by 
boiler feedwater. Other approaches would be to fire slightly more wood fuel in the boiler or to purchase a small amount of make-up steam from another source.

Table 19: Calculations of steam flow reductions in the steam turbines of Biomass-Fueled Boilers $C, H$ and $M$ as the inlet steam temperature is raised by 50 and 100 Celsius degrees.

\begin{tabular}{|l|l|l|l|l|l|l|}
\hline \multirow{2}{*}{$\begin{array}{l}\text { Biomass } \\
\text { Boiler }\end{array}$} & \multicolumn{5}{|l|}{ Steam Flow, kg/sec } \\
\cline { 2 - 7 } & Case & $\begin{array}{l}\text { HP } \\
\text { Extraction }\end{array}$ & $\begin{array}{l}\text { MP } \\
\text { Extraction }\end{array}$ & $\begin{array}{l}\text { LP } \\
\text { Extraction }\end{array}$ & Exhaust & Total \\
\hline $\mathrm{C}$ & Current operation & 0.00 & 15.12 & 104.58 & 0.00 & 119.70 \\
\hline $\mathrm{C}$ & $+50^{\circ} \mathrm{C}$ & 0.00 & 14.59 & 100.89 & 0.00 & 115.48 \\
\hline $\mathrm{C}$ & $+100^{\circ} \mathrm{C}$ & 0.00 & 14.10 & 97.51 & 0.00 & 111.61 \\
\hline $\mathrm{H}$ & Current operation & 0.00 & 15.00 & 44.99 & 0.00 & 59.99 \\
\hline $\mathrm{H}$ & $+50^{\circ} \mathrm{C}$ & 0.00 & 14.45 & 43.35 & 0.00 & 57.80 \\
\hline $\mathrm{H}$ & $+100^{\circ} \mathrm{C}$ & 0.00 & 13.96 & 41.87 & 0.00 & 55.83 \\
\hline $\mathrm{M}$ & $\mathrm{Current}$ operation & 15.12 & 6.05 & 39.31 & 0.00 & 60.48 \\
\hline $\mathrm{M}$ & $+50^{\circ} \mathrm{C}$ & 14.57 & 5.83 & 37.88 & 0.00 & 58.28 \\
\hline $\mathrm{M}$ & $+100^{\circ} \mathrm{C}$ & 14.07 & 5.63 & 36.58 & 0.00 & 56.28 \\
\hline
\end{tabular}

\subsubsection{Environmental Benefits of Higher Steam Conditions}

Increasing the energy efficiency of biomass-fueled boilers would directly improve energy efficiency in all industries that use biomass fuels. In addition, improvements in energy efficiency would make renewable fuels more attractive as replacements for fossil fuels.

Assuming there are at least 500 biomass-fired boilers in the U.S. that could be converted within a ten-year period to operate with final steam temperatures 100 Celsius degrees above current conditions and that the additional energy generated would replace energy currently produced from fossil fuels. The cumulative savings resulting from use of biomass instead of a natural gas for this incremental increase in energy would be as shown in Tables 20 and 21. These calculations assume that power production would increase $25 \%$ with a $100^{\circ} \mathrm{C}$ increase in final steam temperature, based on the increases calculated in Tables 14 and 15 above.

Table 20: Cumulative energy benefits from using additional energy produced in improved biomass-fired boilers to displace energy from fossil (natural gas) fired boilers

\begin{tabular}{|l|l|l|}
\hline & Year 2020 & Year 2025 \\
\hline Total primary energy displaced & 268 trillion Btus & 1,406 trillion Btus \\
\hline Cumulative economic benefit & $\$ 1.5$ billion/yr & $\$ 8.5$ billion/year \\
\hline
\end{tabular}

Table 21: Cumulative environmental benefits from using additional energy produced in improved biomass-fired boilers to displace energy from fossil (natural gas) fired boilers

\begin{tabular}{|l|l|l|}
\hline & Year 2020 & Year 2025 \\
\hline $\mathrm{CO}_{2}$ emissions displaced (C equivalent) & 5.3 million tons & 27.4 million tons \\
\hline $\mathrm{NO}_{\mathrm{x}}$ reductions & 47,000 metric tons & 243,000 metric tons \\
\hline
\end{tabular}

Replacing fossil fuel boilers with renewable fuel boiler would also bring substantial economic benefits. Assuming that state-of-the-art biomass-fired boilers could economically replace fossil fuel units, then for 500 installed units with a $2 \%$ growth rate per year, an ultimate potential accessible market of $90 \%$ and a likely technical market share of $90 \%$, there could be $21 \%$ market penetration in 2020 and $71 \%$ penetration 
in 2025. The savings shown in the Table 22 and 23 are based on the replacement of fossil fuel (natural gas) fired boilers.

Table 22: Cumulative energy benefits from replacing natural gas fired boilers with biomass-fired boilers

\begin{tabular}{|l|l|l|}
\hline & Year 2020 & Year 2025 \\
\hline Total primary energy displaced & 160 trillion Btus & 866 trillion Btus \\
\hline Cumulative economic benefit & $\$ 774$ million/yr & $\$ 4,300$ million/yr \\
\hline
\end{tabular}

Table 23: Cumulative environmental benefits from replacing fossil fuel (natural gas) fired boilers with biomass-fired boilers

\begin{tabular}{|l|l|l|}
\hline & Year 2020 & Year 2025 \\
\hline $\mathrm{CO}_{2}$ emissions displaced (C equivalent) & 2.31 million tons & 12.5 million tons \\
\hline $\mathrm{NO}_{\mathrm{x}}$ reductions & 17,000 metric tons & 92,000 metric tons \\
\hline
\end{tabular}

\subsubsection{Discussion and Conclusions}

It was noted earlier that biomass-fueled boilers typically operate with electrical efficiencies about 35\%, substantially lower than that those of coal-fired units [126] because their final steam conditions are limited in order to restrict fireside corrosion of the superheater tubes. In Europe, where the development of power from renewable fuels has been defined as a strategic priority by many nations, innovative approaches have been developed to improve the efficiency of biomass-fueled boilers, not only by identifying alloys with greater corrosion resistance [4], but also by using combinations of design modifications, process modifications and corrosion-resistant alloys to enable higher steam conditions [3].

The calculations presented here using data from two recovery boilers and three wood-fired boilers suggest that the value of the increased power that could be generated if the steam in a biomass-fired boiler could be heated 50 Celsius degrees above current operational temperatures would be worth between about $\$ 1,260,000$ and $\$ 5,890,000$ per year. If the steam could be heated 100 Celsius degrees above current operational temperatures, the increased value of the power generated would be between about $\$ 2,420,000$ and $\$ 11,210,000$ per year. Gains for other biomass-fueled boilers would depend on local plant conditions and the price of power. The calculations indicate that the increased steam value could justify the use of corrosion resistant alloys costing orders of magnitude more than current superheater alloys if the use of more corrosion-resistant alloys were coupled with the introduction of superheater designs that allowed very rapid superheater replacement.

Most modern wood-fired boilers in Europe also incorporate design improvements to remove corrosive fly ash before it reaches the superheater, or to remove the superheater from the flue gas path altogether. Given the likelihood of relatively low natural gas prices for many years, the option of installing an external superheater fired by this less-corrosive fuel seems a particularly attractive route to higher superheated steam temperatures. To achieve a five-year payback, a boiler redesign and rebuild to achieve a 100 Celsius degree steam temperature increase would have to cost less than $\$ 12,000,000$ to $\$ 56,000,000$. A wood-fired boiler at Nässjö near Jönköping in Sweden, which has its superheater located in the loop seal, already operates with a steam temperature of $540^{\circ} \mathrm{C}$ and another boiler with a loop seal superheater at Avedøre in the suburbs of Copenhagen, Denmark which fires coal with straw containing up to $1 \%$ chloride, already operates with a steam temperature of $580^{\circ} \mathrm{C}$ [3].

Another approach used widely in Europe to achieve higher superheated steam temperatures in biomassfueled boilers without excessive corrosion is the use of combustion additives to convert (corrosive) potassium chloride into less-corrosive sulfates or silicates. The increased value of higher steam conditions could offset the cost of such corrosion control additives. 
Although the costs and benefits of achieving higher superheated steam conditions in specific biomassfueled boilers depend on local conditions, the magnitude of the increased power that can be generated by increasing superheated steam temperatures are so substantial that ongoing studies of technical pathways to achieving substantial steam temperature increases (such as the 100 Celsius degree increase studied in the current project) are likely to pay substantial dividends. The most economic pathways to higher steam temperatures will almost certainly involve combinations of more corrosion-resistant alloys and either boiler redesign or the removal of the superheater from the flue gas path. 


\section{BENEFITS ASSESSMENT AND COMMERCIALIZATION}

The objective of this project was to determine if there are approaches that could be used to make it technically and economically feasible to operate biomass-fired boilers at temperatures 100 Celsius degrees higher than the maximum temperature at which they are currently being operated. In Europe, the need to meet emission requirements and disposal restrictions has forced evaluation and introduction of alternate boiler designs that operate at higher efficiencies. In North America, regulations are less demanding, and, consequently, boiler operators have not been forced to aggressively pursue ways to get more efficient boiler operation.

The results of this project establish that there are alternate superheater designs as well as alternate alloys that would permit construction of biomass-fired boilers that would operate at higher than current temperatures. This would result in more efficient boiler operation. Calculations show that, even without strict emission regulations and disposal restrictions, there is a strong financial incentive for boiler operators to consider modifications of current biomass boilers and to utilize design modifications and/or alternate superheater alloys in any new biomass boilers.

For the results of this study to be put into commercial practice, it is essential to get this information to boiler designers, fabricators and operators as well as tube/alloy producers. The four boiler fabricators, eight boiler operators and six alloy/tube producers have been involved in the project from the beginning through the completion of the project. They participated in the selection of sample materials and test conditions for the laboratory tests, they provided guidance and recommendations for the selection of sample materials and exposure sites for the field tests, and they provided data for the calculations of economic benefits. In addition they participated in the project's annual review meetings and received copies of the quarterly reports. Consequently, these project partners were very knowledgeable about what was being done on the project. In addition, wider distribution of the project's results has been made through the papers which have been presented at conferences and published in conference proceedings.

The calculations made for two recovery boilers and three wood-fired boilers show the value of the increased power that could be generated if the steam in a biomass-fired boiler could be heated 50 Celsius degrees above current operational temperatures would be worth between about $\$ 1,260,000$ and $\$ 5,890,000$ per year. If the steam could be heated 100 Celsius degrees above current operational temperatures, the increased value of the power generated would be between about $\$ 2,420,000$ and $\$ 11,210,000$ per year. Gains for other biomass-fueled boilers would depend on local plant conditions and the price of power. These calculations indicate that the increased steam value could justify the use of corrosion resistant alloys costing orders of magnitude more than current superheater alloys. The financial gains could, alternatively, be used for use of more corrosion-resistant alloys coupled with the introduction of combustion additives as well as use of an alternative superheater design such as one that allowed very rapid superheater replacement.

Adoption of the results of this project will probably not be rapid. For any new boiler, designers would need to consider the type of contaminants in the fuel as well as the facility's steam requirements. In addition, the capacity and temperature limitations of the turbine can be addressed. For retrofits, each facility's steam requirements and turbine limitations will have to be considered. There are clear financial benefits to making changes that would enable operation at 100 Celsius degrees higher temperature, but an investment would have to be made in the alternate technologies or materials before the benefits could be realized.

Although the costs and benefits of achieving higher superheated steam conditions in specific biomassfueled boilers depend on local conditions, the magnitude of the increased power that can be generated by increasing superheated steam temperatures are so substantial that ongoing studies of technical pathways 
to achieving substantial steam temperature increases (such as the 100 Celsius degree increase studied in the current project) are likely to pay substantial dividends. 


\section{ACCOMPLISHMENTS}

The accomplishments associated with this project include nine conference presentations/publications including one paper that received the conference's Best Paper Award. In addition, the thesis "Recovery Boiler Superheater Corrosion - Solubility of Metal Oxides In Molten Salt” was submitted in partial fulfillment of the requirements for a Master’s Degree.

Publications

- W.B.A. (Sandy) Sharp, “Superheater Corrosion In Biomass Boilers: Today’s Science and Technology”, ORNL/TM-2011/399, September 30, 2010.

- W.B.A. (Sandy) Sharp, D.L. Singbeil and J.R. Keiser, "Energy from Biomass - Lessons from European Boilers” Proceedings of 2011 TAPPI PEERS Conference, Portland, OR, published by TAPPI Press, Atlanta, GA 2011.

- W.B.A. (Sandy) Sharp, Douglas L. Singbeil and James R Keiser, "Superheater Corrosion Produced By Biomass Fuels”, Paper No. C2012-0001308, published by NACE International, Houston, TX, 2012.

- James R. Keiser, W. B. A. (Sandy) Sharp, Douglas L. Singbeil, Laurel A. Frederick, and Curtis Clemmons, "Performance of Alternate Superheater Materials in a Potassium-rich Recovery Boiler Environment”, Proceedings of 2012 TAPPI Peers Conference, Savannah, GA, October 2012, published TAPPI Press, Atlanta, GA, 2012.

- Douglas L Singbeil and Laurie Frederick, “Improving Heat Recovery in Biomass-Fired Boilers Corrosion of Superheater Tube Materials for High Temperature Black Liquor and Bark-fired Boilers", Final Report ORNL Subcontract 4000089243, December 2012.

- James R Keiser, W.B.A. (Sandy) Sharp and Douglas L. Singbeil, "Performance Of Alternate Superheater Tube Materials In Extreme Boiler Environments", presented at the $8^{\text {th }}$ International Black Liquor Colloquium: Black Liquor and Biomass to Bioenergy and Biofuels, Belo Horizonte, Brazil, May, 2013.

- Douglas L Singbeil, Laurie A Frederick, James R Keiser, and W.B.A. (Sandy) Sharp, “Could BiomassFueled Boilers Be Operated At Higher Steam Temperatures? 1. Laboratory Evaluation Of Candidate Superheater Alloys” Proceedings of 2013TAPPI PEERS Conference, Green Bay, WI, September, 2013. - James R. Keiser, W.B.A. (Sandy) Sharp and Douglas L. Singbeil, “Could Biomass-Fueled boilers be Operated at Higher Steam Temperatures? 2. Field Tests of Candidate Superheater Alloys," to be published by TAPPI Press, Atlanta, GA 2011 in Proceedings of 2013 TAPPI PEERS Conference, Green Bay, WI, September, 2013.

- W.B.A. (Sandy) Sharp, W. J. (Jim) Frederick, James R Keiser and Douglas L Singbeil, “Could Biomass-Fueled Boilers Be Operated At Higher Steam Temperatures? 3. Initial Analysis Of Costs And Benefits” Proceedings of 2013TAPPI PEERS Conference, Green Bay, WI, September, 2013.

\section{Best Paper Award}

The paper presented at the 2012 TAPPI conference (James R. Keiser, W.B.A. (Sandy) Sharp, Douglas L. Singbeil, Laurie A Frederick and Curtis Clemmons, "Performance Of Alternate Superheater Materials In A Potassium-Rich Recovery Boiler Environment” Proceedings of 2012 TAPPI PEERS Conference, Savannah, GA, October, 2012) received the Joseph Wolf Founders Best Paper Award. As a result, this paper is scheduled for publication in the July 2013 issue of TAPPI Journal.

Thesis

A Master's Degree thesis titled "Recovery Boiler Superheater Corrosion - Solubility of Metal Oxides In Molten Salt" was submitted by Joseph Meyer in partial fulfillment of the requirements for a Master of Science Degree in Materials Science and Engineering from the Georgia Institute of Technology. 


\section{CONCLUSIONS AND RECOMMENDATIONS}

The objective of this project was to determine what would be the financial benefits and superheater materials issues from operating biomass-fired boilers with outlet steam temperatures 100 Celsius degrees higher than currently used.

The laboratory and field corrosion studies showed there are materials that appear capable of operating under the particularly hostile conditions used in these studies. The two studies did not always agree on which were the most suitable alloys for specific environments. However, it has to be recognized that the laboratory tests were conducted at well controlled temperatures in a carefully controlled environment selected to simulate field conditions as much as possible. In the field tests the environments were realistic but did not remain constant, and significant temperature variations occurred very frequently. Consequently, some difference in results between the two test methods should not be surprising. Nevertheless, it is clear that alloys with sufficient corrosion resistance are available.

Calculations of the financial benefits of higher steam temperatures were made using conditions of five biomass boilers, and these calculations showed that very substantial gains could be realized in power recovered and, therefore, in monetary benefits. The magnitude of this increased power that can be generated by increasing superheated steam temperatures are so substantial that ongoing studies of technical pathways to achieving substantial steam temperature increases (such as the 100 Celsius degree increase studied in the current project) are likely to pay substantial dividends. The most economic pathways to higher steam temperatures will almost certainly involve combinations of more corrosionresistant alloys and either boiler redesign or the removal of the superheater from the flue gas path.

A next step that should be considered is the installation of tubes of selected alloys in the superheater area of one of these "hostile" boilers using the configuration of the current superheater tubes but with cooling of the experimental tubes controlled so that the tube temperatures remain at about 100 Celsius degrees above the temperature of the other tubes. A demonstration of this type would provide more evidence to boiler designers, manufacturers and operators of the corrosion resistance of alternate tube alloys. 


\section{REFERENCES}

1.Craig Reid, Acuren, personal communication to Joey Kish and Doug Singbeil, April, 2007. 2. James R Keiser, Joseph R Kish, Laurie A Frederick, Adam W Willoughby, Limberly A Choudhury, Douglas L Singbeil, François R Jetté and J Peter Gorog, "Recovery Boiler Superheater Corrosion Studies”. Proceedings of International Chemical Recovery Conference, Quebec City, Quebec, May 29June 1, 2007.

3. W.B.A.(Sandy) Sharp, D.L. Singbeil and J.R. Keiser, "Energy from Biomass - Lessons from European Boilers”, Proceedings of 2011 TAPPI PEERS Conference, Portland, Oregon, October, 2011, published TAPPI Press, Atlanta, GA, 2011.

4. W.B.A. (Sandy) Sharp, Douglas L. Singbeil and James R Keiser, "Superheater Corrosion Produced By Biomass Fuels”, Paper No. C2012-0001308, published by NACE International, Houston, TX, 2012.

5. W.B.A. (Sandy) Sharp, "Superheater Corrosion in Biomass Boilers: Today’s Science and Technology”, ORNL/TM-2011/399, September 30, 2010.

6. Timo Jantti, Juha Sarkki and Harry Lampenius, "The utilization of CFB technology for large-scale biomass-firing power plants, presented at Power-Gen Europe 2010, Amsterdam, The Netherlands, June 8 - 10, 2010 and available at http://www.fwc.com/publications/tech_papers/files/TP_CFB_10_03.pdf 7.Marko Natunen, "Co-firing of REF and biofuels in a CFB plant with advanced steam parameters and a high efficiency in Igelsta plant, Sweden, presented at Power-Gen Europe 2010, Amsterdam, The Netherlands, June 8 - 10, 2010 and available at http://www.fwc.com/publications/tech_papers/files/TP_CFB_10_01.pdf.

8.Sonja Enestam, Pekka Lehtonen and Bengt Heikne, "Operating experience of the novel FBHE superheater at Norrköping energy-from-waste facility”, presented at $9^{\text {th }}$ International Conference on Circulating Fluidized Beds, in conjunction with $4^{\text {th }}$ International VGB Workshop "Operating experience with fluidized bed firing systems”, May 13-16, 2008, Hamburg, published TuTech Innovation, Hamburg, Germany.

9.Ragnar Warnecke, Bernd Benker, Christian Deuerling, Ferdinand Haider, Siegried Horn, Jürgen Maguhn, Volker Müller, Hermann Nordsieck, Barbara Waldmann and Ralf Zimmermann, "The mechanisms of corrosion and how to avoid them", presented at 5th ISWA Beacon conference on Wasteto-Energy. October 25-26, 2007, Malmö, Sweden and available at http://www.beaconwte.org/fileadmin/avfallsverige/Documentation 2007/0940 Ragner Warnecke.pdf 10.From GKS website: http://www.gkssw.de/index.php?option=com content\&task=view\&id=26\&Itemid=42 11.Anders Hjörnhede, Vattenfall Power Consultant, Racksta, Sweden, Private communication, June 28, 2010.

12.Ragnar Warnecke, "Beläge und Korrosion, Verfahrenstechnik und Konstruction in Chlor-belasteten thermischen Anlagen”, presented at VDI-Wissensforum seminar, Frankfurt, June 12-13, 2007 and available at http://www.gks-sw.de/images/stories/vdi_tagung_2007/19-vdi-wf-07-korrosionsmodell\%20\%20warnecke\%20-\%20manu.pdf

13.Niels Henriksen, Rudolph Blum and Ole Hede Larsen, "Investigations of the possibilities of influencing the corrosive environment in an external ash cooler", pages 271 to 294 in TOTem 24 conference "Challenges in the development of high efficiency combustion - the excess enthalpy combustion project”, Velsen Noord, the Netherlands, 19 March 2003, published International Flame Research Foundation, Livorno, Italy Available at: ftp://www.ifrf.net/pub/pdf/JOF3-CT95-0024-pdffiles/JOF3-CT95-0024-06-Henriksen-ElsamP.pdf

14.P.J. Henderson, P. Ljung, P. Kallner and J. Tollin, "Fireside corrosion of superheaters in a wood-fired circulating fluidized bed boiler”, EUROCORR 2000 conference, September 10-14, 2000, London, U.K., published Institute of Materials, Minerals and Mining, London, 2000.

15. "Supercritical steam comes to CFBs", Materials and Components in Fossil Energy Applications, published U. S. Department of Energy's Office of Fossil Energy Advanced Research Materials Program, Winter 2003, No. 161, pages 6-7. 
16.Reijo Simonen, “Under Control”, published Metso, Tampere, Finland, September 23, 2009 and available at http://www.metso.com/automation/results_articles_ep.nsf/WebWID/WTB-091119-225706EE29?OpenDocument\&mid=294A0747A7A03CA6C22570C8003BF464

17.Anna Nafari and Anders Nylund, "Erosion corrosion of tubes in the loop seal of a biofuel boiler fired CFB plant”, $7^{\text {th }}$ Liege Conference on Materials for Advanced Power Engineering, Liege, Belgium, September 30 - October 2, 2002, published as Materials for advanced power engineering 2002 Schriften des Forschungszentrum, Jülich, Germany, 2002.

18.Anna Nafari and Anders Nylund, "Field study on superheater tubes in the loop seal of a wood-fired CFB plant”, Materials and Corrosion, $\underline{55}$ (12), 909-920, 2004.

19.S. Rajaram, “Next Generation CFBC”, Chemical Engineering Science, 54, pages 5565-5571, 1999. 20.Dong Energy, “The Enstedværket CHP Plant”, available at http://www.dongenergy.com/SiteCollectionDocuments/business_activities/generation/Enstedværket_UK[ 1].pdf

21.Peter A. Jensen, Flemming J. Frandsen, Jern Hansen, Kim-Dam-Johansen, Niels Henriksenand Stefan Hörlyck, "SEM investigation of Superheater deposits from biomass-fired boilers", Energy Fuels, 18 (2), 378-384, 2004.

22."Boiler 15: an investment in cogeneration for sustainable energy solutions”, published E.ON Värme Sverige, Sweden and available at http://www.eon.se/upload/eon-se-2-0/dokument/broschyrarkiv/inenglish/H\%C3\%A4ndel\%C3\%B6\%20cogeneration\%20plant.pdf

23."Value from waste: waste-fired power plant - the new standard for recovery of sustainable energy, metals and building materials for urban waste,” published Afval Energie Bedrijf, Amsterdam, the Netherlands, 2006.

24.Frans Lamers, “Corrosion experiences after two years operating the Amsterdam plant”, presented at ISWA Beacon Conference 2009, Malmö, Sweden, November 24, 2009, published International Solid Waste Association, Vienna, Austria, 2009. Available at http://www.beaconwte.org/fileadmin/avfallsverige/Documentation_2009/F_Lamers.pdf

25.E. Skog, L-G. Johansson, J-E. Svensson, J. Petterson, C. Petterson, N. Folkeson, "Why does bio-mass and waste cause severe corrosion of superheater tubes?”, $33^{\text {rd }}$ International Technical Conference on Clean Coal \& Fuel Systems, Clearwater, FL, June 2008, published Coal Technologies Associates, North Potomac, MD, 2008.

26.K. Segerdahl, J. Pettersson, J-E. Svensson and L-G. Johansson, "Is KCl(g) corrosive at temperatures above its dew point? Influence of $\mathrm{KCl}(\mathrm{g})$ on initial stages of high temperature corrosion of $11 \% \mathrm{Cr}$ Steel at $600^{\circ} \mathrm{C}$," Materials Science Forum, 461-464, 109-116, 2004.

27.C. Pettersson, J-E, Svensson and L-G Johansson, "Corrosivity of $\mathrm{KCl}(\mathrm{g})$ at temperatures above its dew point - Initial stages of the high temperature corrosion of Alloy Sanicro 28 at $600^{\circ} \mathrm{C}$ ”, Materials Science Forum, 522-523, pp 539-546, 2006.

28.Marko Palonen, Pekka Lehtonen and Tero Luomaharju, "Increase of steam data with challenging fuels”, October 8, 2009. Available as www.processeng.biz/iea-fbc.org/upload/59_3_Palonen.pdf. 29.Ana Žbogar, Peter A. Jensen, Flemming J. Frandsen, Jern Hansen and Peter Glarborg, "Experimental investigation of ash deposit shedding in a straw-fired boiler”, Energy Fuels, 20 (2), 512-519, 2006. 30.M. Montgomery, Søren A. Jensen, Annette Hansson, Ole Biede and Tommy Vilhelmsen, "High temperature corrosion testing at Maribo Sakskøbing and Avedøre straw firing power plants”, Manuscript associated with poster SS 2-P-7984 at EUROCORR European Corrosion Congress, Nice, France, 6-10 September, 2009.

31.Paul Kilgallon, Nigel Simms and John Oakey, "Modeling corrosion in biomass-fired power plants", Paper 05318 at NACE International CORROSION/2005 conference, April 3-7, Houston, TX, published NACE, Houston, TX, 2005.

32.D.C. Dayton, B.M. Jenkins, S.Q. Turn, R.R. Baker, R.B. Williams and D. Belle-Oudry and L.M. Hill, "Release of inorganic constituents from leached biomass during thermal conversion”, Energy Fuels, $\underline{13}$ (4), 860-870, 1999.

33.P.A. Jensen, B. Sander and K. Dam-Johansen, "Pretreatment of straw for power production by 
pyrolysis and char wash”, Biomass and Bioenergy, 20 (6), 431-446, 2001.

34.P.A. Jensen, B. Sander and K. Dam-Johansen, "Removal of K and $\mathrm{Cl}$ by leaching of straw char", Biomass Bioenergy, 20 (6), 447-457, 2001.

35.Linda S. Johansson, Bo Leckner, Claes Tullin, Lars-Erik Åmand and Kent Davidsson, "Properties of particles in the fly ash of a biofuel-fired circulating fluidized bed (CFB) boiler”, Energy Fuels, 22 (5), 3005-3015, 2008.

36.C. Andersson, “A method for operating a heat-producing plant for burning chlorine-containing fuels”, Patent WO 02059526, August 1, 2002.

37.“Chlorout”, published Vattenfall Business Services Nordic AB, August, 2005. Available as www.vattenfall.com/en/file/chlorout_8459980.pdf.

38.Kent O. Davidsson, Klass Engvall, Magnus Hagström, John G. Korsgren, Benny Lönn and Jan B.C. Pettersson, "A surface ionization instrument for on-line measurements of alkali metal components in combustion: instrument description and applications”, Energy Fuels, 16 (6), 1369-1377, 2002.

39.P. Henderson, P. Szákalos, R. Pettersson, C. Andersson, J. Hogberg, "Reducing superheater corrosion in wood-fired boilers”, Werkstoffe, und Korrosion - Weinheim, 57 (2), 128-134, 2006.

40.Markus Broström, Håkan Kasseman, Anna Helgesson, Magnus Berg, Christer Andersson, Rainer Backman and Anders Nordin, "Sulfation of corrosive alkali chlorides by ammonium sulfate in a biomass fired CFB boiler”, Fuel Processing Technology, $\underline{88}$ (11-12), 1171-1177, 2007

41.Martti Aho, Pasi Vainikka, Raili Taipale and Patrik Yrjas, "Effective new chemicals to prevent corrosion due to chlorine in power plant superheaters", Fuel 87, 647-654, 2008.

42.M. Aho, "Method for preventing chlorine deposition on the heat transferring surface of a boiler", Finnish Patent FI117631B, December 29, 2006.

43.Michaël Becidan, Lars Serum, Flemming Frandsen and Anne Juul Pedersen, "Corrosion in waste-fired boilers: a thermodynamic study”, Fuel, 88 (4), 595-604, 2009.

44.Beatrice Coda, Martti Aho, Roland Berger and Klaus R.G. Hein, "Behavior of chlorine and enrichment of risky elements in bubbling fluidized bed combustion of biomass and waste assisted by additives", Energy Fuels, 15 (3), 680-690, 2001.

45.K.O. Davidsson, B-M. Steenari and D. Eskilsson, "Kaolin addition during biomass combustion in a 35MW circulating fluidized bed boiler”, Energy Fuels, 21 (4), 1959-1966, 2007.

46. Greg F. Weber and Christopher J. Zygarlicke, "Barrier issues to the utilization of biomass", Semiannual Technical Progress Report on US DOE Contract DE-FC26-00NT41014.

47. “Renewable energy consumption and electricity: preliminary statistics 2010”, U.S. Energy Information Administration, Office of Coal, Nuclear, Electric and Alternative Fuels, U.S. Department of Energy, Washington D.C., published June, 2011.

48. F.H. Stott, “Influences of alloy additions on oxidation”, Materials Science and Technology, August 1989, $\underline{5}$, pages 734-740.

49. W.B.A.(Sandy) Sharp, “Corrosion and Cracking in Chemical Recovery Equipment”, 2011 Kraft Recovery Course, Published TAPPI Press, Atlanta, Georgia, 2011.

50. D.C. Crowe, W.C. Youngblood, “Recovery Boiler Superheater Corrosion,” Preprints of $9^{\text {th }}$

International Symposium on Corrosion in the Pulp and Paper Industry, CPPA, Montreal, PQ, pages 225230, 1998.

51. T.N.Adams, W.J. Frederick, T.M. Grace, M. Hupa, K. Iisa, A.K. Jones and H.N. Tran, editors, “Kraft Recovery Boilers”, TAPPI Press, Atlanta, GA, 1997.

52. D. W. Reeve, D. C. Pryke and H. N. Tran, “Corrosion in the closed cycle mill”, Pages 85-90 in

Proceedings of the Fourth International Symposium on Corrosion in the Pulp and Paper Industry, published by Swedish Corrosion Institute, Stockholm, Sweden, as "Pulp and Paper Industry Corrosion Problems, Volume 4, 1983.

53. Matthew J. Estes, Institute of Paper Chemistry, Atlanta, GA, Private communication, 1989.

54. F. Bruno, “Thermochemical Aspects on Chloride Corrosion in Kraft Recovery Boilers”, Paper No. 01426 at NACE International CORROSION/2001 conference, Houston, TX, published NACE, Houston, 2001. 
55. M.Mäkipää, E, Kauppinen, T. Lind, J. Pyykönen, J. Jokiniemi, P. McKeough, M. Oksa, Th. Malkow, R.J. Fordham, D. Baxter, L. Koivisto, K. Saviharju, E. Vakkilainen, "Superheater tube corrosion in recovery boilers," 10th International Symposium on Corrosion in the Pulp and Paper Industry, Volume 1, published VTT, Espoo, Finland: 157-180, 2001.

56. J. Tuiremo, K. Salmenoja, “Control of superheater corrosion in black liquor recovery boilers” 10th International Symposium on Corrosion in the Pulp and Paper Industry, Volume 1, published VTT, Espoo, Finland: 181-200, 2001.

57. Joseph R. Kish, "Superheater corrosion and alloy performance in current generation high pressure recovery boilers”, pages 53 to 59 in Final Technical Report: Materials for Industrial Heat Recovery Systems, project period 04/01/2004 to 03/30/2007, by James R. Keiser, Joseph. R. Kish, Gorti R. Sarma, Jerry Yuan, J. Peter Gorog, Laurie A. Frederick, Francois R. Jetté, Roberta A. Meisner and Douglas L. Singbeil, December 31, 2007.

58. Esa K. Vakkilainen and Pekka Pohjanne, "Selecting the right material for recovery boiler superheaters”, Baltica VIII Conference on Life Management and Maintenance for Power Plants, Vol. 2, pages 37-51, published VTT, Espoo, Finland, 2010.

59. J. Pettersson, J-E. Svensson and L-G. Johansson, “Alkali-induced corrosion of 304-type austenitic stainless steel at $600^{\circ} \mathrm{C}$; comparison between $\mathrm{KCl}, \mathrm{K}_{2} \mathrm{CO}_{3}$ and $\mathrm{K}_{2} \mathrm{SO}_{4}$ ”, Materials Science Forum, 595598, 367-375, 2008.

60. H. Tran, Y. Arakawa, “Recovery Boiler Technology in Japan,” Paper 12-6 at TAPPI 2001

Engineering/Finishing and Converting Conference, Published TAPPI Press, Atlanta, GA, pages 49-62, 2001.

61. John L. Clement and Thomas M. Grace, "Investigation of superheater design and performance - Part 1, TAPPI Engineering, Pulping and Environmental Conference, October 11-14, 2009, Memphis, TN, 27 pages, published TAPPI Press, Atlanta, GA, 2009.

62. B-J. Skrifvars, R. Backman, M. Hupa, K. Salmenoja and E. Vakkilianen, "Corrosion of superheater steel materials under alkali salt deposits Part 1: The effect of salt deposit composition and temperature”, Corrosion Science 50, 1274-1282, 2008.

63. Rainer Backman, Mikko Hupa, Juha Lagerbom and Toivo Lepisto, "Influence of partially molten alkali deposits on superheater corrosion in black liquor recovery boilers”, $10^{\text {th }}$ International Symposium on Corrosion in the Pulp and Paper Industry, Volume 1, pages 137-155, published VTT Technical Research Center of Finland, Espoo, Finland, 2001.

64. B-J. Skrifvars, M. Westén-Karlsson, M. Hupa and K. Salmenoja, "Corrosion of super-heater materials under alkali salt deposits. Part 2: SEM analyses of different steel materials”, Corrosion Science 52, 10111019, 2010.

65. David A. Tillman, Dao Duong, Sheila Figueroa and Bruce Miller, "Chlorine in solid fuels fired in pulverized coal boilers - sources, forms, reactions and consequences: a literature review”, Fuel Conference, Banff, Canada, September 28 - October 3, 2008. Energy Fuels, 23 (7), 3379-3391, 2009. 66. Dao N.B. Duong and David A. Tillman, "Chlorine issues with biomass co-firing in pulverized coal boilers: sources, reactions and consequences - a literature review”, $34^{\text {th }}$ International Technical Conference on Coal Utilization and Fuel Systems, Clearwater FL, May 31 - June 4, 2009.

67. K. Salmenoja and K. Mäkela, "Prevention of superheater corrosion in the combustion of biofuels", Paper 00238 at NACE International CORROSION/2000 conference, published NACE, Houston, 2000. 68. Matti Hiltunen, Vesna Barišić and Edgardo Coda Zabetta, "Combustion of different types of biomass in CFB boilers", $16^{\text {th }}$ European Biomass Conference, Valencia, Spain, June 2-6, 2008.

69. Len Pinder, “Materials challenges in biomass combustion”, MATUK Energy Materials Working Group Conference, Loughborough UK, 09-10/10/2008.

70. Lars-Gunnar Johansson, Jan-Erik Svensson, Erik Skog, Jasper Pettersson, Carolina Pettersson, Nicklas Folkeson, Henrik Asteman, Torbjörn Jonsson and Mats Halvarsson, "Critical corrosion phenomena on superheaters in biomass and waste-fired boilers", Proceedings of the Sino-Swedish Structural Materials Symposium, 2007, pages 35-39. 
71. Y.Y.Lee and M.J. McNallan, “Ignition of nickel in environments containing oxygen and chlorine”, Metallurgical Trans. A, 18 (6), 1099-1107, 1987.

72. Armin Zahs, Michael Spiegel and Hans J. Grabke, "Chloridation and oxidation of iron, chromium, nickel and their alloys in chloridizing and oxidizing atmospheres at $400-700^{\circ} \mathrm{C}$ ”, Corrosion Science 42, 1093-1122, 2000.

73. J. Pettersson, J-E. Svensson and L-G Johansson, "KCl-induced corrosion of a 304-type austenitic stainless steel in $\mathrm{O}_{2}$ and in $\mathrm{O}_{2}+\mathrm{H}_{2} \mathrm{O}$ environment: The influence of temperature", Oxidation of Metals, 72 (3-4), 159-177, 2009.

74. J Pettersson, H. Asteman, J-E. Svensson and L-G. Johansson, "KCl-induced corrosion of a 304-type austenitic stainless steel at $600^{\circ} \mathrm{C}$; the role of potassium”, Oxidation of Metals $\underline{64}$ (1-2), 23-41, 2005.

75. C. Pettersson, J. Pettersson, H. Asteman, J-E. Svensson and L-G. Johansson, "KCl-induced high temperature corrosion of the austenitic Fe-Cr-Ni alloys 304L and Sanicro 28 at $600^{\circ} \mathrm{C}$ ”, Corrosion Science, 48 (6), 1368-1378, 2006.

76. J. Pettersson, C. Pettersson, N. Folkeson, L-G. Johansson, E. Skog and J-E. Svensson, "The influence of sulphur additions on the corrosive environment in a waste-fired CFB boiler”, Materials Science Forum, 522-523, 563-570, 2006.

77. N. Folkeson, L-G. Johansson and J-E. Svensson, "Initial stages of the HCl-induced high-temperature corrosion of Alloy 310”, J. Electrochem. Soc., 154 (9), C515-C521, 2007.

78. L. Paul, G. Clark and M. Eckhardt, "Laboratory and Field Corrosion Performance of a High Chromium Alloy for Protection of Waterwall Tubes from Corrosion in Low NOx Coal Fired Boilers," Paper No. 06473 at NACE International CORROSION/2006 conference, published NACE, Houston, TX, 2006.

79. K.E. Coleman, N.J.Simms, P.J. Kilgallon and J.E. Oakley, “Corrosion in biomass combustion systems”, Materials Science Forum, 595-598, 377-386, 2008.

80. Paul J. James, E.ON Engineering Group, Ratcliffe-on-Soar, UK, Private Communication, August 18, 2010.

81. M. Mäkipää, David J. Baxter, S. Sroda and M. Oksa, "Laboratory testing for evaluation of steels and alloys used in superheater area of boilers for biomass fuels”, Materials Science Forum, Volumes 461-464, (High temperature corrosion and protection of materials), pages 989-998, 2004.

82. Rachel Pettersson, Jasper Flyg and Peter Viklund, "High temperature corrosion under simulated biomass deposit conditions”, Paper 09168 at NACE International CORROSION/2009 conference, March 22-26, 2009, Atlanta, GA, published NACE, Houston, 2009.

83. K. Salmenoja, K. Mäkelä, M. Hupa and R. Backman, "Superheater corrosion in environments containing potassium and chlorine”, Journal of the Institute of Energy, 69 (480). 155-162, 1996.

84. Shang-Hsiu Lee, Nickolas J. Themelis and Marco J. Castaldi, “High temperature corrosion in wasteto-energy boilers”, Journal of Thermal Spray Technology, 16 (1), 1-7, 2007.

85. A. Wilson, U. Forsberg and J. Noble, "Experience of composite tubes in municipal waste incinerators”, Paper 97153 at NACE Corrosion/97 conference, published NACE International, Houston, TX, 1997.

86. M. Uusitalo, M. Kaipiainen, P. Vuoristo and T. Mäntylä, “High temperature erosion-corrosion of superheater materials and coatings in chlorine-containing environments", Materials Science Forum, $\underline{369-}$ 372, 475-482, 2001.

87. Satu Tuurna, Tommi Varis, Kimmo Ruusuvuori, Stefan Holmström, Jorma Salonen, Pertti Auerkari, Tuomo Kinnunen, Partik Yrjas, Risto Finne, Matti Nupponen, Ulla McNiven, Hannu Ahonen and Ari Kapulainen, "Managing corrosion in biomass boilers: benefits and limitations of coatings", Baltica VIII Conference on Life Management and Maintenance for Power Plants, Vol. 2, pages 22-36, published VTT, Espoo, Finland, 2010.

88. M. Spiegel, "Salt melt induced corrosion of metallic materials in waste incineration plants", Materials and Corrosion, 트, 373-393, 1999. 
89. E. Otero, A. Pardo, M.C. Merino, M.V. Utrilla, M.D. Lopez and J.L. dePeso, "Corrosion behavior of IN-600 superalloy in waste-incineration environments: hot corrosion by molten chlorides", Oxidation of metals, 31 (516), 507-525, 1999.

90. E. Otero, A. Pardo, F.J. Pérez, M.V. Utrilla and T. Levi, "Corrosion behavior of 12CrMoV steel in waste incineration environments: hot corrosion by molten chlorides”, Oxidation of Metals 49 (516), 467484, 1998.

91. Y.S. Li, Y. Niu and W.T. Wu, "Accelerated corrosion of pure Fe, Ni, Cr and several Fe-based alloys induced by $\mathrm{ZnCl}_{2}-\mathrm{KCl}$ at $450^{\circ} \mathrm{C}$ in oxidizing environment”, Materials Science and Engineering $\underline{\mathrm{A} 345}$, 6471, 2003.

92. T.J. Pan, C.L. Zeng and Y. Niu, "Corrosion of three commercial steels under $\mathrm{ZnCl}_{2}-\mathrm{KCl}$ deposits in a

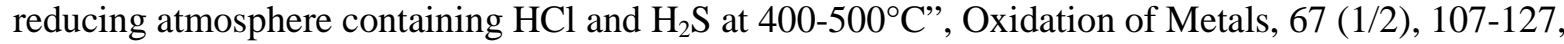
2007.

93. W.M. Lu, T.J. Pan, K. Zhang and Y. Niu, “Accelerated corrosion of five commercial steels under a $\mathrm{ZnCl}_{2}-\mathrm{KCl}$ deposit in a reducing environment typical of waste gasification at $673-773^{\circ} \mathrm{K}$ ”, Corrosion Science 50, 1900-1906, 2008.

94. Dorota Bankiewicz, Patrik Yrjas and Mikko Hupa, "High temperature corrosion of superheater tube materials exposed to zinc salts”, Energy Fuels, 23 (7), 3469-3474, 2009.

95. Andreas Ruh and Michael Spiegel, "Thermodynamic and kinetic consideration on the corrosion of Fe, $\mathrm{Ni}$ and $\mathrm{Cr}$ beneath a molten KCl-ZnCl${ }_{2}$ mixture”, Corrosion Science 48, 679-695, 2006.

96. Y.S. Li and M. Spiegel, "Models describing the degradation of FeAl and NiAl alloys induced by $\mathrm{ZnCl}_{2}-\mathrm{KCl}$ melt at 400-450 ${ }^{\circ} \mathrm{C}$ ”, Corrosion Science 46, 2009-2023, 2004.

97. Edgardo Coda Zabetta, Vesna Barišić and Brad Moulton, "Foster Wheeler references and tools for Biomass- and waste-fired CFBs", $34^{\text {th }}$ International Technical Conference on Coal Utilization and Fuel Systems, Clearwater FL, May 31 - June 4, 2009, published Coal Technology Association, Gaithersburg, MD, 2009.

98. Vesna Barišić, Edgardo Coda Zabetta and Juha Sarkki, "Prediction of agglomeration, fouling and corrosion tendency of fuels in CFB co-combustion", $20^{\text {th }}$ International conference on Fluidized Bed Combustion, Xi’an, China, May 18-20, 2009.

99. S. Enestam, J. Niemi and K. Mäkelä, "STEAMAX - a novel approach for corrosion prediction, materials selection and optimization of steam parameters for boilers firing fuel and fuel mixtures derives from biomass and waste”, $33^{\text {rd }}$ International Technical Conference on Clean Coal and Fuel Systems”, Clearwater, FL, June 6-10, 2008, published Coal Technology Association, Gaithersburg, MD, 2010. 100. Aaron Fuller, Jörg Maier and G. Scheffknecht, "Impact of co-combustion on emission behavior and ash quality by co-firing high shares of biomass and residues", $35^{\text {th }}$ International Technical Conference on Clean Coal and Fuel Systems”, June 6-10, 2010, Clearwater, FL, published Coal Technology Association, Gaithersburg, MD, 2010.

101. P.J. Henderson, T. Eriksson, J. Tollin and T. Abyhammar, "Corrosion testing of superheater steels for $600^{\circ} \mathrm{C}$ steam in biomass/co-fired boilers", Proceedings of conference on advanced heat resistant steels for power generation, San Sebastian, Spain, April 27, 1998, published Maney Publishing, Leeds, UK, 1999.

102. Flemming J. Frandsen, "Utilizing biomass and waste for power production - a decade of contributing to the understanding, interpretation and analysis of deposits and corrosion processes”, Fuel 84, 1277-1294, 2005.

103. Fleming J. Frandsen, “Ash research from Palm Coast, Florida to Banff, Canada: Entry of biomass in modern power boilers”, Energy Fuels 23 (7), 3347-3378, 2009.

104. Karin H. Andersen, Flemming J. Frandsen, Peter F.B. Hansen, Kate Wieck-Hansen, Ingvar

Rasmussen, Peter Overgaard and Kim Dam-Johansen, "Deposit formation in a 150MWe utility PF boiler during co-combustion of coal and straw”, Energy Fuels 14 (4), 765-780, 2000.

105. Hanne-P. Nielsen, Flemming J. Frandsen and Kim Dam-Johansen, "Lab-scale investigation of high temperature corrosion phenomena in straw-fired boilers”, Energy Fuels, 13 (6), 1114-1121, 1999. 
106. Xiaoyang Liu, Joerg Maier and Klaus R.G. Hein, “The kinetics of fireside corrosion in biomass combustion system and the influence from gas and deposit ash chemistry”, Electrochemical Society 201st Meeting - Philadelphia, PA, May 16, 2002.

107. Xiaoyang Liu, Joerg Maier, Klaus R.G. Hein, “The kinetics and influence factors on chlorineinduced fireside corrosion in biomass combustion system. Part 3: Corrosion morphology of chlorine corrosion”, $15^{\text {th }}$ International Corrosion Congress, Granada, Spain, September 22-27, 2002. Proceedings edited by Manuel Morcillo, published 2002.

108. Douglas L Singbeil and Laurie Frederick, "Improving Heat Recovery in Biomass-Fired Boilers Corrosion of Superheater Tube Materials for High Temperature Black Liquor and Bark-fired Boilers", Final Report ORNL Subcontract 4000089243, December 2012.

109. Douglas L Singbeil, Laurie A Frederick, James R Keiser, and W.B.A. (Sandy) Sharp, “Could Biomass-Fueled Boilers Be Operated At Higher Steam Temperatures? 1. Laboratory Evaluation Of Candidate Superheater Alloys” Proceedings of 2013TAPPI PEERS Conference, Green Bay, WI, September, 2013.

110. James R. Keiser, W.B.A. (Sandy) Sharp and Douglas L. Singbeil, "Could Biomass-Fueled boilers be Operated at Higher Steam Temperatures? 2. Field Tests of Candidate Superheater Alloys,” Proceedings of 2013 TAPPI PEERS Conference, Green Bay, WI, September, 2013.

111. James R. Keiser, W.B.A. (Sandy) Sharp, Douglas L. Singbeil, Laurie A Frederick and Curtis Clemmons, "Performance Of Alternate Superheater Materials In A Potassium-Rich Recovery Boiler Environment” Proceedings of 2012 TAPPI PEERS Conference, Savannah, GA, October, 2012. 112. Rapp, R., Zhang Y.S. “Hot Corrosion of Materials: Fundamental Studies” JOM p. 47-55, 1994.

113. D. Inman, D.M. Wrench, “Corrosion in Fused Salts” Brit Corros. J., Vol 1, p. 246,1966.

114. R. Rapp.”Hot corrosion of materials: a fluxing mechanism?” Corrosion, Vol 22 Iss. 2 p. 209-221, 2002

115. Rapp, R. Goto, K. Braunstein, J. Selman, J. "Hot Corrosion of Metals by Molten Salts, Molten Salts 1, Electrochem. Soc. p. 1591981.

116. Hwang, Y. Rapp, R. "Synergistic Dissolution of Oxides in Molten Sodium Sulphate” J.

Electrochem. Soc., vol 137 p. 1276 (1990).

117. Private communication, Laurie A Frederick, FPInnovations

118. D. Bankiewicz, S. Enestam, P. Yrjas and M. Hupa, "Experimental Studies of Zn and Pb Induced High Temperature Corrosion of Two Commercial Boiler Steels”, Fuel Processing Technology, 2012. 119. W.B.A. (Sandy) Sharp, W. J. (Jim) Frederick, James R Keiser and Douglas L Singbeil, “Could Biomass-Fueled Boilers Be Operated At Higher Steam Temperatures? 3. Initial Analysis Of Costs And Benefits” Proceedings of 2013TAPPI PEERS Conference, Green Bay, WI, September, 2013.

120. K.E. Heselton, “Efficiency”, pages 100-105 in Boiler Operator’s Handbook, published Fairmont Press, Lilburn, GA, 2005. Also available at http://books.google.com/books?id=8y0qRQ17XDEC\&pg=PA101\&lpg=PA101\&dq=heat+loss+method+b oiler+efficiency\&source=bl\&ots=Rdm1iVHNe1\&sig=QQX9ouWVLetj19fQ8KQjuzaOj4\&hl=en\&sa=X\&ei=s_PVUPKeFMjxigL6lYD4DQ\&sqi=2\&ved=0CFIQ6AE wAg\#v=onepage\&q=heat\%20loss\%20method\%20boiler\%20efficiency\&f=false

121. T.N. Adams, page 26, tables 1 to 8 in "Kraft Recovery Boilers", published TAPPI Press, Atlanta, GA, 1997.

122. J.W. Gibbs, "A Method of Geometrical Representation of the Thermodynamic Properties of Substances by Means of Surfaces", Transactions of the Connecticut Academy II, pages 382-404, December, 1873.

123. Ulrich, G.D. A Guide to Chemical Engineering Process Design and Economics. John Wiley \& Sons, New York, 1984, pp. 87 and 90-91.

124. John D. Andrews, MWV, Charleston, WV.

125. A. Stålenheim and P. Henderson, “ Materials for higher steam temperatures 
(up to $600^{\circ} \mathrm{C}$ ) in biomass and waste fired plant - a review of present knowledge”, Report M08-833 published by Varmeforsk Service AB, Stockholm, Sweden, 2011.

126. B. Kamuk, "Technical, economical, operating consequences by operating at extreme steam parameters”, Waste-to-Energy Research and Technology Council, 2010 Annual Meeting, Brno, Czech Republic. Also available at http://www.admas.vutbr.cz/files/wtert-prezentace/Kamuk_Technical_economical operating_consequences by operating at extreme steam parameters.pdf 